\title{
BIBLIOGRAFÍA
}

OBSERVACiones: La presente Bibliografía trata de cubrir todo el territorio hispánico en lo que se refiere a Lingüistica (español europeo y americano, judeoespañol, portugués peninsular y extrapeninsular, catalán, vasco); en lo que se refiere a Literatura, cubre todo el campo peninsular, o sea que excluye la información sobre la América española y el Brasil.

Las reseñas se consignan a continuación del libro (o articulo) reseñado. Cuando éste se ha descrito ya en una entrega anterior de la Bibliografia, se pone entre paréntesis el numero de la ficha correspondiente. También se hacen referencias a ediciones anteriores de una obra, a tomos anteriores de una obra en curso de publicación, etc. En todos estos casos, la cifra que precede al numero de referencia indica el volumen de la NRFH en que figura la ficha en cuestión. Asi, el "núm. 14-39695" corresponde a la ficha 39695, la cual está en el volumen 14 de la NRFH. Cuando no hay cifra inicial, ha de entenderse que el número remite a una ficha incluida en el presente fasciculo.

\section{SECGION GENERAL}

\section{OBRAS BIBLIOGRÁFICAS Y DE CONSULTA}

21-3303. "Bibliografía".-NRFH, 20 (1971), 450-596.-V. núm. 21-1.

21-3304. "1967 MLA International bibliography"--PMLA, 83 (1968), 551-966.

21-3305. L'année philologique. Publiée par Juliette Ernst et al. T. 38: Bibliographie de l'année 1967 et complément d'années antérieures.-Les Belles Lettres, Paris, 1969. xxix + 768 pp.-V. núm. 21-4.

21-3306. "Registo bibliográfico [Portugal y Brasil]".-BIB, $11(1970), 169-259$, 521-622.-V. núm. 21-6.

21-3307. "Bibliographie" [Edad Media].CCM, 12 (1969), 1*-235*; 13 (1970), 1*-326*.-V. núm. 19-4238.

2I-3308. The year's work in modern language studies. T. 31: 1969. Ed. by R. G. Popperwell.-The Modern Humanities Research Assoc., Cambridge, 1970. 976 pp.-V. núm. 21-7. || FS, 25 (1971), 357-358 (Ullmann).

21-3309. Chatham, James R. \& Enrique RuIZ-ForNELLS-Dissertations in Hispanic languages and literatures: An index of dissertations completed in the United States i Canada, 1876-1966.-Univ. Press of Kentucky, Lexington, 1970. xiv + $120 \mathrm{pp} .|| H, 54$ (1971) , 599-600 (Beardsley).
21-3310. HuLET, C. L.-"Dissertations in the Hispanic languages and literatures, 1969".- $-H, 53(1970), 230-241,436-437 .-$ V. núm. 21-11.

21-3311. Arnaud, V., et V. Tuson-Guide de bibliographie hispanique (N. 204189). || BDGA, 1970, núms. 111/3, 9596 (Plaza).

21-33I2. Foster, David W., \& Virginia RAmos Foster-Manual of Hispanic bibliography.-Univ. of Washington Press, Seattle, 1970. $\mathrm{x}+206 \mathrm{pp}$. $\| B A b r, 45$ (1971), 291-292 (Carter); Hf, 1972, núm. 44, 79-80 (Clark); HR, 40 (1972), 216 (Espantoso de Foley); CuH, 86 (1971), 211-212 (Navas Ruiz); $M L J, 56$ (1972), 404-405 (Zubatsky).

21-3313. Thompson, LAWrence S.-Essays in Hispanic bibliography. With an introduction by $\mathrm{H}$. C. Woodbridge.Shoe String Press, Hamden, Conn., 1970. xi + 117 pp. $H A H R, 51$ (1971), 701-702 (Read).

21-3314. Palau y Dulcet, Antonio-Manual del librero hispanoamericano. 2: ed. T. 22: Son-Tebib.-Palau, Barcelona, 1970. 500 pp.-V. núm. 20-10.

21-3315. Serís, Homero-Nuevo ensayo de una biblioteca española de libros raros y curiosos. T. 2: C-F.-Hispanic Society of America, New York, 1969. 391 pp.V. núm. 18-4210. || HR, 39 (1971), 444445 (Beardsley) .

21-3316. Miró, J.-Catalogue de la Biblio- 
thèque Espagnole. Romans de chevalerie, poèmes, romanceros, cancioneros, chroniques diverses des $15 e$, 16e et $17 e$ siècles.-Amsterdam, 1970. xvi +180 pp. [Reimpr. de la ed. de París, 1878].

21-3317. SEMPERE y GUARINOS, JUAN-Ensayo de una biblioteca española de los mejores escritores del reynado de Carlos III. Ed. facs.-Gredos, Madrid, 1969. 3 ts. (BRH, Facsimiles).

21-3318. LÓPEZ SERRANo, M.-“Incunables españoles en la Biblioteca de Palacio". -RUM, 19 (1970), núm. 75, 105-142.

21-3319. Martínez Díez, G.-"Dos catálogos inéditos de la Biblioteca del Monasterio de Ripoll".-HS, 22 (1969), núms. $43 / 4$.

21-3320. Hernández ANdrés, J. M.-Catálogo de una serie miscelánea procedente del convento de San Antonio del Prado (N. 21-23) . || $A I A, 30$ (1970), 246-249 (Barrado).

21-3321. Molina NavarRo, G.-Indice para facilitar el manejo y consulta de los catálogos de Salvá y Heredia, 2a ed. (N. 20-4223) || $A I A, 30$ (1970), 251 (Castro) .

21-3322. Indice de la Biblioteca Menéndez Pelayo. - Ayuntamiento de Santander, Santander, 1969. 3 ts.

21-3323. Lanning, J. T.-“The Hispanic collection" [de Duke University]. Gnomon: Essays for the dedication of the... Library (Durham, N.C.), 1970, $82-95$.

21-3324. Guillett, Theresa, \& Helen MCINTYRE-Catalog of Luso-Brazilian materials in the University of New Mexico libraries. - Scarecrow Press, Metuchen, N. J., 1970. xiv +961 pp. $\| H A H R$, 51 (1971), 224 (Tolman).

21-3325. Index translationum. Répertoire international des traductions. T. 20: 1967.-Unesco, Paris, 1969. 909 pp.-V. núm. 21-13.

21-3326. MÜLLER, JeAN, \& ERNST RothAussereuropäische Druckereien im 16. Jahrhundert. Bibliographie der Drucke mit 60 Abbildungen. - Heitz, BadenBaden, 1969. 176 pp. || $B H R, 33$ (1971), 214-216 (Bernard-Maitre).

21-3327. Norton, F. J.-Printing in Spain, 1501-1520 (N. 19-23) - || RQ 23 (1970), 179-180 (Rodríguez Moñino); Fil, 14 (1970), 192-196 (Weber de Kurlat) .V. núm. 20-13.

21-3328. Norton, F. J. - "Typographical evidence as an aid to the identification and dating of unsigned Spanish books of the sixteenth century".-IR, 2 (1970), 96-103.

21-3329, BEzzEL, I. - "Bartholomäus May (ca. 1515-1576) aus Bern, ein Sammler spanischer Drucke". - IR, 1 (1969), núm. 3.

21-3330. Aguilar Piñal, F.-"Diego Alejandro y el origen de la imprenta sevillana".- $A H, 1969$, núms. $153 / 8$.

21-3331. Aguilar PIÑal, F.-“Adiciones a la tipografía hispalense del siglo xvi".$A H, 50 / 51$ (1969), 193-201.

21-3332. Aguillar Piñal, F.-“Más adiciones a la tipografía hispalense del siglo xvi".-AH, 52/53 (1970), 359-369.

21-3333. Gallego Morell, antonio-Cinco impresores granadinos de los siglos xvi y xvii.-Universidad, Granada, 1970. $151 \mathrm{pp}$.

21-3334. ENCISO Recio, L. M.-“La Imprenta Real a fines del siglo xvir (17821795)". - RUM, 19 (1970), núm. 73, 169-194.

21-3335. Martínez Barbeito, Carlos-Impresos gallegos de los siglos xvi, xvii $y$ xviii.-Instituto P. Sarmiento, Santiago de Compostela, 1970. 108 pp., ilustr. (CUEG, anejo 17) .

21-3336. Aguilar Piñal, Francisco - Impresos castellanos del siglo xvi en el British Museum.-C.S.I.C., Madrid, 1970. 137 pp. (Cuadernos bibliográficos, 24).

21-3337. Gómez Aparicio, P.-Historia del periodismo español (N. 20-49) . || RHM, 35 (1969), 146 (Dennis).

21-3338. Andrés, Gregorio DE - La Real Biblioteca de El Escorial.-Aldus, Madrid, 1970. 114 pp.

21-3339. Bianchini, M. C. (ed.)-Repertorio bibliografico delle opere di interesse ispanistico (spagnolo e portoghese) pubblicate prima dell'anno 1801 in possesso delle Biblioteche Veneziane.-Consiglio Nazionale delle Richerche. Venezia, 1970, xiii + 408 pp.

21-3340. Catálogos dos reservados da Biblioteca Geral da Universidade de Coimbra.-Universidade, Coimbra, 1970. xvi +753 pp.

21-3341. Ferreira de Assunção, G. J.-“Os folhetos da Biblioteca do Palácio Nacional de Mafra".-BIB, 11 (1970), 263$325,625-637 .-V$. núm. 20-27.

21-3342. Catálogo de la Exposición bibliográfica. III Congreso Internacional de Bibliofilia (Barcelona - Madrid, 1963); 145 pp.

21-3343. [Oriol Puig, José], e Ildefonso M. GóMEz-Escritores cartujanos españo- 
les.-Abadía de Montserrat, 1970. 228 pp. -V. núm. 20-4227. || ZRPh, 86 (1970), 688-689 (Muntaner).

21-3344. Pérez Embid, Florentino y FranCISCO MORAles PADRóN-Bibliografia española de historia maritima (1932-1962). -Sevilla, 1970. xvi +158 pp.

21-3345. Oliva Escribano, J. L.-"Bibliografía de Madrid y su provincia".AIEM, 6 (1970), 621-642.-V. núm. 204217.

21-3346. BarbazÁn Beneit, Jullán - $R e$ cuerdos de un librero anticuario madri. leño (1897-1969). Pról. de A. Pérez Gómez.-J. Sánchez Ocaña, Madrid, 1970. $\mathrm{x}+279 \mathrm{pp}$.

21-3347. Altabella, J.--Las Provincias", eje histórico del periodismo valenciano (1866-1969).-Madrid, 1970. 209 pp.

21-3348. Galindo, M.-“Breves notas sobre el periodismo y el folletín en la prensa castellonense del siglo $\mathrm{xIx}$ ". $-B S C C, 46$ (1970), núm. 2.

21-3349. Boletin de la Real Sociedad Vascongada de los Amigos del Pais. Indices de los ts. 1-25 (1945-1969). - BSV, 26 $(1970)$, núm. 1; 160 pp.

21-3350. Der kleine Pauly. Lexikon der Antike auf der Grundlage von Pauly's Realencyclopädie der classischen Altertumswissenschaft. Bearb. und hrsg. von K. Ziegler und W. Sontheimer. Bd. 3: Iuppiter-Nasidienus. - Druckenmüller, Stuttgart, 1967-69. 1584 cols.-V. núm. 21-34. || RSC, 16 (1968), 119-120, 345346 (d'Agostino) ; BBF, 13 (1968), 935936; 14 (1969), 139 (Ernst); Augu, 9 (1969), 187 (Gavigan); Paideia, 23 (1968), 366-367 (Pisani); AC, 37 (1968), 793-794 (Severyns) .

21-3351. Documentación y terminologia cientificas. Bibliografía de diccionarios cientificos y técnicos plurilingües, $5^{\text {a }}$ ed. -Unesco, Paris, 1969.

21-3352. Viller, M., F. Cavallera et al. -Dictionnaire de spiritualité, ascétique et mystique, doctrine et histoire. T. 7: Haakman-Hypocrisie. - Beauchesne, $\mathrm{Pa}$ ris, 1968-69. 1216 cols.-V. núm. 204256.

21-3353. Agulló y Сово, M.-Relaciones de sucesos. T. 1: Años 1477-1619 (N. 19-4253). \|RVF, 7 (1963-66), 99 (Esquer Torres).

21-3354. Vaz Araujo, Lino-Agustin Millares Carlo.-Univ. Central de Venezuela, Caracas, 1969. 94 pp.

V. también núms. 3392, 3546-8, 4237, 4409-11, 4504, 5051-5, 5730.
Archivos, manuscritos, textos, crítica textual, paleografia, ciencias auxiliares

21-3355. Inventario general de manuscritos de la Biblioteca Nacional. T. 9: Mss. 2825-3026.-Dir. Gen. de Archivos y Bibliotecas, Madrid, 1970. 551 pp. - V. núm. 19-4297.

21-3356. Miquel Rosell, Francisco-Inventario general de manuscritos de la Biblioteca Universitaria de Barcelona. T. 4: 1501-2030.-Direcciones Generales de Enseñanza Universitaria y de Archivos y Bibliotecas, Madrid, 1969. 548 pp. -V. núm. 17-69. || $A I A, 31$ (1971), 254 (Uribe) .

21-3357. VerísSIMO SERRÃo, JOAQUIM-Manuscritos portugueses ou referentes a Portugal, da Biblioteca Nacional de Paris. - Fundação Calouste Gulbenkian, Paris, 1969. 188 pp. || Ocid, 78 (1970), 128 (Paxeco).

21-3358. Martínez Ferrando, Jesús ErnesTo-Indice cronológico de la colección de documentos inéditos del archivo de la Corona de Aragón.-Dir. Gen. de Archivos y Bibliotecas, Barcelona, 1968. 451 pp.-V. núm. 13-36122.

21-3359. Lrokens y RAGA, P. L.-“Catálogo de pergaminos del archivo de la S. I. Catedral de Segorbe".- RABM, 77 (1964-65) , 36-65.

21-3360. García y García, A. y R. GonzÁLVEZ - Catálogo de los manuscritos juridicos medievales de la catedral de Toledo. - C.S.I.C., Roma-Madrid, 1970. xxvi +230 pp. (Cuadernos del Instituto Juridico Español, 21) .

21-3361. Fábrega I GraU, ÁNGEL, I JOSEP Baucenlls I ReIG - Catàleg de l'Arxiu Capitular de la S.E. Catedral Basilica de Barcelona. T. 1: Index general de les sèries documentals.-Imp. Fidel, Barcelona, 1969. $28 \mathrm{pp}$.

21-3362. Rubio García, L.-"Los documentos del Pilar, siglo xir. Primera serie". $-A F A, 16 / 17$ (1965-66), 213-452. - V. núm. 19-98.

21-3363. DíAZ y DíAz, M. C.--"E1 manuscrito 22 de la catedral de León". ALeon, 23 (1969), 133-168.

21-3364. BUCher, FrançoIs-The Pamplona Bibles. A facsimile compiled from two picture Bibles with martyrologies commissioned by King Sancho el Fuerte of Navarra (1194-1234). Amiens manuscript Latin 108 and Harburg MS. 1, 2, Lat. $4^{\circ}, 15 .-$ Yale Univ. Press, New 
Haven-London, 1970. T. 1: xiv +382 pp., 131 ilustr. T. 2: 570 facs.

21-3365. Montgomery, Thomas \& SpurGEON W. BALDWIN (eds.) - El Nuevo Testamento según el manuscrito escurialense I-I-6. Desde el evangelio de San Marcos hasta el Apocalipsis.-Real Academia Española, Madrid, 1970. 647 pp. ( $B R A E$, anejo 22).

21-3366. Lipton, W. S.-“Anti-iconic preliminaries to the Biblia de Alba". $R P h, 23$ (1969-70), 17-38.

21-3367. Wemple, S. F. - "The Codex Holstenianus in Toledo: a collection of ninth, tenth and eleventh century capitularies".-MS, 13 (1969), 90-95.

21-3368. Kontzi, ReInhold - AljamiadoTexte. Ausgabe mit einer Einleitung zur Sprache und Glossar. - [Habilitationsschrift, Universität Tübingen, 1969].

21-3369. Kontzi, R.-“Aspectos del estudio de textos aljamiados".-BICC, 25 (1970), 196-213.

21-3370. Manzanares de Girre, M.-"Nota sobre la aljamía”. - $A E M, 5$ (1968), 479-482.

21-3371. MoreIra dE SÁ, A. (ed.)-Chartularium universitatis Portugalensis (1288-1537) T. 3: 1409-1430; t. 4: 1431-1445. - Instituto de Alta Cultura, Lisboa, 1969-1970. 501, 535 pp. - V. núm. 21-72.

21-3372. Pérez Soler, María DesamparaDos (ed.)-Cartulario de Valpuesta.Valencia, 1970. 108 pp.

21-3373. Cantera y Burgos, F.-"El libro becerro de Bujedo de Campajares".RUM, 19 (1970), núm. 73, $107-129$.

21-3374. MuÑoz y RoMero, Tomás-Colección de fueros municipales y cartas pueblas de los reinos de Castilla, León, Corona de Aragón y Navarra. T. 1.Madrid, 1970. 560 pp. [Reimpr. en facs.].

21-3375. Bobes Naves, M. Del C.-"Cuestiones semánticas en torno a documentos leoneses".-ALeon, 23 (1969), 351-368.

21-3376. VIÑEs, H.-“El Fuero general de Navarra. Notas para datar el último ms. publicado, en función de la alternancia $c / z " .-I R, 1$ (1969), 314-318.

21-3377. Colò, Germà, I ArCadi Garcia (eds.) -Furs de València. T. 1.-Barcelona, 1970. 253 pp. (Col. Els nostres clàssics, vol. 101) .

21-3378. FONT RIUS, JosÉ MARÍA-Cartas de población y franquicia de Cataluña. T. 1: Textos. (Introducción, diplomatario, presentación monográfico-local e indices). - C.S.I.C., Madrid-Barcelona, 1969. 1079 pp. (Textos, 36) . || CCM, 13 (1970), 374-375 (Carrère) .

21-3379. LACARRA, José María y ÁNGEL J. MARtín DuQue-Fueros derivados de Jaca: Estella-San Sebastián--Diputación Foral de Navarra-Príncipe de Viana, 1969. 364 pp. (Fueros de Navarra). II Sef, 31 (1971), 116-118 (Cantera Burgor) .

21-9380. Bohigas Balaguer, P.-“La illuminació de les Leges palatinae de Mallorca".-Scrip, 23 (1969), 94-100.

21-3381. Matéu y Llopis, Felipe (ed.) Establiments de la villa de El Boixar.Sociedad Castellonense de Cultura, Castellón de la Plana, 1969. 94 pp. (Libros raros y curiosos, 29).

21-3382. Benito Ruano, E.-“Las más antiguas actas conservadas del Ayuntamiento de Toledo".-RUM, 19 (1970), núm. 74, 41-102.

21-3383. Maluquer de Motes, J--Epigrafia prelatina de la Península ibérica (N. 21-81). $\| B z N, 5$ (1970), 215-217 (Schmoll) .

21-3384. VIVES, JosÉ (ed.) -Inscripciones cristianas de la España romana y visigoda.-Barcelona, 1969. 240 pp., ilustr.

21-3385. Muñoz y RIVERo, Jesús-Manual de paleografia diplomática española de los siglos xii al xvii. Método teóricopráctico para aprender a leer los documentos españoles de los siglos xii al xvii. 2a ed., corr. y aum.-Madrid, 1970. 500 pp., ilustr. [Reimpr. de la ed. de 1917]. 21-3386. NunEs, EdUARDo-Album de pa. leografia portuguesa. T. 1.-Livr. Portugal, Lisboa, 1969. 138 pp., ilustr.

21-3387. Mazzoleni, Jole-Paleografia e diplomatica $e$ scienze ausiliarie.-Scientifica Editrice, Napoli, 1970. 474 pp., ilustr.-V. núm. 13-34199.

21-3388. GANz, F. P. \& W. Schröder (eds.) - Probleme mittelalterlicher Überlieferung und Textkritik. Oxforder Colloquium 1966.-Schmidt, Berlin, 1968. 196 pp. I| $N, 55$ (1971), 345-346 (Van der Lee).

21-3389. Prete, Sesto-Observations on the history of textual criticism in the medieval and Renaissance periods. - St. John's Univ. Press, Collegeville, Minn., [1970?]. 27 pp. || $B H R, 33$ (1971), 232234 (Saffrey).

21-3390. LowE, E. A.-Handwriting: Our medieval legacy. Transcriptions of facs. by W. B. Ross, Jr.-Storia e Letteratura, Roma, 1969. 


\section{HISTORIA}

21-3391. Johnson, Jerah, \& William A. PERCY, JR.-The age of recovery: The fifteenth century-Cornell Univ. Press, Ithaca-London, 1970 . xiii +157 pp. II $B H R, 33$ (1971), 448-450 (Ashley).

21-3392. JuchноF, Rudolf-Die Druckerund Verlegerzeichen des 15. Jahrhun. derts in den Niederlanden, England, Spanien, Böhmen, Mähren und Polen. -Georg Olms Verlag, Hildesheim-New York, 1972. 132 pp., 120 láms. [Reimpr. facs. de la ed. de Munich, 1927].

21-3393. Febvre, Lucien-Etasmo, la contrarreforma y el espiritu moderno. Trad. de C. Piera. Nota prel. de F. Braudel.Martínez Roca, Barcelona, 1971. 258 pp. (Novo-curso). || EAg, 6 (1971), 319 (Aparicio) .

\section{Españ}

21-3394. Repeto Álvarez, A.-"La historia de España y la historia de Europa".$R E P, 1969$, núm. 164, 115-137.

21-3395. Carretero y Jiménez, Anselmo -España y Europa. Pról. de S. de Madariaga.-Fomento de Cultura, Valencia, 1971. 402 pp.

21-3396. Ubieto, A., J. Reglí, M. Jover y C. SEco-Introducción a la historia de España.-Teide, Barcelona, 1970. xv + 1062 pp., ilustr.-V. núm. 19-4362.

21-3397. SChNelle, K,-“Historia y metodología. Acerca del pensamiento histórico en España".-BRPh, 9 (1970), 229 245.

21-3398. Menéndez Pidal, Ramón (ed.) Historia de España. T. 17: La España de los Reyes Católicos (1474-1516). Vol. 1, por Luis Suárez fernández y Juan de Mata Carriazo-Espasa-Calpe, Madrid, 1969. cxvi + 929 pp., ilustr. II ROcc, 26 (1969) , 238-240 (Gil Novales).

21-3399. Menéndez Pidal, Ramón (ed.) Historia de España. T. 17: La España de los Reyes Católicos (1474-1510). Vol. 2, por L. Suárez Fernández y M. FerNÁndez Álvarez,-Espasa-Calpe, Madrid, 1969. 810 pp., ilustr. \|ROcc, 28 (1970), 109-111 (Gil Novales); $A 1 A, 31$ (1971), 587-588 (Meseguer Fernández).

21-3400. Oliveira Martins, J. P. $-A$ history of Iberian civilization. Trad. by A. F. G. Bell.--Cooper Square Pubs., New York, 1969. xix +292 pp.

21-3401. Vicens VIVEs, J. - An economic history of Spain. With the collaboration of J. Nadal Oller. Tr. by F. M. LópezMorillas. - Princeton Univ. Press, New Jersey, 1969. 825 pp. || RIB, 20 (1970), 72-74 (Ayensa); HAHR, 50 (1970), 576578 (Fagg) ; BHS, 47 (1970), 245 (Naylon).

21-3402. Hills, George-Spain. - Praeger, New York, 1970. 480 pp., ilustr. \|l $H A H R, 51$ (1971), 187-188 (Jackson).

21-3403. Sínchez-AlborNoz, C.-Investigaciones sobre historiografia hispana medieval (N. 20-132). USef, 30 (1970), 95-98 (Cantera Burgos); BHi, 71 (1969), 674-675 (Cotrait) ; RH, 242 (1969) , 455 457 (Defourneaux); ALeon, 22 (1968), 409-410 (Fernández Catón).

21-3404. Thompson, E. A.-The Goths in Spain.-Clarendon Press, Oxford; Oxford Univ. Press, New York, 1969, xiv +358 pp.

21-3405. DíAz y DíAz, M.-"Eremitical life in Visigothic Spain".-CF, 23 (1969), 209-227.

21-3406. García de Cortázar, José ANGel - El dominio del monasterio de San Millán de la Cogolla (siglos $x$ a xiii). Introducción a la historia rural de Castilla alto medieval. - Salamanca, 1969. 371 pp., ilustr. (ACS, 59) . \|CCM, 13 (1970), 159-163 (Gautier Dalché); $S p$, 45 (1970), 462-465 (Kennelly).

21-3407. OlagüE, Ignacio - Les arabes n'ont jamais envahi l'Espagne. - Flammarion, Paris, 1969. 347 pp., ilustr. II $L N L, 1971$, núm. 197, 67-75 (Cotrait). 21-3408. HOENERBACH, WILHELM - Islamische Geschichte Spaniens. - ArtemisVerl., Stuttgart, 1970. 648 pp. (Bibliothek des Morgenlandes). I| Mundus, 7 (1971), 18-20 (Wagner) .

21-3409. W' WTT, MONTGOMERY-Historia de la España islámica.-Alianza Editorial, Madrid, 1970. 211 pp. (El libro de bolsillo). || ROcc, 34 (1971), 357-359 (Marín).

21-3410. Kress, Hans-Joachim-Die islamische Kulturepoche auf der Iberischen Halbinsel.-Selbstverlag des Geographischen Instituts, Marburg, 1970. 393 pp., ilustr. (Marburger Geographische Schriften, 43) - || Mundus, 7 (1971), 214-215 (Ehlers)

21-3411. Monroe, James T.-Islam and the Arabs in Spanish scholarship. (Sixteenth century to the present). - E. J. Brill, Leiden, 1970. $\mathrm{x}+297$ pp. (Texts and studies, 3) - || HAHR, 51 (1971), 535537 (Glick). 
21-3412. Burckhardt, Trtus-Die maurische Kultur in Spanien.-Georg D. W. Callwey, München, 1970. 232 pp., ilustr. 21-3413. Pastor dE TOGNeri, R., et $M$. Bonaudo - "Problèmes d'assimilation d'une minorité. Les Mozarabes de Tolède (de 1085 à la fin du xirre siècle)". -AESC, 25 (1970), 351-390.

21-3414. Kofman de Guarrochena, L. C. y M. I. Carzolio de Rossi-"Acerca de la demografía asturleonesa y castellana en la Alta Edad Media".-CuHE, 1968, núms. 47/8, 136-170.

21-3415. Belmaktino, S. M. - "Estructura de la familia y *edades sociales, en la aristocracia de León y Castilla según las fuentes literarias e historiográficas. (Siglos X-XIII)".-CuHE, 1968, núms. 47/8, 256-328.

21-3416. Pérez de Urbel, fray Justo-El Condado de Castilla. Los 300 años en que se hizo Castilla.-El Siglo Ilustrado, Madrid, 1969. 3 ts.: 1500 pp., ilustr.

21-3417. Valentín de LA Cruz-Patria $y$ altares. (Donaciones religiosas del conde Fernán González).-Institución "Fernán González", Burgos, 1970. 142 pp. II BHi, 73 (1971), 189-191 (Cotrait).

21-3418. ArbeloA, JoAquín-Los orígenes del reino de Navarra.-Auñamendi, San Sebastián, 1969. || ROcc, 30 (1970), 377-380 (Uribarri).

21-3419. Chalon, L. - "L'histoire de la monarchie asturienne, de Pelayo à Alphonse II le Chaste, dans le Poema de Fernán González". - MRo, 20 (1970), 61-67.

21-3420. REgLÁ, JUAN-Introducció a la historia de la Corona d'Aragó. Dels origens a la nova planta.-Palma de Mallorca, 1969. 188 pp.

21-3421. D'ABadal I DE VINyals, R.-Dels visigots als catalans. T. 1: La Hispània visigótica i la Catalunya carolingia. Ed. J. Sobrequés i Callicó.-Eds. 62, Barcelona, 1969. 499 pp., ilustr. \| CRAI, 1969, 511 (Ganshof).

21-3422. Dufourco, Charles EmmanuelL'expansió catalana a la Mediterrania occidental. Segles xiii $i$ xiv. Trad. de J. Vallverdú y revisión historiográfica de S. Sobrequés Vidal. - Barcelona, 1969. xxviii + 574 pp.-V. núm. 20-140.

21-3423. BuRNs, R. I.-The crusader kingdom of Valencia (N. 20-4348) . $\| S p, 45$ (1970), 116-118 (Bishko) .

21-3424. Ubieto ARTETA, Antonio-Ciclos económicos en la Edad Media española. -Valencia, 1969. 174 pp., ilustr.
21-3425. Valdeavellano, Luis G. De-Origenes de la burguesia en la España medieval.-Espasa-Calpe, Madrid, 1969. 220 pp. (Austral). || EAg, 5 (1970), 523524 (Armesto) ; HAHR, 51 (1971), 685687 (Glick) .

21-3426. Serra Ruiz, Rafael - Honor honra e injuria en el derecho medieval español.-Murcia, 1969. 306 pp.

21-3427. Steinhaus, Federico - Ebraismo sefardita. Storia degli ebrei di Spagna nel Medio Evo.-Forni, Bologna, 1969. $\mathrm{xv}+450 \mathrm{pp}$.

21-3428. Millás Vallickosa, J. M.-“Aportaciones científicas de los judios españoles a fines de la Edad Media". SES (1), 33-42. [Discusión, pp. 370-371] 21-3429. Gómez-MeNor, José - Cristianos nuevos y mercaderes de Toledo.-Gómez-Menor, Toledo, 1970. 1xi + $255 \mathrm{pp}$.

21-3430. Moxó, S. DE-“De la nobleza vieja a la nobleza nueva. La transformación nobiliaria castellana en la baja Edad Media". - Cuadernos de Historia, 3 (1969) , 1-210.

21-3431. La sociedad castellana en la baja Edad Media.-C.S.I.C., Madrid, 1969. x +368 pp. (Cuadernos de historia, 3). II HAHR, 50 (1970), 578-580 (Glick); $B H S, 47$ (1970), 144 (Lomax).

21-3432. Round, N. G.-"Politics, style and group attitudes in the Instrucción del relator".-BHS, 46 (1969), 289-319.

21-3433. NoBLE, IRIs-Spain's golden Queen Isabella.-J. Messner, New York, 1969. $191 \mathrm{pp}$.

21-3434. Rodríguez Valencia, Vicente Isabel la Católica en la opinión de españoles y extranjeros.-Inst. "Isabel la Católica" de Historia Eclesiástica, Valladolid, 1970. 3 ts.: xiv $+566,648$, $286 \mathrm{pp}$.

21-3435. VAlla, LoRenzo - Historiarum Ferdinandi regis Aragoniae libri tres.Valencia, 1970. [Reimpr. facs. de la ed. de París, 1521].

21-3436. García ORo, José-La reforma de los religiosos españoles en tiempo de los Reyes Católicos.-Inst. "Isabel la Católica" de Historia Eclesiástica, Valladolid, 1969. 591 pp. (Estudios y documentos).

21-3437. Caro Baroja, Julio-Inquisición, brujeria y criptojudaismo.-Ariel, Barcelona, 1970. 315 pp. (Ariel quincenal, $37)$.

21-3438. Burford, Eleanor-The Spanish Inquisition: its rise, growth and end.Citadel Press, New York, 1969. 3 ts. 
21-3439. Hauben, Paul J.-The Spanish Inquisition.-John Wiley \& Sons, New York, 1969. xiii + 140 pp. $\| B H S, 47$ (1970), 253-254 (Round).

21-3440. Testas, Guy y JeAn-La Inquisición.-Barcelona, 1970. 126 pp. - V. núm. 19-4405.

21-3441. Novalín, José Luis G.-El inquisidor general Fernando de Valdés (1483-1568).-Univ. de Oviedo, 1968-1971. 2 ts.: xxvii + 394, xxvi + 419 pp. BHi, 72 (1970) , 468-469 (Bourligueux); $R y F, 181$ (1970), $441-442$ (Hornedo); $B H S, 47$ (1970) , 74-75 (Lomax); RAM, 45 (1969), 106-107 (Ricard).

21-3442. Kinder, A. G.-"Cipriano de Valera, Spanish reformer (1532?-1602?)". $-B H S, 46$ (1969), 109-119.

21-3443. KindER, A. G.-"Further unpublished material and some notes on Cipriano de Valera". $-B H R, 31$ (1969), 169-171.

21-3444. Kinder, A. G.-“Notes on Cassiodoro de Reina and his family and descendants in Frankfurt". - BHR, 32 (1970), 427.431.

21-3445. Carande, Ramón-Siete estudios de historia de España-Ariel, Barcelona, 1969. 229 pp. || ROcc, 29 (1970, 256257 (Barnadas); CuH, 85 (1971), 645648 (Massieu).

21-3446. Maravall, José ANTonio-Las comunidades de Castilla. Una primera revolución moderna. 2a ed., rev. y aum.Rev. de Occidente, Madrid, 1970, 275 pp.-V. núm. 18-4309.

21-3447. Fernández Álvarez, Manuel-La sociedad española del Renacimiento.Anaya, Salamanca, 1970. 270 pp., ilustr. (Bibl. Anaya).

21-3448. LYNCH, JoHN-Spain under the Habsburgs. T. 2: Spain and America 1598-1700.-Oxford Univ. Press, LondonNew York, 1969. 297 pp., ilustr.-V. núm. 19-4412. || BHS, $47(1970), 255-$ 256 (Ball); HAHR, 50 (1970), 358360 (Kagan) .

21-3449. Moragas, Jerónimo de-De Carlos I Emperador a Carlos II el Hechizado. Historia humana de una dinastia. -Juventud, Barcelona, 1970. 382 pp., ilustr. (Grandes biografias).

21-3450. CHUDOBa, BOHDAN-Spain and the empire, 1519-1643.-Octagon Books, New York, 1969. 299 pp. [Reimp. de la ed. de 1952].-V. núm. 8-12243.

21-3451. Hume, Martin Andrew S.-Philip II of Spain. Ed. by H. Ketcham.-Haskell House, New York, 1969. 325 pp.
21-3452. Cadoux, CeCIL JohN-Philip of Spain and the Netherlands: An essay on moral judgments in history.-Shoe String Press, Hamden, Conn., 1969. 251 pp. [1 1 a ed., 1947].

21-3453. Carrasco Urgoiti, María SoleDAD-El problema morisco en Aragón al comienzo del reinado de Felipe II. (Estudio y apéndices documentales),-Univ. of North Carolina, Chapel Hill, 1969. 182 pp. (Estudios de Hf, 2) .

21-3454. AlCALÁ-Zamora y QueIPo de LlANo, J.-"En torno a los planteamientos hegemónicos de la monarquía hispana de los Felipes".-RUM, 19 (1970), núm. $73,57-106$.

21-3455. SARTori, G.-“Decadenza, messianesimo e genio della nazione nella cultura spagnola del secolo xviI". $-A F L M$, 22 (1969), 309-345.

21-3456. Domínguez Ortiz, Antonio-Crisis y decadencia de la España de los Austrias. - Ariel, Barcelona, 1969. 217 pp. \| $A I A, 30$ (1970) , 527-528 (Castro) . 21-3457. Davies, R. Trevor-La decadencia española, 1621-1700. Trad. de J. M. García de la Mora. - Barcelona, 1969. 190 pp.-V. núm. 12-32444.

21-3458. ANes, Gonzalo - Economia $e$ "Ilustración" en la España del siglo xvii.-Ariel, Madrid, 1969. 215 pp. II fns, 1969, núm. 277 (Mz. Cuadrado); $\mathrm{CuH}, 81$ (1970), 729-732 (Massieu).

21-3459. KAMEN, HENRY - The War of Succession in Spain, 1700-15.-Weidenfeld \& Nicholson, London, 1969. \| ROcc, 29 (1970), 124-126 (Elorza); BHS, 48 (1971) , 71-75 (Ilie); HAHR, 50 (1970), 580-581 (Ogelsby) .

21-3460. Grimberg, CarL-El siglo de la Ilustración. El despotismo ilustrado y los enciclopedistas.-Madrid, 1968. 448 pp., ilustr.

21-3461. Elorza, ANTonio-la ideologia liberal en la Ilustración española.-Tecnos, Madrid, 1970. 309 pp. || ROcc, 33 (1971), 250-253 (Aguilar Piñal).

21-3462. Peset Reig, Mariano y José Luis - El reformismo de Carlos III y la Universidad de Salamanca. Plan general de estudios dirigido a la Universidad de Salamanca por el Real y Supremo consejo de Castilla en 1771.-Universidad, Salamanca, 1969. 69 pp. (ACS, Historia de la Universidad, 16).

21-3463. HERR, RICHARD-The eighteenthcentury revolution in Spain.-Princeton University Press, Princeton, N. J., 1969. 454 pp.-V. núm. 16-41994. 
21-3464. Jiménez de Gregorio, F.-“Notas geográfico-históricas de los pueblos de la actual provincia de Madrid en el siglo XVII".-AIEM, 4 (1969), 247-266.

21-3465. Artola, M.-"América en el pensamiento español del siglo xvII".-RIM, 29 (1969), 51-77.

21-3466. Almela y Vives, Francisco-La Real Sociedad Económica de Amigos del Pais de Valencia. - Valencia, 1967. 38 pp., ilustr.

21-3467. Demerson, Jorge-La Real Sociedad Económica de Valladolid (17841808). Notas para su historia.-Univ. de Valladolid, Valladolid, 1969. 49 pp. (Estudios y documentos del Departamento de Historia Moderna, 28) . ||CuH, 81 (1970), 502-503 (Gil Novales); BDGA, 1969, núm. 107, 98 (Pérez-Rioja) .

21-3468. Martínez Albiach, Alfredo Religiosidad hispana y sociedad borbónica.-Fac. Teológica del Norte de España, Burgos, 1969. 675 pp. \|lns, 1969 , núm. 274 (Aguilar Piñal).

21-3469. Aguilar Piñal, F.-"Noticia bibliográfica de la Real Sociedad Económica Matritense en el siglo xvrr".AIEM, 6 (1970), 319-349.

21-3470. Gómez de LA SERNa, GasPar Goya y España.-Alianza Editorial, Madrid [1969?]. (El libro de bolsillo). \| fns, 1969, núms. 275/6 (Cano).

21-3471. Valdelomar, MarquÉs DE - Fernando VII y la masoneria. Españoles: Unión y alerta.-Prensa Española, Madrid, 1970. 219 pp.

21-3472. Alonso Tejeda, Luis-Ocaso de la Inquisición en los últimos años del reinado de Fernando VII. Juntas de fe, juntas apostólicas y conspiraciones realistas.-Algorta (Vizcaya), 1969. $257 \mathrm{pp}$.

21-3473. CARR, RAYMOND - España, 18081939. Trad. de J. R. Capella. - Ariel, Barcelona, 1969. 734 pp.-V. núm. 20186. || Ins, 1969, núm. 277 (Martínez Cuadrado); RyF, 180 (1969), 258-260 (Revuelta).

21-3474. Simón Palmer, M. del C.-“El Colegio de San Mateo (1821-1825)".AIEM, 4 (1969), 309-363.

21-3475. Aronson, Theo-Venganza real. La Corona de España, 1829-1965. Con un apéndice, 1966-68. Trad. por E. de Obregón.-Barcelona, 1968. 270 pp.-V. núm. 20-187.

21-3476. Ollé I Romeu, Josep MaríaIntroducció del socialisme utópic a $\mathrm{Ca}$ talunya, 1835-1837. - Barcelona, 1969. $105 \mathrm{pp}$.
21-3477. LORENzo, GÉSAR M.-Les anarchistes espagnols et le pouvoir (1868).-Ed. du Seuil, Paris, 1969, 430 pp. $\| A E S C$, $25(1970), 402-404$ (Souyri).

21-3478. Nettlau, Max-La Première Internationale en Espagne (1868-1888). Rév., trad., introd., notes, appendices, tableaux et cartes par R. Lamberet.Instituut voor Sociales Geschiedenis, Dorbrecht-Amsterdam, 1969. xxvii + 683 pp. || $R y F, 1971$, núm. 886, 391-393 (Calvo); BHS, $47 \quad(1970), \quad 261-264$ (Carr) .

21-3479. Gil Gremades, Juan José - El reformismo español. Krausismo, escuela histórica, neotomismo.-Barcelona, 1969. xxiv + 410 pp., ilustr. (Horas de España). II Ins, 1970, núm. 281 (Abellán). 21-3480. López PrÑero, José María-La introducción de la ciencia moderna en España.-Ariel, Barcelona, 1969. 172 pp. $\| \mathrm{CuH}, 85$ (1971), 355-358 (Albarracín Teulón) .

21-3481. García Camarero, Ernesto y EnRIQUE (eds.) - La polémica de la ciencia española. - Alianza Editorial, Madrid, 1970, 557 pp. (El libro de bolsillo).

21-3482. Gómez MolledA, M. D.-Los reformadores de la España contemporánea (N. 20-192) . \|CuA, 1970, núm. 6, 5462 (Landa),

21-3483. Núñez de Arenas, M. y M. TuÑóN DE LARA-Historia del movimiento obrero español.-Nova Terra, Barcelona, 1970. I| ROcc, 32 (1971), 252-253 (Elorza).

21-3484. SObrequés VIDAL, SANTIAgo-Historia de la España contemporánea. Barcelona, 1967. 528 pp.

21-3485. TERrón, Eloy-Sociedad e ideologia en los orígenes de la España contemporánea.-Barcelona, 1969. $278 \mathrm{pp}$.

21-3486. Fernández Almagro, MelghorHistoria politica de la España contemporánea. T. 1. 2a ed.-Alianza Editorial, Madrid, 1969. 503 pp. (El libro de bolsillo, 107).-V. núm. 16-45950.

21-3487. Fernández Almagro, MelchorHistoria política de la España contemporánea. Ts. 2 y 3.-Alianza Editorial, Madrid, 1968. 455, 348 pp. (El libro de bolsillo, 117, 120).-V. núm. 16-45950.

21-3488. Payne, Stanley G.-The Spanish revolution.-W. W. Norton, New York, 1970. xvi + 398 pp. \|HAHR, $50(1970)$, 765 (Hamilton).

21-3489. JeLlinek, FRANK-The Civil War in Spain. - Fertig, New York, 1969. 641 pp. 
21-3490. Weintraub, S. - The last great cause. The intellectuals and the Spanish Civil War-London, 1968. 340 pp.

21-3491. Hemingway, ERnest - The fifth column, and four stories of the Spanish civil war.-Scribner's, New York, 1969. $151 \mathrm{pp}$.

21-3492. Pik:, David W. - ¡Vae Victis! Los republicanos españoles refugiados en Francia, 1939-1944.-París, 1969. 139 pp., ilustr. || Carav, 1970, núm. 14, 187188 (Mauro).

21-3493. Martínez Cachero, Luis Alfonso -La emigración española a examen.Madrid, 1969. 194 pp.

21-3494. Vilanova, Antonio-Los olvidados: Los exilados españoles en la segunda guerra mundial. - París, 1969. 512 pp.

21-3495. Gallo, Max-Histoire de l'Espagne franquiste. - $\mathrm{R}$. Laffont, Paris, 1969. 491 pp., ilustr. Gérard et Cie., Verviers, 1969. 2 ts.: 237,253 pp., ilustr. |) $R y F, 183(1971), 110$ (Echánove); LNL, 1970, núm. 195, 99-100 (Ressot).

\section{Portugal}

21-3496. Quadros, ANTónio (ed.) $-A$ teoria da história em Portugal. T. 2: A dinâmica da história. Notas bio-bibliográficas de Pinharanda Gomes.-Espiral, Lisboa, 1969. 252 pp.-V. núm. 20-200.

21-3497. Dos Passos, John-The Portugal history. - Doubleday, New York, 1969. 394 pp.

21-3498. Carew, Dorothy - Portugal. Macmillan, London, 1969. 122 pp., ilustr.

21-3499. KempNer, MARY JEAN-Invitation to Portugal. - Atheneum, New York, 1969. $301 \mathrm{pp}$.

21-3500. Madden, Daniel M. - Spain d Portugal: Iberian portrait. - Nelson, Camden, N. J., 1969. 224 pp.

21-3501. Cucurull, Félix - Dos pobles ibèrics: Portugal i Catalunya.-Barcelona, 1967. $196 \mathrm{pp}$.

21-3502. BLÖCKER-WALTER, M. - Alfons $r$. von Portugal (N. 20-205). \|l Sp, 45 (1970), 276 (O'Callaghan) .

21-3503. MatToso, José - Le monachisme ibérique et Cluny. Les monastères du diocèse de Porto de l'an mille à 1200.Publications Universitaires, Louvain, 1968. $\mathrm{xx}+438$ pp., ilustr. (Recueil de trav. d'hist. et de philol., 39) . \| BHi, 72 (1970) , 405-410 (Cotrait); CCM, 13 (1970), 86-89 (Durand).
21-3504. Dalllezz, L. - "Essai historique sur l'Ordre souverain de Saint Jean de Jérusalem, de Rhodes et de Malte, au Portugal (xıIe-xve siècles)".-ACGP, I (1969), 13-52.

21-3505. Silva Dias, José Sebastião da$A$ politica cultural da época de D. João III. T. 1,-Instituto de Estudios Filosóficos da Universidade, Coimbra, 1969. lxxxiv + 1003 pp. $\| H A H R, 51$ (1971), 388-390 (Johnson).

21-3506. Saratva, ANTónio José-Inquisi. ção e cristãos-novos. - Inova, Porto, 1969. 319 pp. || BEP, 31 (1970), 365367 (Bourdon); HAHR, 51 (1971), 688-689 (Nevins) ; AION-R, 12 (1970), 116-117 (Reali) .

21-3507. BRANDÃo, MárIo-A Inquisição $e$ os professores do Colégio das Artes. T. 2, 1? parte.-Acta Universitatis Conimbrigensis, Coimbra, 1969. 1048 pp.

21-3508. Domingues, Mário-D. João IV e a campanha da Restauração.-Romano Torres, Lisboa, 1970. 508 pp. (Série Lusiada).

21-3509. SÁ, VICTOR DE-A crise do liberalismo $e$ as primeiras manifestaçóes das ideias socialistas em Portugal (1820-1852). -Seara Nova, Lisboa, 1969. 432 pp. !! Carav, 1971, núm. 16, 246-247 (Mauro); AION-R, 13 (1971), 153-155 (Melillo Reali) .

21-3510. Pinto da França, António-Portuguese influence in Indonesia.-Gunung Agung, Djakarta, Indonesia, 1970. xi + 118 pp., ilustr. || Ocid, 79 (1970), 270-273 (Paxeco).

\section{HISPANISMO Y VIAJES DE EXTRANJEROS}

21-3511. Zlotescu-Cioranu, I.--“Cel de-al treilea Congres al Asociatiei Internationale a Hispanistilor". - SLU, 13 (1969), 217-219.

21-3512. Labertit, A.--"Première réunion d'hispanistes européens (Santander, août 1969)".-LNL, 1969, núm. 191, 89-92.

21-3513. Elizalde, I.--“IV Congreso Internacional de Hispanistas en Salamanca (30 agosto-4 septiembre 1971)".- $-L D$, 1971, núm. 2, 137-140.

21-3514. Haensch-Zapp-Franzbach - Das Spanische in der Bundesrepublik Deutschland. - M. Hueber, München, 1970. $30 \mathrm{pp}$.

21-3515. Janner, H.-“El amor a España de Karl Vossler".-BRAE, 50 (1970), 349-363. 
21-3516. Alberich, J.- "Un hispanista inglés en la ruta de Don Quijote".-Arb, 73 (1969), núms. 283/4.

21-3517. Harvey, L. P.-"Samuel Miklos Stern".-BHS, 47 (1970), 57-59.

21-3518. Alonso Ibarkola, J. M.-"Redescubrimiento de un ilustre hispanista: Mario Penna".-CuH, 82 (1970), 429 . 432.

21-3519. BrLtRÁN, I.UIS-La cultura hispánica en Africa negra. (Los estudios hispánicos en las universidades negroafricanas y proposiciones para una acción cultural).-Centro de Estudios Afrohispánicos, Kinsangani, 1970. $28 \mathrm{pp}$.

21-3520. García-Lorenzo, L.-."Los estudios hispánicos en las Universidades canadienses". - BFE, 1969, núms. 32/3, 16-24.

21-3521. MeAD, R. G., JR.-"Progress in Hispanic studies in the United States since World war II". - H, 53 (1970), 386-396.

21-3522. GonzÁlez, M. P.-“A propósito del hispanismo norteamericano".-CuA, 1969, núm. 3, 221-234.

21-3523. Padilla, R. y E. Thompson, JR.El hispanismo en la Universidad de Illinois en Urbana".-BFE, 1970, núm. $34 / 5$.

21-3524. Morales Lezcano, V.-."Literatura de viajes como fuente histórica: Reedición de tres relatos".-MCan, 27/ 30 (1966-69), 187-219.

21-3525. ScudierI Ruggieri, J.-“II pellegrinaggio compostellano e l'Italia". CuN, 30 (1970), 185-198.

21-3526. Lomax, D. W.-"Algunos peregrinos ingleses a Santiago en la Edad Media".-PV, 31 (1970), 159-169.

21-3527. Devos, JÉrôme P.-Description de l'Espagne par J. Lhermite et H. Cock, humanistes belges, archers du Corp de la Garde Royale (1560-1622). - Paris, 1969. 135 pp.-V. núm. 9-13636.

21-3528. Domínguez ORTIz, A.- "La descripción de Madrid de Diego Cuelbis". -AIEM, 4 (1969), 135-144.

21-3529. Young, ARThur-Viatge a Catalunya (1787). Pròleg i trad, de R. Boixareu.-Barcelona, 1970. 113 pp.

21-3530. RIPOLL, LuIs-The Majorcan episode of Chopin and George Sand, 18381839. Transl. by W. Kirkbride.-A., Palma de Mallorca, 1969. 123 pp., ilustr.

21-3531. Gallut, A.- "Lisbonne et le Portugal de J. Pourcet de Fondcyre. De la caricature au fantastique". - $B E P, 31$ (1970) , 285-334.
21-3532. WeIner, J. - "El diario español de Alexander Nikolaevich Veselovskii (1859-1860)". - CuH, 84 (1970), 737 755.

21-3533. Borrow, GeOrge-La Biblia en España, o Viajes, aventuras y prisiones de un inglés en su intento de difundir las Escrituras por la Peninsula. Introd., notas y trad. de M. Azaña. - Alianza Editorial, Madrid, 1970. (El libro de bolsillo). || Íns, 1971, núm. 292 (Castroviejo) .

21-3534. FARnham, C. E.-American travellers in Spain.-AMS Press, New YorkLondon, 1969. [Reimpr. de la ed. de New York, 1921].

21-3535. Jackson, Gabriel - Historian's quest: $A$ twenty-year journey into the Spanish mind.-A. A. Knopf, New York, 1969. $235 \mathrm{pp}$.

21-3536. Clissold, StePhen-Spain.-Walker, New York, 1969. 186 pp.

21-3537. FORD, RICHARD-Gathering from Spain.-London, 1970. 824 pp.

21-3538. Ehrenburg, IlyA - Corresponsal en España. - Tiempo Contemporáneo, Buenos Aires, 1969. 212 pp.

21-3539. "Obras de autores estrangeiros sobre Portugal".-BIB, 10 (1969), 329. 363.

21-3540. OrwfLl, Gerge - Homenatge a Catalunya. Un testimoni sobre la revolució espanyola. Introd. de L. Trilling. Trad. de R. Folch i Camarasa.Barcelona, 1970. 218 pp. (Hores de Catalunya).

21-3541. ORwELl, GeORge - Homenaje a Cataluña. Un testimonio sobre la revolución española. Pról. de L. Romero. Introd. de L. Trilling. - Barcelona, 1970. 263 pp. (Horas de España).

21-3542. Iribarren, José María-Hemingway y los sanfermines.-Gómez, Pamplona, 1970. 215 pp. (Col. Ipar, 34).

21-3543. WRIGHT, RICHARD-España pagana. Trad. de A. Leal--Buenos Aires, 1970. 256 pp.-V. núm. 13-34312.

21-3544. Alan, RAy - Spanish quest. Macmillan, London, 1969. xi + $340 \mathrm{pp}$. 21-3545. EPTON, Nina-Spanish fiestas.Barnes, Cranbury, N. J., 1969. 250 pp. V. también núms. $3311,3500,3812,3820$, 4858.

\section{LINGÜÍSTICA}

\section{OBRAS GENERALES}

21-3546. Bibliographie linguistique de l'année 1966 et complément des années 
précédentes.-Spectrum, Utrecht-Anvers, 1968. xlvii + 528 pp.-V. núm. 21-207.

21-3547. Gipper, Helmut, \& HaNs Schwarz -Bibliographisches Handbuch zur Sprachinhaltforschung. Teil 1, Lief. 12-13.Westdeutscher Verl., Köln, 1969-70; pp. 1287-1542.--V. núm. 21-208.

21-3548. Index to "Language" 41-45 (19651969).-Lan, 46 (1970), No 2, Part. 2; 59 pp.-V. núm. 20-253.

21-3549. Actes du Xe Congrès International des Linguistes. (28 août-2 septembre 1967). Ts. 1, 2, 3, 4.-Académie de la République Socialiste de Roumanie, Bucarest, 1970. xcvi + 773, 1158, 777, 1184 pp.-V. núm. 19-292.

21-3550. Meetham, A. R., \& R. A. Hudson (eds.) - Encyclopaedia of linguistics, information and control. - Pergamon Press, London, 1969. xiv $+718 \mathrm{pp}$.

21-3551. Simone, RAFFAELE-Piccolo dizionario della linguistica moderna.-Loescher, Torino, 1969. 42 pp. (La ricerca, Serie didatica, 2) * \| LiS, 6 (1971), 149-151 (Conte).

21-3552. MARtinet, ANdré (ed.) - La linguistique.-Denoël, Paris, 1969. 490 pg. (Guides alphabétiques Médiations). "I $E m, 38$ (1970), 499 (Villar Liébana).

21-3553. PEI, M.-Glossary of linguistic terminology (N. 20-4445). \| LingP, 1968, núm. 2, 148-149 (Kovacec).

21-3554. Gerson, Stanley-A glossary of grammatical terms: an aid to the student of languages.-Univ. of Queensland Press, St. Lucia, 1969. 72 pp.

21-3555. SIMEON, RIKARD-Enciklopedijski rjecnik lingvistickih naziva na 8 jezika hrvatskosrpski, latinski, ruski, njemacki, engleski, francuski, italijanski, spanjolski. T. 1: A-O, T. 2: P-Z.-Matica hrvatska, Zagreb, 1969, lxiv + 1012, xiv + 926 pp. \| $R J, 21$ (1970), 195 (Muljacic).

21-3556. Linguistic studies presented to André Martinet on the occasion of his sixtieth birthday by his colleagues, students, friends. T. 1: General linguistics. Ed. by A. Juilland.-W. Clowes \& Sons, London, 1969. 591 pp. || PhP, 13 (1970), 167-168 (Polák); RRL, 15 (1970), 292-299 (Vintila Radulescu).

21-3557. Mélanges de philologie offerts à Alf Lombard à loccasion de son so $i$ xante-cinquième anniversaire par ses collègues et ses amis.-C.W.K. Gleerup, Lund, 1969. 252 pp. (Études romanes de Lund, 18) . I| SLC, 20 (1969), 666668 (Roceric) ; ZRPh, 86 (1970), 625647 (Schwake).

\section{Teoría del lenguaje}

21-3558. ARENS, HANs-Sprachwissenschaft. Der Gang ihrer Entwicklung von der Antike bis zur Gegenwart. 2. Aufl.-K. Alber, Freiburg, 1969. 832 pp.-V. núm. 11-25909. || Mundus, 6 (1970), 291-292 (Szemerényi) .

21-3559. Leroy, MaUrice-Las grandes corrientes de la lingüistica; lengua y estudios literarios. - Fondo de Cultura Económica, México, 1969.-V. núm. 19309. II BICC, 25 (1970), 303-305 (Martínez).

21-3560. Сномsкy, NoAm-Current issues in linguistic theory.-Mouton, The $\mathrm{Ha}$ gue, 1969. 119 pp. (Janua linguarum, Series minor, 38).-V. núm. 19-319.

21-3561. Mounin, GeORges-Clefs pour la linguistique. - Seghers, Paris, 1968. $186 \mathrm{pp}$.

21-3562. Mounin, G.-Claves para la lingüistica. - Edit. Anagrama, Barcelona, 1969. \| CuH, 82 (1970), 713-718 (Demonte).

21-3563. Hill, ARchibald A. (ed.) -Linguistics today.-Basic Books, New York, 1969. xii $+291 \mathrm{pp}$.

21-3564. Cerdá Massó, Ramón-Lingüistica, hoy.-Teide, Barcelona, 1969. 160 pp.-V. núm. 21-238. \| PhP, 13 (1970), 172-173 (Cerny); RRL, 14 (1969), 587588 (Sandru).

21-3565. Waterman, J. - Perspectives in linguistics (N. 18-4374). \|RBPH, 44 (1966), 222-223 (Jucquois).

21-3566. Waterman, J. T.-Die Linguistik und ihre Perspektiven (N. 20-278) $R F, 82(1970), 128-130$ (Lüdtke) .

21-3567. Chamorro, M. I. (ed.) -El Circulo de Praga. Tesis 1929. Trad. y bibliografía de...-Madrid, 1970. 61 pp.

21-3568. Travaux linguistiques de Prague (N. 19-304) . || SCL, 20 (1969), 680-683 (Popa-Tumescu) .

21-3569. VACHEK, J.-“On some less known aspects of the early Prague linguistic school".-CL(10), 2, 333-337.

21-3570. GodeL, ROBERT (ed.) -A Geneva school reader in linguistics. - Indiana Univ. Press, Bloomington, 1969. 361 pp.

21-3571. Gleason, H. A.-Introduction à la linguistique. Trad. de F. DuboisCharlier.-Larousse, Paris, 1969. 380 pp. (Sciences humaines et sociales). \| RLiR, 33 (1969), 439-440 (Perrin).

21-3572. WARTBURG, WALTER voN-Einführung in die Problematik der Sprachwis. senschaft. 3, durchgesehene Aufl.-Nie- 
meyer, Tübingen, 1970. 248 pp. - V. núm 18-4366. || RLiR, 34 (1970), 425 (Gardette) .

21-3573. Wartburg, Walther voN - Problems and methods in linguistics. Rev. ed. with the collaboration of S. Ullman. Transl. by J. M. Reid.-Basil Blackwell, Oxford; Barnes \& Noble, New York, 1969. $\mathrm{xl}+268$ pp. (Language and style series, 7). || MLR, 66 (1971), 160-161 (Potter); FS, 25 (1971), 501-502 (Spence) .

21-3574. Georgiev, V. I.--"Problèmes méthodologiques de la linguistique". $C L(10), 1,213-219$. [Discusiones, pp. 219$221]$.

21-3575. Salus, Peter H. - Linguistics. The Bobbs-Merril Co., Indianapolis-New York, 1969. xiv + 66 pp. \| Lan, 47 (1971), 181-185 (Percival).

21-3576. Perrot, JeAN - La lingüistica. Trad. de N. Clará.-Oikos-Tau, Vilasar de Mar, 1970. 127 pp. (¿Qué sé?, 6) -V. núm. 9-16019.

21-3577. Silva Borba, Francisco da-Introdução aos estudos lingüísticos. 2a ed., revista e ampl.--Editora Nacional, São Paulo, 1970. 316 pp. (Bibl. universitária, 3) .-V. núm. 20-281.

21-3578. HundSNURSCHER, F., B. InSAM, et al. - Linguistik. Bd. 1: Lehr- und Ubungsbuch zur Einführung in die Sprachwissenschaft.-M. Niemeyer, Tübingen, 1970.

21-3579. Aкhмanova, O. S.-“Linguistics and the quantitative approach" $-C L(10)$, 1, 151-156. [Discusiones, pp. 156-174].V. núm. 20-313.

21-3580. LANTERT, LAURA, et al.-Introducción al estructuralismo.-E1 Mangrullo, Buenos Aires, 1969. 193 pp.

21-3581. PIAGET, J.-Le structuralisme (N. 21-262) . || LingP, 1969, núm. 1, 139142 (François).

21-3582. MaLAgoli, LUIGI - Strutturalismo contemporaneo.-Pàtron, Bologna, 1969. 279 pp. || LiS, 6 (1971) , 166-167 (Conte).

21-3583. Corvez, MaUrice-Les structuralistes, - Aubier, Paris, 1969. 203 pp. II LiS, 6 (1971), 165-166 (Arcaini); $B A b r, 44$ (1970), 255 (Gershman).

21-3584. MALMBerg, Bertil - Lingüistica estructural y comunicación humana. Introducción al mecanismo del lenguaje $y$ a la metodologia de la lingüistica. Versión de E. Rodón Binué.-Gredos, Madrid, 1970. 325 pp. (BRH, Manuales, 20).-V. núm. 19-349. \| Fil, 14 (1970), 222-232 (Lois).
21-3585. Rodríguez Adrados, FranciscoLingüistica estructural. - Gredos, Madrid, 1969. 2 ts.: 544, 561 pp. (BRH, Manuales, 22) .

21-3586. USPENSKY, B.-Principles of structural typology.-Mouton, The Hague, 1969. 80 pp. (Janua linguarum).

21-3587. Greimas, A. J., et al.-Estructuralismo y lingüistica. - Nueva Visión, Buenos Aires, 1969. (El pensamiento estructuralista).

21-3588. BALdinger, K.-"Structures et systèmes linguistiques" (N. 20-307) . ||VR, 29 (1970), 136-138 (Wunderli).

21-3589. Save, H., et al-Dialéctica y estructuralismo.-El Mangrulo, Buenos Aires, 1969. $222 \mathrm{pp}$.

21-3590. MARCUS, S.-Introduction mathématique $\grave{a}$ la linguistique structurale (N. 20-306). $\|$ Rev. Roum. des Math. Pures et Appl., 15 (1970), 158-159 (Craciun); LingP, 1969, núm. 2, 155. 158 (Jannot).

21-3591. Cosfriu, E. - "Georg von der Gabelentz et la linguistique synchronique".-HAM, 1, 74-100.

21-3592. MalmberG, B. - "Synchronie et diachronie".-CL(10), I, 13-25 [Discusiones, pp. 25-36].-V. núm. 20-298.

21-3593. Gutu-Romalo, V. - “Diachronie et synchronie".-CL(10), 1, 483-488.

21-3594. ArCaini, E.-"Sincronia e diacronia nelle prospettive della ricerca e dell' applicazione".-LiS, 4 (1969), 351-365.

21-3595. Coseriu, Eugenio - Sincronia, diacronia e historia. El problema del cambio lingüístico. - Tubingen, 1969. 164 pp. [Reimpr.].-V. núm. 13-34345.

21-3596. CoSERIU, E.-"Sincronía, diacronía y tipología".-CLR(11), 1, 269-281.

21-3597. Mounin, Georges (ed.) - Saussure. Presentación y textos. Trad. de J. Argente.-Barcelona, 1969. 159 pp. (Argumentos, 3) .

21-3598. GODEL, ROBERT-Les sources manuscrites $d u$ "Cours de linguistique générale" de Ferdinand de Saussure.Droz, Genève, 1969. 282 pp. (Publ. romanes et françaises, 61).-V. núm. 1334343. \| $R P h, 23(1969-70), 201-214$ (Connors) .

21-3599. Wittman, H. G. - “Saussure's theory of language".-CL(10), 2, 279-283. 21-3600. Martinet, ANdré - Elements of general linguistics. With a foreword by L. R. Palmer. Tr. by E. Palmer.-Faber \& Faber, London, 1969. 228 pp.-V. núm. 19-339.

21-3601. RoBins, R. H.-Manuale di lin- 
guistica generale. Introd. di T. De Mauro. Trad. di R. Simone.-Laterza, Bari, 1969. xii + 480 pp.-V. núm. 19-336. || LiS, 4 (1969), 461-464 (Scalise).

21-3602. Rodríguez Adrados, FranciscoEstudios de lingüistica general.-Planeta, Barcelona, 1969. 325 pp. (Ensayos Planeta). \| Proh, 1 (1970), 136-138 (Villar Liébana).

21-3603. Herdan, G.-"The crisis in modern general linguistics".-LingP, 1967, núm. 1, 27-37.

21-3604. Bos, Gijsbertha F. - Categories and border-line categories. A synchronic study in general linguistics.-A Hakkert, Amsterdam, 1967. 75 pp.

21-3605. Uldall, HANS JORGEN-Outline of glossematics. Part. I: General theory. 2nd. ed.-T.C.L.C.X., Copenhague, 1967. $92+$ xxii pp. $\| R R L, 16(1971)$, 359361 (Belchita).

21-3606. Christensen, B. W.-“Glossématique, linguistique fonctionnelle, grammaire générative et stratification du language".-HAM, 1, 57-73.

21-3607. Сномкку, Noam-Saggi linguistici. T. 1: L'analisi formale del linguaggio.-Boringhieri, Torino, 1969. $420 \mathrm{pp}$.

21-3608. Сномяку, NoAм-Lingüistica cartesiana. Un capitulo de la historia del pensamiento racionalista. Trad. de E. Wulff.-Gredos, Madrid, 1969. I58 pp. (BRH, Estudios y ensayos, 135). - V. núm. 20-263.

21-3609. Otero, C. P.-Introducción a la lingüistica transformacional. (Retrospectiva de una confluencia).-Siglo XXI, México, 1970. 332 pp., ilustr. (Teoria y critica).

21-3610. Saltarelli, Mario-La grammatica generativa trasformazionale. (Con introd. alla fonologia, sintassi e dialettologia italiana). - Sansoni, Firenze, 1970. 157 pp. || Proh, 1 (1970), 488498 (Barrado Belmar).

21-3611. Arcaini, E.-“Contributi recenti all'analisi generativo-trasformazionale". -LiS, 4 (1969), 423-434.

21-3612. LeUNINGER, HELEN-Scholastische und transformationelle Sprachtheorie. Ein Beitrag zur Theorie der allgemeinen Grammatik.-[Tesis, Univ. de Frankfurt, 19707 .

21-3613. Lehmann, Winfred P.-Einführung in die historische Linguistik. Ubers. von R. Freudenberg.-C. Winter, Heidelberg, 1969. 230 pp. (Sprachwissen. schaftliche Studienbücher).-V. núm. 18465.
21-3614. LehmanN, Winfred P.-Introducción a la lingüistica histórica. Versión de P. Gómez Bedate-Gredos, Madrid, 1969. 354 pp. (BRH, Manuales, 21).-V. núm. 18-465.

21-3615. Devoto, G.-“Il metodo comparativo classico e le correnti linguistiche attuali".-CL(10), 1, 123-135. [Discusiones, pp. 136-149].-V. núm. 20-290.

21-3616. Gleason, H. A., JR.-Introducción a la lingüistica descriptiva. Trad. E. Wulff Alonso. - Gredos, Madrid, 1970. 700 pp. (BRH, Manuales, 26).V. núm. 17-3529. || $C D, 185$ (1972), 173-175 (Justel).

21-3617. WALlwork, J. F.-Language and linguistics. An introduction to the study of language.-Heinemann, London, 1969. 184 pp. || SCL, 21 (1970), 698-699 (Roceric).

21-3618. MARTINeT, ANDrÉ - Langue et fonction, une théorie fonctionnelle $d u$ langage. Trad. par $\mathrm{H}$. et G. Walter.Denoël, Paris, 1969. 199 pp. (Coll. Médiations). \| ZRPh, 85 (1969), 636 (Baldinger) .

21-3619. SAPIR, E.-Il linguaggio. Introduzione alla linguistica. A cura di P. Valesio.-Einaudi, Torino, 1969. xxxiv + 227 pp. || LiS, 4 (1969), 279-280 (Scalise) .

21-3620. CoHEN, MARCEL-Language: its structure and evolution. Tr. by $\mathrm{L}$. Muller.-Univ. of Miami Press, Coral Gables, 1970. 157 pp. (Miami linguistics series, 7).-V. núm. 6-7763.

21-3621. Schlauch, Margaret - Language and the study of languages today. Polish Scientific Pubs., Warsaw, 1969. 176 pp.-V. núm. 20-276.

21-3622. Rossi, ALeJANdro - Lenguaje y significado. - Siglo XXI, México, 1969. 152 pp. (Ser. Teoria critica).

21-3623. Serbanescu, F. - Conversazioni sulla statistica linguistica.-Ed. Tecnico Scientifica, Pisa, 1969. 114 pp. $\|$ LiS, 5 (1970), 334-335 (Albano Leoni).

21-3624. Dolezel, Lubomír, \& Richard W. BAILey (eds.) - Statistics and style.American Elsevier, New York, 1969. x + 245 pp. (Mathematical linguistics and authomatic language processing, 6). II Lan, 46 (1970), 227-229 (Miles); $M L R$, 66 (1971), 164-165 (Tallentire).

21-3625. JAKOBson, R.-“Linguistics in its relation to other sciences". - $C L(10), 1$, 75-111. [Discusiones, pp. 111-122].

21-3626. JAKOBSON, ROMAN - Lingüistica $e$ comunicaşão. Pref. de I. Blikstein. Trad. 
de I. Blikstein e J. P. Paes.-Cultrix, São Paulo, 1969. 162 pp. \|StL, 24 (1970), 69-72 (Malmberg).

21-3627. WHORF, BENJAMIN L.-Linguistique et anthropologie. Les origines de la sémiologie.-Denoël, Paris, 1969. 220 pp.

21-3628. Fishman, JoshuA A. (ed.)-Readings in the sociology of language. 2nd printing. - Mouton, The Hague, 1970. 808 pp.

21-3629. Uribe Villegas, ÓSCAR-Sociolingüistica - U.N.A.M., México, 1970. 201 pp.

21-3630. PoнL, J--"Probleme actuale ale sociolingvisticii". - LbR, 19 (1970), 283-293.

21-3631. ELLIS, J.-"Some lines of research in sociolinguistics". - CL(10), 1, 565568. [Discusiones, pp. 568-570].

21-3632. TABOURET-Keller, A., et R. B. LE PAGE-“L'enquête sociolinguistique à grande échelle".-LingP, 1970, núm. 2, 103-118.

21-3633. WIDLAK, S. - "Sur la relation entre la psycholinguistique et la stylistique". - CL(10), 3, 223-228.

21-3634. La stylistique. - Larousse, Paris, 1969. 128 pp. (Langue française, 3). II Proh, 1 (1970), 130-135 (Rolland).

21-3635. Prieto, L. J.-“Langue et style". -LingP, 1969, núm. 1, 5-24.

21-3636. UITTI, KARL D. - Linguistics and literary theory. - Prentice Hall, Englewood Cliffs, N. J., 1969. xv + 272 pp. (Princeton studies of humanistic scholarship in America). || $M L R, 66$ (1971), 161-162 (Culler) ; BAbr, 43 (1969), 607608 (Hart) ; RPh, 23 (1969-70), 323335 (Malkiel) ; FS, 26 (1972), 244-245 (Ullmann) .

\section{Estudios lingüísticos generales}

21-3637. MALMBERG, BERTIL - Introduktion till fonetiken som vetenskap.-Natur och Kultur, Stockholm, 1969. 238 pp.

21-3638. MARTINeT, ANDRÉ-Économie des changements phonétiques. Traité de phonologie diachronique. 3e éd. Francke, Berne, 1970. 396 pp.-V. núm. 11-27277.

21-3639. Monot, P. - "Note au sujet des précurseurs de la phonologie". $-H A M$, $1,414-421$.

21-3640. Trubetzkoy, N. S.-Principles of phonology. Tr. by Chr. A. M. Baltaxe. -Univ. of California Press, Berkeley, 1969. xvi + 344 pp. || Lan, 47 (1971). 918-931 (Cairns).
21-3641. Grimes, Joseph E. - Phonological analysis. Part I. - Summer Institute of Linguistics, Santa Ana, Calif., 1969. $187 \mathrm{pp}$.

21-3642. Ebfling, C. L. - "Some premises of phonemic analysis". $-H A M, 1,122-$ 137.

21-3643. MULJACIC, Zarko - Fonologia generale e fonologia della lingua italiana. - Il Mulino, Bologna, 1969. 595 pp. |l $R J, 21(1970), 203-204$ (Giese) .

21-3644. HAтtoRI, S. - "The principle of assimilation in phonemics". - $H A M, 1$, 257-264.

21-3645. Ducrot, O. - "La commutation en glossématique et en phonologie".HAM, 1, 101-121.

21-3646. НАMm, JosepH (ed.) -Phonologie der Gegenwart. - Hermann Böhlhaus, Wien-Köln, 1967. 388 pp. \| LingP, 1971, núm. 2, 147-153 (Milner); SCL, $21(1970), 700-701$ (Vincenz) .

21-3647. Haldricourt, A. C. - “Consonnes nasales et demi-nasales dans l'évolution des systèmes phonologiques". CL(10), 4, 105-108.

21-3648. Rodón, E.- "On the grammatical relevance of prosodemes". $-C L(10), 2$, $721-724$.

21-3649. Humboldt, G. dE - De l'arigine des formes grammaticales. [Seguido de] Lettre à $M$. Abel Rémusat. - Ducros, Bordeaux, 1969. 155 pp. || FS, 25 (1971), 503-504 (Spence) .

21-3650. Al.ARcos LxORACH, EMILIO-Gramática estructural. (Según la escuela de Copenhague, y con especial atención a la lengua española). 1? reimpr.-Gredos, Madrid, 1969. 128 pp. (BRH, Manuales, 3) .-V. núm. 6-7846.

21-3651. Akнmanova, Olga, \& Galina MIKAFL'AN - The theory of syntax in modern linguistics. - Mouton, The Hague, 1969. 149 pp. (Janua linguarum). 21-3652. SGall, Petr, et al.-A functional approach to syntax in generative description of language. - Elsevier, New York, 1969. 122 pp. (Mathematical linguistics and automatic language processing, 7) . \|Lan, 47 (1971), 691-700 (Loockwood). 21-3653. KIEFFr, F. (ed.) - Studies in syntax and semantics. - DordrechtHolland, 1969. 242 pp. (Foundations of language, Supplementary series, 10). I ZRPh, 87 (1971), 602-611 (Rohrer) .

21-3654. RonA, J. P. - "Les parties du discours: un niveau d'organisation du langage". - $C L(10), 1,337-341$.

21-3655. Koch, W. A. - Von Morphem 
zu Textem. From morpheme to texteme. -Georg Olms, Hildesheim, 1969. x + $245 \mathrm{pp}$.

21-3656. Weinrich, Harald - Estructura y función de los tiempos en el lenguaje. -Gredos, Madrid, 1968. 430 pp. (BRH, Estudios y ensayos, 115). \|ALM, 9 (1971), 262-265 (Colombo Airoldi); Proh, 1 (1970), 143-148 (Fente).

21-3657. WeINRICH, H.-“Tense and time". $-A L$, new series, 1 (1970), 31-41.

21-3658. SkrÉlina, L. M.--"Sur le problème de l'économie des changements morphologiques". - $C L R(12), 1,535-540$.

21-3659. Mounin, G. - "Travaux récents de sémantique". - LingP, 1968, núm. 1, 131-140.

21-3660. WeINREICH, URIEL - Erkundungen zur Theorie der Semantik. Ins Deutsche über. und mit einem Vorwort versehen von L. Lipka. - M. Niemeyer, Tübingen, 1970. $\mathrm{x}+117$ pp. (Konzepte der Sprach- und Literaturwissenschaft, 4).

21-3661. Heger, K. - "La semántica ante la dicotomía de lengua y habla". PILEI(4), 116-123.

21-3662. Filipec, J. - "Zum Aufbau einer struckturellen Lexikologie und lexikalischen Semantik". - CL(10), 2, 601-607.

21-3663. DuChíceK, O. - "Sur le problème de la structure du lexique". - $C L R(12)$, 1, 863-867.

21-3664. Poldauf, I. - "Semantics, lexicology, and generative grammar". - $P h P$, $13(1970), 65-73$.

21-3665. Azevedo Filho, L. A. de - "A teoria neológica de Prieto". - $R P, 39$ (1968) , 121-152.

21-3666. Rey-Debove, Josette (ed.) $-L a$ lexicographie. - Didier-Larousse, Paris, 1970. 119 pp. (Langages, 19) .

21-3667. Roceric-Alexandrescu, A.-"Probleme generale de lexico-statistica".SCL, 20 (1969) , 373-383, 535-543.

21-3668. Wahring, G. - Neue Wege in der Wörterbucharbeit (N. 20-4565). I $N, 54$ (1970), 195-196 (Tollenaere).

21-3669. IsING, E.-"Methodologische Probleme eines sprachwissenschaftlichen Wörterbuches auf historischer Grundlage". - $C L(10), 4,465-469$.

21-3670. Martinet, A. - "Pourquoi des dictionnaires étymologiques?" - LingP, 1966, núm. 2, 123-131.

21-3671. KLARE, J.-"Zur Problematik der Wortschatzgliederung". - $C L(10), 1,713$ 718. [Discusiones, pp. 718-720].

21-3672. SCHMID, WOLFGANG, P. - Skizze einer allgemeinen Theorie der Wortarten. - F. Steiner, Wiesbaden, 1970. 26 pp. || ZRPh, 86 (1970), 671 (Baldinger). 21-3673. CoLón, G.-“Zum Zwanzigersystem der Zahlwörter". - Festschrift Gamillscheg, 127-133.

21-3674. KrAMSKY, JIRI - The word as a linguistic unit. - Mouton, The HagueParis, 1969. 83 pp. (Janua linguarum, Series minor, 75). II PhP, 13 (1970), 166-167 (Nosek) .

21-3675. Mizutani, S. - "A method for semantic description of words". $-C L(10)$, 2, 345-348.

21-3676. Kflemen, B. - "Un problème controversé de la lexicologie: la structure sémantique des mots". - CLR(12), 1, 855-861.

21-3677. Rechenbach, Charles W., \& EUgene R. GARNeTt - A bibliography of scientific, technical and specialized dictionaries: polyglot, bilingual, unilingual. - The Catholic University of America Press, Washington, 1969. 158 pp.

21-3678. Bergman, Peter M. (ed.) - The concise dictionary of 26 languages in simultaneous translation. - The New American Library, New York, 1968. 408 pp. \|l $L b R, 20$ (1971), 619-622 (Danaila).

21-3679. Benveniste, EMILE - Le vocabulaire des institutions indo-européennes. T. 1: Économie, parenté, société. T. 2: Pouvoir, droit, religion. - Editions de Minuit, Paris, 1969. 376, 340 pp.

21-3680. Baldinger, K.-"Zur Entwicklung der Tabakindustrie und ihrer Terminologie".-Philologische Studien für J.-M. Piel (1969), 30-61.

21-3681. Bibliographia onomastica, 1963.On, 13 (1968), 1-167.-V. núm. 21-337. 21-3682. SмITH, E. C. - "Bibliography of personal names, 1968". - Names, 17 (1969), 223-234. - V. núm. 21-338.

21-3683. Proceedings of the IX International Congress of onomastic sciences (N. 21-336) - || Names, 18 (1970), 53-54 (Smith) .

21-3684. LutTERER, I. - "Sociolinguistics and the study of personal names". $C L(10), 1,581-586$. [Discusiones, pp. 586$587]$.

21-3685. Cốrtes RIEdel, D. - "Os nomes próprios na construção da obra literária".-HJC, 77-88.

21-3686. Huвschmid, J. - "Toponymie". -Ann. de l'École Pratique des Hautes Etudes, Paris, 1969-70, 517-521.

21-3687. Losique, S.-"Dictionnaire étymo- 
logique des noms de pays et de peuples". -On, 14 (1969), 50-54.

21-3688. IORDAN, I. - "Les rapports entre la toponymie et l'anthroponymie". On, 14 (1969) , 14-22.

21-3689. Stellmacher, D. - "Der Name in der dialektgeographischen Untersuchung". - On, 15 (1970), 45-51.

21-3690. VoIGr, W. - "Les niveaux des variantes de proverbes. (Un ancien problème du folklore sous un éclairage nouveau)". - $A L B, 20$ (1970), 357-364.

21-3691. Atti del Convegno Internazionale sul tema: Gli atlanti linguistici, problemi e risultati. Roma 20-24 ottobre 1967.Accademia Nazionale dei Lincei, Roma, 1969. 338 pp. (Problemi attuali di scienza e di cultura, 111) . ||ZRPh, 87 (1971), 592-596 (Wolf) .

21-3692. GoOssens, JAN - Strukturelle Sprachgeographie: eine Einführung in Methodik und Ergebnisse. - C. Winter, Heidelberg, 1969. 148 pp. (Sprachwissenschaftliche Studienbücher, 2).

21-3693. Rusu, V. - "Tradition et innovation dans le domaine de la dialectologie". - CL(10), 2, 95-100.

21-3694. BEYER, E. - "Structuralisme et dialectologie moderne. Points de vue d'un dialectologue". - CL(10), 2, 5-12.

21-3695. Francescato, G. - "Linguistique typologique et dialectologie structurale". $-C L(10), 3,627-635$.

21-3696. Alvar, MANuel - Estructuralismo, geografia lingüistica y dialectologia actual. - Gredos, Madrid, 1969. 222 pp. (BRH, Estudios y ensayos, 137). II BH $i$, 72 (1970), 491-492 (Cotrait); Rom, 3 (1970) , 182-187 (Díaz Vélez); RLiR, 35 (1971) , 225-227 (Gardette); Orbis, 19 (1970) , 237-241 (Larochette); BICC, 25 (1970), 295-297 (Montes Giraldo).

21-3697. HuBschmid, J. - "Sprachgeographie und Substratforschung". - HWW, 2, 3-17. || RJ, 20 (1969), 167 (Muljacic).

21-3698. KUEN, H. - "Die Sprachgeographie als Wissenschaft vom Menschen". - [En sus] Romanistische Aufsätze (Nürnberg, 1970), 203-240. - V. núm. 18-595.

21-3699. ReNsch, K. H. - "Die adia-synchronische» Verwandtschaft von Phonemsystemen. Ein Beitrag zur strukturellen Dialektologie". - Orbis, 19 (1970), 94-101.

21-3700. Alvar, M. - "Lengua y dialecto: Delimitaciones históricas estructurales". -Arb, 76 (1970), núm. 299.

21-3701. Hall, R. A., JR. - "Idioletto, dialetto, lingua". - Studi... Vittore Pisani (Brescia, 1970), 515-534.

21-3702. Moulton, W. G.-"Contributions of dialectology to phonological theory". $-C L(10), 2,21-26$.

21-3703. Fishman, J. A., \& E. Herasimchuk - "The multiple prediction of phonological variables in a bilingual speech community". - AA, 71 (1969), 648-657.

21-3704. Ellrs, S. - "The assessment of linguistic boundaires by local dialect speakers". - CL(10), 2, 109-112.

21-3705. Petrovici, E. - "Interpénétration des systèmes linguistiques". - CL(10), 1, 37-56. [Discusiones, pp. 57-73].

\section{LATIN}

21-3706. Stolz, F., A. Debrunner, e W. P. SCHмID - Storia della lingua latina. Trad. di C. Benedikter; introd. e note di A. Traina. - Pàtron, Bologna, 1968. xlii + 236 pp. - V. núm. 20-407. $\| A A b$, 1969 núms. 2/3, 88-90 (Bertoli); Conv, 37 (1969), 704-707 (Catalini); PI, 10 (1968) , 381 (Frassinetti) ; $A C, 38$ (1969), 618-620 (Liénard); Helm, 20 (1969), 186 (Oroz); Maia, 21 (1969), 188-192 (Puccioni); Lat, 28 (1969), 790 (Thomas).

21-3707. Pasini, G. F. - "Postille a una storia della lingua latina". - LiS, 6 (1971), 499-505.

21-3708. RuBIo, L. - Introducción a la sintaxis estructural del latin, t. 1 (N. 20-413). II Aevum, 43 (1969), 355 (Semi) -V. núm. 20-4607.

21-3709. Traina, A., e T. Bertotti - Sintassi normativa della lingua latina. $\mathrm{T}$. 1: Le concordanze. Il nome. T. 2: Il verbo. T. 3: Il periodo. $2^{\text {a }}$ ed., corr.Cappelli, Bologna, 1969. 386, 258, 341 pp.

21-3710. Mignot, X. - Les verbes dénominatifs latins. - Klincksieck, Paris, 1969. 417 pp. || Em, 38 (1969) , $472-473$ (Gil) . 21-3711. QUELLET, HeNRI - Les dérivés latins en "-or". Etude lexicographique, statistique, morphologique et sémantique. - Klincksieck, Paris, 1969. 246 pp. || Em, 38 (1970), 473-474 (Villar Liébana).

21-3712. "Beiträge aus der Thesaurusarbeit, XVI". - MHe, 26 (1969) , 40-45.V. núm. 21-364.

21-3713. MrккоLA, E. - Die Abstraktion im Lateinischen, 1. Teil (N. 19-513) . II LingP, 1968, núm. 1, 141-143 (Bader). 


\section{Lattn vulgar y medieval}

21-3714. Grandgent, C. H. - Introducción al latin vulgar. 4a ed. - C.S.I.C., Madrid, 1970. 383 pp. - V. núm. 18-611.

21-3715. Safarewicz, J.-“A quelle époque commence le latin dit vulgaire".-Stu. di... Vittore Pisani (Brescia, 1970), 863-872.

21-3716. Engels, J. - "Latin vulgaire, roman comun, latin médiéval". CLR(12), 1, 121-124.

21-3717. Graur, A. - "Latin vulgaire?"CLR(12), 1, 117-119.

21-3718. Rohlfs, GerHARD - Sermo vulgaris latinus. Vulgärlateinisches Lesebuch. 3. Aufl. - Niemeyer, Tübingen, 1969. 110 pp. - V. núm. 14-38238. \|Em, 38 (1970), 503 (Tovar) .

21-3719. Gaeng, Paul A. - An inquiry into local variations in Vulgar Latin, as reflected in the vocalism of Christian inscriptions. - Univ, of North Carolina Press, Chapel Hill, 1968. 299 pp. (Studies in the Romance languages and literatures, 77) . - V. núm. 20-4634. \| RRL, 15 (1970) , 404-411 (Tekavcic); $R J, 21$ (1970), 196-197 (Väänänen).

21-3720. Gasc.4 Queirazza, G. - "Note storiche sulla formazione del tipo avverbiale latino-volgare agg. + -mente". $-C L R(12), 1,109-113$.

21-3721. "Dictionnaire du latin médiéval". $-B A B, 55$ (1969), 408-415.

21-3722. Blatr, Frans (ed.) - Notum glossarium mediae latinitatis $a b$ anno DCCC usque ad annum MCC. Fasc. Norma-Nysus. - Munksgaard, Köbenhavn, 1969; cols. 1369-1584. - V. núm. $21-378$.

21-3723. PrInZ, O., et al. - Mittellateinisches Wörterbuch bis zum ausgehenden 13. Jahrhundert. Bd. 2. Lief. 2: canicularis-casalinus. - Beck, München, 1969; cols. 161-320. - V. núm. 21-379.

21-3724. Glossarium mediae latinitatis Cataloniae. Fasc. 5-6: clausa-cyrographare. - C.S.I.C., Barcelona, 1969-1971; cols. 513-768. - V. núm. 20-424.

21-3725. Arnaldi, F., \& P. Smiraglia "Latinitatis Italicae medii aevi Lexicon imperfectum. Addenda 2: Ba-Cleris".ALMA, 36 (1967-68), 5-50. - V. núm. $21-380$.

21-3726. Kostrencic, M., et al--Lexikon latinitatis medii aevi Iugoslaviae. T. 1: A-clericellus. - Hakkert, Amsterdam, 1969. xxi $+232 \mathrm{pp}$.

21-3727. Glossarium mediae latinitatis
Sueciae. T. 1, fasc. 1-2: a-confinis. Almqvist \& Wiksell, Stockholm, 19681969; pp. 1-216. || Em, 39 (1971), 234235 (Codoñer); Zpráuy Jednoty Klasickysh Filologu, Praha, 11 (1969), 103105 (Martinková).

\section{LINGÜISTICA ROMÁNICA}

21-3728. Revue de Linguistique Romane. Table des tomes 1-30 (1925-1966). T. 1: Table des mots, par P. Gardette. Strasbourg, 1969. 469 pp. [RLiR, numéro spécial]. || $B H i, 72$ (1970), 523 (Pellen). 21-3729. Actas del XI Congreso Internacional de Lingüistica y Filologia Románicas.-C.S.I.C., Madrid, 1968. 4 ts. (RFE, anejo 86) .-V. núm. 19-539.

21-3730. Paiva Boléo, M. DE - Os estudos de linguistica românica na Europa $e$ América desde 1939 a 1960. T. 2.-Casa do Castelo, Coimbra, 1969. xi +461 pp. - v. núm. 6-8487. || ZRPh, 86 (1970), 664-666 (Giese); RJ, 21 (1970), 360-361 (Kröll) .

21-3791. Cornea, P. - "Cîte ceva despre activitatea romanistilor cehoslovaci". Revista de Istorie si Teorie Literara, Bucuresti, 18 (1969), 293-297.

21-3732. Philologische Studien für Joseph M. Piel. Hrsg. von W.-D. Lange und H. J. Wolf. - C. Winter, Heidelberg, 1969. 239 pp. \| ZRPh, 86 (1970), 617622 (Christmann).

21-3733. SGhwake, H. P. - "Kurt Baldinger: notice bio-bibliographique à l'occasion de son cinquantieme anniversaire". - RLiR, 33 (1969), 392-405.

21-3734. Contini, G. - "Rapporti fra la filologia (come critica testuale) e la linguistica romanza". - CLR(12), 47-65. 21-3735. JORDAN, I. - Lingüistica románi$c a$ (N. 20-4676). || $A L I L, 21$ (1970), 179-181 (Istrate).

21-3736. Taglavini, C. - Le origini delle lingue neolatine. Introduzione alla filologia romanza. $5^{\mathrm{a}}$ ed. interamente rielaborata.-R. Pàtron, Bologna, 1969. xxxv + 681 pp., ilustr.-V. núm. 19-555. || $Z R P h, 86$ (1970), 672 (Baldinger); LiS, 5 (1970), 339-340 (Scalise) ; RJ, 21 (1970), 199-202 (Schürr) .

21-3737. Pottier, B. - "Linguistique générale et linguistique romane. (Synthèse) ". - CLR(12), 1, 99-105.

21-3738. ROHR, RUPPRECHT - Einführung in das Studium der Romanistik. 2. Aufl. -Erich Schmidt Verlag, Berlin, 1969. 187 pp. - V. núm. 19-552. 
21-3739. KUEN, HeINRICH-Romanistische Aufsätze. - Hans Carl, Nürnberg, 1970. $\mathrm{xi}+437$ pp. (Erlanger Beiträge zur Sprach- und Kunstwissenschaft, 35) . II ZRPh, 86 (1970), 590-591 (Baldinger).

21-3740. Hall, R. A., JR.-"Coerenza e realismo nella ricostruzione del protoromanzo". - LiS, 4 (1969), 399-404.

21-3741. VÄ̈̈NÄNEN, V. - "Sur le recensement des faits protoromans".-CLR(12), $1,141-145$.

21-3742. EyssenhaRdT, F. - Römisch und Romanisch. Ein Beitrag zur Sprachgeschichte. - M. Sänding, Wiesbaden, 1969. 204 pp. [Reimp. de la ed. de 1882].

21-3743. Mendeloff, Henry - A manual of comparative Romance linguistics. Phonology and morphology. - The Catholic Univ. of America Press, Washington, 1969. xiv + 123 pp. $\| Z R P h, 87$ (1971), 131-134 (Baldinger); $M L J, 55$ (1971), 13I-132 (Klausenburger) ; Orbis, $19(1970), 241-243$ (Larochette) .

21-3744. Wfinrich, Harald - Phonologische Studien zur romanischen Sprachgeschichte. 2 Aufl--Aschendorff, Münster, 1969. 291 pp. - V. núm. 14-38264.

21-3745. ManczaK, Witold - Le développement phonétique des langues romanes et la fréquence. - Jagiellonski Universitet, Kraków, 1969. 98 pp.

21-3746. Ivanescu, G. - "Les problèmes des tendances phonétiques romanes".CLR(12), 1, 409-417.

21-3747. Vasiliu, E. - "La chronologie de la diphtongaison des lat. [e long, $e$ bref] et quelques problèmes connexes". CLR(12), 1, 391-392.

21-3748. SCHürR, F. - "Epilegomena à la diphtongaison romane en général, roumaine et ibéroromane en particulier". -RLiR, 33 (1969), 17-37.

21-3749. Hilty, G. - "Zur Diphthongierung im Galloromanischen und im Iberoromanischen". - HJMP, 95-107.

21-3750. Avram, A. - "Parallèles romans dans l'évolution des consonnes vibrantes". - CLR(12), 1, 299-304.

21-3751. PISANI, V.-“Tipi d'accento nelle lingue dell'Europa". - CL(10), 2, 57-61.

21-3752. Munteanu, S. - "Mijloacele gramaticale de expresie stilistica în limbile romanice".-CLR(12), 1, 427-430.

21-3753. Tutescu, M. - "Le type nominal *ce fripon de valet»". - RLiR, 33 (1969), 298-316.

21-3754. MANCzAK, W. - "Survivance du nominatif singulier dans les langues romanes". - RRo, 4 (1969), 51-60.
21-3755. Illescu, M. - "Stammen die romanischen Substantive lateinischen Ursprungs von der Akkusativform ab?"RRL, 14 (1969), 477-479.

21-3756. Manoliu-Manea, M. - "Accusativus cum infinitivo» dans les langues romanes. (Complétive ou relative?)".-Cahiers de Ling. Théorique et Appliquée, Bucarest, 6 (1969), 125-136.

21-3757. Ilifscu, M. - "Ressemblances et dissemblances des langues romanes $\mathrm{du}$ point de vue de la structure verbale".CLR(12), 1, 239-240.

21-3758. Iliescu, M. - "Ressemblances et dissemblances entre les langues romanes du point de vue de la morpho-syntaxe verbale". - RLiR, 33 (1969), 113-143.

21-3759. Silnitsky, G. - "Les verbes bifonctionnels dans les langues romanes, l'anglais et le russe". - $C L R(12), 1,273$ 276.

21-3760. VALfsio, P.-“La genèse du futur roman". - GLR(12), 1, 807-813.

21-3761. VAlesio, P. - "La genesi del futuro romanzo". - LiS, 4 (1969), 405. 412.

21-3762. WunderLI, P.-“Die Bedeutungsgrundlagen der romanischen Futurbildungen”. - ZRPh, 85 (1969), 384-415.

21-3763. Mülcer, B. - "Futur und Virtualität". - ZRPh, 85 (1969), 416-427. [Réplica a Wunderli].

21-3764. MEIER, H. - "Futuro y futuridad" (N. 19-58I). \|AIL, 10 (1970), 122-123 (Rastrilla).

21-3765. KLeiN, Horst G. - Das Verhalten der telischen Verben in den romanischen Sprachen, erörtert an der Interferenz von Aspekt und Aktionsart. [Tesis, Univ, de Frankfurt, 1969].

21-3766. AвEL, FrITz - L'adjectif démons. tratif dans la langue de la Bible latine. Etudes sur la formation des systèmes déictiques et de l'article défini des langues romanes. - [Tesis, Univ. de Tübingen, 1969].

21-3767. Doppagne, A. - "Pronoms, adjectifs et politesse dans quelques langues romanes". - CLR(12), 1, 541-545.

21-3768. Avram, M. - "Sur quelques pronoms et adverbes indéfinis dans les langues romanes". - $C L R(12), 1,481$ 485.

21-3769. LAmíquiz IBÁÑEz, VIDAL - El demostrativo de la Romania occidental.Universidad, Madrid, 1967. 37 pp. - V. núm. 19-1049.

21-3770. Niculescu, A. - "Sur l'interaction des pronoms allocutoires révéren. 
ciels avec le système pronominal dans quelques langues romanes". - CL(10), 4, 339-344.

21-3771. TOGeby, K.-"Prépositions latines et prépositions romanes". $-L i S, 4$ (1969), 413-421.

21-3772. Coseriu, E. - "Coordinación latina y coordinación románica". CEC(3), 3, 35-57.

21-3773. Carlsson, Lennart-Le type "c'est le meilleur livre qu'il ait écrit" en espagnol, en italien et en français.-Almqvist \& Wiksell, Uppsala, 1969. 92 pp. (Studia Romanica Upsalensia, 5) . ||RF, 81 (1969), 601-602 (Meier); RRL, 15 (1970), 411-412 (Reinheimer-Rîpeanu).

21-3774. Wunderl., P. - "Zum Konjuntivproblem: Statistik und Theorie. Anlässlich von: Lennart Carlsson, Le type -C'est le meilleur livre qu'il ait jamais écrit * en espagnol, en italien et en français". - RJ, 21 (1970), 25-53.

21-3775. Manoliu, M. - "Le genre neutre dans les langues romanes. Grammaire comparće et typologie". - $C L R(12), 1$, 189-195.

21-3776. LuHT, L. - "Quelques remarques sur la typologie romane. (Morphologie)". - CLR(12), 1, 203-207.

21-3777. WoLF, E. M. - "Variaciones morfofonémicas en la estructura de las lenguas románicas".-CLR(12), 1, 261-266.

21-3778. CopceaG, D. - "Sur la place des déterminants nominaux dans les langues romanes (en comparaison des langues germaniques et slaves)". - CLR(12), 1, 179-183.

21-3779. Levy, ANita KATz - Factors in the distribution of suffixes in the Romance languages. - [Tesis, University of Pennsylvania, 1969].

21-3780. Hubschmid, Johannfs - Die "asko-/usko-" Suffixe und das Problem des Ligurischen.-D'Artrey, Paris, 1969. 235 pp. - v. núm. 20-447. || ZRPh, 86 (1970), 462-466 (Dietrich) .

21-3781. Craddock, Jerry Russell - Latin legacy versus substratum residue: The unstressed "derivational" suffixes in the Romance vernaculars of the western Mediterranean. - Univ. of California Press, Berkeley-Los Angeles, 1969. 141 pp. (UCPL, 53) . - V. núm. 20-724. II $R F, 82$ (1970) , 142-145 (Greive) .

21-3782. Alexander, L. H. - Participial substantives of the "ata" type in the Romance languages. - AMS Press, New York-London, 1969. [Reimpr. de la ed. de New York, 1912].
21-3783. Iliescu, M. - "Sur l'origine de la désinence de la première personne du singulier de l'indicatif présent dans les langues romanes". - BSR, 6 (1969), 61-66.

21-3784. DifT, FRIEdRICH - Etymologisches Wörterbuch der romanischen Sprachen. Mit einen Anhang von August Scheler [5a ed., Bonn, 1887]. JohanN URbaN JARNIK, Neuer vollständiger Index zu Diez' Etymologischen Wörterbuchs der romanischen Sprachen [Heilbronn, 1889]. - Georg Olms Verlag, Hildesheim-New York, 1969. xxvi + 866, 378 pp. [Reimpr. facs.].

21-3785. Makarov, V. V. - "Différenciation lexicale des langues romanes. (Problèmes et méthodes)". - CLR(12), 1, 841-845.

21-3786. Korolenko, I. - "Algunas observaciones acerca de los asemicultismos, en las lenguas romances". - CLR(12), $1,1037-1042$.

21-3787. GODDARD, K. A. - "Loan-words and lexical borrowing in Romance".RLiR, 33 (1969) , 337-348.

21-3788. Gurrer, H. - "Corrélations de signifiants et de signifiés dans les langues romanes".-TLL, 7 (1969), 131-159.

21-3789. Scurtu, V. - "Unitatea romanica în terminologia înrudirii”. - $C L R(12)$, $1,817-822$.

21-3790. Krs, E. - "La structure informationnelle de quelques mots invariables dans les langues romanes". - BSR, 6 (1969) , 67-75.

21-3791. KRATZ, BERND - Zur Bezeichnung von Pflugmesser und Messerpflug in Germania und Romania. - W. Schmitz, Giessen, 1966. 131 pp. (Beiträge zur deutschen Philologie, 34) . | RDTP, 27 (197I) , 455-458 (García de Diego).

21-3792. Doвroru, E. - "Una nuova etimologia per andare". - CLR(12), I, 133-140.

21-3793. ARveiller, R.-"Barraque, bagne, guépard et la langue franque".-Mélanges... Pierre Fouché (Paris, 1970). [Origenes españoles e italianos].

21-3794. Bork, H.-D. -- Die Familie von lateinisch "quatere" im Romanischen.Carl Winter, Heidelberg, 1969. 290 pp. (RomEt, 2) . - V. núm. 19-606. \|RRL, 16 (1971), 439-441 (Iliescu); $R F, 82$ (1970), 383-388 (Wunderli).

21-3795. JrGA, C. T. - "Sur la typologie sémantique de quelques proverbes dans les langues romanes". - $C L R(12), 1$, 169-177.

21-3796. Alvar, M. - "Estado actual de 
los estudios de la dialectología románica". - CLR(12), 1, 77-97.

21-3797. Alvar, M. - Los nuevos Atlas lingiüisticos de la Romania (N. 17-422). || CFil, 1969, núms. 2/3, 209-211 (Marambio Pinochet).

21-3798. Borodina, M. A. - "La géographie linguistique et la classification typologique des langues et des dialectes romans". - $C L R(12)$, 1, 209-215.

21-3799. Bruno, L. - Parentesco lingüistico (N. 21-1163). \| Rom, 3 (1970), 189-191 (Quiroga Salcedo).

21-3800. RoHLFs, G. - "Les avatars du latin vulgaire: promenade de géographie linguistique à travers les langue romanes (avec projection de cartes linguistiques)". - $C L R(12), 1,17-46$.

21-3801. Rogeric-AleXandrescu, A. "Parallèles statistiques entre les langues romanes". - $C L R(12), 1,241$.

21-3802. Heger, K. - "L'apport des études créoles à la linguistique romane". Revue de la Fac. d'Ethnologie, Port-auPrince, 13 (1968), 12-24.

\section{LINGUUISTICA HISPÁNICA}

21-3803. Simposio de México. Enero de 1968. - PILEI-UNAM, México, 1969. 414 pp.

21-3804. Mourelle-Lema, Manuel $-\boldsymbol{L a}$ teoria lingüistica en la España del siglo xix. - Prensa Española, Madrid, 1968. 438 pp. (El soto, 8$)$. V. núm. $18-4720$.

21-3805. SÁnchez Díaz, C. - "El ideal de unidad idiomática de Bello". - Bol. de la Biblioteca General, Maracaibo, 5/6 (1965-66) , 213-220.

21-3806. Rivas Sacconi, J. M. - "Homenaje a don Andrés Bello en Bogotá".$B I C C, 25(1970), 142-150$.

21-3807. "Ramón Menéndez Pidal (18691968) ". - RHA, 1969 , núms. $67 / 8,348-$ 349.

21-3808. Fradejas SÁnchez, L. - "La continuidad tradicional, teoría de Menéndez Pidal",-Memorias de la Academia Ecuatoriana, Quito, 1969, núm. 23, 27-41.

21-3809. Malkiel, Y. - "Charles E. Kany (1895-1968)".-RPh, 22 (1968-69), 35.

21-3810. Webber, E. J. - "Charles Emil Kany (1895-1968) ". - HR, 38 (1970), 119.

21-3811. VASILIEVA-SHVEDE, O. - "Algunas tendencias en la evolución de la estruc- tura gramatical del español, catalán y portugués". - CLR(12), 1, 497-504.

21-3812. Barrutia, R. - "La lingüística y la enseñanza del español y del portugués en los Estados Unidos".-PILEI(4), 323-337.

21-3813. WaLsh, Donald D. $-A$ handbook for the teaching of Spanish and Portuguese.-D. C. Heath, Lexington, Mass., 1969. 338 pp. || $H, 53$ (1970), 163168 (Mirsky, Lawlor \& McKinney).

21-3814. PötTers, Wilhelm - Vergleichende spanisch-portugiesische Semantik. - [Tesis, Univ. de Colonia, 1969].

\section{LENGUAS PENINSULARES}

Catalán y valenciano

21-3815. CoRomines, JOAN - El que s'ha de saber de la llengua catalana.-Moll, Palma de Mallorca, 1970. 141 pp.-V. núm. 10-20126.

21-3816. Dorandeu, J. - "La langue catalane". - LNL, 1970, núm. 195, 30-37.

21-3817. MeLí́, JosEP - Informe sobre la lengua catalana. - Magisterio Español, Madrid, 1970. 366 pp. (Novelas y cuentos, 66) .

21-3818. Moll, Francesc de B.-Els meus primers trenta anys (1903-1934).-Moll, Palma de Mallorca, 1970. 302 pp. I| ZRPh, 87 (1971), 573-575 (Haensch).

21-3819. "A. M. Badia-Margarit. Notice bio-bibliographique à l'occasion de son cinquantième anniversaire". - $R L i R$, 35 (1971), 182-196.

21-3820. LORDA Alaiz, F. M. - "Gerald Brenan y el catalán”.-Norte, 10 (1969), núm. 3.

21-3821. Badia i Margarit, ANtoni M.La llengua dels barcelonins. Resultats d'una enquesta sociològico-lingüistica. T. 1: L'enquesta. La llengua $i$ els seus condicionaments. - Eds. 62, Barcelona, 1969. 684 pp. || fns, 1971, núm. 293 (Lorda Alaiz).

21-3822. RiBelles Comín, J--Bibliografia de la lengua valenciana. - New York, 1969. 3 ts. [Reimpr. de la ed. de Madrid, 1915-43].

21-3823. Ninyoles, R. L. - Conflicte linguistic valenciá. Substitució linguistica $i$ ideologies diglòssiques. - Barcelona, 1969. 184 pp.

21-3824. Moll, Francesc de B.-La lengua de las Baleares enseñada a las personas de habla castellana. - Moll, Palma de Mallorca, 1969. 142 pp., ilustr. 
21-3825. Brummer, R. - "Eine altkatalanische Urkunde in Montblanc (Prov. Tarragona)". - Orbis, 18 (1969), 367373.

21-3826. BadíA, A. M. - "Les oppositions phonologiques [ $e$ ouvert/e fermé] et $[o$ ouvert/o fermé] du catalan dans les rimes des poètes modernes".-CLR(12), 1, 341-374.

21-3827. Artells, E. - Llenguatge $i$ gramàtica. Aspectos generals de la depuració del catald.-Barcelona, 1969. 112 pp.

21-3828. Gallina, ANNAMARIA - Grammatica della lingua catalana.-Barcelona, 1969. 246 pp.

21-3829. Garriga, PaciÁ-El catalá sense "lo" neutre.-Barcelona, 1969. $72 \mathrm{pp}$.

21-3830. SolÀ, J., et A. VerJAT-“L'article et l'affaiblissement des bases en catalan". $-C L R(12), 1,621-625$.

21-3831. Blömer, Berniard - Consecutio temporum im Katalanischen. - [Tesis, Univ. de Bonn, 1969].

21-3832. MACARIE, L. - "Point de vue au sujet de quelques particularités dans la morphologie du verbe catalan". $-R R L$, 14 (1969), 23-24.

21-3833. Badia i Margarit, A. M., y M. CARdús de BAdiA - "Sociologia del pretèrit simple en el català de Barcelona”. $-I R, 1$ (1969), 273-298.

21-3834. Miracle, José. - Diccionari catalá-castellá y castellá-catalá. - Casals, Barcelona, 1969. 1136 pp.

21-3835. DoRAndeu, J. - "El diccionari català-valencià-balear”. - LNL, 1969, núm. 191, 77-80.

21-3836. Pey Estrany, S. - Diccionari de sinònims, idees afins $i$ antònims. Pròleg de J. Rubió i Balaguer. - Barcelona, 1970. 823 pp.

21-3837. Almela y Vives, Francisco Aportación a un vocabulario valenciano de arquitectura. - Valencia, 1969. 142 fols.

21-3838. Griera, A. - "Fòssils de la llengua i trasfusió lexical”. - Mélanges Jean Boutière (Liège, 1970) .

21-3839. Vernet, J. - "El nombre de Cataluña". - BABL, 33 (1969-70).

21-3840. VENY I CLAR, J. - "EIs noms de l'esternut en català". - ER, 13 (196368), 95-125.

21-3841. Griera, A.-Els ormeigs de pescar. El noms dels peixos.-Inst. Internacional de Cultura Románica, Diputación Provincial, Barcelona, 1968. 95 pp. (Bibl. filologico-histórica, 23) .

21-3842. GrierA, A. - "Interprétation de quelques cartes de l'Atlas linguistique du Val d'Aran". - TLL, 7 (1969), 269-274. -V. núm. 20-4761.

V. también núms. 3378, 3724, 3811, 4052, 4135 .

\section{Gallego y portugués}

\section{1-3843. II Simpósio de lingua e literatura} portuguesa. Homenagem a Emmanuel Pereira Filho. - Edições Gernasa, Rio de Janeiro, 1969. 249 pp.

21-3844. Mata Machado Filho, Aires da -Grande coleção da lingua portuguésa. - Graf. Urupês-Edit. e Distribuidora Nac. de Livros, São Paulo, 1969. 5 ts.

21-3845. VAz VAlente, J. A. - "Língua: instrumento de colonização". - RHSP, 35 (1967), 85-104.

21-3846. Lopes dos SANTos, C. - "O intercâmbio de estudantes, a difusão do livro, o intercâmbio de locutores e a criação de escolas de tradução referidos a Portugal e ao Brasil: sua contribuição para a unidade da língua portuguesa". SLB (1), 229-255.

21-3847. Morais-Barbosa, J. DE - "Meios de garantir uma colaboração eficaz de brasileiros e portugueses na realização das tarefas inerentes ao estudo, cultivo e difusão da língua portuguesa". SLB(1), 259-263; Estudos Políticos e Sociais, 6 (1968), 109-113.

21-3848. CunhA, C. - "Para uma eficaz colaboração de brasileiros e portugueses na realização das tarefas inerentes ao estudo, cultivo e difusão da língua portuguesa". - SLB(1), 265-288.

21-3849. Mattoso Câmara JR,, J. - "Os estudos de português no Brasil".- $L P a$, 1969, núm. 17, 23-52.

21-3850. BARBosA, OSMAR - Conheca o seu idioma. - CIL, São Paulo, 1967. 7 ts.

21-3851. Mata Machado Filho, Aires da -Principais dificuldades. 2a ed. - Boa Leitura Editôra, São Paulo, 1966. 218 pp. (Escrever certo, 1).

21-3852. Gomes, A.-"Do ensino da língua portuguesa". - $S L B(I), 107-119$.

21-3853. Saraiva Barreto, M. - "O ensino do português como língua segunda em Africa". - SLB(1), 1145-1157.

21-3854. Enciclopédia prática da lingua portuguêsa. - Li-La, São Paulo, 1969. 6 ts.

21-3855. Mattoso CẦmara, JoAquim-Em prol da lingua portuguesa. Como falar... Como escrever... (Colectánea de nótulas filológicas: ortográficas, sintácticas $e$ 
lexicográficas). T. 2. - Porto Editora, Porto, [1969?]. $342 \mathrm{pp}$.

21-3856. Magro, Haydée S., \& Paulo DePaula - Português: Conversação $e$ gramática. - Brazilian American Cultural Institute, Washington, D. C., 1969. xviii +234 pp. || $M L J, 54(1970), 128$ (Fernández); $\boldsymbol{H}, \quad 52$ (1969), 978-979 (MacNicoll) .

21-3857. Carolino, Pedro - English as she is spoke: the new guide of the conversation in Portuguese and English. With an introduction by Mark Twain. - Dover, New York, 1969. 114 pp. [Reimp. de la ed. de 1883].

21-3858. SLeTSJöE, Lrif-Loerbok e portugisisk. - Universitets Forlaget, OsloBergen-Tromso, 1969. 148 pp. (Scandinavian University books).

21-3859. Leite Teixeira, A. - "Problemas relacionados com o estabelecimento do português fundamental". - $S L B(1)$, 171-190.

21-3860. VAZ LEÃo, A. - "A elaboração do português fundamental. Problemas e sugestões". - $S L B(1)$, 161-169.

21-3861. Monterro, G. - "The Portuguese element in New England by Henry R. Lang: Notes from another century".REt, 13 (1969) , 339-352.

21-3862. Herculano de Carvalho, J. G.Estudos linguisticos. T. 2. - Atlântida, Coimbra, 1969. 319 pp. - V. núm. $19-688$.

21-3863. Mattos, G. - "Estilística portuguêsa". - Humanitas, Curitiba, 11 (1968), 77-240.

21-3864. Head, B. F. - "A descrição das variedades cultas do português contemporâneo como língua padrão". $-S L B(1)$, 63-86.

21-3865. SAId Ali, MANOEL - Gramática histórica da lingua portuguêsa. 6: ed., melh. e aum. - Melhoramentos, São Paulo, 1967. 375 pp. - V. núm. 19-694.

21-3866. Silva RosA, J. R. DA - "Sincronia e diacronia na língua portuguêsa". Simpósio de lingua e literatura portuguêsa, I (Rio de Janeiro, 1967), 75-94.

21-3867. Vermeer, H. J. - "Einige Strukturmerkmale des Portugiesischen und angenommene west-europäische «Substrat»-Eigenarten". - Orbis, 18 (1969), 190-219.

21-3868. Lopés, DAvid - Expansäo da lingua portuguêsa no Oriente nos séculos $x v i$, xvii e xviii. 2a ed., com pref. e abundantes notas de L. de Matos. Portucalense, Lisboa, 1969. 269 pp.
21-3869. Belo Galvão, J. - "Fonema e estrutura". - HCJ, 109-119.

21-3870. Madonia, G. - "Les diphtongues décroissantes et les voyelles nasales du portugais". - LingP, 1969, núm. 1, 129132.

21-3871. Nobre Gouveia, M. A. - "A nomenclatura gramatical portuguesa". $S L B(1)$, 203-226.

21-3872. MAcedo, Walmírio de - Nôvo $e$ completo dicionário de gramática. Li-La, São Paulo, 1969. 220 pp. (Enciclopédia prática da lingua portuguêsa, 1) .

21-3873. Dias de Carvalho, J. - "Estudos de sintaxe portuguêsa". - $S L P(2), 49-60$.

21-3874. Guterres DA Silveira, O.- "Onde fica a concordância?” - $H C J, 171-175$.

21-3875. Maurer, T. H., JR. - "Um sufixo de comportamento original: o diminutivo em -zinho". - HCJ, 235-246. II $Z R P h, 86(1970), 624$ (Baldinger).

21-3876. Pimenta, A. - "Género e número, duas motivaçôes semânticas do português" (N. 19-4816). || RJ, 20 (1969), 391-392 (Kröll) .

21-3877. Mattoso CÂmara, J. - "Problemas de lingüística descritiva, VIIIIX”. - Vozes, Petrópolis, 62 (1968), 820-824, 924-929. [Género y número en portugués].

21-3878. Barbosa, Osmar - Dicionário de verbos da lingua portuguêsa. - Li-La, São Paulo, 1969. 336 pp. (Enciclopédia práctica da lingua portuguêsa, 2).

21-3879. Fernandes, Francisco - Dicionário de verbos e regimes. Mais de onze mil verbos em suas diversas acep̧ões. 4a ed. - Globo, Pôrto Alegre, 1969. 606 pp. - V. núm. 12-29498.

21-3880. PONTES, EUNICE - Estrutura do verbo no português coloquial. - Belo Horizonte, 1969. $143 \mathrm{pp}$.

21-3881. Brinkmann, Margarete - Das portugiesische Verb im Ubersetzungsvergleich. Portugiesisch, Spanisch, Italienisch, Französisch: Die semantische Verteilung von "perfeito simple" und "perfeito composto". - [Tesis, Univ. de Tübingen, 1969].

21-3882. Peixoto da Fonseca, F. V. - "O emprego do conjunctivo português contemporâneo". - CLR(12), 1, 475-480.

21-3883. KNoBLoCH, J. - "Deminuierte Verbalabstrakta im Portugiesischen?"ASNS, 206 (1969), núm. 3.

21-3884. RochA LiMA - "Sôbre o sincretismo de $a$ e em no exprimir direção". $-H C J, 223-231$.

21-3885. Maurer, Th. H., JR.-“"A origem 
da locução conjuntiva do que introdutora do segundo têrmo da comparação em português". - HSN, 269-286.

21-3886. Mattoso CÂmara, J. - "Muta cum muta in Portuguese?" - Word, 24 (1968), 286-289.

21-3887. Prado Coello, J. do - "Sôbre a restituição da motivação lexical no português literário". - IISN, 89-93.

21-3888. Tenório d'Albuquerque, AcirDicionário de linguagem. 3a ed. - Conquista, Rio de Janeiro, 1969. 2 ts., 893 pp.

21-3889. NASCentes, ANTENor - Dicionário de sinônimos. 2a ed. - Livros de Portugal, Rio de Janeiro, 1969. 384 pp. (Col. brasileira de filologia portuguêsa). -V. núm. 14-40147. || $L P a, 1969$, núm. 17, 199-201 (Mansur Guérios) .

21-3890. Florenzano, Everton - Dicionário de sinônimos \&̀ antônimos e idéias semelhantes. - Li-La, São Paulo, 1969. 250 pp. (Enciclopédia prática da língua portuguêsa, 4) . - V. núm. 18-821.

21-3891. Pereira Lima, L. (ed.) - Dicionário enciclopédico comercial DEC. Honor Editorial, São Paulo, 1969. 4 ts.

21-3892. Folgosa, J. M. - Dicionário de numismática. - Porto, [1969?].

21-3893. Chaves de MeLo, G.-"Extensão e restricão dos significados". - HCJ, 99-105.

21-3894. Machado, J. P. - "Etimologia portuguêsa". - $H C J$, 123-140.

21-3895. Piel, J. M.--"Beiträge zur portugiesischen Etymologie und Wortgeschichte". - APK, 8 (1968).

21-3896. Mansur Guérios, R. F.-"Alguns verbêtes do Dicionário de etimologias da lingua portuguêsa”. - $L P a, 1969$, núm. 17, 53-59.

21-3897. PIEL, J. M. - "Duas notas etimogicas: presuria/presura e albende/alvende". - AEM, 6 (1969).

21-3898. MichaËlis de VAsconcelos, C."Estatinga estantiga?" - CMD, 2, 200214.

21-3899. Bechara, E. - "Dar de conselho". $-H C J, 91-96$.

21-3900. Sletsjöe, L. - "So malandro, Seu burro, Din Idiot!"' - Mélanges... Alf Lombard (Lund, 1969), 196-215.

21-3901. Relação dos nomes geográficos de São Tomé e Principe. - Sá da Costa, Lisboa, 1968. $82 \mathrm{pp}$.

21-3902. Cunha, C. - "Para o estudo da poética dos nomes próprios". - HCJ, 49-62.

21-3903. Mansur Guérios, R. F.-“'Onio- nímia ou onomástica industrial"'- $-H C J$, 179-208. || $Z R P h, 86$ (1970), 624-625 (Baldinger) .

21-3904. Rossi, N. - "El Proyecto de estudio del habla culta y su ejecución en el dominio de la lengua portuguesa".PILEI(4), 248-254.

21-3905. Patva Boléo, M. DE - "Linguistique, géographie et unités dialectales subjectives au Portugal". - $C L R(12), 2$, 323-342.

21-3906. Veiga de Olivirira, Ernesto Vinte anos de investigação etnológica do Centro de Estudos de Etnologia Peninsular. - Instituto de Alta Cultura, Lisboa, 1968. $77 \mathrm{pp}$.

21-3907. Paiva BolÉo, M. DE - "Alcuni problemi del paesaggio dialettale portoghese, specialmente della parlata meridionale". - Sep. de $A A N L, 1969$, quad. $111 ; 18 \mathrm{pp}$.

21-3908. FAgan, David S.-Santa Leocádia: a linguistic study of a northern Portuguese comunity. - [Tesis, Univ. of Wisconsin, 1969].

21-3909. Nascentes, A. - "O queijo". HCJ, 43-45.

21-3910. Piñeiro López, R. - "Galician in Luso-Brazilian studies".-CIEL(6), 47-50.

21-3911. Carballo Calero, R. - Um manuscrito de D. Mariano Cubí y Soler. (Observaciones sobre el gallego y otras curiosidades lingüísticas) ". - CuEG, 24 (1969), 275-289.

21-3912, Alonso Montero, J. - "Textos griegos y latinos traducidos al gallego. Bibliografia". - $C E C(3), 2,9-17$.

21-3913. Lorenzo, R. - Sobre cronologia do vocabulário galego-português. (Anotações ao "Dicionário etimológico" de José Pedro Machado). - Galaxia, Vigo, 1968. $382 \mathrm{pp}$.

21-3914. Piel, J. M. - "Apontamentos de etimologia galega". - HSN, 149-154.

21-3915. Rodrigues Lapa, Manuel - Vocabulario galego-portugués. - Galaxia, Vigo, 1965. 110 pp.

21-3916. LoRenzo Vázquez, R. - "Contribución al léxico gallego". - RDTP, 25 (1969), 211-250.

21-3917. Lorenzo Vázquez, R. - "Contribución al léxico gallego: palabras de Amaía y aledaños". - CuEG, 24 (1969), 172-193.

21-3918. Rabanal Álvarez, M. - "Materiales para el estudio de celeuma y salomeiro, formas gallegas de un helenismo romance". - CuEG, 24 (1969), 585-588. 
21-3919. Moralejo Laso, A. - "Toponimia gallega de cereales de cultivo". CuEG, 24 (1969), 206-224.

21-3920. Fernández Rodríguez, M. - "El habla de Goyán". - CuEG, 24 (1969) , 194-205.

21-3921. Mattoso CÂmara, J. - "Brazilian linguistics". - Current trends in linguistics, ed. T. A. Sebeok, t. 4 (The Hague, 1968), 229-247.

21-3922. Barbosa lessa, luis Carlos - $O$ modernismo brasileiro e a lingua portuguêsa. - Fund. Getulio Vargas, Rio de Janeiro, 1966. 460 pp. (Monografia, 2) .

21-3923. JuGÁ Filho, C. - "Aspectos da linguagem brasileira". - $R P, 33$ (1968), 457-476; SLP(2), 23-47.

21-3924. Rodrigues, A. Dall'I.-“Problemas relativos à descrição do português contemporâneo como língua padrão no Brasil". - SLB(1), 41-60.

21-3925. Gomes de Matos, F. - "Some cases of divided usage in spoken Brazilian Portuguese".- H, 52 (1969), 434436.

21-3926. Rossi, N. - "Sôbre eafricadas" no Brasil. (À margem de uma tese de Serafim da Silva Neto)". - PILEI(4), 207-221.

21-3927. Guterres dA Silveira, O.-"Norma gramatical brasileira". - $S L P(2)$, 17-22.

21-3928. Thomas, EARL W. - The syntax of spoken Brazilian Portuguese.-Vanderbilt University Press, Nashville, 1969. $\mathrm{xx}+363$ pp. || RevIb, 36 (1970), 509510 (Bagby); MLJ, 54 (1970), 203-205 (Fernández) ; BHS, 47 (1970), 282-284 (Graziani); H, 52 (1969), 983-984 (Hensey).

21-3929. Gomes de Matos, F. - "On the review of The syntax of spoken Brazilian Portuguese".-H, 53 (1970), 440442.

21-3930. Dias de Carvalho, J. - "Mistura de tratamentos no português do Brasil". -HSN, 95-99.

21-3931. Hampl-HampeJs, Z. - "Tratamento coletivo do português no Brasil". $-H S N, 287-289$.

21-3932. Vázquez Cuesta, P. - "Algunas observaciones sobre el uso del artículo en portugués del Brasil". - CL(10), 1, 871-876.

21-3933. Zamarin, L. M. - "Diferenças lexicais luso-brasileiras".- $H$, 52 (1969), 45-52.

21-3934. Silva, Felisbelo da - Dicionário de giria. - Prelúdio, São Paulo, 1969.
21-3935. Hessel, L. F. - "Intercambios culturales en la sátira gaucha de lengua portuguesa". - Carav, 1969, núm. 13, 33-47. [Hispanismos].

21-3936. Mota, Mauro - Os bichos na fala da gente.-Instituto Joaquim $\mathrm{Na}$ buco de Pesquisas Sociais, Recife, 1969. 230 pp. || Carav, 1971, núm. 17, 256257 (Emorine).

21-3937. Câmara Cascudo, L. da-"Notícia das chuvas e dos ventos no Brasil". REt, 13 (1969), 234-256.

21-3938. CÂmara Cascudo, Luís da-Nomes da terra: geografia, história e toponimia do Rio Grande do Norte.-Fund. José Augusto, Natal, Brazil, 1968. 321 pp.

21-3939. França furtado, Nelson - Vocábulos indigenas na geografia do Rio Grande do Sul. - Pontificia Univ. Católica do Rio Grande do Sul, Pôrto Alegre, 1969. $193 \mathrm{pp}$.

21-3940. INÁcio Filho, José - Têrmos $e$ tradições populares do Acre.-Companhia Brasileira de Artes Gráficas, Rio de Janeiro, 1968? 130 pp.

21-3941. Faria, Oswaldo Lamartine de, e GUILHERME DE AZEvedo - Vocabulário do criatório norteriograndense. - Ministério da Agricultura, Rio de Janeiro, 1966. 88 pp. (Estudos brasileiros, 23).

21-3942. Bunse, Heinrich A. W.-Estudos de dialetologia no Rio Grande do Sul. (Problemas, métodos, resultados). Univ. do Rio Grande do Sul, Pôrto Alegre, 1969. 60 pp. \|LPa, 1970, núm. 18, 177 (Castagnola).

21-3943. ANDREETTA, T. M. M. - "Algumas particularidades lingüísticas de Laranjeiras do Sul, Paraná". - LPa, 1969, núm. 17, 179-184.

V. también núms. $3811,3813-4,4135$.

$V$ asco

21-3944. BerriochoA, H. V. - "Notas de bibliografía vasca. Kantika eskuarak de Hasparren: 1900". - BSV, 25 (1969), 590-592.

21-3945. Tauer, N. - "Cincuenta años de la Academia de la Lengua Vasca". PhP, 12 (1969), 114-115.

21-3946. Enciclopedia general ilustrada del pais vasco. Cuerpo B: Enciclopedia sistemática. T. 1: Literatura.-Auñamendi, San Sebastián, 1969. 719 pp. ilustr.

21-3947. Bertolaso Stella, J. - "Afinidade entre o basco e o caucásico".-Alfa, 1968, núms. 13/4, 249-252. 
21-3948. Berriochoa, H. V. - "Textos euskéricos del siglo xIx. Sermones inéditos de los franciscanos Orueta Mayora y Ariztimuño". - BSV, 25 (1969), 581582.

21-3949. Gavfl, H. - Éléments de phonétique basque. - Bilbao, 1970. [Reimpr. del año 1921 de la Rev. Internacional de Estudios Vascos].

21-3950. MOUtARD, N. - "Une gémination expressive en basque". - LingP, 1970, núm. 1, 81-90.

21-3951. MENdizÁbal, Fernando - Euskaldunentzat oiñarrizko gramatika euskeraz. - T. G. Santuario de Aranzazu, Oñate, 1969. 305 pp., ilustr.

21-3952. AzKue, ResurRección María dE -Morfología vasca. Gramática básica dialectal del euskera. Pról. de A. Irigoyen. - La Gran Enciclopedia Vasca, Bilbao, 1969. 3 ts.

21-3953. LAFON, R. - "Structure de la déclinaison basque". - $C L(10), 4,297$ 301.

21-3954. Azkuf, Resurrección María de - Diccionario vasco-español-francés. Reprod. facs., con próls. y apéndice, de la ed. original de 1905. - Bibl. Magna de La Gran Enciclopedia Vasca, Bilbao, 1970. 2 ts.: 1169 pp.

21-3955. Oyerfgur Arbelaitz, BuenavenTURA DE - Diccionario vasco-castellano, castellano-vasco de voces comunes a dos o más dialectos del euskera. - Bilbao, 1969. $372 \mathrm{pp}$.

21-3956. Michelena, Luis - Estudio sobre las fuentes del Diccionario de Azkue.Bilbao, 1970. $151 \mathrm{pp}$.

21-3957. Sansinenea, J. M. - "Ur" de los vascos. Teoria toponimica. - Bilbao, 1967. 3 ts.

21-3958. Manso ZÚÑ YGA, G. - "Nombres vascos en el Reino de León". - BSV, 25 (1969) , 584-586.

21-3959. Echaide, A. M. - "Encuestas preliminares para el Atlas lingüístico del país vasco". - CL(10), 2, 101-106.

V. también núms. 3987, 4163-7, 5719.

\section{ESPANOL}

21-3960. Diego, G. - "Don Luis Martínez Kleiser (1883-1971)". - BRAE, 51 (1971) , 369-382.

21-3961. Criado de VAl, Manuel-Teotía de Castilla la Nueva. La dualidad cas. tellana en la lengua, la literatura y la historia. 2: ed., ampliada.-Gredos, Ma- drid, 1969. 400 pp. (BRH, Estudios y ensayos, 46) . - V. núm. 16-46668.

21-3962. Alvar, Manuel-Variedad y unidad del español. Estudios lingüisticos desde la historia. - Prensa Española, Madrid, 1969. 231 pp. (El soto, 9).

21-3963. Carnicer, Ramón - Sobre el lenguaje de hoy. - Prensa Española, Madrid, 1969. 314 pp. \|l fns, 1970, núm. 278 (Martínez Palacio).

2]-3964. Gili Gaya, Samuel - Nuestra lengua materna. - Inst. de Cultura Puertorriqueña, San Juan, P. R., 1966. 140 pp. (Bibl. popular).

21-3965. MARÍAs, JULIÁN - La realidad histórica y social del uso lingüistico.Real Academia Española, Madrid, 1965. 93 pp. [Discurso. Contestación de R. Lapesa].

21-3966. Romero Mendoza, Pedro - Critica sin hiel. (Voces y expresiones viciosas). - Gráf. Clavileño, Madrid, 1969. 383 pp.

21-3967. Salas, Rodrigo - El español correcto, el español eficaz. - Barcelona, 1968. 320 pp.

21-3968. Ragucci, Rodolfo M. - Cartas a Eulogio. Problemas idiomáticos.-Sopena, Buenos Aires, 1969. 318 pp.

21-3969. Rojas, JUdith J. ZelenkA $-A n$ analysis of the linguistic and cultural features stressed in Castilian and Mexican primers. - [Tesis, Univ. of Illinois, 1969].

21-3970. Strevenson, C. H. - The Spanish language today.-Hutchinson, London, 1970. xii + 146 pp. $\| H, 54$ (1971), 982-983 (Cárdenas).

21-3971. Green, Jerald R. - A gesture inventory for the teaching of Spanish.Chilton Books, Philadelphia, 1968. xiii + 114 pp. \|MLJ, 55 (1971), 411 (Hayes) .

21-3979. CelA, C. J.--"Noticia de algunas ediciones quizá no muy conocidas". PSA, 55 (1969), 227-246. [De la Gramática, la Ortografía y el Diccionario de la Academia. - Cf. también PSA, 57 (1970), 10-11].

21-3973. "Ortografía aprobada por la Real Academia Española".-BACol, 29 (1969), 257-299.

21-3974. Agürro Chaves, Arturo-Nuevas normas de prosodia y ortografia (y otras noticias importantes). - A. Lehmann, San José de Costa Rica, 1969. 56 pp.

21-3975. Pellen, R. - "Accentuation et orthographe en espagnol". - $L N L, 1969$, núms. 188/9, 69-74. 


\section{Textos lingüísticos}

2I-3976. Craddock, J. R.-“'On Old Spanish municipal charters as primary sources for linguistic history". - RPh, 24 (197071), 119-128.

21-3977. MONTGOMERY, T. - El Evangelio de San Mateo según el manuscrito escurialense (N. 18-1016). \|BHi, 72 (1970), 410-420 (Morreale). - V. núm. $20-664$.

21-3978. González Ollé, Fernando-Textos lingüisticos navarros. - Universidad de Navarra, Pamplona, 1970. $274 \mathrm{pp}$.

21-3979. Pensado, J. L. - "Comentario lingüístico a algunos decumentos del Monasterio de San Salvador de Sobrado de Trives". - $B A G, 30$ (1969), 163-177.

21-3980. TrLANDER, G. - Traducción española de "Dancus Rex" y "Guillelmus Falconarius" (N. 20-667). || RPh, 23 (1969-70) , 612-616 (Galmés de Fuentes) .

V. también núms. $3365,3368-70,3375$.

\section{Historia de la lengua}

21-3981. Tovar, A. - "El oscuro problema de la lengua de los tartesios".-[En] Tartessos y sus problemas. Symposium internacional de prehistoria peninsular (Barcelona, 1969), 341-346.

21-3982. Wilkinson, Hugh E.-The latinity of Ibero-Romance. - S.1., s.f. [ca. 1968]. 34 pp. || $R P h, 24$ (1970-71), 363-364 (Lloyd) .

21-3983. KueN, H. - "Über Kurt Baldingers Herausbildung der Sprachräume auf der Pyrenäenhalbinsel"'. - [En sus] Romanistische Aufsätze (Nürnberg, 1970), 408-418.

21-3984. VÀrVARo, Alberto - Manuale di filologia spagnola medievale. T. 2: Letteratura. - Liguori, Napoli, 1969. 314 pp. - V. núm. 19-966.

21-3985. Carrillo Ramírez, Alfredo-Del castellano al español: introducción lingüistica a la historia. - J. de Pineda Ibarra, San José, P. R., 1968. 175 pp., ilustr. (Col. cientifico-pedagógica, 20).

21-3986. Ruiz García, L. - El habla de Murcia en tiempos de Sancho IV (12841295). - Murcia, 1968. 75 pp.

21-3987. Sturcken, H. T.-"Basque-Cantabrian influence on Alphonsine Spanish". $-S t N, 41$ (1969), núm. 2.

21-3988. BRIESEMEISTER, D. - "Das Sprachbewusstsein in Spanien bis zum Erschei- nen der Grammatik Nebrijas (1492)". $-I R, 1$ (1699), 35-55.

21-3989. Malktel, Y. - "Le nivellement morphologique comme point de départ d'une sloi phonetique.. La monopthongaison occasionnelle de $i e$ et $u e$ en ancien espagnol". - HJF, 2, 701-735.

21-3990. Crabb, Daniel M. $-A$ comparative study of word order in Old Spanish and old French prose works. - AMS Press, New York-London, 1969. xviii $+66 \mathrm{pp}$. [Reimpr. de la ed. de Washington, 1955]. -V. núm. 10-20192.

21-3991. Guglielmi, N.-"Posada y yantar. Contribución al estudio del léxico..." (N. 19-4960) - || AESC, 25 (1970), 392 (Ponsot) .

21-3992. LOPE BLANCH, J. M. - "Observaciones sobre el uso del verbo en Diego de Ordaz". - ALM, 8 (1970), 39-55.

21-3993. Alfau de Solalinde, Jesusa Nomenclatura de los tejidos españoles del siglo xiii. - Madrid, 1969. 203 pp. (BRAE, anejo 19). \| ZRPh, 86 (1970), 286-288 (Höfler).

V. también núms. 3368-9, 3375, 3804, $4000,6617$.

\section{Fonética}

21-3994. NAvarro, Tomás - Manual de pronunciación española. 15: ed.-C.S.I.C., Instituto "Miguel de Cervantes", Madrid, 1970. $328 \mathrm{pp}$. (RFE, publicaciones, 3).-V. núm. 20-682.

21-3995. Quilis, ANTonio - Fonética española en imágenes. - Madrid, 1970. 32 pp., 60 diapositivas en color.

2I-3996. Dalbor, John B. - Spanish pronunciation: Theory and practice.-\$olt, Rinehart \& Winston, New York, 1969. 332 pp. || H, 52 (1969), 975-976 (Phillips).

21-3997. Navarro, Tomás, Güntrer HaENSCH, und BERNHARD LECHNER - Spanische Aussprachelehre.-Hucber, München, 1969. $152 \mathrm{pp}$.

21-3998. Harris, James W. - Spanish phonology. - The M.I.T. Press, Cambridge, Mass., 1969. 218 pp. (Research monograph, 54) .

21-3999. GREen, Jerald R. - Spanish phonology for teachers: $A$ programmed introduction.-The Center for Curriculum Development, Philadelphia, 1970. xiii -1 131 pp. || $H, 54$ (1971), 408-409 (Hadlich).

21-4000. Malkiel, Y. - "Sound changes rooted in morphological conditions. The 
case of old Spanish / $\mathrm{sk} /$ changing to $/ \theta \mathrm{k} / " .-R P h, 23$ (1969-70), 188-200.

21-4001. Granda, G. DE - "La desfonologización de $/ \mathbf{r} / \cdot / \overline{\mathbf{r}} /$ en el dominio lingüístico hispánico". - BICC, 24 (1969), $1-11$.

21-4002. Montes Giraldo, J. J. - "Dominancia de las labiales en el sistema fonológico del habla infantil".-BICC, 25 (1970), 487-488.

21-4003. Delattre, P., \& C. Olsen-“Syllabic features and phonic impressions in English, German, French and Spanish". -Lingua, 22 (1969), núms. 2/3.

21-4004. Flórez, L. - "Detalles de acentuación". - BACol, 20 (1970), 318-319.

21-4005. Matluck, J. H. - "Entonación: lo fonético y lo fonológico".-PILEI(4), 124-134.

21-4006. Reyes-Cairo, Orlando M. - Utterance: Final frequency and amplitude contours in the perception of questions in Spanish. - [Tesis, Univ. of Michigan, 1970].

V. también núms. 3637-47, 3743-51, 3989, $4211-2,4224,4234,4246,4257,4284-9$, $4299,4313-4,4324-5$.

\section{Gramática \\ Morfología y sintaxis}

21-4007. Huberman, G. B. - "Panorama de los estudios de la gramática española en el siglo $\mathrm{xx}$. - CuA, 1970, núm. 6, 103-107.

21-4008. RocA PoNs, JosÉ - Introducción a la gramática. Pról. de A. M. Badía Margarit. 2a ed., corr. y actualizada.Vergara, Barcelona, 1970. 487 pp.-V. núm. 17-4032.

21-4009. Bardón, S. J. - Estudio estructural del español. Partes: 1-3.-Louvain, 1968. 2 ts.

21-4010. Capdevilla, Arturo - Consultorio gramatical de urgencia. - Losada, Buenos Aires, 1967. 224 pp. (Bibl. clásica y contemporánea).

21-4011. Bellini, GIUSEPPE - Sintaxis española. - Milano, 1967. $256 \mathrm{pp}$.

21-4012. NúÑEz, EMILIo - Construcciones sintácticas del español. - Santander, 1970. 277 pp.

21-4013. NáÑez Fernández, Emilio - Diccionario de construcciones sintácticas del español. Proposiciones. Pról. de E Lorenzo. - Santander, 1970. 277 pp.

21-4014. Arutiunova, N. - "Las relaciones indirectas en la sintaxis española". $-C L R(12), 1,731-734$.
21-4015. Foster, D. W.-"Spanish so-called impersonal sentences". $-A n L, 12$ (1970), I-9.

21-4016. Borel, J.-P. - "Le «sujet du verbe»: comparaison entre le français et l'espagnol". - CLR(12), 1, 661-669.

21-4017. Hatcher, A. G. - "The inverted in Spanish with thing-subject and thingobject". - CL(10), 2, 1049.

21-4018. Cortés, Carmen María-Comparación de dos estudios sincrónicos del sustantivo en español.-[Tesis, Georgetown Univ., 19707.

21-4019. Stevens, C. E. - A characterization of Spanish nouns and adjectives (N. 20-726) . || BHi, $72(1970), 241$ (Pottier) .

21-4020. Otero, C. P. - "The syntax of mismo". - CL(10), 2, 1145-1151.

2I-4021. Otero, C. P. - "El otro lo". CLR(12), 1, 649-659.

21-4022. LAPESA, R. - "El artículo con calificativos o participios no adjuntos a sustantivo en español". - RLiR, 34 (1970) [=HGS, 2], 78-86.

21-4023. Contreras, H. - "The structure of the determiner in Spanish".-Ling, 1968, núm. 44, 22-28.

21-4024. KVaviK, Karen L. Halladay Noun suffixes in modern Spanish: $\boldsymbol{A}$ synchronic study of formal and statistical properties.-[Tesis, Stanford Univ., 1970].

21-4025. GogA, E. - "Observaciones acerca de unos tipos nominales en español". $-R R L, 15$ (1970), 369-376.

21-4026. Dinnes, I. S. - "Must all unclassified Spanish words be memorized for gender?" - $H, 54$ (1971) , 487-492.

21-4027. García, E. C. - "Gender switch in Spanish derivation (with special reference to $-a \rightarrow$-ero, $-o \rightarrow$ era, $-a \rightarrow$ -in, -ón)". - $\overrightarrow{R P h}, 24$ (1970-71), 39-54. ["Postscript" de Y. MaLkIEL, pp. 55-57].

21-4028. Connors, K. - "Studies in feminine agentives in selected European languages". - $R P h, 24(1970-71), 573-$ 598.

21-4029. Saltarelli, M. - "Spanish plural formation: apocope or epenthesis?" Lan, 46 (1970), 89-96.

21-4030. KNittloví, D.-"Notes on Spanish plural formation". - $P h P, 13$ (1970), 47-50.

21-4031. HARris, J. W. - "A note on Spanish plural formation".-Lan, 46 (1970), 928-930.

21-4032. Quicis, A. - "Sobre la morfonología. Morfonología de los prefijos en 
español". - RUM, 19 (1970), núm. 74, 223-248.

21-4033. GARAS, RITA - Élude comparée du suffixe populaire "-aison" en français, "azón" en espagnol, "-agione" en italien dans le sens de 'temps opportun'. -[Mémoire de maîtrise, Univ. de Strasbourg, 1970].

21-4034. Zuluaga Ospina, A. - "La función del diminutivo en español”. $B I C C, 25$ (1970), 23-48.

21-4035. Kendrio, Christopher - Dictionnaire de 201 verbes espagnols, conjugés $\dot{a}$ tous les temps et à toutes les personnes. - Barron's Woodbury, New York, 1969. xiii $+220 \mathrm{pp}$.

21-4036. PAsaliu, I. - "Le verbe dans le cadre des préoccupations de sémantique structurale". - CLTA, 7 (1970), 111142.

21-4037. Bobes Naves, María del CarMEN - Las personas gramaticales.-Universidad, Santiago de Compostela, 1971. 46 pp. (Monografias, 1).

21-4038. LAPESA, R. - "Personas gramaticales y tratamientos en español". RUM, 19 (1970), núm. 74, 141-167.

21-4039. Fontanella de Weinberg, M. B. -“Los auxiliares españoles". - AIL, 10 (1970), 61-73.

21-4040. BABCOCK, SANDRA S. - The syntax of Spanish reflexive verbs: the parameters of the middle voice. - Mouton, The Hague, 1970. 96 pp. (Janua linguarum, Series practica, 105). - V. núm. 19-5040.

21-4041. Sabatini, R. N. - "Further considerations of passive substitutes". $-\boldsymbol{H}$, 54 (1971), 883-884.

21-4042. Roca Pons, J.-"Estudio morfológico del verbo español" (N. 19-5049). II $A I L, 10$ (1970), 129-130 (Castro).

21-4043. Terrell, Tracy Dale - The tense-aspect system of the Spanish verb: $A$ diachronic study on the generativetransformational model. - [Tesis, Univ. of Texas, 1970].

21-4044. Rubio, William A. - Opposition of subjunctive and indicative in old Spanish. - [Tesis, Columbia Univ., $1971]$.

21-4045. Mansilla García, Matilde Análisis estilistico del uso del subjuntivo español en la lengua hablada y su comparación con el inglés. - [Tesis, Univ. de Madrid; resumen en RUM, 17 (1968), 73-74].

21-4046. Mansilla García, Matilde Análisis lingüistico de los usos del sub. juntivo en el español y su comparación con el inglés. - Universidad, Madrid, 1969. 43 pp.

21-4047. Woehr, Richard ARThur - $\boldsymbol{A}$ contribution to the syntax of the subjunctive in contemporary Spanish. [Tesis, Stanford Univ., 1971].

21-4048. Farley, R. A. - "Time and the subjunctive in contemporary Spanish".H, 53 (1970), 466-475.

21-4049. Staubach, C. N. - "More notes on subjunctive tenses". $-H, 54$ (1971), 333-335.

21-4050. Schmidely, J. - "Le conditionnel: mode ou temps?" - LNL, 1971, núm. $196,2-5$.

21-4051. Lamíquiz, V. - "El modo de la concesiva en español y francés". CLR(12), 1, 447-453.

21-4052. Carlsson, L. - "Sur l'usage des modes après (me) parece que en castillan et (em) sembla que en catalan". - St $N$, $42(1970)$, núm. 2.

21-4053. Predevello Molina, Nora Lilí -Contribución al estudio del perfecto y el indefinido en español. - [Tesis, Univ. de Madrid; resumen en $R U M, 18$ (1969), núm. 72, 45-47].

21-4054. Cerny, J. - "El pretérito español y la categoría del aspecto".-CLR(12), 1, 787-792.

21-4055. Cartagena, N. - "Irse-venirse / llevarse-traerse. Acerca de una construcción pronominal en español".-CLR(12), 1, 519-526.

21-4056. Molнo, M. - "Soy (voy, estoy, doy)". - Mélanges Jean Boutière (Liège, 1970).

21-4057. Zierer, E. - "Sobre los adverbios y expresiones modales del castellano y sus equivalentes en el idioma alemán". -PILEI(4), 90-94.

21-4058. Rivero, M.-L. - "A surface structure constraint on negation in Spanish". -Lan, 46 (1970), 640-666.

21-4059. González Rivero, Marie-Luisa - The Spanish quantifiers. - [Tesis, Rochester Univ., 1970].

21-4060. López, MARÍa Luisa - Problemas y métodos en el análisis de preposiciones. - Gredos, Madrid, 1970. 223 pp. (BRH, Estudios y ensayos, 143). $\| H$, 54 (1971), 980-981 (Terrell).

21-4061. López Fernández, María LuisaAportación al estudio de la preposición en el español moderno. - [Tesis, Univ. de Madrid; resumen en $R U M, 17$ (1968), 38 ].

21-4062. López Fernández, M. L. - "Al- 
gunos aspectos en el estudio de las preposiciones en español". - CLR(12), 1 , 627-633.

21-4063. FisH, G. T. - “De". - H, 53 $(1970), 266-268$.

21-4064. Pfusfr, G. - Die Partikel "de" im modernen Spanischen (N. 21-914). || $\mathrm{BHS}, 48$ (1971), 57-58 (Keightley) .

21-4065. WONDER, J. P. - "Complementos de adjetivo del genitivo". $-H, 54$ (1971). 114-120.

21-4066. Meisel, Jürgen Michael - Das Präpositionalobjekt im Spanischen. Universität, Frankfurt/M., 1970. 173 pp. [Tesis].

21-4067. Vanriest B., J. - "Les prépositions en français et en espagnol: prendre au collet - agarrar de la solapa".-LyC, 11 (1971), 85-88.

21-4068. Suprún, A. - "La locución idiomática y el contexto (basándose en el idioma español)". - CLR(12), 1, 919. 924.

21-4069. ["Las construcciones camino a seguir, tarea a realizar, etc.']. - $B A C o l$, $20(1970), 187-206$. [Escriben R. Gómez Hoyos, J. Sanín Echeverri, E. Guzmán Esponda y L. Flórez].

21-4070. Skelton, R. B. - “La locución adverbial de en balde y la fusión fonética". - BRAE, 51 (1971), 459-473.

21-4071. ARANGo, G. - "De acuerdo $a$, locución viciosa”, $-H, 54$ (1971) , 509-510.

21-4072. BÄсKVALL, H. - “"Algo bueno o algo de bueno?" - StN, 42 (1970), núm. 2.

21-4073. Morreale, M. - "Poco, un poco". $-B I C C, 25(1970), 485-486$.

V. también núms. 3375, 3648-58, 3752-83, $3811,3881,3972,3990,3992,4258$, 4303-9, 4359-61, 6093 .

\section{Lexicografía y semántica}

21-4074. Diccionario de la Real Academia Española. 19a ed., totalmente modificada. - Real Academia Española, Madrid, 1970. xxix + 1424 pp. - V. núm. 19-5063. || $B A V, 1970$, núm. 126, 52-55 (Tablante Garrido).

21-4075. Sf.Co, M. - "El nuevo Diccionario de la Academia".-ROcc, 33 (1971), 90-96.

21-4076. ZAMORA Vicente, A. - "Para el uso del diccionario".-ROcc, 34 (1971), $327-334$.

21-4077. Benarroch, C. - "La Real Academia Española y los judíos. Apostillas al Diccionario académico de 1970 ". TI, 1971, núm. 291.

21-4078. "Enmiendas y adiciones a los diccionarios de la Academia aprobadas por la Corporación (septiembre-diciembre de 1969 y enero-abril de 1970)".$B R A E, 50$ (1970) , 209-231, 429-430.V. núm. 21-932.

21-4079. "Nuevas palabras y enmiendas aceptadas por la Real Academia". $B A C o l, \quad 20$ (1970), 122-126, 173-178, 320-343, 545-570. - V. núm. 20-4962.

21-4080. "Revisión de algunas definiciones zoológicas y botánicas del Diccionario académico". - BAPaL, 1970, núm. 5.

21-4081. Diccionario enciclopédico González Porto. - Renacimiento, México, 1971. 2 ts.: xliv + 1898 pp., ilustr.

21-4082. Jackson. Diccionario hispánico universal. Enciclopedia ilustrada en lengua española. 15: ed. - W. M. Jackson, México, 1970. 2 ts., ilustr.-V. núm. 20-794.

21-4083. Raluy Poudevida, A. - Diccionario Porrúa de la lengua española. 3a ed. - Porrúa, México, 1970. 849 pp.

21-4084. Corominas, Juan - Diccionario critico etimológico de la lengua castellana. Reimpresión. - Gredos, Madrid, 1970. 4 ts.: lxviii + 993, 1082, 1118, 1226 pp. - V. núm. 13-36514.

21-4085. SolA, S. - "Notas al BDELC de J. Corominas".-LD, 1 (1971) , 179-185.

21-4086. Díez Mateo, Félux - Diccionario español etimológico. 2a ed., corr. y aum. -Madrid, 1968. 616 pp.

21-4087. BARcIa, RoQUe - Sinónimos castellanos. 10a ed. - Sopena, Buenos Aires, 1971. 591 pp. - V. núm. 20-4975.

21-4088. Horta Massanes, Joaquín-Diccionario de sinónimos $e$ ideas afines $y$ de la rima.-Madrid, 1970. $363 \mathrm{pp}$.

21-4089. Rofer, Francrsco - Diccionario de sinónimos españoles. - Edit. Mexicanos Unidos, México, 1971. $371 \mathrm{pp}$.

21-4090. Cruz Aufrere, José, y José Mary O. DE CRuz (eds.) - Diccionario de homónimos castellanos. - Los Amigos del Libro, Cochabamba, 1970. $242 \mathrm{pp}$.

21-4091. Fatás, Guillermo, y Gonzalo BORRÁs - Vocabulario de términos de arte. - Zaragoza, 1970. 151 pp., ilustr.

21-4092. Terreros Y Pando, Esteban deDiccionario castellano con las voces de ciencias $y$ artes $y$ sus correspondientes tres lenguas: francesa, latina $e$ italiana. -Madrid, 1970. 4 ts.: 3332 pp. [Reprod. facs. de la ed. de 1786]. 
21-4093. Moscoso VegA, L. A. - "Terminología científica". - AUC, 24 (1968), núms. $1 / 2$.

21-4094. Pina, RAfael DE - Diccionario de derecho. 2a ed. - Porrúa, México, 1970. 355 pp. - V. núm. 19-1124.

21-4095. Ezaine Chávez, Amado - Diccionario de derecho penal. 2a ed. - J. Mejía Baca, Lima, 1971. 303 pp.

21-4096. Pallares, Eduardo - Diccionario de derecho procesal civil. 6. ed., corr. y aum. - Porrúa, México, 1970. 877 pp. - V. núm. 19-5085.

21-4097. Capitant, Henri - Vocabulario juridico. Trad. de A. H. Guaglianone. Reimpr. inalterada. - Buenos Aires, 1966. xvii +630 pp. - V. núm. 17-710.

21-4098. Damm, UlRich, GÜNTHer HaEnsch y Manuel Moral García. - Terminologia juridica en español y alemán. Rechtsprache spanisch und deutsch. - Hueber, München, 1970. $351 \mathrm{pp}$.

21-4099. Zaragüeta, J. - "Problemas de la terminología jurídica". - Anales de la Real Academia de Ciencias Morales y Politicas, Madrid, 1970, núm. 47.

21-4100. Diccionario de términos legales: español-inglés e inglés-español. - México, 1969. 228 pp.

21-4101. Terceiro, José B. - Diccionario de economia. - Algorta, Vizcaya, 1971. 208 pp.

21-4102. SuAvet, Thomas - Diccionario económico y social. - Estela, Barcelona, 1970. 347 pp. (Cristianismo y tiempo, 46). \| EAg, 5 (1970), 512 (Barrio).

21-4103. Diccionario de electrónica. - Cía. Ibérico-Europea de Ediciones, Madrid, 1970. 146 pp.

21-4104. Malaret, Augusto - Lexicón de fauna y flora. - Asoc. de Academias de la Lengua Española, Madrid, 1970. 569 pp. - V. núm. 18-1161.

21-4105. HaY, R., y P. M. SINGE - Diccionario ilustrado en color de plantas de jardin. - G. Gili, Barcelona, 1970. 364 pp., ilustr.

21-4106. Diccionario técnico de términos ferroviarios (N. 20-809) . \|BFE, 1970, núms. 26/7, 81-83 (Torres Martínez).

21-4107. Torres Martínez, J. C. DE-"Notas sobre el léxico ferroviario". - $B F E$, 1969, núms. 30/1, 9-25.

21-4108. Ferrater Mora, José - Diccionario de la filosofía abreviado. - Edit. Sudamericana, Buenos Aires, 1970. 480 pp. - V. núm. 19-5091. || RUNP, 22 (1970), 272-273 (Presas).

21-4109. Runes, D. D. - Diccionario de filosofia (N. 21-958). || EAg, 5 (1970), 491 (Casado).

21-4110. Lledó, E. - "El lenguaje filosófico griego. Hacia una revisión de la terminología filosófica occidental". CEC(3), 1, 299-319.

21-4111. SÁNCHEZ-MONGE Y PARELladA, ENRIQUe - Diccionario de genética. 2: ed. - Inst. Nacional de Investigaciones Agronómicas, Madrid, 1970. 355 pp. V. núm. 17-4118.

21-4112. Smith, Geneviere Love, \& Phylus E. Davis - Terminología médica. Texto programado. Versión de M. A. Mota Guzmán. - L. Wiley, México, 1970. $271 \mathrm{pp}$.

21-4113. SABatier, Robert - Dicionario ilustrado de la muerte. - G. Gili, Barcelona, 1970. 600 pp., ilustr.

21-4114. Warren, Howard C. (ed.) - Diccionario de psicologia. Trad. y revisión de E. Imaz, A. Alatorre y L. Alaminos. Reimpr. - FCE, México, 1970. 399 pp. - V. núm. 20-825.

21-4115. Sillamy, N. - Diccionario de la psicologia (N. 21-968) . || EAg, 5 (1970), 222-223 (Martínez) .

21-4116. Mota, Ignacio H. DE LA - Diccionario de la publicidad. La prensa.Gráf. Torroba, Madrid, 1970. 503 pp.

21-4117. Mulas PÉrez, I. - Diccionario taurino. - Barcelona, 1970. 510 pp., ilustr. - V. núm. 12-29599.

21-4118. Torres Martínez, J. C. - Contribución al estudio diacrónico del léxico taurino en España. Fuentes y clasificación del mismo (siglos xvi-xx).Fac. de Filosofía y Letras, Madrid, 1971. $29 \mathrm{pp}$.

21-4119. Bouyer, L. - Diccionario de teologia (N. 20-5007). $\mid$ EAg, 4 (1969), 412 (Garrido).

21-4120. Ramm, Bernard - Diccionatio de teología contemporánea.-Casa Bautista, El Paso, Texas, 1970. 144 pp.

21-4121. Corriente, Federico - Diccionario español-arabe. - Instituto HispanoArabe de Cultura, Madrid, 1970. 480 pp. 21-4122. MeINZAK, Emilio - Woordenlijst en samenspraak: Nederlands-SurinaamsSpaans en Surinaams vertaald in het Nederlands (alphabetisch). 12: ed.-1965. $51 \mathrm{pp}$.

21-4123. SteIner, Roger J. - Two centuries of Spanish and English bilingual lexicography, 1590-1800. - Mouton, The Hague, 1970. 130 pp. (Janua linguarum, Series practica, 108).--V. núm. 18-4827. 21-4124. EDAF. Nuevo diccionario gene- 
ral inglés-español. New comprehensive English-Spanish dictionary. 2a ed. E.D.A.F., Madrid, 1970. 2 ts.: 3000 pp.V. núm. 19-5123.

21-4125. Dífz Mateo, Félix, y Frida HochLEITNER - Diccionario manual inglésespañol, español-inglés.-Madrid, 1971. $1008 \mathrm{pp}$.

21-4126. Boselli, Carlo - Dizionario spagnolo-italiano, italiano-spagnolo. - Garzanti, Milano, 1968. xxvii + 499 pp.V. núm. 16-46834.

21-4127. Guardia Mayorga, César - Diccionario kechwa-castellano $y \quad v / v$. 4a ed. - J. Mejía Baca, Lima, 1970. 217 pp. - V. núm. 20-845.

21-4128. Juilland, A., \& E. Chang-RodríGUEZ - Frequency dictionary of Spanish words (N. 19-1085). II LingP, 1966, núm. 1, 145-147 (Mounin). - V. núm. 20-4973.

21-4129. Szabó, M. - "El estado actual de las investigaciones sobre el recuento del vocabulario español". - ALitt, 12 (1970), 197-201.

21-4130. SadeAnU, F. - "Aspects de la relatinisation du vocabulaire en espagnol". - CL(10), 4, 555-559.

21-4131. Lira Urquieta, P. - "Sobre vocablos". - BACh, 1970, núm. 59.

21-4132. Skultéty, J. - "La característica de los tecnicismos españoles". - HuNL, 11 (1970), 305-312.

21-4133. García de Diego, V. - "Nombres de acción". - BRAE, 50 (1970), 19-29.

21-4134. García de Diego, V. - Diccionario de voces naturales (N. 20-5025). II HuNL, 11 (1970), 787-789 (Alanís G.).

21-4135. NAGEL, INGO-Die Bezeichnungen für 'dumm' und 'verrückt' im Spanischen, unter Berücksichtigung ihrer Entsprechungen in anderen romanischen Sprachen, insbesondere im Katalanischen und Portugiesischen. - [Tesis, Univ. de Erlangen, 1970].

21-4136. TORRES Villaseñor, H. E.-"Léxico relativo al vestuario infantil". $-A L M$, 8 (1970), 241-253.

21-4137. KidmaN, J. M. - "Mots espagnols et hispano-arabes: quelques datations nouvelles". - Ro, 91 (1970), 527-528.

21-4138. Fernández García, antonio Anglicismos. - [Tesis, Univ. de Madrid; resumen en $R U M, 18$ (1969), núm. 72, 87-88].

21-4139. Fernández García, Antonio Anglicismos en el español. - Universidad, Madrid, 1971. 46 pp.
21-4140. Past, R. - "Border golf". - $H$, 53 (1970), 475-477. [Anglicismos en el vocabulario del golf].

21-4141. Alfaro, Ricardo J. - Diccionario de anglicismos. 2a ed., aum.-Gredos, Madrid, 1970. 514 pp. - V. núm. 19-1178.

21-4142. Trujillo, Ramón - El campo semántico de la valoración intelectual en español. - La Laguna, 1970. 557 pp.

21-4143. Mendiola D., M., et al.-“Algunas peculiaridades léxicas del castellano".$L y C$, 1971, núm. 3, 62-65.

21-4144. Monge, F. - "Los nombres de acción en español". - $C L R(12), 1,961$ 972.

21-4145. MalkieL, Y.-"Form versus meaning in etymological analysis: Old Spanish auze 'luck'" (N. 19-5161). \| RPh, 24 (1970-71), 150-151 (Deyermond).

21-4146. Vidos, B. E.-"Fr. bonace, bonasse". - Mélanges... Pierre Fouché (Paris, 1970) - [Esp. bonanza, etc.]. $\| Z R P h$, 87 (1971), 631-632 (Kuen) .

21-4147. Castro, AMÉrico - "Español", palabra extranjera: razones y motivos. -Taurus, Madrid, 1970. 120 pp. (Cua dernos, 89). I| ROcc, 31 (1970), 381 385 (Marcos-Marín) .

21-4148. Crowley, C. J. - "Old Spanish in honor of J. Alexander Kerns (The monclura and odiçepçon: A problem in etymological reconstruction". - Studies Hague, 1970).

21-4149. Chiossone, T. - "Pelón, pelada y pelarse". - BAV, 1970, núm. 126, 34-38.

21-4150. García Yebra, V. - "Tres acepciones de pienso. (Contribución al estudio de la familia pensar/pesar)". CLR(12), 1, 937-943.

21-4151. Aubrun, C. V. - "Trapero, platero, picaro et tuno, ou les perplexités d'un non spécialiste". - Mélanges... Pierre Fouché (Paris, 1970). $\|$ ZRPh, 87 (1971), 635 (Kuen).

V. también núms. $3555,3659-80,3784-94$, $3814,3954-6,3972,3991,3993,4155,6042$, $6061,6095,6648,7039$.

\section{Toponimia y antroponimia}

21-4152. Aguado, J. M. - "Cuando España era un vergel. Relieves del Diccionario etimológico e histórico. VIII de las Síntesis filológicas". - $B B M P, 46$ (1970), 325-339.

21-4153. Kotzebue, R. DE - "Huellas eslavas en España". - RUM, 19 (1970), 
25-103. [Sobre todo ein la toponimia]. 21-4154. Mariner Bigorra, S. - "Heteróclisis de topónimos en -o / -ona". RUM, 19 (1970), núm. 74, 185-213.

21-4155. Diament, H. - "The toponymic progeny of Latin etyma, Castrum and Castellum". - Names, 18 (1970), 237. 246.

21-4156. Gómez Iglesias, A. - "Algunos topónimos urbanos actuales de ascendencia medieval y ochocentista". AIEM, 4 (1969), 433-441.

21-4157. Terés, E. - "Al-Walaŷa, topónimo árabe". - AlAn, 33 (1968), 291309.

21-4158. Villares, M. - "La hidronimia antigua leonesa". - ALeon, 24 (1970), 247-272.

21-4159. García Rámila, Ismael, y Federico Díez de la Lastra y Díaz GüÉmez -Indice topográfico-alfabético de las villas y lugares de la antigua provincia de Burgos comprendidos en el Catastro del marqués de la Ensenada. - Institución Fernán González, Burgos, 1969. || BIFG, 47 (1969), 144-145 (Echánove).

21-4160. SÁEZ GoDOy, L. - "Topónimos en Lope de Rueda". - CFil, 1969, núms. 2/3, 141-159.

21-4161. Fernández Serrano, F. - "Guadalupe, en la toponimia extremeña del Dr. Soropan de Rieros". - Guadalupe, 1970 , núm. 589.

21-4162. GoldIE, A. - "Reflexiones sobre toponimia de la Montaña”. - PIEF, 1 (1969), 147-165.

21-4163. López De Guereñu, G. - "Toponimia alavesa". - Anuario de EuskoFolklore, San Sebastián, 23 (1969-70), 159-208. - V. núm. 19-4912.

21-4164. Satrústegui, J. M. - "Toponimia de Valcarlos". - Anuario de EuskoFolklore, San Sebastián, 23 (1969-70), 129-158.-V. núm. 21-1026.

21-4165. Arín Dorronsoro, J. DE - "Contribución al estudio de la toponimia (Ataun)". - BSV, 25 (1969), 471-516.

21-4166. Elósegui, J. - "Toponimia y denominaciones de la villa de Tolosa".$B S V, 25$ (1969), 369-408.

21-4167. Gárate, J. - "Hidronimia vasca y su frecuencia en aféresis y duplicación semántica".-AIL, 10 (1970), 5-28.

21-4168. Buentello Chapa, H. - "Toponimias americanas".-HuNL, 10 (1969), 429-445.

21-4169. GILPIN, G. H. - "Street-names in San Antonio: Signposts to history". -Names, 18 (1970), 191-200.
21-4170. Moreno Toscano, A. - "Toponimia y análisis histórico”. - HMx, 19 (1969-70), 1-10.

21-4171. Aragón, Eliseo B. - Toponimias en lengua náhuatl del estado de Morelos. - Herrera, México, 1969. 102 pp., ilustr.

21-4172. García Soto, J. Mario - Geografía general de Chiapas, con etimologias de los nombres indigenas. - Dist. Porrúa, México, 1970. 375 pp., ilustr.

21-4173. MuÑoz PÉREZ, J.-“Algunas precisiones en torno al topónimo nicaragïense de Nueva Segovia". - ESeg, 22 (1970) , 5-16.

21-4174. Bateman, Alfredo D. - Vocabulario geográfico de Colombia. Letras $S$-Z.--Soc. Geográfica de Colombia, Bogotá, 1969. 261 pp. (Cuad. de geografia de Colombia, 24).

21-4175. Furlong, G. - "Nombres y sobrenombres con que otrora fue conocida y llamada la Argentina". - Investigaciones $y$ Ensayos, Buenos Aires, 1967, núm. 3.

21-4176. Stieben, Enrique - Toponimia araucana. - Secretaría General de Gobernación, Santa Rosa, Arg., 1966. 242 pp.

21-4177. BIEdma, J. M. - Toponimia del Parque Nacional Nahuel Huapi (N. 21-1039) . \| USF, 1968, núm. 75, 199201 (Finó).

21-4178. Zapata Gollán, Agustín - Santa $\mathrm{Fe}$, topónimo. - Departamento de Estudios Etnográficos, Santa $\mathrm{Fe}$ (Argentina), 1969. 23 pp. \| RDTP, 26 (1970), 393-394 (Manrique).

21-4179. HARRINGTON, T. - "Toponimia del Gününa Küne". - Investigaciones y Ensayos, Buenos Aires, 5 (1968), 331362.

21-4180. Álvarez, G. DE J. C. - Topónimos en apellidos hispanos (N. 21-1041). || Names, 17 (1969), 294-295 (Hinkle).

21-4181. SALCEDO, SANDERS - Los nombres masculinos y su significado astrológico. - Bruguera, Barcelona, 1970. 336 pp. (Libro práctico, 37) .

21-4182. SALCEDO, SANDERS - Los nombres femeninos y su significado astrológico. - Bruguera, Barcelona, 1970. 339 pp. (Libro práctico, 35) .

21-4183. Kremer, D. - "Germ. -ara(ne) in hispano-gotischen Personennamen". $B z N, 5$ (1970) , 164-171.

21-4184. Sandru-Olteanu, T. - "Gentilicios transformados en apelativos en español". - $C L R(12), 1,973-979$. 
21-4185. Gutif́rrez Macías, V. - "Breve ensayo sobre los nombres gentilicios usados en la Alta Extremadura".-REE, 26 (1970), 155-185.

21-4186. Origen genealógico de algunos apellidos existentes en Mallorca e historia de los judios de España. Origen, genealogía, pruebas de nobleza y blasones de los apellidos: Aguiló, Bonnin, Cortés, Fortexa, Fuster, Marti, Miró, Pico, Piña, Pomar, Segura, Valls y Vives. - Valencia, 1965. 343 pp., con 50 escudos.

21-4187. Huacuja, Daniel - Gentilicios del Estado de México. - Jus, México, 1968. 22 pp. (Bibl. enciclopédica del Estado de México, 11).

21-4188. SuÁrEz, V. M. - "Onomástica y toponimia yucatecas". - RUY, 1968, núm. 59, 70-79.

V. también núms. 3681-9, 3957-8, 4196.

\section{Paremiologia}

21-4189. Morgan, Frances - Proverbs from four didactic works of the thir. teenth century. - [Tesis, Univ. of Kentucky; resumen en $D A I, 30$ (1969-70), $1533 \mathrm{~A}]$.

21-4190. Hulme, F. Edward - Proverb lore. Being a historical study of the similarities, contrasts, topics, meanings, and other facets of proverbs, truisms, and pithy sayings, as expressed by the peoples of many lands and times. Gale Research, Detroit, 1968. 269 pp. [Reimpr. de la ed. de 1902].

21-4191. Clarasó, Noel (ed.) - Antología de textos, frases, modismos y decires.Barcelona, 1970. 1082 pp.

21-4192. Maldonado, Felipe C. R. (ed.) -Refranero clásico español y otros dichos populares. $3^{\mathrm{a}}$ ed. - Taurus, Madrid, 1970. 211 pp. (Temas de España, 12). - V. núm. 19-5213.

21-4193. Recio Flores, Sergio - Diccionario comparado de refranes y modismos: Español-English. - Libros de México, México, 1968. xvi + 390 pp. $\|$ $H, 54$ (1971), 223-224 (O'Kane).

21-4194. PAREDES, A. - "Proverbs and ethnic stereotypes". - Prov, 1970, núm. $15,95-97$.

21-4195. O'KANE, E.-"What's in a name?" - Prov, 1970, núm. 15, 92-94.

21-4196. García Huetos, M. L. - "Los nombres propios en la paremiología latina y castellana". - RUM, 19 (1970), núm. 75, 7-23.
21-4197. Allué Morer, Antonio - Los pronósticos del tiempo en el refranero castellano. - Autor, Valladolid, [1969]. $303 \mathrm{pp}$.

21-4198. Castillo de Lucas, A. - "EI gaHo, simbolismo refraneado de su preferente figura en la alfarería popular". -REt, 14 (1970), 361-367.

21-4199. Arora, S. L. - "Como la carabina de Ambrosio". - Prov, 1970, núm. 15, $12-24$.

21-4200. Arora, S. L. - “El que nace para tamal...: A study in proverb patterning". $-\boldsymbol{F A}, 1968$, núm. 2, 55-79.

21-4201. Fradejas Lebrero, J. - "Hidalgo como un gavilán". - EL, 1970, núm. 452.

21-4202. Devoto, D. - "Stolen fruit en español”. - Prov, 1970, núm. 15, 23-25.

V. también núms. 3690, 3795, 5744 .

\section{Dialectología}

21-4203. "Bibliografía" [de dialectología y tradiciones populares]". - RDTP, 25 (1969) , 383-408. - V. nủm. 21-1056.

21-4204. Rosenblat, Ángel - El castellano de España y el castellano de América. Unidad y diferenciación.-Taurus, Madrid, 1970. 69 pp., ilustr. (Cuadernos Taurus, 94) . - V. núm. 19-5249.

21-4205. LOPE BLANCH, J. M. - "El Proyecto de estudio coordinado de la norma lingüistica culta de las principales ciudades de Iberoamérica y de la Península Ibérica. (Su desarrollo y estado actual) ". - PILEI(4), 222-233.-V. núm. $20-961$.

21-4206. Montes Giraldo, José Joaquín - Dialectología y geografía lingüistica. Notas de orientación. - Inst. Caro y Cuervo, Bogotá, 1970. xii + 129 pp.

21-4207. Escobar, A. - "Problemática de las lenguas nacionales". - PILEI(4), $35-43$.

21-4208. Bunster, C. - "El doctor Rodolfo Oroz y su obra en la filología chilena". - AUCh, 1966, núm. 140, 34-43.

21-4209. CorneJo, J. - "Humberto Toscano Mateus y su tarea lingüistica".Memorias de la Academia Ecuatoriana, 1969, núm. 24.

V. también núms. 3691-3705, 3796-9.

Peninsular

21-4210. Zamora Vicente, Alonso-Dialectología española. 2a ed. muy aum. 
la reimp. - Gredos, Madrid, 1971. 588 pp., 22 maps. (BRH, Manuales, 8) . - V. núm. 20-5090. || $R R L, 16$ (1971), 445446 (Sandru).

21-4211. Navarro, T. - "Areas geográficas de consonantes finales". - $L T, 1970-71$, núms. 70/1, 199-219. [Según el $\boldsymbol{A} L P I]$. 21-4212. López SANtos, L. - "Los diptongos decrecientes en el dialecto leonés". -ALeon, $24 \quad(1970), 273-298$.

21-4213. Neira Martínez, J. - "El prefijo tres- en las hablas leonesas". - CLR(12), 1, 1063-1068.

21-4214. GonZÁlez, F. - "Vocabulario de uso frecuente en la montaña leonesa". $-R D T P, 25$ (1969), 357-361.

21-4215. Penny, R. J. - "Mass-nouns and metaphony in the dialects of NorthWestern Spain". - $A L, 1$, new series $(1970), 21-30$.

21-4216. Fernández GonzÁlez, A. R. $-E l$ habla y la cultura popular de Oseja de Sajambre (N. 14-40414). II RPh, 24 (1970-71), 189-200 (Fainberg \& Lefkowitz). - V. núm. 16-46958.

21-4217. Lluza, XULIN DE - Primer diccionario de la lengua asturiana, madre del idioma español. - La Nueva España, Oviedo, $1970.89 \mathrm{pp}$.

21-4218. Rodríguez Castellano, L. - "E1 dialecto asturiano". - [En] El libro de Asturias (Oviedo, 1970), 210-232.

21-4219. Malkiel, Yakov - Patterns of derivational affixation in the Cabraniego dialect of East-Central Asturian. - Univ. of California Press, BerkeleyLos Angeles, 1970. 95 pp. (Linguistics, 64).

21-4220. Blanco Piñán, S. - "Vocabulario asturiano de la parroquia de Meré (Llanes)". - BIEA, 1970, núm. 71, 507-556.

21-4221. Ferto, J. M. - "Los caldereros de Miranda y su jerga dialectal".-BIEA, 1970, núm. 71, 483-506.

21-4222. MartíneZ, E. - "Nuevas aportaciones al lenguaje de los tejeros de Llanes". - RDTP, 25 (1969), 301-306.

21-4223. Penny, Ralph J. - El habla pasiega: ensayo de dialectologia montanesa. - Tamesis Books, London, 1969. 470 pp. || ZRPh, 87 (1971), 662 (Baldinger) ; RDTP, 27 (1971), 425-427 (Pérez Vidal) .

21-4224. Penny, R. J. - "Vowel-harmony in the speech of the Montes de Pas (Santander)". - Orbis, 18 (1969), 148166.

21-4225. González del Valle, M. - "Geo- grafía e idioma en el Valle de Lamasón".-PIEF, 1 (1969), 167-173. [Santander].

21-4226. Oroz, F. J. - "Al margen del vocabulario navarro". - $P V, 31$ (1970), 133-139.

21-4227. Alvar, Manuel-El dialecto riojano. - U.N.A.M., Centro de Lingüística Hispánica, México, 1969. 93 pp. \| ZRPh, $86 \quad(1970), 688$ (Baldinger); RLiR, 35 (1971), 225-227 (Gardette); $A L M, 8(1970)$, 261-264 (Moreno de Alba).

21-4228. Llorente Maldonado, A. - "Las encuestas del Atlas lingüistico y etnográfico de Aragón y (las encuestas) del Atlas lingüistico y etnográfico de $\mathrm{Na}$ varra y Rioja". - AFA, 16/17 (196566), 81-100.

21-4229. Kunn, A. - "Estudios sobre el léxico del Alto Aragón". - $A F A, 16 / 17$ (1965-66) , 7-56.

21-4230. Ballarín Cornel, A. - "Vocabulario de Benasque". - AFA, 16/17 (1965-66) , 127-212.

21-4231. Mondé\}AR, José - El verbo andaluz. Formas y estructuras. - C.S.I.C., Instituto "Miguel de Cervantes", Madrid, 1970. xvi +196 pp., 63 mapas. (RFE, anejo 90).

21-4232. Paraíso de Leal, I. - "Notas sobre el habla popular de Rociana". RDTP, 26 (1970) , 245-252.

21-4233. BECKER, F. - "La influencia del español sobre el inglés de Gibraltar".$B F E, 1970$, núms. $34 / 5$.

V. también núms. 3978, 5948-9.

\section{Extrapeninsular}

21-4234. Alvar, M. - "La articulación de la $s$ herreña (Canarias occidentales)". -HGS, 1, 105-114.

21-4235. PÉREZ, JUAN RÉGUlo-Notas acerca del habla de la isla de La Palma.Univ. de La Laguna, La Laguna de Tenerife, 1970. 174 pp. [Sep. de $R H C$ ]. II RDTP, 27 (1971), 450-452 (Pérez Vidal) .

21-4236. Trujillo, Ramón - Resultado de dos encuestas dialectales en Masca. - Instituto de Estudios Canarios, La Laguna de Tenerife, 1970. 84 pp., ilustr. 21-4237. Solé, Carlos alberto - Bibliografia sobre el español en América, 1920-1967. - Georgetown Univ. Press, Washington, D. C., 1970. 175 pp. || ALM, 8 (1970), 258-261 (Moreno de Alba). 
21-4238. Lope Blanch, J. M. - El español de América (N. 20-5111). \|RRL, 15 (1970), 301-303 (Grossmann) .

2I-4239. JIMÉNEz BORJA, J. - "Contribución bibliográfica a la dialectología hispanoamericana".-BAPL, 1970, núm. 5 , 81-105.

21-4240. Coseriu, E. - "Ibero-American and Caribbean linguistics".-[En] Current trends in linguistics, 4 (The Hague, 1969) , 5-62.

21-4241. SANDRU, T. - "Problemas y orientaciones actuales en la investigación del español americano". - $R R L, 15$ (1970), 279-292.

21-4242. Malmberg, Bertil - La América hispanohablante. Unidad y diferenciación del castellano. Trad. de J. López F. y K. Lindstrom. - Istmo, Madrid, 1970. $317 \mathrm{pp}$.

21-4243. Montes Giraldo, J. J. - "La geografía lingüística y la unidad del español americano". - BICC, 25 (1970), 290-294.

21-4244. Rosenblat, ANGel - Lengua li. teraria y lengua popular en América.Univ. Central de Venezuela, Caracas, 1969. 128 pp. (Cuadernos del Inst. de Filologia Andrés Bello). \|l QIA, 5 (1970), 120-123 (Bertini).

21-4245. Herrero Mayor, A. - Contribución al estudio del español americano: El prosista y su prosa. - Ministerio de Cultura y Educación, Buenos Aires, 1970. 109 pp.-V. núm. 19-1314.

21-4246. Rosenblat, A. - "El debatido andalucismo del español de América". -PILEI(4), 149-190.

21-4247. Di Pietro, R. J. - "Bilingualism [in Latin America]".-Current trends in linguistics, ed. T. A. Sebeok, t. 4 (The Hague, 1968), 399-414.

21-4248. Granda, G. DE - "On the study of the Creole dialects in Spanish-speaking areas". - Orbis, 19 (1970), 72-81.

21-4249. Granda, G. DE - "Cimarronismo, palenques y hablas "criollas» en Hispanoamérica".-BICC, 25 (1970), 448-469.

21-4250. Granda, G. DE - "Un temprano testimonio sobre las hablas "criollas" en Africa y América".-BICC, 25 (1970), 1-11.

21-4251. Richards, H. J. - "Some Spanish words in the English-based dialect of Trinidad". $-H, 53$ (1970), 263-266.

21-4252. Zamora, JuAN C. - Contribución al estudio de los indigenismos en el español americano. - [Tesis, State Univ. of New York, Buffalo, 1971].
21-4253. MejíA SÁnchez, E. - "Un vocabulario de indigenismos americanos del siglo XVII". - ALM, 8 (1970), 19-38.

21-4254. URibe-VILLEGAS, O. R. - "La «resistencia indígena a la castellanización. Proyecto para medirla y correlacionarla snciológicamente". - $C L(10), 4$, 805-812.

21-4255. Rona, J. P. - “¿Qué es un americanismo?" - PILEI(4), 135-148.

21-4256. Alvar, M. - "Colón en su aventura". - Proh, 2 (1971), 165-193. [La lengua de Colón y los primeros "americanismos"'].

21-4257. Willis, Bruce Edward - The alternation of so-called learned/popular vocabulary in a phonological description of Latin American Spanish.-[Tesis, Univ. of Illinois, 1970].

21-4258. Kany, Charles E.-Sintaxis hispanoamericana. - Gredos, Madrid, 1970. 552 pp. (BRH, Estudios y ensayos, 136). -V. núm. 6-7941.

21-4259. SALA, M.-“Arhaisme si inovatii în lexicul spaniolei americane". - $S H$, 1970, 87-93. - V. núm. 21-1083.

21-4260. Balcázar Bugher, Cegilia - $A$ transformational analysis of a Spanish dialect. - [Tesis, Georgetown Univ., 1971].

21-4261. Ludwig, Ed., \& James SantibáñeZ (eds.) - The Chicanos: American voices. - Penguin Books, Baltimore, 1971. 286 pp. (A pelican original).

21-4262. Tsuzakr, Stanley M. - English influences on Mexican Spanish in Detroit. - Mouton, The Hague, 1971. 92 pp. (Janua linguarum, series practica, 107). - V. núm. 18-4992.

21-4263. Blanco, A. - La lengua española en la historia de California. Contribución a su estudio. - Madrid, 1971. $826 \mathrm{pp}$.

21-4264. Cerda, Gilberto, et al.-Vocabulario español de Texas.-Univ. of Texas Press, Austin, 1970. 347 pp.- V. núm. 10-22718. || BICC, 26 (1971), 147-150 (Galván) .

21-4265. Kercheville, Francis M. $-A$ preliminary glossary of Southwestern and Rio Grande Spanish. - Kingsville, Tex., 1969.

21-4266. CAMPA, A. L. - "Cultural variations in the Anglo-Spanish Southwest". -Western Review, Silver City, N. M., 1970, núm. 1, 3-9. [Interferencias lingüísticas $y$ otras].

21-4267. Solé, Y. R. - "Correlaciones socioculturales del uso de $t \dot{u} /$ vos y usted 
en la Argentina, Perú y Puerto Rico". $-B I C C, 25$ (1970), 161-195.

21-4268. Rosario, R. DEL - "La investigación dialectal en Puerto Rico". PILEI(4), 244-247.

21-4269. Tovar, A. - "Ni un día $\sin$ línea. Lengua y literatura en Puerto Rico (II)". - BAAC, 6 (1970), 41-46.

21-4270. LAguerre, E. A. - "Sobre la lengua”. - EPR, 1970, núm. 29. 75-90.

21-4271. Schiavo, E. - "Puerto Rico: El idioma como posibilidad". - MN, 1970, núm. 50, 27-31.

21-4272. Calvo Hernando, M. - "El idioma español en Puerto Rico”. - $A r b$, $75(1970), 275-290$.

21-4273. Arce de Vázquez, M. - "Problemas con que se confronta la lengua en Puerto Rico". - Noticias Culturales, Boogotá, 1968, núm. 95.

21-4274. GRANDA, G. DE-Transculturación $e$ interferencia lingüistica en el Puerto Rico contemporáneo (N. 21-1092). II ZRPh, 85 (1969), 651-652 (Baldinger); BICC, 25 (1970), 114-122 (BallesterosGaibrois) ; $Q I A, 5$ (1970), 115-116 (Pellegrini); ROCc, 29 (1970), 371-376 (Uribarri) .

21-4275. Fonfrías, Ernfsto Juan - De la lengua de Isabel la Católica a la taina del cacique Agueybana: origen y desarrollo del habla hispano-antillana. Club de Prensa, San Juan, P. R. 1969.

21-4276. DíAz Quĩ̃ones, Arcadio-Documentos lingüisticos de Puerto Rico: Siglo xyi. - [Tesis, Univ. de Madrid; resumen en $R U M, 17$ (1968), 32-34].

21-4277. Davis, I. C.-"Tú, ¿qué tú tienes?" $-H, 54$ (1971), 331-333.

21-4278. Hostos, A. DE - "Vocabulario araguaco". - BAAC, 6 (1970), 335-336.

21-4279. BRAU, S. - "Casabe, arepa, chicha”. - BAAC, 6 (1970), 337.

21-4280. Lloréns, W. - “E1 coquí, cantor nocturno de Puerto Rico". - $B A A C, 6$ (1970) , 341-359.

21-4281. Rosario, R. DeL - "Uso y función del inglés en Puerto Rico". PILEI(2), 69-77.

21-4282. López Morales, Humberto - Es tudio sobre el español de Cuba.-Las Americas, New York, 1971. 188 pp.

21-4283. GRANDA, G. DE - "Algunos datos sobre la pervivencia del "criollo" en Cuba". - BRAE, 51 (1971), 481-491.

21-4284. Goodgall de Pruna, R. - "La pronunciación del idioma español en el centro de Cuba". - Islas, 1970, núm. 37, 155-16 6 .
21-4285. LÉvina, I. - "Algunos fenómenos fonéticos en los límites de un sintagma”. -Islas, 1970, núm. 35, 129-136. [Cuba].

21-4286. Goodgall de Pruna, R. - "La geminación de consonantes en el habla de Trinidad [Cuba]".-Islas, 1970, núm. 35, 125-128.

21-4287. Isbasescu, C. - “Despre. existenta unei fricative labiodentale sonore /v/ în spaniola din Cuba". - $S H, 1970,67-$ 72.-V. núm. 21-1100.

21-4288. Vallejo-Claros, Bernardo - La distribución $y$ estratificación de $/ r /$, $|\bar{r}| y|s|$ en el español cubano.-[Tesis, Iniv. of Texas, 1970].

21-4289. Cuéllar, B. V. - “Observaciones sobre la $r r$ velar y la $y$ africada en Cuba". - EAC, 1971, núm. 20.

21-4290. Farray, N. - "Homonimias y polisemias en la nomenclatura zoológicobotánica del español hablado en Cuba". $-C L(10), 2$, 365-377.

21-4291. Arrom, J. J. - "Para la historia de las voces canuco y guajiro".-BRAE, 50 (1970), 337-348.

21-4292. Galván, R. A. - “Chichecano, neologismo jergal”. - $H, 53$ (1970), 86-88.

21-4293. Jiménez Moreno, W.-“Los estudios lingüísticos en México".-PILEI(4), 14-22.

21-4294. Fernández de Miranda, M. T."25 años de investigación lingüística". -HMx, 19 (1969-70), 445-458. [México].

21-4295. Uribe Villegas, O. - "La situación sociolingüística de México como marco de la condición indígena".-RMS, 31 (1969), 1019-1025.

21-4296. URIBE Villegas, OsCAR-Un mapa del monolingüismo $y$ del bilingüismo de los indigenas de México en 1960. Un sub-producto del proyecto sociolingüistico del Instituto de Investigaciones Sociales--UNAM, México, 1970. $33 \mathrm{pp}$. 21-4297. Paulín, Georgina - Monolingües y bilingües en la población de México, en 1960. Estadisticas del proyecto sociolingüistico.-UNAM, México, 1971. 253 pp., mapas.

21-4298. Parodi de Teresa, C. - "Para el estudio de la lengua traída a la Nueva España". - ALM, 8 (1970), 205-218.

21-4299. Lope Blanch, J. M. - "Sobre la influencia del sustrato en la fonética del español de México". - CL(10), 4, 773-776.

21-4300. Lope Blanch, J. M. - "Para la delimitación de las zonas dialectales de México". - PILEI(4), 255-261. 
21-4301. Lope BLANCH, JuAN M. - Cuestionario para la delimitación de las zonas dialectales de México. - El Colegio de México, México, 1970. $86 \mathrm{pp}$. || $Z R P h, 86$ (1970), 688 (Baldinger). 21.4302. LAstra, X.-" The status of $|s|$ in Mexican Spanish".-Linguistic studies... Richard Slade Harrell (Washington, 1967), 113-121.

21-4303. Moreno de Alba, José G. - La expresión verbal de lo futuro en el español hablado en México.-Universidad Nacional Autónoma, México, 1970. 157 pp. [Tesis]. || BICC, 25 (1970) , 489-490 (Montes Giraldo).

21-4304. Moreno de Alba, J. G. - "Vitalidad del futuro de indicativo en la norma culta del español hablado en México". - ALM, 8 (1970), 81-102.

21-4305. BREND, R. M. - A tagmemic analysis of Mexican Spanish clauses (N. 20-1002). || Lan, 46 (1970), 185-188 (Cressey) .

21-4306. Magallanes, D. M. - "Oraciones independientes del gerundio en el español de México". - $A L M, 8$ (1970), 235239.

21-4307. Luna Trail, E. - "Observaciones sobre el infinitivo final en el español mexicano".-ALM, 8 (1970), 57-79.

21-4308. Rojas Nieto, C. - "Los nexos adversativos en la norma culta del español hablado en México". - ALM, 8 (1970), 103-124.

21-4309. Millán Orozco, A. - "Anomalías en la concordancia del nombre en el español de la ciudad de México".ALM, 8 (1970), 125-146.

21-4310. Lope Blanch, Juan M.-El léxico indígena en el español de México.-El Colegio de México, México, 1969. 75 pp. (Jornadas, 63). || ZRPh, 85 (1969), 555-557 (Baldinger).

21-4311. OlstaD, C. - "Frito: an English loan-word in Mexican Spanish". - $\boldsymbol{H}$, 53 (1970), 88-90.

21-4312. Galván, R. A. - "More on frito as an English loan-word in Mexican Spanish". - H, 54 (1971), 511-512.

21-4313. Perissinotto, Giorgio Sabino ANTONIO - The phonology of the Spanish spoken in Mexico City.-[Tesis, Columbia Univ., 1971].

21-4314. Spyropoulos, E. M.-“The phonology of the word in a Spanish dialect". -Languages and Linguistics, Washington, 1969, núm. 1, 24-41. [En Chihuahua, México].

21-4315. Villarelo Vélez, Ildefonso-El habla de Coahuila. Pról. de F. Berrueto Ramón. - Eds. Mástil, Saltillo, Coah., (México), 1970. $74 \mathrm{pp}$.

21-4316. Gavaldón, L. - "Aspectos fonéticos del habla de Múzquiz, Coahuila". $-A L M, 8 \quad(1970), 219-234$.

21-4317. Alvar, M. - "Nuevas notas sobre el español y el maya yucateco".PILEI(4), 200-206.

21-4318. Barrera VÁsquez, A. - "El español yucateco como fenómeno histórico". - RUY, 1967, núm. 54, 61-74.

21-4319. Ríos Meneses, M. B. - "Análisis dialectológico del español yucateco, con notas filológicas de algunas voces mayas y mayismos". - RUY, 1968, núm. 55, 37-70.

21-4320. Arzípalo, R. - "The social role of the indigenous languages of Mexico and Guatemala".-CJL, 14 (1969), 133141.

21-4321. Solano, F. DE - "Castellanización del indio y áreas del castellano en Guatemala en 1772".- $R U M, 19$ (1970), núm. 73.

21-4322. RiverA, A. H. DE - "Hondureñismos". - HuNL, 12 (1971), 179-202.

21-4323. ARroyo SOTO, Víctor MANUELEl habla popular en la literatura costarricense. - [Tesis, Univ. de Madrid; resumen en RUM, 18 (1969), núm. 72, 36-37].

21-4324. Wilson, JACK Leroy - A generative phonological study of Costa Rican Spanish. - [Tesis, Univ. of Michigan, 1971].

21-4325. Grafll. Stanziola, Matilde Contribución al estudio de la fonologia y fonética del español hablado en Panamá. - [Tesis, Univ. de Madrid; resumen en RUM, 18 (1969), núm. 72, 43-44].

21-4326. Amado, M. - "El lenguaje en Panamá”. - BAPaL, 1970, núm. 5.

21-4327. Gurtarte, G. L. - "Para una historia del español de América basada en documentos: el seseo en el Nuevo Reino de Granada (1550-1650)". - PILEI(4), 191-199.-V. núm. 20-5152.

21-4328. Cock Hincapie, OLGa - El seseo en el Nuevo Reino de Granada. Pról. de G. L. Guitarte. - Instituto Caro y Cuervo, Bogotá, 1969. 172 pp. \| AIL, $10(1970)$, 101-103 (Fontanella de Weinberg) ; Carav, 1971, núm. 17, 222-224 (Fontanella de Weinberg); $A L M, 8$ (1970), 265-268 (Parodi de Teresa); $B I C C, 24$ (1969) , 156-158 (X) .

21-4329. Flórez, L. - "Dos proyectos para 
investigación de léxico en Colombia".BACol, 20 (1970) , 481-492.

21-4330. González-Rodas, P. - "Léxico de borrachera en Colombia". - $M N, 1970$, núm. 53, 64-68.

21-4331. Flórez, L. - El español hablado en Santander (N. 19-1376). $\|$ AIL, 10 (1970), 111-117 (Aranalde).

21-4332. Bickerton, D. - "Palenquero: a Spanish-based Creole of northern Colombia". - Lingua, 24 (1970), 254-267.

21-4333. Ocampo Marín, J. - "Determinación del dialecto popular en Venezuela por el sistema vocálico y consonántico". - CL(10), 2, 149-158.

21-4334. Gómez de IVashevsky, Aura Lenguaje coloquial venezolano. - Inst. de Filología "Andrés Bello", Caracas, 1969. 502 pp. || RDTP, 26 (1970), 195196 (Pérez Vidal); ASNS, 208 (1971), 437-440 (Schneider).

21-4335. Novoa Montero, D. - "El lenguaje médico de nuestro pueblo". RVFo, 1970, núm. 3, 105-126.

21-4336. Fish, G. T. - "Papiamento in a nutshell". - H, 53 (1970), 92-93.

21-4337. Eastlack, C. L. - "More on Papiamentu". - $H, 53$ (1970), 443.

21-4338. Birmingham, J. C., JR. - "Still more on Papiamentu". - H, 54 (1971), 300-301.

21-4339. Coomans, H. E. - "Volksnamen voor weekdieren op de Nederlandse Antillen".-Nieuwe West-Indische Gids, The Hague, 47 (1970), 158-186. [Incluye el papiamento].

21-4340. Moscoso VegA, Luts A. - Deformaciones fonéticas y gráficas en el léxico de las artesanias azuayas. - Departamento de Extensión Cultural, Cuenca, Ecuador, 1968. 67 pp. (Cuadernos de ensayistas cuencanos contemporáneos).

21-4341. CoRnejo, Justino - El quichua en el castellano del Ecuador. - Edit. Ecuatoriana, Quito, 1967. 116 pp.

21-4342. BurNs, D. H. - "Bilingual education in the Andes of Peru". - Language problems of developing nations, ed. J. A. Fishman (New York, 1968), 403-413.

21-4343. Bratt Paulston, C. - "Algunas notas sobre la enseñanza bilingüe del idioma en el Perú". - América Indigena, México, 30 (1970), 99-106.

21-4344. fĩ̃ıo Madrigal, L. - "Lo popular en La Araucana". - Boletin de la Universidad de Chile, Santiago de Chile, 1969, núm. 99.

21-4345. Navarro Maraví, A. R. - "La pronunciación en los pueblos del centro del Perú". - Revista de Educación, Huancayo, Perú, 1 (1964), 145-147.

21-4346. Hilderrand, M. - "Papeletas lexicográficas: Recién, concho, daño, emoliente, emolientero, grifero, huacho, malero, penar". - BAPL, 1970, núm. 5, 107-114.

21-4347. Soukup, S. B. D. - Vocabulario de los nombres vulgares de la flora peruana. - J. Mejía Baca, Lima, 1971. $380 \mathrm{pp}$.

21-4348. McGourn, Francis Thomas-A study of the Spanish of the Aymara Indians of the Department of Puno, Perú. - [Tesis, Stanford Univ., 1971]. 21-4349. Echevarkía, E. - "El léxico de la novela social boliviana". $-H, 53$ (1970) , 982-985.

21-4350. Fortún, J. E. - "Al margen del castellano". - BICC, 25 (1970), 470484. [Expresiones para-idiomáticas de Bolivia].

21-4351. Lira Urquieta, P. - "Chilenismos. La nueva edición del Diccionario". $-B A C h, 1970$, núm. 58.

21-4352. Bustamante Pina, D. - "Algunos neologismos en el lenguaje administrativo chileno". - CLR(12), 1, 875-892.

21-4353. Smiricky, L. - "Acerca de los nombres de establecimientos comerciales en Chile". - CLR(12), 1, 1069-1073.

21-4354. Ramírez S., C. - "El telar indigena o huitral en la provincia de Cautín (Chile). (Estudio lingüístico etnográfico)". - RDTP, 26 (1970) , 275-296.

21-4355. Bernales, M. - "La carreta de Chiloé". - RDTP, 26 (1970), 27-40.

21-4356. Potrier, B. - "Bibliographie linguistique sélective du Rio de la Plata". - LNL, 1971, núms. 192/3, 4-6.

21-4357. Biancolini, L. - "El castellano en el habla de $E l$ gaucho Martin Fierro". - CL(10), 2, 37-42.

21-4358. Buffa, J. L. - "Variación lingüística en el ambiente natural". CL(10), 1, 747-758.

21-4359. BarrenecheA, A. M., y M. M. DE RoserTI-"La voz pasiva en el español hablado en Buenos Aires".-PILEI(4;, 234-243.

21-4360. Barrenechea, A. M., y T. OrecCHIA-"La duplicación de objetos directos en el español hablado en Buenos Aires". - $R P h, 24$ (1970-71), 58-83.

21-4361. Fontanella de Weinberg, M. B. -"La evolución de los pronombres de tratamiento en el español bonaerense". $-B I C C, 25$ (1970), 12-22.

21-4362. Villamayor, Luis C., y Enrique 
Ricardo del Valle - El lenguaje del bajo fondo. Vocabulario lunfardo. Ed. crítica con pról. y notas. - Schapire, Buenos Aires, 1969. 192 pp.

21-4363. Guarnieri, Juan Carlos - Diccionario del lenguaje campesino rioplatense. - Florensa \& Lafon, Montevideo, 1970. 140 pp.-V. núm. 20-5178.

21-4364. Pacheco, Agenor - Etimología gaucha: vocablos, modismos y refranes rioplatenses y sureños. - Servicio de Informaciones del Ejército, Buenos Aires, 1968. 105 pp., ilustr.

21-4365. Donni de Mirande, Nélida E.El español hablado en Rosario. - Inst. de Lingüistica y Filología, Univ. Nac. del Litoral, Rosario, 1969. 175 pp. II ZRPh, 85 (1969), 650-651 (Baldinger); BHi, 72 (1970), 492 (Pottier) ; ALM, 8 (1970), 269-271 (Solís Acevedo).

21-4366. Guarnieri, Juan Carlos-El lenguaje popular que hablamos y escribimos. Páginas sobre sus origenes y su historia. - Delta, Montevideo, 1969. $61 \mathrm{pp}$.

21-4367. Marsilio, Horacio de - El lenguaje de los uruguayos. - Nuestra Tierra, Montevideo, 1969. 60 pp., ilustr.

21-4368. Rubin, J.-"Language and education in Paraguay".-Language problems of developing nations, ed. J. A. Fishman (New York, 1968), 477-488. - V. núm. 21-1173.

21-4369. Potrier, B.- "La situation linguistique du Paraguay". - Carav, 1970, núm. 14, 43-50.

21-4370. Fernández Arévalos, E.-"Presupuesto para una "política lingüística" en el Paraguay".-Carav, 1970, núm. 14, 23-29.

21-4371. Rubin, J. - "Bilingual usage in Paraguay". - Readings in the sociology of language, ed. J. A. Fishman (The Hague, 1968), 513-530.

21-4372. Manrique Castañeda, Leonardo -Algunas observaciones sobre el bilingüismo del Paraguay. - Fac. de Humanidades y Ciencias, Univ. de la República, Montevideo, 1969. 28 pp. $\| B I C C$, 25 (1970), 489 (Montes Giraldo).

21-4373. PlÁ, J. - "Español y guaraní en la intimidad de la cultura paraguaya". -Carav, 1970, núm. 14, 7-21. || StL, 25 (1971), 65-66 (Malmberg) .

21-4374. Cassano, P. V. - "Substratum hypothesis concerning the Spanish of Paraguay". - N, 55 (1971), 4I-44.

2I-4375. Collantes y Tomines, RicardoEl idioma español en Filipinas en la época contemporánea. - Madrid, 1967. $19 \mathrm{pp}$.

21-4376. Otanes, Fe T., \& Bonifacio P. SIBAYAN - Language policy survey of the Philippines: initial report. - Philippine Normal College, Manila, 1969. $207 \mathrm{pp}$.

21-4377. López, C. U. - "El estudio del español en Filipinas”. - $H, 53$ (1971), 102-105.

V. también núms. 3969, 4168-79.

Judeoespañol

21-4378. Hassán, I. M. - "Introducción" [sobre el I Simposio de Estudios Sefardíes]. - SES(1), xi-xxvi.

21-4379. Pérez Castro, F. - "Programática [de los estudios sefardíes]". - SES(1), 3-19.

21-4380. "Sefardismo en Sefarad".-SES(1), 637-661.

21-4381. BEINART, H. - "La formación del mundo sefardi". - SES(1), 43-48. [Discusión, pp. 371-376].

21-4382. Kellenbenz, H. - "Tradiciones nobiliarias de los grupos sefardíes". SES(1), 49-54. [Discusión, pp. 377-378]. 21-4383. Bentata, J. - "La cultura española como enlace no solamente de los diversos núcleos sefardíes con la Península, sino tambiẻn de los distintos centros dispersos entre sí". - SES(1), 191 196. [Discusión, p. 414].

21-4384. Révah, I. S. - "Hispanisme et judaïsme des langues parlées et écrites par les Sefardim". - SES(1), 233-242. [Discusión, pp. 444-453].

21-4385. SchiBy, B.-“Notes sur les Juifs de Thessalonique".-SES(1), 91-94. [Discusión, pp. 378-380].

21-4386. ATrias, M. - "The work in Ladino of Rabbi Abraham Toledo". Shevet va'Am, Jerusalem, 1 (1970), 116-135. [En hebreo].

21-4387. EsH, S. - "Some observations on the place of the Sepharadim in modern Jewry". - SES(1), 132-140. [Discusión, pp. 395-399].

21-4388. Quilis, A. - "Causas de desaparición de formas dialectales". - SES(1), 225-232. [Discusión, pp. 453-455].

21-4389. Criado de Val, M. - "Posibilidades de conservación del judeo-español por medio de versiones literarias". SES(1), 277-279. [Discusión, pp. 478-488]. 21-4390. Besso, H. V. - "Decadencia del judeo-español. Perspectivas para el fu- 
turo".-SES(1), 249-261. [Discusión, pp. 414-426].

21-4391. YeshaiA, S. B. - "Jerusalén y sus comunidades sefarditas". - SES(1), 95105. [Discusión, pp. 399-403].

21-4392. Romano, D. - "Notas sobre el judeo-español en una obra de Bassani". -Sef, 30 (1970), 198-200.

21-4393. Elyachar, J. R. - "The situation of Sephardim in the United States and Israel and their educational and cultural potentials". - SES(1), 197-203 [Discusión, pp. 457-458].

21-4394. BeNARDETE, M. J. - "Las comunidades sefardies en Nueva York. Pro. mesas de futuro". - SES(1), 149-154 [Discusión, pp. 431-432].

21-4395. PÉrez, L. S. - "El área de sefardización secundaria: América latina".SES(1), 141-148. [Discusión, pp. 410-411]. 21-4396. Hassán, I. M.-"Bibliografía de publicaciones judeoespañolas aljamiadas: fondo Molho". - Sef, 30 (1970), 201204. [Resumen].

21-4397. Benarroch, C. - "Ojeada sobre el judeoespañol de Marruecos".-SES(1), 263-275. [Discusión, pp. 433-439].

21-4398. SALA, Marius - Estudios sobre el judeoespañol de Bucarest. Trad. F. Botton-Burlá. - UNAM, México, 1970. 193 pp. (Filosofia y Letras, 73).

21-4399. Crews, C. M. - "Some data concerning medical nomenclature in sixteenth-century Judeo-Spanish".-SES(1), 243-247. [Discusión, pp. 443-444].

21-4400. Uziel, B. - "Características del ladino y su fo"iklore". - $S E S(1)$, 319 330. [Discusión, pp. 439-443].

21-4401. Martínez Ruiz, J. - "Arabismos en el judeo-español de Alcazarquivir (Marruecos), 1948-1951" (N. 20-5199). || $A I L, 10$ (1970), 128-129 (Castro).

21-4402. Alvar, Manuel - Endechas judeo-españolas. Con notación de melo días tradicionales por M. T. Rubiato. Ed. refundida y aum. - Instituto Arias Montano, Madrid, 1969. xx +236 pp. -V. núm. 10-21729. || RLiR, 35 (1971), 225-227 (Gardette).

21-4403. Abramson, S. - "Expresiones lingüísticas en poesía y prosa". - OYS, $11 / 12(1969-70), 52-56$.

21-4404. Atrias, M. - "Sobre la poesia popular judeo-española". - SES(1), 295 305. [Discusión, pp. 466-478].

21-4405. Rubiato, M. T. - "Seis canciones sefardíes". - SES(1), 559-567.

21-4406. Katz, I. J. - "The «myth" of the Sephardic musical legacy from Spain'.
-Sef, $30(1970), 204-205$. [Resumen. Se refiere a la música de los romances].

21-4407. Armistead, Samuel G., \& J. H.

SILVERMAN (eds.) - Judeo-Spain ballads from Bosnia. - Univ. of Pennsylvania Press, Philadelphia, 1971. $\mathrm{x}+129 \mathrm{pp}$. V. también núms. 5722-6.

\section{LITERATURA}

\section{ESTUDIOS GENERALES}

21-4408. Hess, Rainfr, \& Gustav SifbenMANN-Literaturwissenschaftliches Wörterbuch für Romanisten. - Athenäum Verlag, Frankfurt/M., 1971. 300 pp.

21-4409. Mackerrow, Ronald B. - An introduction to bibliography for literary students. - Clarendon Press, Oxford, 1967. $\mathrm{xv}+355 \mathrm{pp}$.

21-4410. SchreIBER, Klaus - Bibliographie laufender Bibliographien zur romanischen Literaturwissenschaft. Ein kritischer Überblick 1960-1970. - Klostermann, Frankfurt/M., 1971. $80 \mathrm{pp}$.

21-4411. Braet, H., et J. Lambert (eds.) Encyclopédie des études littéraires ro. manes. Répertoire bibliographique. Éditions Scientifiques, Gand, 1971. 97 pp.

21-4412. Parks, George B., \& Ruth Z. TeMple (eds.) - The Romance literatures. - Ungar, New York, 1970. 2 ts. (The literatures of the world in English translation, 3).

\section{Teoría y crítica literaria}

21-4413. Zitner, Shfldon P. (ed.) -The practice of modern literary scholarship. -Scott, Foresman \& Co., Glenview, III., 1966. xxiv + 392 pp. $\| N, 56$ (1972), 114-115 (Birrell).

21-4414. WATson, George - The study of literature. A new rationale of literary history. - The Penguin Press, London, 1969. 237 pp. || JHI, 31 (1970), 148-151 (Boas) .

21-4415. Torre, Guillermo De - Doctrina y estética literaria. - Guadarrama, Madrid, 1970. 810 pp.

21-4416. Castagnino, Raúl H. - iQué es literatura? - Nova, Buenos Aires, 1970. 160 pp. - V. núm. 19-5354.

21-4417. Rossı, G. C. - "Reflexiones de un tradicionalista". - HEOL, 77-83.

21-4418. Pomorska, KrystyNa - Russian 
formalist theory and its poetic ambiance. -Mouton, The Hague, 1968. \| AESC, 26 (1971), 249-250 (Kahn) .

21-4419. Molino, J. - "Sur la méthode de Roland Barthes". - LingP, 1969, núm. 2, 141-154.

21-4420. BARTHES, RolAND - Estructuralismo y literatura. Sel. de J. Sazbón. - Nueva Visión, Buenos Aires, 1970. 223 pp. (El pensamiento estructuralista, 9). BAbr, 45 (1971) , 289-290 (Foster).

21-4421. Senabre Sempere, R. - "El influjo del público en la estructura de la obra literaria". - HEOL, 19-28.

21-4422. Kayser, Wolfgang - Análise $e$ interpretação da obra literária. Trad. P. Quintela. 5a ed. - A. Amado, Coimbra, 1970. 349 pp.-V. núm. 18-5076.

21-4423. KAYSER, WOLFGANG - Interpretación y análisis de la obra literaria. Versión de M. D. Mouton y V. García Yebra. 4a ed., rev. 2a reimpr. - Gredos, Madrid, 1970. 594 pp. (BRH, Tratados y monografias, 3).-V. núm. 19-5364.

21-4424. Heller, L. G., \& James MaerisToward a structural theory of literary analysis: Prolegomena to evaluative descriptivism.-Clark University, Worcester, Mass., 1970. 65 pp.

21-4425. Tonorov, Z. - "Les études du style. Bibliographie sélective". - Poetique, Paris, 2 (1970).

21-4426. Spitzer, Leo - Etudes de style. Trad. par E. Kaufholz, A. Coulon et M. Foucault. - Gallimard, Paris, 1970. 533 pp. || BAbr, 45 (1971), 278 (Caws).

21-4427. Guiraud, Pierre, et Pierre Kuentz -La stylistique. - Klincksieck, Paris, 1970. 327 pp. (Initiation à la linguistique: Lectures).

21-4428. Guiraud, Pierre - La estilistica. - Nova, Buenos Aires, 1970. 132 pp. V. núm. 12-29724.

21-4429. LORIAN, A. - "Stylistique 1970".RLiR, 34 (1970) [=HGS, 2], 113-122.

21-4430. LAMB, ANTHONY - La estilistica aplicada.-Scott, Foresman \& Co., Glenview, Ill., 1970. 140 pp.

21-4431. Romanr, W.-“Stilistica, retorica, poetica. Intorno ad alcuni recenti studi e proposte di testi". - LiS, 5 (1970), 487-498.

21-4432. Cambours Ocampo, arturo Lenguaje y creación: Notas para una fenomenologia del estilo literario.-La Reja, Buenos Aires, 1970. 124 pp.

21-4433. GeNeTte, GÉRARd - Figuras. Retórica y estructuralismo. - Córdoba, Argentina, 1970. 292 pp.
21-4434. Dubois, Jacques - Rhétorique générale. - Larousse, Paris, 1970. 206 pp. (Langue et langage). || FS, 26 (1972), 365-367 (France).

21-4435. Weinberg, Bernard (ed.) -Trattati di poetica e retorica del '500. T. 1. -Laterza, Bari, 1970.

21-4436. Pound, EzRA-El arte de la poesia. Trad. de J. Vázquez Amaral.-J. Mortiz, México, 1970. $132 \mathrm{pp}$.

21-4437. Paz, Octavio - El arco y la lira. El poema. La revelación poética. Poesía $e$ historia. 2a ed.-F.C.E., México, 1970. 302 pp. (Lengua y estudios literarios).V. núm. 12-29741.

21-4438. SEIDLER, H. - Dichtkunst und Literaturwissenschaft (N. 20-1113) . II MLR, 65 (1970), 688-689 (Peacock) .

21-4439. COHEN, JEAN - Estructura del lenguaje poético. Versión de M. Blanco Alvarez. - Gredos, Madrid, 1970. 226 pp. (BRH, Estudios y ensayos, 140).V. núm. 20-1186.

21-4440. Blumenberg, H.-Paradigmi per una metaforologia.-Il Mulino, Bologna, 1969. xiv + 194 pp. \| LiS, 5 (1970), 333-334 (X).

21-4441. HenRy, ALBert - Métonymie et métaphore. - Centre de Philologie et de Littératures Romanes, Strasbourg, 1971. 162 pp. (Manuels et études linguistiques, 21) .

21-4442. Forster, LEONARD - The poet's tongues: Multilingualism in literature. - University Press, Cambridge, 1971. xii +101 pp.

21-4443. LeVy, JIRI - Die literarische Ubersetzung. Theorie einer Kunstgattung. - Athenäum Verl., FrankfurtBonn, 1969. 308 pp.

21-4444. KLOepfer, R. - Die Theorie der literarischen Übersetzung (N. 20-5220). \| RJ, 21 (1970), 226-229 (Wittschier).

21-4445. Crane, R. S. - Critical and historical principles of literary history.Univ. of Chicago Press, Chicago, 1971. $128 \mathrm{pp}$.

21-4446. Guillén, Claudio - Literature as system: Essays toward the theory of literary history.-Princeton Univ. Press, Princeton, N. J., 1971. 528 pp.

21-4447. Jauss, H. R.-Literaturgeschichte als Provokation der Literaturwissenschaft (N. 20-1089). \| N, 54 (1970), 434-435 (Dyserinck); $R P h, 24$ (197071), 548-549 (Friedman); BAbr, 45 (1971), 305 (Grawe).

21-4448. TACCA, OSCAR - La historia literaria. - Gredos, Madrid, 1968. 204 pp. 
(BRH, Estudios y ensayos, 120) . | ROcc, 25 (1969), 374-375 (Amorós); $R J, 20$ (1969), 366-368 (Kruse); BHS, 46 (1969), 345-346 (Pierce); LPa, 1969, núm. 17, 205-206 (Teixeira de Oliveira).

21-4449. SORIA, A. - "Notas sobre métodos de historia literaria".-HEOL, 3-18.

21-4450. Praz, Mario - Mnemosyne: The parallel between literature and the visual arts. - Princeton Univ. Press, Princeton, 1970. 261 pp. \| $M L N, 86$ (1971), 597-602 (Vannier) .

21-4451. Rasch, WOLFDIETRICH (ed.) Bildende Kunst und Literatur. Zum Problem der Wechselbeziehungen im 19. Jahrhundert. - V. Klostermann, Frankfurt, 1970. 192 pp., 88 láms.

21-4452. KaYser, WOLFGang - The grotesque in art and literature. $\mathrm{Tr}$. by $\mathrm{U}$. Weisstein.-Peter Smith, s. 1., 1968. 224 pp., ilustr.-V. núm. 18-5078.

21-4453. Escarpit, Robert (ed.) - Le littéraire et le social. Eléments pour une sociologie de la littérature. - Flammarion, Paris, 1970. 315 pp.

21-4454. Sarkany, S. - "Essai sur la sociologie de la littérature". - $R L C, 45$ (1971), 60-73.

21-4455. TODOROv, TzvetaN - Introduction à la littérature fantastique. - Ed. du Seuil, Paris, 1970. || BAbr, 45 (1971), 471-472 (Gershman); Proh, 1 (1970), 499-503 (Hernández Esteban).

21-4456. Hobsbaum, Philip-Theory of criticism.-Indiana Univ. Press, Bloomington-London, 1970. $\mathrm{xv}+272 \mathrm{pp}$.

21-4457. Trilling, Lionel (ed.)-Literary criticism. An introductory reader. Holt, Rinehart \& Winston, New York, 1970. xiv + 629 pp.

21-4458. Carnetro Leão, E. - "Crítica literária e existencialismo". - $S L P(2)$, 171-178.

21-4459. Konder, L. - "Crítica literária e marxismo". - SLP(2), 179-193.

21-4460. Houaiss, A. - "Crítica literária e estruturalismo". - SLP(2), 207-237.

21-4461. WELLEK, RENÉ - Discriminations. Further concepts of criticism. - Yale Univ. Press, New Haven, 1970. 387 pp. -V. núm. 19-1524. || BAbr, 45 (1970), 325-326 (Ziolkowski).

21-4462. Beardsley, Monroe C.-The possibility of criticism. - Wayne State Univ. Press, Detroit, 1970. 123 pp.

21-4463. Lawall, Sarah N. - Critics of consciousness. The existential structures of literature. - Harvard Univ. Press, Cambridge; Oxford Univ. Press, Lon- don, 1969. 281 pp. $\| F S, 25$ (1971), 363-364 (Clark).

21-4464. WELLEK, RENÉ - Historia de la critica moderna. T. 1: La segunda mitad del siglo xviii. 1? reimpr.-Gredos, Madrid, 1969. 396 pp. (BRH, Tratados y monografias, 9) . - V. núm. 16-47133.

21-4465. WELLEK, RENÉ - Storia della critica moderna. L'età di transizione. Trad. di A. Lombardo e F. Gambino.Il Mulino, Bologna, 1969. 465 pp.-V. núm. 16-47135.

21-4466. Porqueras Mayo, A. - "El knew criticism», de Yvor Winters". - HEOL, 57-63.

21-4467. ARCE, J. - "La crítica italiana de hoy entre historicismo y estructuralismo". - HEOL, 65-76.

21-4468. Jones, Robert E. - Panorama de la nouvelle critique en France de Gaston Bachelard à Jean-Paul Weber. - Soc. d'Édition d'Enseignement Supérieur, Paris, 1968. 363 pp. $\| R R$, 63 (1972), 75-76 (Caws) .

21-4469. Therrien, Vincent - Gaston Bachelard et la critique littéraire. Du nouvel esprit scientifique d̀ un «nouvel esprit littéraire». - [Tesis, Université de Paris (Nanterre); resumen en $A U P$, 38 (1968), 764-766].

21-4470. Doubrovsky, S. - Pourquoi la nouvelle critique (N. 20-1142). || RLSP, 10 (1967), 193-195 (Lorencini).

21-4471. TORRe, GUILLERMo DE - Nuevas direcciones de la critica literaria. Alianza Editorial, Madrid, 1970. 212 pp. (El libro de bolsillo, 261). I| Ins, 1971, núm. 293 (Amorós).

21-4472. MACKSEY, RichaRd, \& EUGENIO Donsto (eds.) - The languages of criticism and the sciences of man: The structuralist controversy. - The Johns Hopkins Press, Baltimore-London, 1970. xiii + 367 pp. $\| R R, 62$ (1971), 310313 (Roudiez).

\section{LITERATURA GENERAL Y COMPARADA}

21-4473. Mélanges offerts à Rita Lejeune. -Duculot, Gembloux, 1969. 2 ts.: xxxii +1762 pp. $\| M A, 76(1970), 515-551$ (Joset).

21-4474. Pichois, Claude, y André-M. ROUSSEAU - La literatura comparada.Gredos, Madrid, 1970. 246 pp. (BRH, Manuales, 23). - V. núm. 21-1234. II Proh, 1 (1970), 310-315 (Prieto). 
21-4475. Block, Haskell M. - Nouvelles tendances en littérature comparée. Nizet, Paris, 1970. 61 pp. $\| B A b r, 45$ (1971), 278-279 (Heiney) .

21-4476. Friederich, Werner P. - The challenge of comparative literature and other adresses. Ed. by W. J. DeSua. Univ, of North Carolina, Chapel Hill, 1970. 152 pp. (Unit. of N. C. studies in comp. lit.).

21-4477. Moreno BÁez, E. - "El nuevo comparatismo". - HEOL, 49-56.

21-4478. Strelka, JosePH - Vergleichende Literaturkritik. - Francke, Bern-München, 1970. 110 pp. \|MLJ, 55 (1971), 530-531 (Rudnick).

21-4479. MuschG, Walter - Tragische Literaturgeschichte. - Francke, München, 1969. 639 pp.-V. núm. 9-17385.

21-4480. Prampolini, Giacomo - Storia universale della letteratura. T. 6: Letterature iberiche. Letteratura catalana. Letteratura galega. Letteratura portoghese. Il Novecento nelle letterature di Francia, Germania, Italia, Inghilterra e Stati Uniti. 3a ed.-U.T.E.T., Torino [1970?]. 1079 pp., 470 ilustr.

21-4481. Weil, Gonthier, et JeAn ChasSARD-Les grandes dates des littératures étrangères. - P.U.F., Paris, 1969. 128 pp. (Que sais-je?, 1350) . \|FS, 25 (1971), 366 (Furst)

21-4482. WAIS, K. - "Le cosmopolitisme littéraire à travers les âges".-CLC(4), 18-29.

21-4483. VodickA, F. - "La storia della risonanza delle opere letterarie". - $L i S$, 5 (1970), 499-509.

21-4484. Grundriss der romanischen Literaturen des Mittelalters. T. 6: La littérature didactique, allégorique et satirique. Partie documentaire. - Winter, Heidelberg, 1970. 496 pp. - V. núm. 21-1240.

21-4485. Hatzfeld, H. - "Les études de style et la littérature médiévale".-HRL, 1601-1611.

21-4486. CurTius, ERNST ROBERT-Europäische Literatur und lateinisches Mittelalter. - Francke, München, 1969. 608 pp. - V. núm. 20-1159.

21-4487. Parkes, Henry B. - The divine order: western culture in the Middle Ages and the Renaissance. - Gollancz, London, 1970. 480 pp.

21-4488. LewIs, C. S. - La alegoria del amor. Estudio sobre la tradición medieval. - Eudeba, Buenos Aires, 1969. 340 pp.-V. núm. 14-38694.
21-4489. REIss, E. - "Number symbolism and medieval literature". - $M H u, 1$ (1970), 161-174.

21-4490. RIQUER, M. DE - "La influencia de la transmisión manuscrita en la es. tructura de las obras literarias medievales". - HEOL, 31-37.

21-4491. WeIss, RoBerto - The Renaissance discovery of classical antiquity.Basil Blackwell, Oxford, 1969. xii + 222 pp. II Sp, 46 (1971), 193-195 (Molho) .

21-4492. Howard, Martha W. - Plutarch in the major European literatures of the 18th century. - Univ, of North Carolina Press, Chapel Hill, 1969. 220 pp. (Studies in comparative lit., 50).V. núm. 20-5293.

21-4493. PATCH, HowARD RoLlin - The tradition of Boethius: a study of his importance in medieval culture. - Russell \& Russell, New York, 1970. 200 pp. [1: ed., 1935].

21-4494. FORSTER, LEONARD - The icy fire: Five studies in Petrarchism.-Cambridge Univ. Press, London-New York, 1969. xvi + 204 pp., ilustr.

21-4495. Hösle, Johannes (ed.) - Texte zum Antipetrarkismus. - Niemeyer, Tübingen, 1970. xx + 55 pp. || FS, 26 (1972), 190-191 (Forster).

21-4496. CiocchinI, H. - "Papel de las élites en el fenómeno pan-europeo".CLC(4), 158-168.

21-4497. JONARD, N.-“Goldoni européen". $-R L C, 44$ (1970), 30-55.

21-4498. Iser, Wolfgang, \& Fritz Schalk (eds.) - Dargestellte Geschichte in der europäischen Literatur des 19. Jahrhunderts. - V. Klostermann, Frankfurt/ M., 1970. 164 pp. (Studien zur Philosophie und Literatur, 7).

21-4499. BAHNER, WERNER - Zur Gegenwartsliteratur in den romanischen Ländern. - Wissenschaftliche Buchgesellschaft, Darmstadt, 1970. $200 \mathrm{pp}$.

\section{Períodos literarios}

21-4500, Bibliographie internationale de l'humanisme et de la Renaissance. T. 4: Travaux parus en 1968.-Droz, Genève, 1970. 609 pp.-V. núm. 21-1316. || $B H R$, 33 (1971), 459 (Margolin).

21-4501. Santinello, Giovanni - Studi sull'umanesimo europeo. (Cusa e Petrarca/Lefèvre/Erasmo, Colet, Moro).Antenore, Padova, 1969. 138 pp. || BHR, $32(1970), 736-738$ (Beretta). 
21-4502. KISCH, GuIDo - Gestalten und Probleme aus Humanismus und Renaissance. Neue Studien und Texte. - De Gruyter, Berlin, 1969. 338 pp. \| RF, 83 (1971), 125-133 (Sottili) .

21-4503. Burger, Heinz Otto - Renaissance, Humanismus, Reformation. Gehlen, Bad Homburg-Berlin-Zürich, 1969. $510 \mathrm{pp}$.

21-4504. TAYLOR, R. E. - "Renaissance books". - RQ, 22 (1969) , 100-120, 212227, 306-327, 432-449. - V. núm. 21-1320.

21-4505. Payen, Jean Charles - Les origines de la Renaissance. - Soc. d'Édition d'Enseign. Supérieur, Paris, 1969. 128 pp. \| BHR, 32 (1970), 715 (Margolin).

21-4506. KRISTELleR, P. O. - The Renaissance philosophy and medieval tradition (N. 20-4329). || DtA, 23 (1967), 612-613 (Grundmann).

21-4507. Kristeller, Paul Oskar - "The contribution of religious orders to $\mathrm{Re}$ naissance thought and learning".-The American Benedictine Review, 21 (1970), 1-55. || BHR, 33 (1971), 232234 (Saffrey).

21-4508. Hauser, ARNold - Literatura y manierismo. Trad. de F. González Vicén. - Guadarrama, Madrid, 1969. 254 pp. (Punto omega, 39).

21-4509. FURST, LILIAN R. - Romanticism in perspective. - Macmillan, London; St Martin's Press, New York, 1969. 357 pp. \|MLR, 66 (1971) , 172-173 (Shaffer) .

21-4510. Gleckner, Robert F., \& Gerald E. ENSCOE (eds.)-Romanticism: Points of view. 2nd ed. - Prentice-Hall, Englewood Cliffs, N. J., 1970. 346 pp. - V. núm. 18-1615.

21-4511. Praz, Mario - The romantic agony. Tr. by A. Davidson. 2nd ed., with new foreword by F. Kermode.Oxford Univ. Press, 1970. xxxv +479 pp.-V. núm. 6-7988.

21-4512. Black, Haskell M. (ed.) -The symbolist movement. - Comparative Literature Studies, 4 (1967), núms. 1/2. 227 pp.

\section{Géneros literarios}

21-4513. Garasa, Delfín Leocadio-los géneros literarios. - Columba, Buenos Aires, 1969. 336 pp. $\| H, 54$ (1971), 398-399 (Jaén).

21-4514. Waltz, M. - "Zum Problem der Gattunsgeschichte im Mittelalter. Am
Beispiel des Mirakels". - $Z R P h, 86$ (1970), 22-39.

21-4515. Fubini, Marió - Métrica y poesia. - Planeta, Barcelona, 1970. 386 pp. -V. núm. 18-1627. || Proh, I (1970), 469-476 (Arizmendi).

21-4516. Pazzaclia, M. - "Ricerche sulla versificazione".-LiS, 5 (1970), 457-485.

21-4517. Mariner Bigorra, S. - "Carácter convencional del ritmo".-HEOL, 89-96.

21-4518. Walter, Hans - Carmina medii aevi posterioris Latina. II. Proverbia sententiaeque latinitatis medii aevi. $\mathrm{T}$. 6: Register. - Vandenhoeck \& Ruprecht, Göttingen, 1969. 209 pp. - V. núm. 20-5337.

21-4519. Delbouille, M. - "A propos des origines de la lyrique romane: tradition "populaire» ou tradition "cléricale»".MRo, 20 (1970) , 13-27.

21-4520. BEC, P. - "Quelques réflexions sur la poésie lyrique médiévale. Problèmes et essai de caractérisation". $-H R L$, 1309-1329.

21-4521. GenNRICH, FrIedRICH - Grundriss einer Formenlehre des mittelalterlichen Liedes als Grundlage einer musikalischen Formenlehre des Liedes. 2 Aufl. $-M$. Niemeyer, Tübingen, 1970. [1? ed., 1932].

21-4522. Rosenmeyer, Thomas G. - The green cabinet. Theocritus and the European pastoral lyric. - Univ. of California Press, Berkeley, 1969. 351 pp.

21-4523. Fernández Galiano, M. - "Anacreonte, ayer y hoy". - Atl, 7 (1969), 570-591.

21-4524. Dorfman, Eugene-The narreme in the medieval Romance epic: An in. troduction to narrative structures. Univ. of Toronto Press, Toronto, 1969. xiv + 259 pp. $\| B H i, 72$ (1970), 171179 (Cotrait); BHS, 48 (1971), 58-60 (Chaplin); CCM, 14 (1971), 83-86 (Fotitch); LingP, 1971, núm. 2, 153158 (Kassai) ; $S p, 45$ (1970), 668-669 (Kelly); PhQ, 49 (1970), 137-139 (Scholes) ; H, 54 (1971), 210-211 (Sturm); BICC, 26 (1971), 157-158 (Turner); Lan, 47 (1971), 247-250 (Utley) ; FS, 26 (1972), 55-56 (Whitehead).

21-4525. Giamatti, A. Bartlett - The earthly paradise and the Renaissance epic. - Princeton Univ. Press, Princeton, N. J., 1969. 374 pp. - V. núm. 20-1199.

21-4526. Jacquot, J. (ed.) - Réalisme et poésie au théâtre. - Centre National de la Recherche Scientifique, Paris, 
1967. 295 pp. || EAg, 3 (1968), 199-200 (Tostón) .

21-4527. Astey V., Luis (ed.) - Dramas latinos medievales del ciclo de Navidad. - Inst. Tecnológico y de Estudios Superiores, Monterrey, 1970. 116 pp.

21-4528. Sticca, SANdro - The Latin Passion play: its origins and development. Foreword by $O$. Jodogne. - State Univ. of New York, Press, Albany, 1970. xvi +209 pp.

21-4529. Platzer, Christine - Das religiöse Spiel, das heute noch im Volk der romanischen Länder lebending ist (Frankreich, Italien, Spanien). - [Tesis. Univ. de Munich, 1970].

21-4530. StÄuble, A. - "Nuove pubblicazioni sul teatro del Rinascimento". BHR, 32 (1970), 649-675.

21-4531. Schalk, F. - "Teoría del drama en las literaturas románicas del Renacimiento". - PhP, 13 (1970), 203-213.

21-4532. Hfilman, Robert Bechtold Tragedy and melodrama: Versions of experience.-Univ. of Washington Press, Seattle-London, 1969. xiv + 326 pp. $\|$ MLR, 66 (1971), 165-167 (Waith).

21-4533. Le baroque au théâtre et la théatralité du baroque. Actes 1966 de la $2 e$ session des Journées internationales d'étude du Baroque. - Montauban, 1967. $\|$ AESC, 24 (1969), 1230 (Boquet) .

21-4534. ERWIN, JoHn WALTER - Narcissus ludens: Person and performance in baroque drama. - [Tesis, Yale Univ., 1970].

21-4535. Jacquot, J. (ed.) - Le théatre moderne (N. 14-38680). \| EAg, 3 (1968), 686 (Bouzas).--V. núm. 19-5475.

21-4536. Heinsieck, ARnold-Das Groteske und das Absurde im modernen Drama. -W. Kohlhammer, Stuttgart, 1969. 144 pp. \|I LMFA, 4 (1971), 24-25 (Vaget).

21-4537. KNIGHT, EVERETT - A theory of the classical novel. - Barnes \& Noble, New York, 1970. 156 pp.

21-4538. Pizarro, Narciso - Análisis estructural de la novela. - Siglo Veintiuno de España, Madrid, 1970. x + $176 \mathrm{pp}$.

21-4539. Jauss, Hans Robert (ed.) Nachahmung und Illusion. 2 Aufl. W. Fink, München, 1969. 252 pp.-V. núm. 19-1644.

21-4540. Marichal, R. - "Naissance du roman". - Entretiens sur la renaissance du xiie siècle (Paris-La Haye, 1968), 449-476.
21-4541. Taylor, A. B. - An introduction to medieval romance. - Barnes \& Noble, New York, 1969. 268 pp.

21-4542. Peyre, Henri - Fiction in several languages.-Beacon Press, Boston, 1969. $161 \mathrm{pp}$.

21-4543. Goldman, Lucien - Para una sociologia de la novela. - Ciencia Nueva, Madrid, 1970. 285 pp. - V. núm. 20-1214.

21-4544. Jauss, H. R.-"Ernst und Scherz in mittelalterlicher Allegorie". - $H J F$, 433-451.

21-4545. Nichols, F. J. - "The development of Neo-Latin theory of the pastoral in the sixteenth century".-Humanistica Lovaniensia, 18 (1969), 95-114.

\section{Temas literarios generales}

21-4546. Perella, N. J. - The kiss sacred and profane.-Univ. of California Press, Berkeley-Los Angeles, 1969. 356 pp. II $S p, 45$ (1970), 682-684 (Jones); $R Q$. 23 (1970), 279-282 (Smith).

21-4547. Johannan, John D. (ed.) -Joseph and Pothifar's wife in world literature. An anthology of the story of the chaste youth and the lustful stepmother. Tr. by various hands.-New Directions, New York, 1968. 310 pp. \| RPh, 24 (197071), 550-551 (Costa); CJ, 65 (1969), 126-128 (Friedman).

21-4548. Brombert, Victor (ed.) - The hero in literature: Major essays on the changing concepts of heroism from classical times to the present.-Fawcett, Greenwich, Conn., 1969. 288 pp.

21-4549. Togery, Knud - Ogier le Danois dans les littératures européennes. Munksgaard, Copenhague, 1969. 304 po. || $R P h, 24$ (1970-71), 503-505 (Worthington).

21-4550. Thoss, Dagmar - Studien zum "locus amoenus" im Mittelalter.-[Tesis, Univ. de Viena, 1969].

21-4551. Moorman, C. - A knyght there was. The evolution of the knight in literature (N. 20-1227). || CL, 21 (1969), 266-271 (Crampton); RPh, 24 (197071) , 640-644 (Sklute).

21-4552. BARBER, RICHARD - The knight and chivalry. - Scribner's, New York, 1970. $\mathrm{xv}+383 \mathrm{pp}$.

21-4553. SCHRADER, LUDWIG - Sinne und Sinnesverknüpfungen. Studien und Materialien zur Vorgeschichte der Synästhesie und zur Bewertung der Sinne in 
der italienischen, spanischen und französischen Literatur. - C. Winter, Heidelberg, 1969. 293 pp.-V. núm. 21-1349.

21-4554. Rothe, ARNOLD - Der Doppeltitel. $\mathrm{Zu}$ Form und Geschichte einer literarischen Konvention. - Akad. der Wissenschaften und der Literatur, Mainz; Steiner, Wiesbaden, 1970. 37 pp. 21-4555. ROGERs, ROBERT $-A$ psychoanalytic study of the double in literature.Wayne State Univ. Press, Detroit, 1970. 192 pp. [Incluye la pareja Don QuijoteSancho].

21-4556. Anderson, Carleton Q. - The evolution of the Inés de Castro story in drama. - [Tesis, Brigham Young Univ., 1970].

21-4557. Lamet, Pedro Miguel - El Dios sin Dios de la poesía contemporánea.Bilbao, 1970. 222 pp.

\section{Relaciones literarias}

\section{Influencias extranjeras}

21-4558. Lida de MALKIEL, M. R. - " "Las infancias de Moisés» y otros tres estu. dios. En torno al influjo de Josefo en la literatura española". - $R P h, 23$ (1969-70) , 412-448.

21-4559. Vives Coll, A. - "Luciano de Samosata enjuiciado pur españoles (1500-1700)". - CEC(3), «, 186-191.

21-4560. Bayo, Marcial Josê - Virgilio y la pastoral española del Renacimien. to (1480-1550). 2a ed. - Gredos, Madrid, 1970. 281 pp. (BRH, Estudios y ensayos, 44) . - V. núm. 16-47318.

21-4561. SCHEVrll, RUdOLPH - Ovid and the Renascence in Spain.-Georg Olms, Hildesheim-New York, 1971. 268 pp. [Reimpr. facs. de la ed. de Berkeley, 1913].

21-4562. BLÜHER, KARL AlFRED - Seneca in Spanien. Untersuchungen zur Geschichte der Seneca-Rezeption in Spanien vom 13. bis 17. Jahrhundert. - A. Francke, München, 1969. 503 pp. - V. núm. 20-1233. || BHS, 48 (1971), 66-67 (Ettinghausen); $R J, 21$ (1970), 365-368 (Heydenreich) .

21-4563. HeIdenREICH, H. - "Beda Venerabilis in Spain”. - MLN, 85 (1970), 120-137.

21-4564. REYes CANo, R. - "Traducciones españolas de la Arcadia de Sannazaro". $-A H, 52 / 53$ (1970), 161-173.

21-4565. Carvalho, J. A. de - "A leitura de Il Galateo de Giovanni della Casa na Península Ibérica: Damasio de Frías, L. Gracián Dantisco e Rodrigues Lobo". -Ocid, 79 (1970), 137-171.

21-4566. LANGE, W.-D.-“Arbre des batailles of Honoré Bouvet. (Zur Uberlieferung des Arbre des batailles in Spanien)". - Philologische Studien für Joseph M. Piel (Heidelberg, 1969), 113-135.

21-4567. Veríssimo Serrä́, JoAquim (ed.) - Voltaire et la culture portugaise. Exposition bibliographique et iconographique. - Centre Culturel Portugais, Paris, 1969. I Ocid, 81 (1971), 388-399 (Pinharanda Gomes); $L P a, 1970$, núm. 18, 184 (Teixeira de Oliveira) .

21-4568. Pageaux, D.-H. - "Voltaire et la culture portugaise". - RLC, 43 (1969), 565-566.

21-4569. Moura Pacheco, Manuel A. Influências de Hippolyte Taine no pensamento estético português. - Porto, 1969. $103 \mathrm{pp}$.

21-4570. Pujals, E. - "Lord Byron en España”. - Atl, 7 (1969), 32-50.

21-4571. Müller, B. - "La acogida de la literatura alemana en España”. Humboldt, 1970, núm. 43, 58-68.

21-4572. Hirsch, E. F. - "Erasmus and Portugal”. - BHR, 32 (1970), 539-557.

21-4573. Svabova, I. - "Bibliografía de las traducciones españolas de la literatura checa". - IAP, 4 (1970), 275-277.

V. también núms. 3912, 5108, 5932, 6029, 6619 .

\section{Influencias hispánicas}

21-4574. Arce, J. - "Un español en la historia de la lírica italiana". - Atl, 7 (1969), 234-239.

21-4575. Stubings, Hilda U. - Renaissance Spain in its literary relations with England and France. $A$ critical bibliography. - Vanderbilt University Press, Nashville, 1969. xvi + 138 pp.-V. núm. 20-5434. || $M L J, 55$ (1971), 127 (Drake); $R Q, 23$ (1970), 450-451 (Fucilla); Ins, 1970, núm. 282 (Osuna); BHS, 47 (1970), 154 (Wilson).

21-4576. Pujals, E. - "La leyenda del rey Rodrigo en el romanticismo inglés".RUM, 19 (1970), núm. 73, 259-288.

21-4577. Pageaux, DANIEL-Henri - Images du Portugal dans les lettres françaises (1700-1755). - Centre Culturel Portugais, Paris, 1971. 242 pp.

21-45\%8. Kamina, A. - "Le théâtre de 
Lesage et la comedia espagnole".- $R L C$, 43 (1969), 305-319.

21-4579. Godenne, R.-“L'image de l'Espagne romanesque dans la Bibliothèque universelle des romans (1775-1789)".ELitt, 2 (1969), 21-31.

21-4580. Avril, Y.-“L'Espagne de Barbey d'Aurevilly". - ELitt, 2 (1969), 33-55.

21-4581. Ferrerfs, R. - "El hispanismo de Paul Verlaine". - $\mathrm{CuH}, 81(1970)$, 87-105.

21-4582. Werl, Christine - Montherlant et l'Espagne. - [Mémoire de maîtrise, Univ. de Strasbourg, 1970].

21-4583. PörtL, K. - "El mundo español en el teatro alemán”. - NT, 31 (1969), 432-453.

21-4584. BotKINE, VAssILI - Lettres sur l'Espagne. Texte trad., préf., annoté et illustré par A. Zviguilsky. - Institut d'Études Hispaniques, Paris, 1969. 343 pp. II fns, 1970, núm. 286 (Cano); $B H i, 72$ (1970), 231-233 (Picoche); $H$, 53 (1970), 580 (Weiner).

21-4585. Novaceand, D. - "España e Hispanoamérica en Rumania". - $\mathrm{CuH}, 83$ (1970) , 580-588.

21-4586. Kovács, J. - "Ernest Hemingway, Máté Zalka and Spain. To the symbolic meaning of The old man and the sea". - ALitt, 13 (1971), 315-324.

21-4587. JACOBY, GROVER - Translations. Comment in motion. - The Variegation, Los Angeles, 1969. 257 pp. [Incluye a Gil Vicente, Garcilaso, Lope, Calderón, Bécquer y Rosalía].

V. también núms. 3538, 3540-3, 4633, 4792, $5391,5690,5745-7,5820,5916-9,6014$, 6036-7.

\section{LATINISTAS Y HUMANISTAS}

21-4588. Puente Santidrín, P. - "Fernández de Villegas, humanista ascético, traductor de Plutarco".-Burg, 2 (1970).

21-4589. Carrasco, C. - "Los Nebrija en Brozas". - REE, 27 (1971), 303-305.

21-4590. Bellido Ahumada, José-La patria de Nebrija. (Noticia histórica). Madrid, 1971. 366 pp.

21-4591. Camacho-Evangelista, FermínHumanismo y derecho romano en $\mathrm{Ne}$ brija. - Madrid, 1970. 90 pp.

21-4592. Barón Fernández, José-Miguel Servet. Su vida y su obra. Pról. de P. Laín Entralgo. - Espasa-Calpe, Madrid, 1970. 337 pp. || $A I A, 31$ (1971), 243249 (Martínez Ruiz).
21-4593. Norena, Carlos G. - Juan Luis Vives. - Martinus Nijhoff, The Hague, 1970. xii +327 pp. (Archives internationales d'histoire des idées, 34).

21-4594. GuY, Alain-Vivès ou l'humanisme engagé. - Seghers, Paris, 1971. 200 pp. (Philosophes de tous les temps). II AFLT, 7 (1971), 223-224 (Cobos).

21-4595. Coseriu, E. - "Zur Sprachtheorie von Juan Luis Vives". - Festschrift W. Mönch (Heidelberg, 1971), 234-255.

21-4596. Coseriu, E. - "Das Problem des Ubersetzens bei Juan Luis Vives". HMW, 571-582.

21-4597. Castán Vázquez, José María El derecho civil en la obra de Luis Vives. - Madrid, 1958. $72 \mathrm{pp}$.

21-4598. McCully, G. E. - "A letter of Juan Luis Vives to Jerome Aleander, from Louvain, Dec. 17, 1522".-RQ, 22 (1969) , 121-128.

21-4599. Hrubes, J. - "Juan Luis Vives y Bohemia". - IAP, 4 (1970), 217-222.

21-4600. Ezquerro, Milagros - Diego Gracián de Alderete. Contribution à l'étude de l'humanisme espagnol. France-Ibérie, Toulouse, 1970. 422 pp. [En mimeógrafo].

21-4601. Andrís, Gregorio de - Edición de 25 cartas inéditas del humanista Páez de Castro a Jerónimo Zurita.-Madrid, 1969. $40 \mathrm{pp}$.

21-4602. Bourdon, L., et O. Sauvage "Recherches sur Luisa Sigea".-BEP, 31 (1970), 33-176.

21-4603. SigeA, LuisA - Dialogue de deux jeunes filles sur la vie de cour et la vie de retraite (1552). Introd. et trad. par Odette Sauvage. - P.U.F., Paris, 1970. 310 pp. - V. núm. 20-5462. || Co, 1970 , núm. 61 (Cidade); Ocid, 86 (1971), 268-269 (Paxeco) .

21-4604. Puig I Pujol, JoAn - El catalá Joan Cristòfol Calvet d'Estrella.-Rafael Dalmau, Barcelona, 1969. 69 pp. (Episodis de la història, 115/6).

21-4605. Michä̈lis de VAsconcelos, C."Lucius Andreas Resendius Lusitanus". -CMD, 1, 415-434.

V. también núm. 4770.

21-4606. Gallego, ANdrÉ - Les "Refraneros" de Juan Lorenzo Palmireno.Université de Toulouse, 1969. 317 pp. [Tesis].

Mariner: v. núm. 4644.

21-4607. Martínez Ruiz, J.-“Cartas inéditas de Bernardo J. de Aldrete (16081626)". - BRAE, 50 (1970), 77-135. 277-314, 471-515. 


\section{LITERATURAS PENINSULARES}

\section{Catalana}

21-4608. Badia i Margarit, A. M., J. Massot I Muntaner, y J. Molas - "Situación actual de los estudios de lengua y literatura catalanas". - Norte, 1970, núms. 1/2, 1-116.

21-4609. PoBlet, Josep Maria - Els precursors de la Renaixença. Del Rector de Vallfogona a Aribau. - Bruguera, Barcelona, 1968. $56 \mathrm{pp}$.

21-4610. POBLET, JOSE.P MARIA-Catalunya, 1833-1913. Una panorámica amb el teatre $i$ els jocs florals. - Bruguera, Barcelona, 1969. $191 \mathrm{pp}$.

2I-4611. Mir, GREGORI - Literatura i societat a la Mallorca de postguerra. Pròleg de J. M. Llompart. - Palma de Mallorca, 1970. 164 pp.

21-4612. Mateu Ibars, M. D. - "San Vicente Mártir en las Cobles fetes en laors de diversos sants". - BSCC, 46 (1970), 31-45.

21-4613. Hösle, Johannes, \& Antoni Pous -Katalanische Lyrik. Katalanische Fühlen und Denken und die internationale Bedeutung von Dichtern wie Maragall, Riba und Espriu dokumentierend. Eine literarische Kostbarkeit. - Hase \& Köhler, Mainz, 1970. 152 pp.

21-4614. Quiñonero, J. P.-"Notas sobre la poesía catalana". - $\mathrm{CuH}, 86$ (1971), 133-145.

21-4615. Castfllet, J. M., y Joaquim MoLAS (eds.) -Ocho siglos de poesia catalana. Trad. de J. Batlló y J. Corredor Matheos. - Alianza Editorial, Madrid, 1969. 548 pp. (El libro de bolsillo, 216) . [Ed. bilingüe]. \| $H u N L, 12$ (1971), 621-622 (Garciagómez).

21-4616. Llompart, José María - Poesía y paisaje. El tema de «la costa brava" en los poetas mallorquines. - Palma de Mallorca, 1970. 77 pp., ilustr.

21-4617. Carmona, Ángel (ed.) - Antologia de la poesía social catalana. Madrid-Barcelona, 1970. 391 pp.

21-4618. Cartwright, S. (ed.) - Poesia catalana de la guerra d'Espanya (193639) $i$ de la Resistència. - Paris, 1969. $254 \mathrm{pp}$.

21-4619. Bensoussan, M. - "La poésie catalane contemporaine". - $L N L, 1970$, núm. 195, 38-54.

21-4620. Curet, Francesc - História del teatre català. - Aedos, Barcelona, 1969. 700 pp., ilustr. - V. núm. 20-1307.
21-4621. PÉrez de Olaguer, Gonzalo (ed.) - Teatre independent a Catalunya. - Barcelona, 1970. 106 pp.

21-4622. TEIXIDOR, J. - "Un nuevo teatro catalán”. - Ins, 1970, núm. 289.

21-4623. Pacheco, ARseni (ed.)-Novelletes sentimentals dels segles xiv $i \times v$.Barcelona, 1970. 108 pp.

21-4624. Colón, G. - "Un aspecte estilístic en la traducció catalana medieval del Decameron". - HMW.

21-4625. Bensoussan, M. - "Le roman catalan contemporain". - LNL, 1970, núm. 195, 73-82.

21-4626. Aramon i Serra, R. - "El Tristany català d'Andorra". - HRL, 323337.

21-4627. Riquer, M. DE - "Guillem de Berguedá, trovador y señor feudal del siglo XII".-PV, 31 (1970), 281-284.

21-4628. Pérez L. - "La muerte y el martirio de Ramón Llull. Entre la leyenda y la historia". - Revista Balear, Palma de Mallorca, 1969, núms. 14/15, 15-27.

21-4629. URMFNETA, F. DE - "La conversión Iuliana y su lenguaje explicativo". -[En] Lenguaje y filosofia (Madrid, 1969).

21-4630. Soler Planas, J.-“Etica luliana y derecho de propiedad". - Mayurqa, 1968, núm. 1, 63-92.

21-4631. Lullus, Raymundus - Ars brevis. (Palma de Mallorca, 1669).-Frankfurt, 1970. [Reimpr.].

21-4632. Lullus, Raymundus-Ars generalis ultima. (Palma de Mallorca, 1645). -Frankfurt, 1970. [Reimpr.].

21-4633. Brummer, R. - "Zu einer frühen französischen Übersetzung des katalanischen Libre de Blanquerna von Ramon Llull".-HMW.

21-4634. Llull, Ramon - Quattuor libri principiorum. Introd. by R. F. PringMill. - S. R. Publishers, Wakefield, 1970. $208 \mathrm{pp}$.

21-4635. FustER, J. - "Viejas memorias de un hombre de suerte". - ROcc, 29 (1970), 219-228. [La Crónica de Muntaner].

21-4636. Muntaner, RAMÓN - Crónica. Introd. de J. Fuster. Trad., notas e indices de J. F. Vidal Jové.-Alianza Editorial, Madrid, 1970. xxxiv $+700 \mathrm{pp}$. (El libro de bolsillo).

21-4637. Wittlin, C. J. - "Los problemas del Cercapou y el Libre de les dones de fray Francesc de Eiximenis".-BSCC, 46 (1970), 61-95.

21-4638. Via, Francesc de LA-Obres, T. 2: 
A bella Venus. Libre de Fra Bernat. Les cançons, La Cobla. Ed. A. Pacheco. - Biblioteca Catalana d'Obres Antigues, Barcelona, 1968. 133 pp. - V. núm. 19-1802. || $\mathrm{BH} i, \quad 71 \quad(1969), \quad 678-679$ (Guiter) .

21-4639. Вонigas, P. - "La llengua de Jacme i Pere March".-HRL, 339-351.

21-4640. Colon, G. - "El nom de fonts del poeta Ausiàs March". - BSCC, 46 (1970), 161-214.

21-4641. Ramírez Molas, Pere - Evolució interna en la poesia d'Ausiàs March; anàlise lingüistica $i$ mètrica. - [Tesis, Univ. de Basilea, 1968].

21-4642. Bohigas, P. - "Entorn de les cançons VI i VIII d'Ausiàs March".HJF, 1, 145-152.

21-4643. Barallat Barés, Josefina - $A u$ sias March interpretado por sus traductores.-Lérida, 1968. 27 pp. - V. núm. 18-1832.

21-4644. Ramírez Molas, P. - "Utilitat de la traducció llatina de Vicent Mariner, per a la interpretació textual d'Ausiàs March". - BSCC, 46 (1970), 273-303.

21-4645. Moner, Francesc - Obres catalanes. A cura di P. Cocozzella.-Barcelona, 1970. 233 pp.-V. núm. 19-7713.

21-4646. Tomich, Pere - Històries e conquestes dels reys de Aragó e comtes de Barcelona. - Index de I. Sáez Rico.Anubar, Valencia, 1970. 182 pp. [Reimpr. facs. de la ed. de Zaragoza, 1584].

21-4647. SERRA Vilaró, JUAN - El rector de Vallfogona Francesc Vicens García, alies Avellaneda. - Barcelona, 1964. $68 \mathrm{pp}$.

21-4648. Finestres, JOSEP - Epistolari. Ed. por M. Batllori. - Balmes, Barcelona, 1969. $403 \mathrm{pp}$.

21-4649. Poblet, Josep Maria - Federic Soler (Serafi Pitarra). - Bruguera, Barcelona, 1967. $393 \mathrm{pp}$.

21-4650. Arbó, Sebastí Juan - La vida tràgica de Mossen Jacint Verdaguer. Pròleg de l'autor. - Barcelona, 1970. 556 pp., ilustr. - V. núm. 9-14024.

21-4651. Arbó, Sebastín Juan - la vida trágica de Mosén Jacinto Verdaguer. Trad. de J. Fuster. - Planeta, Barcelona, 1970. 739 pp., ilustr.

21-4652. Condeminas, M. - Els exorcismes $i$ Jacint Verdaguer. - Barcelona, 1970. $122 \mathrm{pp}$.

21-4653. Xuriguera, RAMón - Jacint Verdaguer, l'home $i$ l'obra. - Barcelona, 1971. $355 \mathrm{pp}$.
21-4654. Verdaguer, JACINT - Epistolari. T. 3: 1880-1882. Transcripció i notes per J. M. de Casacuberta i J. Torrent i Fábregas. - Barcino, Barcelona, 1971. 279 pp.-V. núm. 20-5510.

V. también núms. 6314, 6869 .

21-4655. Díaz, Modesto Mario - Narciso oller, creador de la novela catalana mo. derna. - [Tesis, Univ. of Illinois, 1970]. 21-4656. FERRER-VIDAL, JORGE - Joan Maragall.-Epesa, Madrid, 1970. $170 \mathrm{pp}$. 21-4657. Serrahima, Maurici - Vida $i$ obra de Joan Maragall. - Barcelona, 1966. $110 \mathrm{pp}$.

21-4658. Guirer, H. - "Un exemple du jeu des démonstratifs chez Jean Maragall". - Mélanges Jean Boutière (Liège, 1970) .

V. también núm. 4613.

21-4659. Poblet, Josep Maria - Vida i obra de Santiago Rusiñol--Bruguera, Barcelona, 1967. $106 \mathrm{pp}$.

21-4660. Santiago Rusiñol per ell mateix. A cura de R. Planes. - Edición 62, Barcelona, 1971. 87 pp.

21-4661. Oller i Rabassa, JoAn-Biografia de Victor Catalá. - Barcelona, 1967. $132 \mathrm{pp}$.

C. Riba: v. núm. 4613 .

21-4662. Foix, J. V.-Els lloms transparents. -Edicions 62, Barcelona, 1969. 168 pp. |l BAbr, 44 (1970), 292-293 (Forcadas).

21-4663. Soldevila, FerRAN - Al llarg de la meva vida. T. I: 1926-39.-Barcelona, 1970. 541 pp.

21-4664. De Joan Oliver a Pere Quart. Homenatge a Joan Oliver-Barcelona, 1970. 93 pp.

21-4665. Arimany, MiQuel. - Simbol vivent. Biografia de Rafael Tasis. - M. Arimany, 1969. || fns, 1969, núm. 274 (Serrahima).

21-4666. POBLet, Josep MARIA - Rafael Tasis. Conducta i exemple. - Bruguera, Barcelona, 1967. 181 pp., ilustr.

Espriu: v. núm. 4613.

21-4667. Espinás, J. M. - Festa major. Barcelona, 1969. 332 pp., ilustr.

21-4668. Fuster, JOAN - Obres completes. T. 1: Llengua, literatura, historia. Barcelona, 1968. $508 \mathrm{pp}$.

21-4669. FusTer, JOAN - Obres completes. T. 2: Diari, 1952-1960. - Barcelona, 1969. 467 pp.

21-4670. FusTer, JOAN - Diccionario para ociosos. - Barcelona, 1970. 213 pp.

21-4671. Villalonga, LoReNzo - Las tentaciones. Trad. de J. Pomar-Barcelona, 1970. 242 pp. 
21-4672. Ferrater Mora, José - Els mots $i$ els homes. - Barcelona, 1970. 90 pp.

\section{Gallega y portuguesa}

21-4673. Prado Coelho, Jacinto do (ed.) -Dicionário de literatura. Literaturas portuguesa, brasileira, galega. Estilistica literária.-Figueirinhas, Porto, 196971. 2 ts.-V. núm. 16-47503.

21-4674. Bell, Aubrey F. G. - Portuguese literature. - Oxford Univ. Press, London, 1970. 395 pp. [Reimpr. de la ed. de 19227 .

21-4675. Saralva, António José, e Óscar LOPES - História da literatura portuguesa. 6a ed. - Porto Editora, Porto, [1970]. 1135 pp. - V. núm. 20-1369.

21-4676. Saraiva, António José - História da literatura portuguesa. 10a ed.Publicações Europa-América. Lisboa, 1970. 252 pp.-V. núm. 16-43680.

21-4677. Frèches, Claude-Henri - $L a$ littérature portugaise. - P.U.F., Paris, 1970. (Que sais-je?, 1404).

21-4678. Prado Coelho, J. do - "A literatura portuguesa, expressão duma cultura nacional".-ACCP, 2 (1970).

21-4679. Selvagem, Carlos, e Hernâni Cidade - Cultura portuguesa. - Empresa Nacional de Publicidade, Lisboa, 1969-1971. 6 ts.

21-4680. Forjaz Trigueiros, L. - “Perspectiva de la literatura portuguesa".EL, 1970, núms. 444/5.

21-4681. MICHAËLIS DE VASCONCELOS, C."Literatura antiga portuguesa"- $-C M D$, 1, 7-22.

21-4682. Rossi, G. C. - "Italia e Germania in momenti del Seicento portoghese".[En] La cultura del secolo xvii nel mondo di lingua italiana e di lingua tedesca nel quadro dell'unità culturale europea (Bolzano, 1970), 489-496.

21-4683. Pina Martins, J. V. DE-"Sobre o conceito de humanismo e alguns aspectos histórico-doutrinários da cultura renacentista". - $A C C P, 2$ (1970) .

21-4684. Mendes de AlmeidA, J.-“'Edições seiscentistas raríssimas de literatura popular". - REt, 15 (1970), 5-40.

21-4685. Martins, W. - "O barroco literário menor". - JIAS, 12 (1970) , 31-46.

21-4686. HATzFELD, H. - "Some aspects of literary Rococo in Portugal". - $A P K$, 8 (1968).

21-4687. Lopes, ÓsCAR - Ler e depois. Crítica e interpretação literária.-Civili- zação Portuguesa, Porto, 1969. || Ins, 1971, núms. 296/7 (Ares Montes); Co, 1970, núm. 57 (Cidade).

21-4688. Prado Coelho, J. DO - A letra $e$ o leitor (N. 21-1520). $\|$ Alfa, 1968, núms. 13/4, 261-264 (Novaes Coelho).

21-4689. Figueiredo, Fidelino DE-Después de Eça de Queiroz. - Espasa-Calpe, Madrid, 1970. 140 pp. (Austral, 1439). 21-4690. Guerrero, C. - "Algunas mujeres en la literatura portuguesa'.-EL, 1970, núms. 444/5.

21-4691. García Mercadal, J.-“La saudade portuguesa". - EL, 1970, núms. 444/5.

21-4692. Carvalho, R. DE - "O lume vivo que a marítima gente tem por santo". - Ocid, 81 (1971), 3-16. [E1 fuego de San Telmo en la literatura portuguesa]. 21-4693. Marques Rebelo (ed.) - Antologia escolar portuguésa. - Ministério da Cultura, Rio de Janeiro, 1970. Ocid, 81 (1971), 124-127 (Machado).

21-4694. Martins, Júlio, e Jaime Mota (eds.) - Selecta literária. 14: ed.-Livr. Didáctica, Lisboa, 1971. 2 ts.

21-4695. Nunes, José JoAquim (ed.) Crestomatia arcaica. Excertos da literatura portuguesa desde o que mais antigo se conhece até ao século xvi. Acompanhados de introd. gramatical, notas e glossário. - Lisboa, 1970. 479 pp.

21-4696. LIND, G. R. (ed.)-Portugiesisches Lesebuch. - Max Hueber, München, 1970. 147 pp.

21-4697. Azevedo Filho, Leodegario A. DE - Estructuralismo e crítica da poesia.Gernasa, Rio de Janeiro, 1970. 150 pp. (Estudos universitários).

21-4698. Martins Moreira, T. - “A contagem do verso em português. (Um êrro histórico generalizado)". - HCJ, 249 . 255 .

21-4699. Quintas Neves, L. - "A poesia popular em suas origens e a etnografia em tempos de S. Frutuoso". - BAu, 22 (1968), 71-75.

21-4700. Michä̈lis de Vasconcelos, C. "Investigações sobre sonetos e sonetistas portugueses e castelhanos". - $C M D, 2$, 115-199.

21-4701. MIchä̈LIS DE VAsconcelos, C."Notas aos *sonetos anónimos:"-CMD, $1,130-144$.

21-4702. Preto-RodAs, RICHARd A. - Negritude as a theme in the poetry of the Portuguese-speaking world. - Univ. of Florida Press, Gainesville, 1970. 98 pp. $\| H, 54$ (1971), 399-400 (Vincent).

21-4703. Breyner Andresen, Sophia de M. 
(ed.) - Quatre poètes portugais: Camões, Cesário Verde, Mário de Sá Carneiro, Fernando Pessoa. Sél., trad. et présentation par... - Centre Culturel Portugais, Paris, 1970. 354 pp. $\| R P$, 80 (1971), 159-161 (Paxeco); Diál, 1971, núm. 40 (Xirau).

21-4704. Menéres, Maria Alberta, e E. M. DE Melo E Gastro (eds.) -Antologia da novissima poesia portuguesa. 3 a ed. -Moraes, Lisboa, 1972. Ixxx + 824 pp. -V. núm. 17-4787.

21-4705. JimÉnez Martos, L. - "A1 hilo de una antología de nuevos poetas portugueses". - $E L, 1970$, núms. 444/5.

21-4706. Guimarães, F. - "Revisão da moderna poesia portuguesa".-Co, 1971, núm. 1, 34-43.

21-4707. LACERDA, A. DE - "A poesia portuguesa entre 1950 e 1970 . Notas para um estudo". - Tulane Studies in Romance Lang. and Lit., 4 (1971), 38-56.

21-4708. Mrssnir, D.-"Das vaterländische Bild in der modernen Lyrik Portugals". $-N S, 70$ (1971), núm. 8.

21-4709. FreIRE, N. - "La actual poesía portuguesa". - EL, 1970, núms. 444/5.

21-4710. SENA, J. DE - "Poesía portuguesa de vanguardia: 1915 y hoy".-ins, 1971, núms. 296/7.

21-4711. Stegagno Picchio, Luciana Ricerche sul teatro portoghese. - Ed. dell'Ateneo, Roma, 1969. 401 pp. (Officina romanica, 14). $\| M L N, 86$ (1971), 289-292 (Hart) .

21-4712. "Literatura de cordel". - $B I B$, 11 (1970), 341-514. [Colección de obras de teatro de la Fundación Gulbenkian].

21-4713. Mendes de AlmeidA, J. - "Teatro português em edicões $\mathrm{e}$ reimpressões dos séculos xviII e xix. (Anotações bibliográficas) ".-REt, 14 (1970), 267-288.

21-4714. Rebello, L. F. - "Situación actual del teatro portugués". $-E L, 1970$, núms. $444 / 5$.

21-4715. ReBeLo, L. F. - "Do teatro em Portugal (Outubro de 1969 a Julho de 1970) ". - Co, 1969, núm. 54; 1970 , núm. 60.

21-4716. DÉcıo, J. - "Três contistas do realismo em Portugal". - Alfa, 1968, núms. 13/4, 183-200. [Eça de Queirós, Abel Botelho y Trindade Coelho].

21-4717. CÉsAr, GUILHERMINo-O brasileiro na fição portuguesa. - Parceria A. M. Pereira, Lisboa, 1970. 155 pp. || Carav, 1970, núm. 15, 145-148 (Roche).

21-4718. Mouräo Ferreira, D. - "Rápida revisión a un cuarto de siglo de novela portuguesa (1944-1969)". - EL, 1970, núms. 444/5.

21-4719. Azevedo Filho, L. A. de - "Tendências da moderna ficção portuguêsa". $-S L P(2), 239-249$.

21-4720. DÉcro, J.-"O conto na moderna literatura portuguêsa". - $L P a, 1970$, núm. 18, 115-118.

21-4721. Barradas de Carvalho, J.-“A literatura portuguêsa de viagens. (Séculos XV, xvI e XVII)". - RHSP, 40 (1970), 51-73.

V. también núm. 5084 .

A utores antiguos

21-4722. Costa Miranda, J. DA - "A moderna contribuição italiana para o estudo da lírica medieval galaico-portuguesa". - Co, 1971, núm. 2, 98-101.

21-4723. Tavani, Gruseppe - Poesia del duecento nella Penisola iberica. Problemi della lirica gallego-portoghese. - Edizioni dell'Ateneo, Roma, 1969. 290 pp. || MLN, 86 (1971), 289-292 (Hart); BHS, 47 (1970), 145-147 (Cummins). 21-4724. Naro, A. J. - "Da métrica medieval galaico-portuguesa". - Ocid, 86 (1971), 227-236.

21-4725. Michä̈lis dE VAsconcelos, C. "Observações sobre alguns textos líricos da antiga poesia peninsular". - $C M D$, I, 56-83, 320-347.

21-4726. Michä̈lLIS DE VAsconcelos, C."Notas ao cancioneiro inédito". - CMD, 1, 145-151.

21-4727. Lesser, Arlene T. - La pastorela medieval hispánica. Pastorelas y serranas galaico-portuguesas.-Galaxia, Vigo, 1970. 179 pp.

21-4728. Correia, Natália - Cantares dos trovadores galego-portugueses. Estampa, Lisboa, 1970. 298 pp. (Clássicos de bolso).

21-4729. Nunes, José Joaquim (ed.) Cantigas d'amigo dos trovadores galegoportugueses. - New York, 1971. 3 ts. [Reimpr. de la ed. de 1926-28].

21-4730. Rodrigues LAPA, Manuel - Cantigas d'escarnho $e$ de mal dizer dos cancioneiros medievais galego-portugueses. Ed. crítica. 2a ed., revista e acrescentada. - Galaxia, Vigo, 1970. 753 pp. -V. núm. 19-1910.

21-4731. Davis, William R. - The role of the Virgin in the "Cantigas de Santa Maria" of Alfonso X. - [Tesis, Univ. of Kentucky; resumen en DAI, 31 (197071), 383A]. 
21-4732. Snow, Joseph Thomas - The "loor" to the Virgin and its appearance in the "Cantigas de Santa Maria".[Tesis, Univ. of Wisconsin, 1971].

21-4733. STURM, S. - "The presentation of the Virgin in the Cantigas de Santa Maria". - PhQ, 49 (1970), 1-7.

21-4734. Bagby, Albert IAN - The Moor and the Jew in the "Cantigas" of $A l$ fonso X. - [Tesis, Univ. of Kentucky; resumen en $D A I, 30(1969-70), 1550 \mathrm{~A}$ $1551 \mathrm{~A}]$.

21-4735. BAgBy, A. I., JR. - "The Jew in the Cantigas of Alfonso X, el Sabio".Sp, 46 (1971), 670-688.

21-4736. Teensma, B. N. - "Os iudeus na Espanha do século XIII, segundo as Cantigas de Santa Maria de Alfonso X o Sábio”. - Ocid, 79 (1970), 85-102.

21-4737. PIEL, T. M. - "Zum Text eines Spottlieds Alfons des Weisen". - HRL, 503-510.

21-4738. Cummrns, J. G. - “The practical implications of Alfonso el Sabio's peculiar use of the zéjel'. - BHS, 47 (1970), 1-9.

21-4739. [Dinis, DoM] - Das Liederbuch des Königs Denis von Portugal. Mit Einl., Anmerkung und Glossar von Henry R. Lang.-Georg Olms Verlag, Hildesheim-New York, 1971. cxlviii + 174 pp. [Reimpr. facs. de la ed. de Halle, 18947 .

21-4740. MichaËlis de VAsconcelos, C.“A propósito de Martim Codax e das suas cantigas de amor"-CMD, 1, 84-95.

21-4741. Zorro, JoAN - Las once cantigas de... Ed. por Manuel Alvar.-El Guadalhorce, Málaga, 1969. 146 pp.

21-4742. MICHAËLIS dE VASCONCELOS, C."João Lourenço da Cunha, a aflor de altura» e a cantiga «Ay donas por quê em tristura?" - CMD, 1, 96-118.

21-4743. Michä̈lis dE VAsconcelos, C."O lais galego-português *Leonoreta, fin roseta» $e$ as origens do adjectivo fin". - CMD, 1, 177-185.

21-4744. Pais, Álvaro - Scritti inediti. A cura de V. Meneghin. - Instituto de Alta Cultura, Lisboa, 1970. 195 pp.

21-4745. Lopes, Fernão - Crónicas. Adapt. A. J. Saraiva. 2a ed.-Portugália, Lisboa, 1970. 458 pp. (Antologias universais).V. núm. 16-47598.

21-4746. Lucena E VAle, A. DE - "Do original da Uirtuosa benffeyturia e o seu actual paradeiro". - Co, 1970, núm. 57, 71-74. [D. Pedro].

21-4747. Rogers, F. M. - The travels of the Infante dom Pedro of Portugal (N. 17-4814) - \| RPh, 24 (1970-71), 355-357 (Woodbridge). - V. núm. 18-5463.

21-4748. MichaËLIS DE VAsconcelos, C."Uma obra inédita do condestável $D$. Pedro de Portugal". - CMD, 1, 348. 414. [Incluye el texto de la Tragedia de la insigne reyna doña Ysabel.

21-4749. MichaëLIS de VAsconcelos, C."Autos portugueses de Gil Vicente e da escola vicentina”. - CMD, 1, 209-299.

21-4750. Pestana, S.-"Silva gil-vicentina". -Ocid, 80 (1971), 425-434.

21-4751. Martins, M. - "Gil Vicente e o texto dos Livros de Horas". - Co, 1971, núm. 3, 29-36.

21-4752. Soares, M. M. R. T. - "Gil Vicente e o folclore". - $B C L, 1970$, núms. 73/4, 253-258. - V. núm. 20-1444.

21-4753. Albuquerque, L. DE - "A astrologia e Gil Vicente". - $A C C P, 3$ (1971).

21-4754. Pratt, Óscar de - Gil Vicente. Notas $e$ comentários. $2^{\text {a }}$ ed. - Lisboa, 1970. $286 \mathrm{pp}$.

21-4755. Mrller, NeIL - O elemento pastoril no teatro de Gil Vicente. - Edit. Inova, Porto, 1970. 185 pp. (Civilização portuguesa).

21-4756. Saraiva, António José - Gil Vicente e o fim do teatro medieval. 3a ed. -Pubs. Europa-América, Lisboa, 1970. 216 pp.-V. núm. 19-1974.

21-4757. Pestana, S. -- "Pequena amostra do Dicionário de Gil Vicente". - Ocid, 81 (1971), 370-387.

21-4758. VICENTE, Gil - Três autos e uma farsa. - Verbo, Lisboa, 1971. 192 pp.

21-4759. Vicente, Gil - Auto da alma. Ed. de A. Nunes de Almeida. 2a ed. melh. - Atlântida, Coimbra, [1970?] 96 pp. - V. núm. 19-1983.

21-4760. VICENTE, Gil - Auto da alma. Ed. de J. Martins e J. Mota. Ed. escolar.-Livr. Didáctica, Lisboa, 1971.-V. núm. 20-5612.

21-4761. Vicente, GiL - Auto da alma. -Edit. Início, Lisboa, 1970. 80 pp. (Clássicos Inicio).

21-4762. Vrcente, Gil - Auto da barca do inferno.-Edit. Início, Lisboa, 1970. 80 pp. (Clássicos Inicio).

21-4763. Vicente, Gir - A barca do inferno. Trad., limiar e notas de X. Landeira Yrago. - Galaxia, Vigo, 1970. $45 \mathrm{pp}$.

21-4764. VICENTE, GIL - Floresta de enganos. A critical ed., with introd. and notes, by Constantine Christopher Stathatos.-[Tesis, Univ. of Oregon, 1970]. 
21-4765. YNDURÁIN, F. - "La dramaturgia de Gil Vicente: Ensayo de estimación". -Co, 1970, núm. 59, 60-63.

V. también núms. 4587, 5927.

21-4766. Lово, M. E.-“Contribuição para o estudo da métrica e da rima do Cancioneiro geral de Garcia de Resende".Ocid, 80 (1971) , 222-244.

21-4767. Mrchä̈lis de VAsconcelos, C."Novos estudos sobre Sá de Miranda". -CMD, 2, 5-114.

21-4768. Michaëlis de VAsconcelos, C."Introdução às Obras de Bernardim Ribeiro e Cristóvão Falcão".-CMD, 2 266 ss.

21-4769. Aubin, J. - "Pour une étude critique de l'Itinerário d'António Tenreiro".-ACCP, 3 (1971).

21-4770. Michaëlis de VAscongelos, C.“André de Resende e a crónica do Mouro Rasis". - CMD, 1, 158-171.

V. también núm. 4605 .

21-4771. Noronha, SANCHO DE - Tratado moral de louvores e perigos de alguns estados seculares. Introd. e notas por M. de Albuquerque. - Junta de Investigações do Ultramar, Lisboa, 1969. 149 pp. (Estudos de ciencias politicas $e$ sociais, 83).

21-4772. Saraiva, António José - Fernão Mendes Pinto. 2a ed. - Pubs. EuropaAmérica, Lisboa, 1971. 208 pp.-V. núm. 14-38813.

21-4773. Pinho, C. S. - "Introdução à lexicologia. Das ediçốes à constituição do Corpus. Prática (à margem dos estudos sobre $A$ linguagem de Fernão Mendes Pinto)".--Ocid, 81 (1971), 155-167.

21-4774. Cusatr, M. L. - "Note lessicali: terminologia mercantile nella Peregrinação, di Fernão Mendes Pinto".-AION-R, 13 (1971), 227-233.

21-4775. Mendes Pinto, Fernão - Peregrinação. Versão e comentários de $\mathbf{M}$. A. Menéres. - Afrodite, Lisboa, 1971. 2 ts.: 508,580 pp.

21-4776. Mendes Pinto, Fernão - Peregrinazione 1537-1558. Trad. di E. Melillo Reali. - Longanesi, Milano, 1970. $369 \mathrm{pp}$.

21-4777. Ferreira de Vasconcelos, JORGEComédia Aulegrafia. Pref., notas e glossário por A. A. Machado de Vilhena. 2a ed.-Porto, [1970?].

21-4778. Ribeiro Chiado, AnTónıo-Auto das regateiras. Introd., ed. e note di Giulia Lanciani. - Ed. dell'Ateneo, Roma, 1970.

Montemor: v. núms. 4783. 6061-5.
21-4779. D'OnOfrio, S.-“O velho do restelo e a consciência crítica de Camóes". -RHSP, 40 (1970) , 75-89.

21-4780. Brasil, R. - "Camões e os povos do Oriente". - ECB, 1969, núm. 29, 90-101.

21-4781. Gallut, A. - Le morgado de Mateus, editeur des "Lusiadas" (N. 21-1601) - || AIA, 31 (1971), 585-586 (Castro); Ocid, 81 (1971), 330-331 (Paxeco) .

21-4782. Santos Alves, Manuel dos-Dicionário de "Os Lusiadas". - Parceria A. M. Pereira, Lisboa, 1971. 200 pp.

21-4783. SENA, JORGe De $-A$ estrutura de "Os Lusiadas" $e$ outros estudos camonianos e de poesia peninsular do século xvi. - Portugália, Lisboa, 1970. 338 pp. (Problemas, 31) . [Cetina, Acuña, Montemayor, Alcázar, Herrera y Góngora]. II Ocid, 86 (1971), 267-268 (Paxeco).

21-4784. Bechara, E. - "Uma fonte importante para o conhecimento da língua portuguêsa no século xvI". - $S L P(2)$, 61-74. [Estudios sobre Os Lusiadas].

21-4785. Falcäo Machado - Ensaio psicosociológico sobre "Os Lusiadas". - Ocidente, Lisboa, 1971. 93 pp.

21-4786. Cirurgião, A. - "S. Helena é a Ilha dos Amores de Os Lusíadas". Ocid, 79 (1970), 260-212.

21-4787. Michä̈lis de Vasconcelos, C."Pedro, Inês e a fonte dos amores".$C M D, 1,33-55$.

21-4788. Arraes de Alencar, J. - “A Divina comédia, o Cruzeiro do Sul e os Lusiadas". - Ocid, 80 (1971), 310-318.

21-4789. Barbandinho Neto, R. - "Um camonista de som alto e sublimado".$H C J$, 211-219. [Sousa de Silveira].

21-4790. SENA, J. DE - "Uma resposta".$B E P, 31$ (1970), 361-364. [A R. Bismut: cf. núm. 20-1493].

21-4791. Cirurgiño, A.-“Um soneto inédito de Camões e dois sonetos desconhecidos de Diogo Bernardes". - Ocid, 80 (1971), 98-104.

21-4792. KandeL, B. L. - “Camoëns dans la littérature russe. Aperçu historicobibliographique". - RLC, 44 (1970), 509-531.

V. también núm. 4703.

21-4793. RoIg, AdRIEN - António Ferreira. Etudes sur sa vie et son oeuvre (15281569). Avant-propos de J. Veríssimo Serrão. - Centre Culturel Portugais, Paris, 1970. 216 pp., 32 ilustr. || Ocid, 80 (1971), 378-380 (Paxeco); LNL, 1970, núm. 194, 79-81 (Roche). 
21-4794. Ferreira, António - Castro. Établissement du texte des éditions de 1587 et 1598, suivi de la traduction française, par Adrien Roig. - Centre Culturel Portugais, Paris, 1971. 399 pp. V. también núm. 4556 .

21-4795. Michä̈lis de Vasconcelos, C."A questão da naturalidade de Diogo Bernardes e frei Agostinho da Cruz".CMD, 1, 172-176; 2, 261-265.

V. también núm. 4791 .

21-4796. Girurgião, António - Fernão Álvarez do Oriente: o homem e a obra. -[Tesis, Univ. of Wisconsin, 1970$].$

21-4797. Veríssimo Serrão, J. - “A Chronica de $D$. João $I I I$, de António de Castilho". - ACCP, 2 (1970).

21-4798. Sousa, FREI Luís DE - Páginas escolhidas. Ed. de J. A. de Carvalho.Verbo, Lisboa, 1970. 139 pp.

21-4799. Machado, SıмÃo - Comédia de Dio. Ed. critique, introd. et commentaire par P. Teyssier. - Edizioni dell'Ateneo, Roma, 1969. 418 pp.

21-4800. RÉvAH, I. S. - "Du smarranisme au judaïsme et au déisme: Uriel da Costa et sa famille" (N. 20-5647). II Sef, 31 (1971), 140 (Cantera Burgos).

21-4801. Michä̈lis de Vasconcelos, C."Uriel da Costa. Notas suplementares relativas à sua vida e sua obra". $-C M D$, 1, 300-319.

21-4802. Lobo, Jerónimo - Itinerário $e$ outros escritos inéditos. - Civilizacão, Porto, 1971. 834 pp., ilustr. (Bibl. histórica, serie ultramarina).

21-4803. Ravara, A. - "Conceito de nobreza em João Pinto Ribeiro". - Ocid, 86 (1971), 255-264.

Rodriguez Lobo: v. núm. 4565 .

21-4804. Michä̈Lis de VAsconcelos, C.“D. Francisco Manuel de Melo. Notas relativas a manuscritos da Biblioteca da Universidade de Coimbra". - CMD, 2, 215-243.

21-4805. Cutler, Charles M.-Dom Francisco Manuel de Melo and Francisco de Quevedo: a study in literary affinity.[Tesis, Univ. of Michigan, 1971].

21-4806. Colomès, JeAN - La critique et la satire de D. Francisco Manuel de Melo. - Centre Culturel Portugais P.U.F., Paris, 1969. 448 pp. ॥ Bro, 91 (1970), 396 (A.R.); Ocid, 78 (1970), 179-181 (Paxeco); Carav, 1970, núm. 14, 181-184 (Roche).

21-4807. Melo, Francisco Manuel de - Le dialogue "Hospital das letras". Texte établi d'après l'édition princeps et les manuscrits, variantes et notes. Ed. par J. Colomès.-Centro Cultural Português, Paris, 1970. lii +377 pp. - V. núm. 20-1508. || Ocid, 81 (1971), 116-123 (Paxeco) .

21-4808. Jean Colomès fala da sua edição do "Hospital das letras" de D. Francisco Manuel de Melo.-Supl. de Ocid, 81 (1971); 44 pp.

21-4809. MAfFre, C. - "La Guerra de Cataluña: Don Francisco Manuel de Melo, écrivain et philosophe de l'histoire".ACCP, 3 (1971).

21-4810. Mrndes, J. - "Vieira, homem fantástico". - Bro, 92 (1971), 16-43.

21-4811. Pulido Valente, V.-“A sociedade, o estado e a história na obra de António Vieira".-APK, 8 (1968).

21-4812. RüHL, K.-“Zur Chronologie der Predigten Vieiras". - $R J, 21$ (1970), 328-358.

21-4813. Nitschкe, A.-“Zum Stil António Vieiras. Das Adjektif in den fünf Sermões der Jahre 1637-1638". - APK, 8 (1968).

21-4814. Saraiva, A. J.-"Les quatre sources du discours ingénieux dans les sermons du Pe António Vieira”- $-B E P, 31$ (1970) , 177-269.

21-4815. ÁvilA, A.-“António Vieira e o *usar bem do jogo»".-Co, 1971, núm. 4, 5-17.

21-4816. Vifira, António-Textos escolhidos.-Verbo, Lisboa, 1971. 192 pp.

21-4817. VAN DEN BEsselAAR, J.-"Variantes da eeditio princeps . da História do futuro de António Vieira".-Ocid, 81 (1971), 65-79.

21-4818. Sousa Gomes, A.-Madre Mariana Alcoforado. Sua graça e seu amor. 2: ed.-Livr. Portugal, Lisboa, 1970. 15 pp. -V. núm. 18-5549.

21-4819. García-Rodríguez, J. M. - "Las cartas de amor de una monja portuguesa".-LT, 1970-71, núms. 70/1, 301312.

A utores modernos

21-4820. Jofre Barroso, H. M.-“Para la historia del teatro portugués. Antonio José, “el judio'”. - Davar, 1970, núm. $124,112-117$.

21-4821. Coimbra Martins, A.-“A propósito de uma tradução de George Dandin atribuida a Alexandre de Gusmão. Subsídios para o estudo da projecção de Molière em Portugal".-ACCP, 1 (1969), 
216-235. || Ocid, 78 (1970), 227-228 (Paxeco).

21-4822. Mendes, M.-"Bocage".-Co, 1970, núm. 61 .

21-4823. [Bocage] - História e vida de Bocage.-Guimarães, Lisboa, 1971.

21-4824. Bocage, Manuel M. Barbosa dUOdes, canções, epistolas, idilios, cantos, cantatas. T. 2.-Bertrand, Lisboa, 1971. 376 pp.

21-4825. BoGAGE-Antologia poética.-Verbo, Lisboa, 1971. $160 \mathrm{pp}$.

21-4826. Bocage-Rimas. Ed. de M. da Silva Freitas.-Pax, Braga, 1971. 224 pp.

21 4827. Costa DiAs, A. DA-"Garrett republicano". $-S N$, 1971, núm. 1505, 3038; núm. 1507, 17-25.

21-4828. Reali, E. M.-“Garrett e i miti del sebastianismo".-AION-R, 12 (1970), 127-146.

21-4829. Pires de Lima, F. DE C.-“A1meida Garrett, o precursor dos estudos etnográficos na Península".-RDTP, 26 (1970) , 229-237. [Trad. española en $E L$, 1970, núms. 444/5].

21-4830. Figueiredo, Fidelino de-Shakespeare $e$ Garrett.-Conselho Estadual de Cultura, São Paulo, 1970. 63 pp.-V. núm. 13-35106.

21-4831. AlmeIDA GaRReTt-Frei Luis de Sousa.-M. Camanho, Lisboa, 1970. 96 pp. (Clássicos Avis).

21-4832. AlmeIda GarRet-Frei Luis de Sousa. Ed. escolar.-Livr. Didáctica, Lisboa, 1971 .

21-4833. Almeida GarretT-Frei Luis de Sousa. 6a ed.-Europa-América, Lisboa, 1971. 196 pp. (Livros de bolso).-V. núm. 19-5835.

21-4834. O. A.-“Apunte sobre un tema cervantino y romántico: el Frei Luis de Sousa".-EL, 1970, núms. 444/5.

21-4835. Almeida GarretT-O arco de Sant'Ana.-Verbo, Lisboa, 1971. 192 pp.

21-4836. Almeida Garrett-O romanceiro. Ed. revista e prefaciada por F. de Castro Pires de Lima.-Domingos Barreira, Porto, 1969. 525 pp.

21-4837. Martins, H.-“Uma censura inédita de Garrett”.-Trip, 9 (1969), 2-4.

21-4838. Saraiva, António José-Herculano desconhecido. - Europa-América, Lisboa, 1971. 296 pp.-V. núm. 9-14054.

21-4839. Barradas dE Carvalho, J.-"'As fontes que Herculano ignorou". - $S N$, 1971, núm. 1511, 12-18.

21-4840. Herculano, Alexandre- $A$ damapé-de-cabra.-Edit. Início, Lisboa, 1970. 100 pp. (Clássicos, 1).
21-4841. Herculano, Alexandre- $A$ morte do lidador. A dama pé de cabra.-Início, Lisboa, 1970. 80 pp.

21-4842. Herculano, Alexandre-O pároco da aldeia.-Bertrand, Lisboa [1970?]. 220 pp. (Obras completas).

21-4843. Peixoto, J.-“Mendes Leal e uma poesia sua sobre Gutenberg".-Ocid, 81 (1971) , 323-327.

21-4844. Oliveira Martins, F. A. DE Castelo Branco nas suas relações com $J$. $P$. de Oliveira Martins.-Livr. Portugal, Lisboa, 1970. 92 pp.

21-4845. Coutinho Lanhoso, Adriano Camilo visto por Freitas Fortuna, seu amigo e seu «irmão.-Casa de Camilo, Vila Nova de Famalicão, 1970. $\| \mathrm{Co}$, 1971, núm. 3, 87-88 (Prado Coelho).

21-4846. MalpiQue, C.-"Camilo. (Aspectos do seu retrato moral e psicológico)". $B C P, 33$ (1970), 20-77.

21-4847. Castelo Branco, Camilo-O anátema.-Parceria A. M. Pereira, Lisboa, 1971.

21-4848. Castelo Branco, Camilo $-A$ bruxa do Monte Córdoba. 7? ed.-Parceria A. M. Pereira, Lisboa, 1971. xv +$280 \mathrm{pp}$.

21-4849. Castelo Branco, Camilo-Cenas contemporâneas. 6: ed.-Parceria A. M. Pereira, Lisboa, 1971. xvii +295 pp.

21-4850. Castelo Branco, Camilo - $A$ doida do Candal. 11: ed.-Parceria A. M. Pereira, Lisboa, 1971. 316 pp.

21-485̃1. Castelo Branco, Camilo - $A$ filha do Dr. Negro. 8a ed.-Parceria A. M. Pereira, Lisboa, 1971. 316 pp.

21-4852. Castelo Branco, Camilo-Maria Moisés.-Verbo, Lisboa, 1970. 192 pp. (Bibl. básica).

21-4853. Castelo Branco, Camilo-Noites de Lamego. - Parceria A. M. Pereira, Lisboa, 1971.

21-4854. Castelo Branco, Camilo-O retrato de Ricardina. - Pubs. EuropaAmérica, Lisboa, 1971. 192 pp. (Livros de bolso Europa-América).

21-4855. Prado Coelfo, J. DO-“Um conto de Camilo: História duma porta".-Co, 1971, núm. 1, 20-29.

21-4856. Castelo Branco, Camilo-Teatro. T. 2.-Parceria A. M. Pereira, Lisboa, 1971.-V. núm. 20-5682.

21-4857. Castelo Branco, Camilo - As polémicas de Camilo. Ed., pref. e notas de A. Cabral. Ts. 3-4.-Portugália, Lisboa [1969?]. 504, 469 pp.-V. núm. 185598.

V. también núm. 4868 . 
21-4858. Blasco, P.-"Ramalho Ortigão, voyageur portugais en Espagne à la fin du xixe siècle".-LNL, 1970, núm. 194, 52-62.

21-4859. Castelo-Branco, F.-“"No centenário de $A s$ farpas: uma carta de João Penha".-Co, 1971, núm. 4, 74-77.

21-4860. Ramalho OrTigão-Farpas escolhidas.-Verbo, Lisboa, 1971. $192 \mathrm{pp}$.

21-4861. FERREIRA, V.-"Sobre um incomemorável centenário: $A$ Rosa do Adro". -Co, 1971, núm. 3, 66-67. [Manuel Maria Rodrigues].

21-4862. Leal DE Martínez, M. T.-"A -filosofia idealista da morte» em Antero de Quental". - Ocid, 81 (1971), 82-98.

21-4863. Oliveira Martins, F. D'A. DeAntero de Quental na mão de Deus.Ocidente, Lisboa, 1971. 56 pp.

21-4864. Peixoto, J. - "Teófilo Braga e uma sua poesia dedicada à arte tipográfica".-Ocid, 80 (1971), 81-85.

21-4865. Medina, J.-“"Breve resenha cronológica da vida e da obra de Eça de Queiroz"-Vértice, 31 (1971), 2-15.

21-4866. Malta Ferraz, Paulo-Viagem ao Portugal de Eça de Queirós.-Rio de Janeiro, 1971.

21-4867. VIANNA Moog-Eça de Queiroz e o século xix. 5a ed.-Civilização Brasileira, Rio de Janeiro, [1970?].

21-4868. Azevedo, Manuela DE-À sombra d'Eça e Camilo.-Parceria A. M. Pereira, Lisboa, 1970. 205 pp.

21-4869. Vianna Moog-"Atualidade e circunstância de Eça de Queiroz".-Tulane Studies in Romance Lang. and Lit., 4 (1971), 64-79.

21-4870. Brown, T., JR.-“Eça de Queiroz: The paradox of tragedy". - RNo, 10 (1968-69) , 77-82.

21-4871. LiND, G. R.-“"Eça de Queiroz und die französische Zwei-Deutschland-Theorie".-APK, 8 (1968).

21-4872. Medina, J. - "Eça e Ega. Duas atitudes perante a acholdra". - $S N$, 1971, núm. 1506, 27-30.

21-4873. Direitos de autor à obra literária de Eça de Queiroz. Peças do processo judicial.-Lisboa, 1969.

21-4874. Berardinelli, C. - "Para uma análise estrutural da obra de Eça de Queirós".-Co, 1971, núm. 2, 22-30.

21-4875. AzEvedo FilHo, L. A. DE-"Aspectos do romance eciano".--Ocid, 81 (1971) , 277-288.

21-4876. Campos Matos, A.-"Para uma prospecção fotográfica dos ambientes urbanos e paisagens do mundo romanesco de Eça de Queiroz".-Vértice, 31 (1971), 16-22.

21-4877. EÇA DE QUeIroz-Cartas de Paris. -Livros do Brasil, Lisboa, 1970. 352 pp.

21-4878. EçA DE QueIros, José MaríaCartas da Inglaterra e crónicas de Lon. dres. - Livros do Brasil, Lisboa, 1970. $352 \mathrm{pp}$.

21-4879. EÇA DE QUEIROZ - Letters from England. Tr. by Dorotyh Ball.-London, 1970.

21-4880. Roche, J.-“'Introduction à l'étude quantitative du style de Eça de Queiroz dans $O$ crime do Padre Amaro".-ACCP, 1 (1969), 387-410.

21-4881. Araújo, N.-“The practice and pretense of religion in Eça de Queiroz's O crime do padre Amaro".-Aquila: Chestnut Hill Studies in Modern Lang. and Lits., 1 (1969), 1-7.

21-4882. EçA DE QUEIRoz-Lendas de santos - Livros do Brasil, Lisboa, 1970.

21-4883. EÇA DE QUEIROZ-Notas contemporâneas. - Livros do Brasil, Lisboa, 1970. $418 \mathrm{pp}$.

21-4884. EÇA DE QUEIRoz-Prosas bárbaras. -Livros do Brasil, Lisboa, 1970. 336 pp.

21-4885. Trullemans, U. - “ $A$ reliquia d'Eça de Queiroz. Notes sur la structure d'un anti-roman picaresque". RRo, 6 (1971) , 85-113.

21-4886. SÉrglo, A.-“O conto de Eça de Queirós O tesouro".-Ocid, 79 (1970), 3-15.

21-4887. Neto, R.-“Eça de Queirós na América latina".- $-S N, 1971$, núm. 1511, 19-23.

V. también núms. 4689, 4716 .

21-4888. Mendes, J.-“Guerra Junqueiro: um profeta-criança”. - Bro, 92 (1971), 608-618.

21-4889. Mendes, J.-"Junqueiro: os temas de um profeta-criança".-Bro, 92 (1971), 754-766.

21-4890. Mendes, J.-“Guerra Junqueiro: as imagens do profeta e da criança”.Bro, 93 (1971), 12-27.

21-4891. "Wenceslau de Moraes, Obras completas". - Ocid, 77 (1969), 51-67. [Noticia de la traducción japonesa, y abundante bibliografía].

21-4892. Moraes, Wenceslao de - Traços do Extremo Oriente. 2a ed.-Parceria A. M. Pereira, Lisboa, 1971.

21-4893. Crabbé Rocha, A - "Cesário Verde, poeta barroco?”-Co, 1971, núm. $1,31-33$.

V. también núm. 4703. 
Abel Botelho: v. núm. 4716.

Trindade Coelho: v. núm. 4716.

21-4894. Castillo, G. DE - "A farsa e a problemática de Raul Brandão". - Co, 1971, núm. 2, 31-34.

21-4895. Malpique, C.-“Raul Brandão, o obsessivo da vida, da morte, do sonho e da dor".-BCP, 32 (1969), 272-338.V. núm. 21-1700.

21-4896. Scotti-Rosin, Michafl - Geschichtsbild, Sozialkritik und Romantechnik Raul Brandãos.-[Tesis, Univ. de Bochum, 19707.

21-4897. Brandão, Raul - $A$ morte do palhaço. Mistério da árvore. - Verbo, Lisboa, 1971. 176 pp.

21-4898. Castilho, G. dE-Antonio Nobre (N. 20-5731) . \| RLSP, 12 (1969), 244246 (Camocardi) .

21-4899. Pessanha, Camilo - Clepsidra e outros poemas. Ed. de J. de Castro Osório. - Ática, Lisboa, 1969. 554 pp. (Col. Poesia). || RLSP, 12 (1969), 247250 (Camocardi); Co, 1970, núm. 60 (Silveira) .

21-4900. Azevedo Filho, L. A. DE - “A poesia de Tasso da Silveira"-Oocid, 77 (1969) , 77-88.

21-4901. Sampelayo, J.-“Breve recuerdo de Eugénio de Castro en su centenario".-CuH, 81 (1970), 204-206.

21-4902. Poupart, R.-“L'évolution d'Eugénio de Castro d'après certaines variantes".-Co, 1970, núm. 61.

21-4903. Pinto de CAstro, A.-“Tradição e renovação na poesia de Eugénio de Castro".-ACo, 24 (1969), 154-181.

\section{A utores contemporáneos}

21-4904. Dantas, Júlıo-A catedral. Peça em 4 actos.-Lisboa, 1970. || Co, 1971, núm. 3, 85-86 (Andrade).

21-4905. Nogueira Rosa, J. M.-“Fernando Pessoa: como eu o conheci”.-Ocid, 77 (1969) , 227-236.

21-4906. SeVErino, A. E.-“La formación artística de Fernando Pessoa". - Ins, 1971, núms. $296 / 7$.

21-4907. MENDONÇA, F. - “O mestre de Fernando Pessoa”. - RLSP, 12 (1969), 45-55.

21-4908. Severino, A. E. - "A primeira publicação literária de Fernando Pessoa".-H, 54 (1971), 68-72.

21-4909. Pradelino DA Rosa, A. - Uma interpretação de Fernando Pessoa. Fac. de Filosofia, Univ. Federal do Rio
Grande do Sul, Pôrto Alegre, 1969. 139 pp. $[=B G P L$, núm. 15, 15-116. Otra edición: Guimarães, Lisboa, 1971 (?) ].

21-4910. Lind, Georg Rudolf - Teoria poética de Fernando Pessoa. Trad. por M. Losa.-Inova, Porto, 1970. 351 pp. \| ZRPh, 86 (1970), 698 (Schwake).

21-4911. Frias, EdUARDo-O nacionalismo místico de Fernando Pessoa. - Pax, Braga, 1971. 104 pp. (Col. Pax, 4) .

21-4912. DEL BENE, O.-"Notas sobre aspectos do romantismo e de "cultura intervalar em Fernando Pessoa".-Ocid, 76 (1969), 150-158.

21-4913. Morfira Duarte, José AFrânioFernando Pessoa $e$ os caminhos da solidão.-Imprensa Oficial, Belo Horizonte [1969?]. I| $B A b r, 44$ (1970), 463 (Lobo Filho) .

21-4914. Lopes, T. R.-“Pessoa, Sá-Carneiro e as três dimensões do sensacionismo". -Co, 1971, núm. 4, 18-26.

21-4915. Camargo Biderman, Maria TeREZA-Análise computacional de Fernando Pessoa. Ensaio de estadistica léxica.[Tesis, Universidade de São Paulo, 1969]. $381 \mathrm{pp}$.

21-4916. Güntert, Georges - Das fremde Ich: Fernando Pessoa.-W. De Gruyter, Berlin, 1971. 223 pp. \| $R F, 84$ (1972), 263-265 (Lind) .

21-4917. Prado Corlho, Jacinto do-Di. versidade $e$ unidade em Fernando Pessoa. $3^{\text {a }}$ ed., refundida e acrescentada.Verbo. Lisboa, 1969. 276 pp.-V. núm. 18-5673.

21-4918. Jennings, H. D.-“Fernando Pessoa, the poet with many faces"-Contrast, South African Quart., 1971, núm. 27, 52-64.

21-4919. Almema Pavão, J. DE-"Pessoa e os heterónimos". - Ocid, 81 (1971), 296-303.

21-4920. Longobardi, R.-"Fernando Pessoa: ancora sugli eteronimi".-AION-R, $12(1970), 43-90$.

21-4921. Numes, B.-“Os outros de Fernando Pessoa".-BEP, 31 (1970), 335-358.V. núm. 19-5911.

21-4922. SheEts, J. M.- "Fernando Pessoa as anti-poet: Alberto Caeiro"--BHS, 46 (1969) , 39-47.

21-4923. Pessoa, Fernando - Poemas de Alberto Caeiro. 4\% ed. - Atica, Lisboa, 1970. 120 pp. (Col. Poesia).-V. núm. $18-5680$.

21-4924. DÉcio, J.-“Notas sôbre a poesia de Alvaro de Campos". - Alfa, 1968, núms. $13 / 4,237-248$. 
21-4925. Severino, A. E.-“A presenca de Milton numa ode de Alvaro de Campos".-Co, 1970, núm. 58.

21-4926. Carvai.ho Barata, F. DE-“Traços anacreônticos na poesia de Ricardo Reis".-SLP(2), 133-153.

21-4927. Pessoa, Fernando-Poesias. $7^{\text {a }} \mathrm{ed}$. -Ática, Lisboa [1969?7. 264 pp. (Col. Poesia).-V. núm. 18-2231.

21-4928. Pessoa, Fernanio-Poesia. Introd. e sel, de A. Casais Monteiro. T. 2.Edit. Confluéncia, Lisłoa [1970?]. (Antologia de autores portugueses e estrangeiros).

21-4929. Pfscoa, Fernando-[Poems]. Tr. by Jean R. Longland. - Poet Lore (Westport, Conn.), Autumn 1970.

21-4930. Pessoa, Fernando-[Poems]. Tr. by Jonathan Griffin. - Carcanet Press, Pin Farm (South Hinksey, Oxford), 1970.

21-4931. Pessoa, Fernando - Sixty Portuguese poems. Introd., sel., trad, and notes by F. E. G. Quintanilha.-Univ. of Wales Press, Cardiff, 1971. xlix + 141 pp. I| Ocid, 86 (1971), 271 (Paxeco)

21-4932. Pessoa, Fernando-Poesias inétitas (1930-1935).-Ática, Lisboa [1969?]. 200 pp. (Col. Poesia). - V. núm. 1647775 .

21-4933. Berardinelli, C.-"Mensagem [de F. Pesssoa]".-Cadernos da PUC, Letras e Artes, Rio de Janeiro, 1969, núm. 1.

21-4934. Portella Bonapace, A.-“Análise do poema «D. Fernando, Infante de Portugal», 2a parte da 1 quina do livro Mensagem, de Fernando Pessoa".-Ocid, 80 (1971), 401-410.

21-4935. DEL BENE, O.-“Elementos para uma tentativa de estudo do Primeiro Fausto de Fernando Pessoa"-OCid, 78 $(1970), 45-75$.

21-4936. Herron, R.-"Nótula acêrca de -O que em mim 'stá pensando."-Alfa, 1968, núms. 13/4, 215-219.

21-4937. Pring-Mill, R. D. F.-"The theme of Fernando Pessoa's English sonnets". -Tulane Studies in Romance Lang. and Lit., 4 (1971) , 9-37.

21-4938. Pina Coelho, António-Os fun damentos filosóficos da obra de F. Pessoa.-Verbo, Lisboa, 1971. 192 pp.

21-4939. Pessoa, Fernando-Textos filosóficos. Estabelecidos e prefaciados por $\mathbf{A}$. de Pina Coelho,-Ática, Lisboa [1969?]. 2 ts.: 240,282 pp.

$\checkmark$. también núm. 4703.

Sá Carneiro: v. núms. 4703, 4914.
21-4940. Beirão, MÁrIo-Ausente, 2a ed.T. Martins, Porto, 1969. 126 pp. [1: ed., 1915]. || B.4br, 44 (1970), 462-463 (Clark) .

21-4941. "Homenagem a Almada Negreiros".-Co, 1970, núm. 60. [Escriben, entre otros, H. Gidade, F. Guimarães ("Acerca da poesia de Almada Negreiros") , E. Prado Coelho ("Sobre Nome de guerra”), L. F. Rebelo y E. de Sousa]. 21-4942. Cabral do Nascimento - Descaminho.-Minerva, Lisboa, 1969. $70 \mathrm{pp}$.

21-4943. Guimaräes, F. - "Linguagem e poesia em Mário Saa, ou uma estranha hierarquia".-Co, 1971, núm. 3, 37-43.

21-4944. Jansen DE FARIA, A.-“A técnica da ficção em Ferreira de Castro". $S L P(2)$, 109-132.

21-4945. Ferreira dE CAstro-Emigrantes. 15. ed--Guimarães, Lisboa [1971?]. 344 pp.-V. núm. 20-1686.

21-4946. Ferreira de Gastro-O instinto supremo. 3a ed. - Guimarães, Lisboa, 1968. 362 pp. || AION-R, 11 (1969) , 127 (Reali) .

21-4947. Ffrreira de CAstro-A lã $e$ a neve. 10 ed.-Guimarães, Lisboa, 1969. 414 pp.-V. núm. 18-5701.

21-4948. Ferreira de CAstro-A missão.Europa-América, Lisboa, 1971. 134 pp. (Livros de bolso).

21-4949. Ferreira de Castro-A selva. 23a. ed. Ed. definitiva.-Guimarães, Lisboa [1969?]. 332 pp. [25ª ed., 1971].-V. núm. 20-1688.

21-4950. Ferreira de Castro-A tempestade. 9a ed.-Guimarães, Lisboa, 1969. 308 pp.-V. núm. 18-2268.

21-4951. Castro, Fernanda DE - Poesia (1919-1969). - Parceria A. M. Pereira, Lisboa, 1970. 2 ts.: 197, 244 pp.

21-4952. Prado Coelho, E.-"Poeta: apenas vê o que não ilumina".-Co, 1970, núm. 61. [Sobre Gomes Ferreira].

21-4953. Prado Coelho, E.-“O real impossível em José Gomes Ferreira". $-\mathrm{SN}$, 1971, núm. 1509, 31-32.

21-4954. Gomes Ferreira, José-Poesia $I$ IV.-Portugália, Lisboa, 1968-1971. 386, $208,285,290$ pp.-V. núm. 18-2276. II Ocid, $78(1970), 185$ (Pinharanda Gomes); Co, 1971, núm. 2, 84-85 (Ramos Rosa).

21-4955. Gomes Ferreira, José-O mundo dos outros. Histórias e vagabundagens. 3a ed,-Portugália, Lisboa, 1969. 236 pp.

21-4956. Gomes Ferreira, José - Tempo escandinavo. - Portugália, Lisboa, 1969. || Co, 1970, núm. 57 (Palma-Ferreira) . 
21-4957. "Homenagem a José Régio".Co, 1970, núm. 57. [Escriben A. de Castro, Branquinho da Fonseca, M. R. Araújo, Moreira das Neves, Natércia Freire y M. A. Galhoz].

21-4958. In memoriam de José Régio.Brasília Editora, Porto, 1970. 554 pp.

21-4959. Serpa, Alberto DE-Retrato imperfeito de José Régio.-Imprensa Portuguesa, Porto, 1970. $11 \mathrm{pp}$.

21-4960. Salema, A.-"Presença interior de José Régio".-Jornal de Letras, Rio de Janeiro, 1971, núm. 248.

21-4961. Crespo, F.-"Sobre um cancioneiro poético de José Régio".-Ocid, 79 (1970), 49-51.

21-4962. RÉcIo, José-Biografia (sonetos). 5? ed. - Portugália, Lisboa, 1969. - V. núm. 11-26421.

21-4963. RÉGIo, José - Cántico suspenso. 2: ed.-Brasília Ed., Porto, 1971. 164 pp. (Obras completas).

21-4964. RÉGIo, JosÉ-Colheita da tarde.Brasília Ed., Porto, 1971. 180 pp. (Obras completas).

21-4965. RégIo, José-Confissão dum homem religioso.-Brasília E., Porto, 1971. 254 pp. (Obras completas).

21-4966. RÉGro, JosÉ-Jogo da cabra cega. -Brasília Ed., Porto, 1971. 444 pp. (Obras completas).

21-4967. Récro, José-Música ligeira. Ed. por A. de Serpa. - Portugália, Lisboa, 1970. 106 pp. || BAbr, 45 (1971), 302 (Cirurgião); Co, 1970, núm. 60 (Martinho) .

21-4968. RéGIo, José-Três peças en um acto. 2a ed.-Portugália, Lisboa, 1969.V. núm. 13-35181.

21-4969. RÉGIO, JosÉ-O vestido cor de fogo.-Verbo, Lisboa, 1970. 192 pp. (Bibl. básica).

21-4970. Figueiredo, TOMÁs DE - A má estrela.-Verbo, Lisboa, 1970. 204 pp. (Obras completas).

21-4971. Figueiredo, Tomás de - Dicionário falado. - Verbo, Lisboa, 1970. 300 pp. (Obras completas).

21-4972. Figueiredo, TOMÁs DE - Nó cego. -Verbo, Lisboa, [1971?].

21-4973. Figueiredo, TOMÁs DE-Uma noite na toca do lobo.-Verbo, Lisboa, 1971. 160 pp. - V. núm. 20-1695.

21-4974. Homem de Mello, Pedro - Nós portugueses somos castos.-Ática, Lisboa, [1969?]. $94 \mathrm{pp}$.

21-4975. Branquinho da Fonseca - $O$ barão (N. 18-5708) . \|Alfa, 1968, núms. 13/4, 333-335 (Décio).
21-4976. BRANQUinho DA FONSECA-O batão. Estudo de D. Mourão Ferreira. 5a ed.Portugália, Lisboa, 1969. 144 pp.-V. núm. 18-5708.

21-4977. BRANQuinho DA Fonseca - Rio turvo. - Verbo, Lisboa [1971?]. $160 \mathrm{pp}$. (Bibl. básica).

21-4978. RIBEIRo, M. A.-"Alguns aspectos de Miguel Torga". - Il Congreso Bras. de Lingua e Lit. (Rio, 1971).

21-4979. CidAde, H. - "Um livro de Torga: O terceiro dia da criação do mundo entre a $1^{\text {a }}$ e a 4 a edições". - Co, 1971, núm. 2, 35-40.

21-4980. Casais Monteiro, ADolfo-Poesias completas. - Portugália, Lisboa, 1969. (Poetas de hoje).

21-4981. Araújo Correia, Joño DE-Contos bárbaros. - Verbo, Lisboa, 1971. 192 pp.

21-4982. ARaújo Correia, JoÃo DE-Enfermaria do idioma.-Imprensa do Douro, Régua, 1971. || Co, 1971, núm. 4, 93 (Andrade).

21-4983. Ares Montes, J. - "Alves Redol en su laberinto neorrealista (19111969) ". - Ins, 1971, núms. 296/7.

21-4984. Alves Redol - O cavalo espantado. 2a ed. - Europa-América, Lisboa, [1969?]. $298 \mathrm{pp}$.

21-4985. AlVES REDOL - Maria Flor abre o "Livro das surpresas". - Publicações Europa-América, Lisboa, 1970. 40 pp., ilustr.

21-4986. Del Bene, O. -- “Apontamentos críticos sobre Álvaro Feijó". - Ocid, 78 (1970), 4-12.

21-4987. Del BenE, O.-"Alguns inéditos de Álvaro Feijó”. - Co, 1971, núm. 2, 41-51.

21-4988. Cochofel, Joño José - Uma rosa no tempo. - Iniciativas Editoriais, Lisboa, 1970. \| Co, 1970, núm. 61 (Ramos Rosa).

21-4989. Sacramento, M. - Fernando Namora (N. 20-1714). I Alfa, 1968, núms. 13/4, 327-328 (Novaes Coelho). 21-4990. Cidade, H. - "Prosa e poesia: A propósito do último livro de poemas de Fernando Namora". - Co, 1971, núm. 1, 45-47.

21-4991. GIL, I.-M. - "Sobre un gran libro de Fernando Namora".-Ins, 1971, núms. 296/7. [Diálogo em setembro].

21-4992. Namora, Fernando - Domingo à tarde. 8 a ed. - Europa-América, Lisboa, 1971. 252 pp.-V. núm. 19-2207.

21-4993. Namora, Fernando - Fogo na noite escura. 7 : ed.-Europa-América, Lisboa, 1971. 460 pp. - V. núm. 19-2208. 
21-4994. Namora, Fernando - Minas de San Francisco. $7^{\text {a }}$ ed. - Publicações Europa-América, Lisboa, 1971. 364 pp. -V. núm. 20-1719.

21-4995. Namora, Fernando $-A$ noite $e$ a madrugada. - Verbo, Lisboa, 1970. 192 pp. (Bibl. básica Verbo).

21-4996. Namora, Fernando - Fields of fate. [ $O$ trigo $e$ o joio]. Tr. by Dorothy Ball. - Crown Publishers, New York, 1970. 224 pp.

21-4997. Oliveira, Carlos DE - O aprendiz de feiticeiro. - Dom Quixote, Lisboa, 1971. || Co, 1971, núm. 2, 87-88 (Osório Mateus) .

21-4998. O'Neill, AleXANDre - As andorinhas não têm restaurante. - Dom Quixote, Lisboa, $1970 . \|$ Co, 1971, núm. 3, 85 (Prado Coelho).

21-4999. O'Neill, AleXANdre - No reino da Dinamarca. Obra poética 1951-1965. - Guimarães, Lisboa, 1969. 190 pp. (Poesia e verdade).

21-5000. César, Amândio - Subsolo.-Sociedade de Expansão Cultural, Lisboa, 1969. 280 pp.

21-5001. CÉsAR, AMÂndIo - Terra triste e nobre. - Pax, Braga, 1968. $110 \mathrm{pp}$.

21-5002. Breyner Andresen, Sofia DE MELo - A floresta. - Figueirinhas, Porto, 1968. 78 pp., ilustr.

21-5003. Breyner Andresen, Sophia de M. -Grades.-Publ. Dom Quixote, Lisboa, 1970. I| Diál, 1971, núm. 40 (Xirau) .

21-5004. Mourão-Ferreira, DAvID - Cadernos de poesia.-Dom Quixote, Lisboa, 1969. 114 pp.

21-5005. Mourão-Ferreira, David - Discurso directo. - Guimarães, Lisboa, 1969. $203 \mathrm{pp}$.

21-5006. Andrade, Eugenio de - Poemas. - Portugália, Lisboa, 1970. 252 pp. V. núm. 20-1734.

21-5007. Couto Viana, Antonio MANueLPátria exausta. - Verbo, Lisboa, 1971. 88 pp.

21-5008. Tavares Rodrigues, Urbano Horas perdidas. - Bertrand, Lisboa, 1969.

21-5009. Tavares Rodrigues, Urbano Os insubmissos. 3a ed.-Bertrand, Lisboa, 1969. - V. núm. 17-5113.

21-5010. Tavares Rodrigues, Urbano $-A$ palma da mão. Sumário dos dias inquietos. - Inova, Porto, 1970. $\| \mathrm{Co}$, 1970, núm. 61 (Prado Coelho).

21-5011. Tavares Rodrigues, Urbano- $A$ porta dos limites. 3! ed. - Bertrand, Lisboa, 1970. $308 \mathrm{pp}$.
21-5012. Lacerda, AlberTo DE - Selected poems. Translated by the author and A. Waley.-University of Texas, Austin, 1969. 95 pp.

21-5013. Gama, Sebastião DA - Cabo da Boa Esperança. 2a ed.-Ática, Lisboa, [1969?]. 180 pp. (Obras, 3) . - V. núm. 16-43981.

21-5014. Gama, Sebastião da - O segredo $\dot{e}$ amar.-Atica, Lisboa, 1969. xxviii + 344 pp. (Obras, 6) . \|AION-R, 12 (1970), 112-113 (Del Bene); BAbr, 44 (1970), 101-102 (Cirurgião).

21-5015. Rodrigues, A. B.-“Mário Cesariny de Vasconcelos e o surrealismo".II Congresso Bras. de Lingua e Lit. (Rio, 1971) .

21-5016. Botelho, Fernanda $-A$ gata $e$ a fábula. 3 a ed. - Bertrand, Lisboa, 1970. 327 pp. - V. núm. 17-5128.

21-5017. Botelho, Fernanda - Terra sem misica. - Livraria Bertrand, Lisboa, 1969. 312 pp.

21-5018. Figufiredo, T. DE - “A respeito de Agustina Bessa Luís”. - Pan, 1968, núm. 28.

21-5019. Bessa Luís, Agustina - A biblia dos pobres. T. 1: Homens e mulheres. T. 2: As categorias. - Guimarães, Lisboa, 1967-70. || Co, 1971, núm. 3, 83-85 (Barahona).

21-5020. Bessa Luís, Agustina - A brusca. -Verbo, Lisboa, [1971?]. 160 pp. (Bibl. básica).

21-5021. Ramos Rosa, António-Nos seus olhos de silêncio. - Pubs. Dom Quixote, Lisboa, 1970. || Co, 1971, núm. 1, 90-91 (Cruz) .

21-5022. Gonçalves, Egrto - $O$ fósforo na palha. - Publs. Dom Quixote, Lisboa, 1970. \| Co, 1970, núm. 61 (Rui de Sousa).

21-5023. Rebello, Luís Francisco - $\mathrm{O}$ dia seguinte. Drama en un acto. - Movimento, Lisboa, 1969. (Teatro, 3) .

21-5024. Caeiro, O. - "Notas a uma autobiografia portuguesa: $O$ mundo à minha procura, de Ruben A."-IR, 1 (1969), núm. 3.

21-5025. Belo, RuY-Homem de palavra(s). - Dom Quixote, Lisboa, 1970. 144 pp. (Cadernos de poesia). \|Co, 1970, núm. 57 (Prado Coelho).

21-5026. Belo, Ruy - Na senda da poesia. -União Gráfica, Lisboa, 1970. 342 pp. (Ensaistas contemporâneos). || Co, 1970, núm. 61 (Cruz) .

21-5027. Boaventura, MANuel DE - Histórias contadas à lareira. - Porto, 1968. 
21-5028. Sttau Monteiro, Luís DE-Angústia para a jantar. 5? ed. - Ática, Lisboa, [1969?]. 242 pp.

21-5029. StTAu Monteiro, Luís DE - As mãos de Abraão Zacut. Peça em 2 actos. -Ática, Lisboa, [1969?]. 188 pp.

21-5030. StTau Monteiro, Luís dE - Um homem não chora e outra novela. 3: ed. - Ática, Lisboa, [1969?]. 172 pp.

21-5031. Carvalho, Maria Judite De-Os idólatras. - Prelo, Lisboa, 1969. \| Co, 1970, núm. 57 (Barahona).

21-5032. MendonçA, F. - "Almeida Faria, romancista de vanguárdia". - II Con. gresso Bras. de Lingua e lit. (Rio, 1971) .

21-5033. Alves Pires - "José Cardoso Pires, um fabulador exemplar". - Bro, 92 (1971) , 810-816.

\section{A utcres gallegos}

21-5034. FernÁndez del RIEgo, F. - Historia de la literatura gallega.-Galaxia, Vigo, 1960. $175 \mathrm{pp}$.

21-5035. Alonso Montero, Xesús (ed.) Os cen mellores poemas da lingua galega. -Lugo, 1970. $268 \mathrm{pp}$.

21-5036. Pondal, Eduardo - Queixumes dos pinos e outros poemas. (Obra lírica completa). - Vigo, 1970. $230 \mathrm{pp}$.

21-5037. Filgueira Valverde, $X$. - "Un poema descoñecido de Pondal".-CuEG, 25 (1970), 119-122.

21-5038. Franco Domínguez, F.-"Rosalía de Castro: Paisaje y emoción de Galicia".-AH, 52/53 (1970), 199-205.

21-5039. Castro, Rosalía DE - Contos do pobo. - Galaxia, Vigo, 1970. 52 pp. (O moucho, 15) .

21-5040. Poullain, C. - "Valor y sentido de la novela de Rosalía de Castro de Murguía, El caballero de las botas azules". - CuEG, 25 (1970), 37-69.

V. también núm. 4587 .

21-5041. Carballo Calero, Ricardo, et al. -Presencia de Curros y doña Emilia.Vigo, 1960. $118 \mathrm{pp}$.

21-5042. Curros Enríquez, M. - Poesias. -Madrid, 1970. $121 \mathrm{pp}$.

21-5043. Curros Enríquez, Manuel - $O$ divino sainete... - Ediciós do Castro, A Cruña, 1969. 176 pp., ilustr. \| $R O c c$, 27 (1969), 389-390 (Fabra Barreiro).

21-5044. Cunqueiro, Álvaro - Un hombre que se parecia a Orestes.-Destino, Barcelona, 1969. 245 pp. \| BAbr, 44 (1970), 275-276 (Fox); $H, 53$ (1970), 152 (Kronik).
21-5045. Cabanili.as, R., et al. - Castelao na voz dos poetas... e Aportaciós para unha bibliografia de Castelao, por X. Alonso Montero et al. - La Coruña, 1970. $113 \mathrm{pp}$.

21-5046. Castelao, Alfonso-Dous contos, cinco cousas e mais un dibuxo inédito. Trad. y pról. de X. Alonso Montero. Ed. en gallego y castellano. - Lugo, 1970. 32 pp., ilustr.

21-5047. Carballo, Luis Amado - Obras en prosa $e$ verso.-Castrelos, Vigo, 1970. 142 pp. (Col. Pombal, serie verde, 4).

21-5048. Leiras Pulpeiro, Manuel-Obra completa. Est. crítico de X. L. Franco Grande. - Galaxia, Vigo, 1970. 453 pp. 21-5049. Rolán, Feliciano - Obras poéticas. - Vigo, 1970. 141 pp.

21-5050. Alonso Montero, X. - Cantigas sociales.-Castrelos, Vigo, 1969. $48 \mathrm{pp}$. (O moucho, 10).

\section{LITERATURA ESPANOLA}

21-5051. Simón DíAz, José - Bibliografía de la literatura hispánica. T. 8: Siglos xvi y xvii (Cervantes-Coquela).-C.S.I.C., Madrid, 1970. xv + 804 pp.-V. núm. 20-5855. || $R y F, 183$ (1971), 660 (Hornedo) .

21-5052. Simón Díaz, José - Manual de bibliografía de la literatura española. 2: ed., aum., con adiciones 1962-64.G. Gili, Barcelona, 1966. 705 pp.-V. núm. 19-6029.

21-5053. Simón Díaz, José (ed.) -.-"Información bibliográfica. Literatura castellana". - RLit, 35 (1969), 131-201.V. núm. 20-5856.

21-5054. Foster, D. W., y V. RAMos Fostek - "Bibliografía anotada de revistas dé actualidad dentro del campo de la literatura y de interés para los hispanistas". - LT, 1970, núm. 67, 125-147.

21-5055. LuCA DE TENA, LucíA-Índices generales de la Biblioteca de Autores Españoles. (Tomos 72 a 225). - Atlas, Madrid, 1970. 361 pp. (BAE).

21-5056. Agulló y Cobo, M. - "Documentos sobre escritores [españoles] de los siglos xvi y xVII".-AIEM, 6 (1970), $161-252$.

21-5057. Gallego Morell, antonio-Sesenta escritores granadinos con sus partidas de bautismo. - Caja General de Ahorros, Granada, 1970. $121 \mathrm{pp}$.

21-5058. Veinticuatro diarios (Madrid, 1830-1900). Articulos y noticias de es- 
critores españoles. Por el Seminario de Bibliografía Hispánica de la Facultad de Filosofía y Letras de Madrid. T. I: $A \cdot C$; t. 2: D.J. - C.S.I.C., Madrid, 19681970. 629, 576 pp. \| ROcc, 25 (1969), 260-261 (Amorós); $\mathrm{BHi}, 73$ (1971), 207-209 (Botrel); Ins, 1970, núm. 289 (Campos); Recensiones, Maracaibo, 1967, núm. 6, 69-71 (Gómez Pérez).

21-5059. Yndurárn, F. - "Menéndez Pelayo, crítico literario". - CMod, 9-27.V. núm. 14-40880.

21-5060. ANDREIS, E. DE - "Recordando a un amigo: Juan Estelrich". - $\mathrm{CuH}$, 78 (1969), 655-670.

21-5061. BlEIBERG, G. - "Algunas revistas literarias hacia 1898". - Arb, 1968, núms. $30 / 6,465-480$.

21-5062. López Estrada, F. - "Recuerdo de don Francisco Rodríguez Marín".BRAE, 44 (1969) , 153-163.

21-5063. García Gómez, E. - "En el centenario del nacimiento de don Miguel Asín".-BRAE, 51 (1971), 403-412.

21-5064. Johnson, Laurence Samuel, JR. - The literary criticism of Amado Alonso and his principal disciples.-[Tesis, Columbia Univ., 1970].

21-5065. Estudios dedicados a James Homer Herriott. - Univ. of Wisconsin Press, Madison, 1966. 233 pp. $\| R P h$, 24 (1970-71), 147-155 (Deyermond); PhP, 12 (1969), 188-189 (Hodousek). 21-5066. Homage to John M. Hill. In memoriam. - Indiana University, Bloomington, 1968. 336 pp. \| BHS, 47 (1970) , 63-64 (Jones) ; HR, 39 (1971), 214-215 (McCready).

21-5067. Homenaje a Antonio RodriguezMoñino. - Alc, 1970, núm. 161. [Escriben D. Alonso, el Conde de Canilleros, E. Segura, D. de la Válgoma, A. de Figueroa, A. Pérez Gómez, A. López Martínez y G. Díaz-Plaja].

21-5068. Calllet-BoIs, J. - "Guillermo de Torre (1900-1971)". - Fil, 14 (1970), 245-247.

21-5069. ["Guillermo de Torre"]. - Ins, 1971, núm. 292. [Escriben J. L. Borges, R. Gullón, J. L. Cano, A. Amorós y C. Bravo-Villasante].

21-5070. Cruset, José - Guillermo DiazPlaja. - Madrid, 1970. 196 pp.

21-5071. Quién es quién en las letras españolas. - Instituto Nacional del Libro Español, Madrid, 1969. 445 pp., ilustr. 21-5072. Marichal, J. - "Criollos y peninsulares: una vieja cuestión docente". - Ins, 1970, núms. 284/5.

\section{Historia y crítica literaria}

21-5073. Díaz-PlajA, G. - "Sobre el concepto de sliteratura españolas".-HEOL, 29-30.

21-5074. BlecuA, J. M. - Atlas de literatura española.-Jover, Barcelona, 1971. 88 pp. (Col. Atlas).

21-5075. Río, ÁNGEL DEL - "Literatura española”--Enciclopedia práctica Jackson, 11: ed., México, 1970, t. 10.

21-5076. AMAdOR dE Los Ríos, José - Historia critica de la literatura española. -Georg Olms Verlag, Hildesheim-New York, 1970. 7 ts. [Reimpr. facs. de la ed. de Madrid, 1861-1875].

21-5077. Alborg, Juan LuIs-Historia de la literatura española. T. 1: Edad Media y Renacimiento. 2a ed., aum.-Gredos, Madrid, 1970. 1082 pp. - V. núm. 20-1783.

21-5078. Alborg, Juan Luis - Historia de la literatura española. T. 2: Época barroca. Reimpr. - Gredos, Madrid, 1970. 996 pp. - V. núm. 20-1783.

21-5079. DESCOLA, JEAN - Historia literaria de España. De Séneca a Garcia Lorca. Trad. de M. Carrión. - Gredos, Madrid, 1969. 406 pp. (Bibl. Univ. Gredos). - V. núm. 19-6064.

21-5080. Flores, ANGel (ed.) - La literatura de España. (Desde sus origenes hasta 1700). - Las Américas, New York, 1970. $636 \mathrm{pp}$.

21-5081. Clarke, Henry Butleer - Spanish literature: an elementary handbook.- Kennikat Press, Port Washington, N. Y., 1970. xii +269 pp. [Reimpr. facs. de la ed. de 1893].

2I-5082. Valverde, José María - Breve historia de la literatura española. Guadarrama, Madrid, 1970. $271 \mathrm{pp}$. (Punto omega).

21-5083. JOSIA, VINCENZo - España en los siglos. Sumario de historia de la literatura española. - Ed. Ciranna, Roma, 1970. 198 pp.

21-5084. Figueiredo, Fidelino de - Pirene. Introducción a la historia comparada de las literaturas portuguesa y española.Espasa-Calpe, Madrid, 1971. 201 pp. (Austral, 1448).

21-5085. GreEN, O. H. - "Imaginative authority in Spanish literature". PMLA, 84 (1969) , 209-216.

21-5086. Brancaforte, B. - "Benedetto Croce and the theory of popularism in Spanish literature". - HR, 38 (1970), 69-79. 
21-5087. WArd, Philip - Spanish literary appreciation. - Univ. of London Press, London, 1969. $143 \mathrm{pp}$.

21-5088. Porqueras-Mayo, A., y J. L. LAURENTI - "Notas para una bibliografía crítica del prólogo en la literatura española".-AION-R, 12 (1970), 91-101.

21-5089. Bellini, Giuseppe - La letteratura spagnola "comprometida". T. 1: Dalle origini al Rinascimento. - La Goliarca, Milano, [1969]. $152 \mathrm{pp}$.

21-5090. Márquez Villanueva, F. - "Sobre la occidentalidad cultural de España". - ROcc, 28 (1970), 54-81. [Sobre la obra de $O$. H. Green].

21-5091. Green, O. H. - "The medieval tradition: sic et non". - LMMS, 1-21.

21-5092. Alonso, Dámaso, y Carlos BousoÑo - Seis calas en la expresión literaria española. Prosa, poesia, teatro. 4 a ed. - Gredos, Madrid, 1970. 446 pp. (BRH, Estudios y ensayos, 3). - V. núm. 18-2429.

21-5093. CASTro, AMÉrico - Aspectos del vivir hispánico. - Alianza Editorial, Madrid, 1970. 176 pp., ilustr. (El libro de bolsillo, 252) . - V. núm. 5-5953.

21-5094. TORroba Bernaldo dE Quirós, Felipe - "El Cid" y "Don Quijote". La España de los caminos históricos y literarios. - Rivadeneyra, Madrid, 1970. 477 pp., 21 láms.

21-5095. MANcini, Guido - Dos estudios de literatura española: Introducción al "Palmerin de Oliva". Perfil de Leandro Fernández de Moratin. - Planeta, Barcelona, 1970. $340 \mathrm{pp}$.

21-5096. Lomax, D. W. - "The Lateran reforms and Spanish literature".-IR, I (1969) , 299-313.

21-5097. Green, O. H. - "Symbols of change". - LMMS, 93-112.

21-5098. Carey, Douglas MacArthur Asides and interiority in Spanish literature of the Golden Age.-[Tesis, Duke Univ., 1970].

21-5099. Blecua, J. M. - "Estructura de la crítica literaria en la Edad de Oro". -HEOL, 39-47.

21-5100. Defourneaux, M. - Daily life in Spain in the Golden Age. - London, 1970. 272 pp., ilustr.-V. núm. 19-164.

21-5101. LedDA, Giuseppina - Contributo allo studio della letteratura emblematica in Spagna (1549-1613). - Università, Pisa, 1970. 217 pp.

21-5102. Shepard, SANFord - El Pinciano y las teorias literarias del siglo de oro. 2a ed. - Gredos, Madrid, 1970. 227 pp.
(BRH, Estudios y ensayos, 58). - V. núm. 18-2420.

21-5103. GReEN, O. H. - "sFingen los poetas»: notes on the Spanish attitude toward pagan mythology". - LMMS, 113-123.-V. núm. 6-6967.

21-5104. Alonso, Dámaso - Dos españoles del Siglo de Oro. Reimp.-Gredos, Madrid, 1970. 257 pp. (BRH, Estudios $y$ ensayos, 45) . [Juan Hurtado de Mendoza y Fernández de Andrada]. - V. núm. 17-5344.

21-5105. Montesinos, José F. - Ensayos y estudios de literatura española. Ed., pról. y bibliografía de J. H. Silverman. -Revista de Occidente, Madrid, 1970. 303 pp. - V. núm. 14-40887.

21-5106. Castro y Calvo, José maría Estudios criticos de literatura española. -Barcelona, 1969. 239 pp.

21-5107. Cossío, José MARía de (ed.) Letras españolas. (Siglos xvi y xvii). Notas y estudios de critica literaria.-Madrid, 1970. 284 pp.

21-5108. ORíA, José A. - Temas de actualidad durable. - Academia Argentina de Letras, Buenos Aires, 1970. 375 pp. (Estudios académicos, 7). [Cervantes, J. Benavente, Stendhal en España, etc.]. I) RUNP, 22 (1970), 287-289 (Adam).

21-5109. BFLIC, OLDRICH - Análisis estructural de textos hispanos. Pról. de J. L. Varela. - Prensa Española, Madrid, 1969. 231 pp. [Novela picaresca, Coloquio de los perros, P. A. de Alarcón, Valle-Inclán, Bécquer y otros].

21-5110. Gallego Morell, antonio - En torno a Garcilaso y otros ensayos.-Guadarrama, Madrid, 1970. 202 pp. (Col. Punto omega). [Garcilaso, Góngora, Valera, Machado, Gironella y otros].

21-5111. Ciocchini, Héctor - Los trabajos de Anfión. - Inst. de Humanidades, Univ. Nacional del Sur, Bahía Blanca, 1969. 120 pp. (Cuadernos del Sur). II Carav, 1970, núm. 14, 173-175 (Tusón); $Z R P h, 85$ (1969), 576 (Wolf).

21-5112. Bonet, Carmelo M.-Pespuntes criticos.-Academia Argentina de Letras, Buenos Aires, 1969. 349 pp. [La Celestina, Juan de Valdés, Cervantes, Mateo Alemán, Quevedo, Gracián, Saavedra Fajardo, La Dorotea, Menéndez Pelayo, Tirano Banderas]. || BHS, 47 (1970), 351-353 (Bermejo Marcos).

21-5113. García Berrio, ANTonio - Sobre los origenes del barroco literario. España e Italia. - Murcia, 1967. $60 \mathrm{pp}$.

21-5114. Díaz-Plaja, Guillermo - El ba- 
rroco literario. - Columba, Buenos Aires, 1970. 117 pp. (Esquemas, 102).

21-5115. Collard, A. - Nueva poesia; conceptismo, culteranismo en la critica española (N. 20-5937). || Fil, 14 (1970). 215-220 (Romanos).

21-5116. Orozco Díaz, Emilio-Manierismo y barroco.-Anaya, Salamanca, 1970. 204 pp., ilustr. (Bibl. Anaya).

21-5117. Green, O. H. - " "Se acicalaron los auditorios»: an aspect of the Spanish literary baroque". - LMMS, 124-132.V. núm. 14-40901.

21-5118. Caso González, J., J. Arce, y J. A. Gaya Nuño - Los conceptos de rococó, neoclasicismo y prerromanticismo en la literatura española del siglo xviii. -Oviedo, 1970. 73 pp. \| RLit, 35 (1969), 122-125 (Aguilar Piñal) .

21-5119. Rossi, G. C. - Estudios sobre las letras en el siglo xviii (N. 20-1818). II QIA, 5 (1969-70), 6I-63 (Cirillo); RHM, 35 (1969), 150-151 (Laurenti); $R R, 61$ (1970), 228-229 (Sebold).

21-5120. Castañón Díaz, Jesús Angel El "Diario de los literatos de España". -[Tesis, Univ. de Madrid; resumen en RUM, 18 (1969), núm. 72, 38-39].

21-5121. BATLloRI, M. - La cultura hispano-italiana de los jesuitas expulsos (N. 20-1819) - || LFr, 23 (1970), 141-142 (Bourligueux); RHM, 35 (1969), 149 (Mades) .

21-5122. Rossi, G. C. - "Studi sul Settecento spagnolo". - NA, feb. 1970; 8 pp.

21-5123. KRÖMER, WOLFRAM - Zur Welt anschauung, $\ddot{A}$ sthetik und Poetik des Neoklassizismus und der Romantik in Spanien. - Aschendorff, Münster, 1968. 253 pp. $(S p F, 2 / 15)$. - V. núm. 20-1828. || $R F, 81$ (1969), 278-281 (Elvira-Hernández); $R R, 62$ (1971), 144-146 (Gramberg); BHS, 46 (1969), 254-255 (Ilie); $R J, 21 \quad(1970), 378-382$ (Mattauch); $B H i, 71$ (1969), 624-630 (Pageard).

21-5124. JURETSCHKe, H. - "E1 neoclasicismo y romanticismo en España: su visión del mundo, estética y poética".$A r b, 74$ (1969) , 5-20.

21-5125. Ruiz Lagos, Manuel - El deán López Cepero y la Ilustración romántica. (Ensayo critico y literario de un ilustre jerezano del siglo xix).-Centro de Estudios Históricos, Jerez de la Frontera, 1970. $157 \mathrm{pp}$. \|Ins, 1971, núm. 290 (Aguilar Piñal).

21-5126. Cardwell, R. A. - "The persistence of romantic thought in Spain".$M L R, 65$ (1970), 803-812.
21-5127. Bravo-Villasante, C. - Biografia $y$ literatura (N. 20-5921). I| SNo, 1970, núm. 2, 92-93 (Zuleta).

21-5128. SOTO, José LuIs - Un siglo de historia literaria (1862-1962), con apendice (1963-1969). - Santiago de Compostela, 1969. $750 \mathrm{pp}$. \| $A I A, 30$ (1970), 260-261 (Pombo).

21-5129. CARNIGer, RAMón - Entre la ciencia y la magia. Mariano Cubi. (En torno al siglo xix español). - Seix Barral, Barcelona, 1969. 467 pp.

21-5130. Davis, G. - "The Spanish debate over idealism and realism before the impact of Zola's naturalism". $-P M L A$, 84 (1969), 1649-1656.

21-5131. Lázaro Carreter, F. - "El realismo como concepto crítico-literario".CuH, 80 (1969) , 128-151.

21-5132. REY Álvarez, A. - "En torno al realismo como concepto crítico-literario". $-\mathrm{CuH}, 83(1970), 533-543$.

21-5133. Lazaro Carreter, F. - "Breves puntualizaciones sobre el artículo del señor Rey Álvarez". - CuH, 83 (1970), 543-549.

21-5134. Ynduráin, Francisco - Clásicos modernos. Estudios de critica literaria. -Gredos, Madrid, 1969. 239 pp. (Campo abierto, 24). |I Ins, 1970, núm. 282 (Amorós) ; PEsp, 1970, núm. 206 (Murciano) ; $H, 53$ (1970), 573-574 (Schwartz); $B H S, 48$ (1971), 75-76 (Shaw).

21-5135. Blanco Aguinaga, Carlos - Juventud del 98. - Siglo XXI, Madrid, 1970. 327 pp.

21-5136. GuLlón, R. - "La invención del 98". - INO, 7-19. - v. núm. 20-5978.

21-5137. Gullón, Ricardo - La invención del 98 y otros ensayos. - Gredos, Ma. drid, 1969. 199 pp. (Campo abierto, 23). || SNo, 1970, núm. 1, 97-98 (Frutos); $H, 53$ (1970), 574-575 (Ibarra); Ins, 1969, núm. 277 (Mainer); $H R, 39$ (1971), 334-337 (Peñuelas); BHS, 47 (1970), 176-177 (Shaw).

21-5138. Pérez de la Dehesa, Rafael El grupo "Germinal": una clave del 98. -Taurus, Madrid, 1970. 116 pp. (Cua. dernos Taurus, 99) .

21-5139. Torre, Gulllermo de - Del 98 al Barroco. - Gredos, Madrid, 1969. 451 pp. (Campo abierto, 22) - [Galdós, Pardo Bazán, Clarín, Valera, Espronceda, Lazarillo, Guzmán, Quevedo]. II ROcc, 30 (1970), 124-126 (Amorós); Ins, 1969, núm. 277 (Mainer); $H, 53$ (1970), 574 (Schweitzer); BHS, 47 (1970), 175-176 (Shaw). 
21-5140. MARChESI, S. - Scrittori spagnoli del 98. - Milano, 1967. 148 pp.

21-5141. SÁNchez BARbudo, A. - Estudios sobre Galdos, Unamuno y Machado (N. 20-5969) . \|EAg, 4 (1969), 647 (Armesto) .

21-5142. Gullón R. - “Rubén Darío, España y los españoles". - INO, 20-32. - V. núm. 20-1852.

21-5143. ONís, F. DE - "Sobre el concepto de modernismo". - Estudios criticos sobre el modernismo, ed. H. Castillo (Madrid, 1968), 35-42. - V. núm. 10-20475.

21-5144. Ferreres, R. - "Los límites del modernismo y la generación del 98".Estudios criticos sobre el modernismo, ed. H. Castillo (Madrid, 1968), 43-65.V. núm. 19-2,310.

21-5145. Castillo, H. (ed.) -- Estudios criticos sobre el modernismo. - Gredos, Madrid, 1968. 416 pp. || EAg, 4 (1969), 463 (Ballarosa); $R I B, 20$ (1970), 475477 (Jiménez) ; CuH, 81 (1970), 752754 (Navas-Ruiz).

21-5146. Salinas, P. - "El problema del modernismo en España".-Estudios criticos sobre el modernismo, ed. H. Castillo (Madrid, 1968), 23-34.

21-5147. HoRnedo, R. M. DE - "El modernismo en España”.- $R y F, 181$ (1970), 79-86.

21-5148. Díaz-PlajA, G. - Soliloquio y coloquio. Notas sobre lirica y teatro (N. 20-6006) - If EAg, 4 (1969), 230-231 (Fernández) .

21-5149. Sal.nas, Pedro - Literatura española, siglo $x x$. - Alianza Editorial, Madrid, 1970. 224 pp. (El libro de bolsillo, 239) . - V. núm. 5-6596.

21-5150. Salinas, Pedro - La responsabilidad del escritor. 3a ed. - Seix Barral, Barcelona, 1970. 269 pp. - V. núm. 17-5572.

21-5151. Paniagua, Domingo - Revistas culturales contemporáneas. T. 2: El ultraismo en España. - Punta Europa, Madrid, 1970. 127 pp.-V. núm. 18-5807. 21-5152. Quintela Ferreiro, L.-"El lenguaje en el pensamiento de Ortega y Gasset, Dámaso Alonso y Lcopold $\mathrm{S}$. Senghor". - [En] Lenguaje y filosofia (Madrid, 1969).

21-5153. Cernuda, Luis - Crítica, ensayos y evocaciones. Ed., pról. y notas de L. Maristany. - Seix Barral, Barcelona, 1970. 242 pp. (Bibl. breve, 297) . || Map, 1970, núm. 22, 229-230 (Blanco); $B A b r$, 45 (1971), 483-484 (Giplijauskaité); Eco, 22 (1970-71), 448-451 (Charry
Lara); ROcc, 33 (1971), 370-373 (de Luis); Íns, 1970, núm. 287 (Mainer) . 21-5154. GulLón, R. - "La generación de 1936".-INO, 162-177.-V. núm. 19-2327.

21-5155. Torrente Ballester, GonzaloLiteratura española contemporánea. $\mathbf{T}$. 1: Estudio critico. 4a ed. - Guadarrama, Madrid, 1969. 427 pp.-V. núm. 20-1875.

21-5156. SchwARTz, KESSEL - The meaning of existence in contemporary Hispanic literature.-Univ. of Miami Press, Coral Gables, 1969. 256 pp. (Hispanic-American studies, 23). \|BHS, 47 (1970), 372-373 (Brotherston); $H, 54$ (1971), 201 (Diaz) .

21-5157. Díaz-Plaja, Gulllermo - Los paraisos perdidos. - Seix Barral, Barcelona, 1970. 212 pp.

21-5158. Torre, Guillermo de - El fiel de la balanza. - Losada, Buenos Aires, 1970. 206 pp. - V. núm. 17-5203.

21-5159. CRuser, José - Valores de $m i$ tiempo. Notas de literatura española actual. - Taber, Barcelona, 1970. 297 pp., ilustr.

V. también núms. 3961, 3987.

\section{Colecciones de textos}

21-5160. Díaz Plaja, Guillermo ed.-Antologia mayor de la literatura española. T. 3: Barroco (siglo xvii). 2a ed., corr.Labor, Barcelona, 1970. - V. núm. 16-44096.

21-5161. díaz Plaja, Guillermo - Antologia mayor de la literatura española. T. 4: Neoclasicismo, romanticismo y realismo. (Siglos xviii y xix). 2a ed. corr.Labor, Barcelona, 1970. xlviii +1426 pp. - V. núm. 17-5217.

21-5162. Walsh, Thomas (ed.) - Hispanic anthology. - Kraus Reprint, New York, 1969. xii + 779 pp.

21-5163. Riquer, MARTín DE - Antologia de la literatura española (siglos $x-x x$ ). 3. ed. - Teide, Barcelona, 1970. - V. núm. 13-37091.

21-5164. Marin, Diego, \& Evelyn RugG (eds.) - Literatura española. Antologia selecta. - Holt, Rinehart \& Winston, New York, 1969. xi +606 pp.

21-5165. Geysse, A., et E. BAGUÉ (eds.) Los autores españoles. - Ed. Bordas, Paris, 1970. || $L N L, 1971$, núm. 197, 77 (Larrieu) .

21-5166. Kohler, Eugène - Antologia de la literatura española de la Edad Media $(1140-1500)$. 2e ed., rev. et corr.- 
Klincksieck, Paris, 1970. 490 pp. - V. núm. 19-6149.

21-5167. Rosseli, F. - "Nota sobre los Saggi [in verso e in prosa di letteratura spagnuola, 1863] de Pietro Monti". Proh, 1 (1970), núm. 3, 439-444.

21-5168. Rey Urbez, Guillermo (ed.) España: Poesia y teatro contemporáneos. 1? parte: 1936-1960. - Lasala, Zaragoza, 1969. 106 pp.

21-5169. Entrambasaguas, Joaquín de (ed.) - Prosa española moderna y contemporánea. Textos para ejercicios de lectura y comentario gramatical. 9a ed. -C.S.I.C., Madrid, 1968. 304 pp. - V. núm. 19-2339.

21-5170. Andrian, Gustave W. (ed.) Modern Spanish prose: An introductory reader, with a selection of poetry. 2nd ed.-Macmillan, New York, 1969. 240 pp.-V. núm. 19-2337.

21-5171. Lrorens, León IgNacio, y José A. Llorens (eds.) - Antologia del amor. 3. sel.-Acervo, Barcelona, 1970. 448 pp. (Antologias).

V. también núms. 5195-6.

\section{Temas literarios}

21-5172. RECKERT, S. - The matter of Britain and the praise of Spain (The history of a panegyric) (N. 20-1880). II BHS, 41 (1970), 349-344 (Davies); MAe, 38 (1969), 99 (Wilson).

21-5173. Cotrait, R. - "Pour une bibliographie de Fernán González". - BHi, 71 (1969), 591-603; 72 (1970), 346-359. [Una comedia anónima de 1797, una novela "perdida" de Blasco Ibáñez y otra redescubierta de Fernández y González].

21-5174. Navarro Porrata, Graciela Actitudes ante herejes, moros y judios según los documentos literarios castellanos. Siglos xii-xiv. - [Tesis, Univ. de Madrid; resumen en $R U M, 18$ (1969), núm. 72, 93-94].

21-5175. Colonge, C. - "Reflets littéraires de la question morisque entre la guerre des Alpujarras et l'expulsion (15711610) ".-BABL, 33 (1969-70), 137-243.

21-5176. ARIAS y ARIAS, Ricardo - El concepto del destino en la literatura medieval española. - [Tesis, New York Univ.; resumen en $D A, 29$ (1968-69), 893A].

21-5177. ARIAS y ARIAS, Ricardo - El concepto de destino en la literatura medie- val española. - Insula, Madrid, 1970. $299 \mathrm{pp}$.

21-5178. Sims, EDNA N. - El antifeminismo en la literatura española hasta 1560. -[Tesis, Catholic Univ., 1970].

21-5179. Rull Fernández, EnRIQue - El mito de Psique en la literatura española $y$ sus relaciones con la universal. $-[\mathrm{Te}-$ sis, Univ. de Madrid; resumen en $R U M$, 18 (1969), núm. 72, 47-48].

21-5180. Osuns, R. - "Nötas para la Fábula de Polifemo en España".-RNo, I1 (1969-70), 130-136.

21-5181. HershberG, D.-"Porcia in Golden Age literature: echoes of a classical theme". - N, 54 (1970), 22-30.

21-5182. McGrady, D. - "Some Spanish and Italian descendants of a medieval Greek tale (*The scholar and his imaginary egg»)". - RPh, 23 (1969-70), 303-305. [Melchor de Santa Cruz, Juan Valera].

21-5183. Llorens, W. - "La gloria en las obras de Erasmo, Gracián, Cervantes y Unamuno". - BAAC, 6 (1970) , 5-16.

21-5184. Rico, Francisco - El pequeño mundo del hombre. Varia fortuna de una idea en las letras españolas. - Castalia, Madrid, 1970. 307 pp.

21-5185. Green, O. H. - "Desengaño".LMMS, 141-170.

21-5186. Schulte, Hansgerd - "El desengaño": Wort und Thema in der spanischen Literatur des goldenen Zeitalters. - Wilhelm Fink, München, 1969. 236 pp. (Freiburger Schriften zur roman. Philologie, 17). - V. núm. 20-1887. II ZRPh, 85 (1969), 645-646 (Baldinger).

21-5187. BlecuA, J. M. - "Una vieja mención de Pedro de Urdemalas". - SPEO, 145-146.

21-5188. Sánchez Borbón Laires, AzaleaPedro Malasartes en las letras hispánicas. - [Tesis, Tulane Univ., 1970].

21-5189. García Berrio, ANtonio - $\mathbf{L a}$ figura de Don Juan en el postromanticismo español. - Murcia, 1966, 32 pp. 21-5190. Colao, A.-Descripciones de Cartagena en el siglo xvi. Hurtado, Cascales, Cervantes (N. 20-6041). \| HAHR, 50 (1970), 360-361 (Pike).

21-5191. Osuna, R. - "Un caso de continuidad literaria: la silva amoena". BICC, 24 (1969), 377-407.

21-5192. Taleb Hatamleh, Mohamed AвDo - El tema árabe en la literatura del siglo xix. - [Tesis, Univ, de Madrid; resumen en RUM, 18 (1969). núm. 72, 91-92]. 
21-5193. Rossı, G. C. - "Roma nella letteratura spagnola contemporanea". SRo, 18 (1970), 87-101.

21-5194. Challis, David - Clowns, harlequins and other disfrazados in $\mathrm{Ba}$ roja, Benavente and Gómez de la Serna. -[Tesis, Univ. of Pittsburgh, 1969].

21-5195. Gallego Morell, Antonio - Literatura de tema deportivo. (Estudio, antologia, ensayos). - Prensa Española, Madrid, 1969. 396 pp., ilustr.

21-5196. Gómez de LA Serna, Gaspar-El tren en la literatura española. Antologia.-Madrid, 1970. 179 pp.

21-5197. Montes, MARía José - La guerra española en la creación literaria. (Ensayo bibliográfico). - Madrid, 1970. 187 pp. (Cuadernos bibliográficos de la guerra de España, anejo 2).

V. también núms. 4546-57, 5195-6, 5217, 5255 .

\section{POESIA}

21-5198. Bousoño, Carlos - Teoria de la expresión poética. 5a ed., muy aum. Versión definitiva. - Gredos, Madrid, 1970. 2 ts.: 676 pp. (BRH, Estudios y ensayos, 7) . - V. núm. 20-1910. II Íns, 1971, núm. 293 (Jiménez) .

21-5199. ORdóñEz, CAsILdA - Siete asaltos poéticos. Belleza, amor y muerte en las imágenes de varios poetas españoles. Palencia, 1970. 109 pp., ilustr.

21-5200. Ferraté, JuAN - Dinámica de la poesia. Ensayos de explicación. - Seix Barral, Barcelona, 1968. 419 pp. (Bibl. breve, 281) . || BHS, 46 (1969), 272-273 (Harris); N, 55 (1971), 343 (Oostendorp) ; $B H i, 72$ (1970), 203-210 (Pellen).

21-5201. Baquero, G. - "La vida inventada, es decir, la poesía”. - PEsp, 1970, núm. 216.

21-5202. Camacho Guizado, Eduardo La elegia funeral en la poesia española. -Gredos, Madrid, 1969. 423 pp. (BRH, Estudios y ensayos, 130). $\| B A b r, 44$ (1970), 442 (Butler); Razón y Fábula, Bogotá, 1970, núm. 17, 70-79 (Lleras); BHi, 73 (1971) , 217 (Pérez); Ins, 1970, núm. 280 (Sánchez); BHS, 47 (1970), 247-249 (Wardropper) .

21-5203. Michä̈lis de VAsConcelos, C. -

"Este es calbi orabi".-CMD, 1, 448-462.

21-5204. Jiménez de BÁEz, YvetTe - L $i$ rica cortesana y popular actual.-El Colegio de México, México, 1969. 98 pp. (Jornadas, 64).

21-5205. SPONSIER, LUCY AGIN-The pre- sence of women in medieval Spanish poetry: The epic and lyric traditions.[Tesis, Yale Univ.; resumen en $D A I$, $31(1970-71), 129 A]$.

21-5206. Barcia, Pedro L. - El mester de clerecia. - Centro Editor de América Latina, Buenos Aires, 1967. 60 pp.

21-5207. Wilson, E. M., \& A. L.-F. Askins - "History of a refrain: De la dulce mi enemiga". - MLN, 85 (1970), 138-156.

21-5208. Sobejano, Gonzalo - El epiteto en la lirica española. 2* ed., rev.-Gredos, Madrid, 1970. 502 pp. (BRH, Estudios y ensayos, 28) .-V. núm. 11-28181.

21-5209. Biecua, José Manuer - Sobre el rigor poético en España. - Real Academia de Buenas Letras, Barcelona, 1969. 54 pp. [Discurso; contestación de J. M. Castro y Calvo].

21-5210. BlecuA, J. M. - "Imprenta y poesía en la Edad de Oro". - SPEO, 25-43. - V. núm. 19-2389.

21-5211. Crosbie, J. - "Amoral «a lo divino» poetry in the Golden Age". MLR, 66 (1971) , 599-607.

21-5212. Rosales, Luis - Poesía española del Siglo de Oro. - Salvat, Barcelona; Alianza Editorial, Madrid, 1970. $193 \mathrm{pp}$. 21-5213. Manzanares de Cirre, M. - “Textos aljamiados. Poesía religiosa morisca". - BHi, 72 (1970), 311-327.

21-5214. BrecUA, J. M. - “Corrientes poéticas en el siglo XVI”-SPEO, 11-24.

21-5215. Gallego Morell, A. - Estudios sobre poesia española del primer siglo de Oro. [Garcilaso, Herrera, Góngora, Soto de Rojas, Trillo y Figueroa]. Insula, Madrid, 1970. $270 \mathrm{pp}$.

21-5216. ERdMAN, E. G.-“Arboreal figures in the Golden Age sonnet",-PMLA, 84 (1969) , 587-595.

21-5217. Navarro González, Alberto-El tema de la Pasión de Cristo en los poetas de Salamanca. - Salamanca, 1969. $56 \mathrm{pp}$.

21-5218. Arce, J. - "Diversidad temática y lingüística en la lírica dieciochesca". $-C u C F, 1970$, núm. 22, 31-51.

21-5219. JIMÉNEz, VINCENT - La temática del romanticismo en la poesía de la "Biblioteca Aldeana". - [Tesis, Univ. of Missouri, 1970].

21-5220. QUinTANA, JosÉ - 96 poetas de las Islas Canarias en el siglo $x x$. Pról. de J. M. Cossío. - Bilbao, 1970. 600 pp. 21-5221. AUB, Max - Poesia española contemporánea.-Era, México, 1969. 239 pp. 21-5222. Cernuda, LuIs - Estudios sobre poesía española contemporánea. 2 ed. 
-Guadarrama, Madrid, 1970. 188 pp. (Punto omega, 82) . - V. núm. 13-35373. 21-5223. LechNer, J. - El compromiso en la poesia española del siglo $x x$. Parte primera: De la generación de 1898 a 1939. - Universitaire Pers, Leiden, 1968. 2 ts. [uno de estudio y otro de antología]: 292, 261 pp. || ins, 1969, núm. 271 (Cano) ; PSA, 54 (1969), 333-335 (González Corugedo) ; BHS, 47 (1970), 369-372 (Grant); CuH, 85 (1971), 597600 (Jareño) ; ROcc, 29 (1970), 245-249 (de Luis); H, 52 (1969), 963 (Young); Diál, 1969, núm. 26 (X).

21-5224. Serafini, Virgilio - Musa ispanica. - Ciranna, Roma, 1969. (Saggi di cultura moderna, 25) . [A. Machado, E. Carrere, R. Darío y M. A. Asturias]. \| $\mathrm{CuH}, 81$ (1970), 762 (Quiñones) .

21-5225. Morris, C. B. - A generation of Spanish poets, 1920-1936. - Cambridge Univ. Press, Cambridge, 1969. xi +301 pp. \| $M L N, 86$ (1971), 309-311 (González Muela); BHS, 48 (1971), 84-87 (Grant); $M L Q, \quad 31 \quad(1970), \quad 516-519$ (Gullón); $H, \quad 54 \quad$ (1971), 228-229 (Young) .

21-5226. Gullón, R. - "La «generación” poética de 1925". - INO, 126-161. V. núm. 10-23537.

21-5227. ZuletA, EMILIA DE - Cinco poetas españoles (Salinas, Guillèn, Lorca, Alberti, Cernuda).-Gredos, Madrid, 1971. 484 pp. (BRH, Estudios y ensayos, 156) . 21-5228. ConchA, V. G. DE LA - "Espadana. (Biografía de una revista de poesía y crítica)"--CuH, 79 (1969), 380-397. 21-5229. Videla, Gloria - El ultraismo. (Estudios sobre movimientos poéticos de vanguardia en España). 2a ed.-Gredos, Madrid, 1971. 246 pp. (BRH, Estudios $y$ ensayos, 69). - V. núm. 18-5962.

21-5230. IrIzarRy dE Rosa, Marta Ileana -El surrealismo en la poesia española. -[Tesis, Univ. of Connecticut, 1970-71].

21-5231. Milewski, Isabella S. - The image of man in Spanish surrealist poetry. (Alberti, Lorca, Cernuda, Aleixandre). - [Tesis, Northwestern Univ., 1971 .

21-5232. Cano, José Luis - La poesia de la generación del 27. - Guadarrama, Madrid, 1970. 290 pp. (Punto omega, 87). $B A B b r, 45$ (1971), 292 (Ciplijauskaité); $H, 54$ (1971), 598-599 (Gicovate); BHS, 48 (1971), 83-84 (Grant); ROcc, 31 (1970), 113-116 (de Luis); Ins, 1970, núm. 282 (Mainer).

21-5233. Ruiz-COPETE, JUAN DE DIOS -
Poetas de Sevilla. De la generación del 27 a los "taifas" del cincuenta y tantos. -Caja Provincial de Ahorros, Sevilla, 1971. 397 pp. || Ins, 1971, núm. 298 (X). 21-5234. Grande, FÉlix - Apunte sobre poesía española de postguerra.-Taurus, Madrid, 1970. 115 pp. (Cuadernos Taurus).

21-5235. Echeverri Mejía, O. - "Tres poetas españoles de la postguerra”. $U d A, 1970$, núm. 179, 595-599. [Morales, Otero, Hierro].

21-5236. Miró, E. - “La obra de tres poetas".-Ins, 1970, núm. 282. [Celaya, Otero, Caballero Bonald].

21-5237. Jiménez, J. O. - "Nueva poesía española (1960-1970)". - Íns, 1970, núm. 288.

21-5238. Caśtellet, José Marí - Nueve novisimos poetas españoles.-Seix Barral, Barcelona, 1970. 263 pp. (Libros de enlace, 4). || Uro, 1970, núms. 5/6, 138 139 (Barnatán); $B A b r, 45$ (1971), 483 (Fox) .

21-5239. Jiménez Martos, L. - “Informe sobre la poesía española en 1969". LEsp, 13 (1970), núm. 147.

21-5240. Conde, C. - "Poesía femenina española, viviente”. - Arb, 75 (1970), 73-84. - V. núm. 20-1981.

21-5241. Montes, Hugo - Poesia actual de Chile y España. 2a ed.-Ed. del $\mathrm{Pa}-$ cífico, Santiago de Chile, 1970. 174 pp. -V. núm. 18-2571.

21-5242. Rodríguez Martín, F. dE P. "La provincia como determinante poético". - ESeg, 22 (1970), núms. 65/6.

V. también núms. 3316, 4519-23, 4557.

\section{Métrica}

21-5243. BALbín, R. DE - "Estructura rítmica y expresión". - Proh, 1 (1970), 101-108.

21-5244. BAEHR, RudolF -- Manual de versificación española. - Gredos, Madrid, 1970. 444 pp. (BRH, Manuales 25).V. núm. 18-2581. || fns, 1970, núm. 288 (Amorós) ; PEsp, 1970, núm. 208 (Murciano) .

21-5245. García Gómez, E. - "Introducción a una métrica de Ben Quzmãn".AlAn, 33 (1968), 241-290.

21-5246. Maldonado de Guevara, F. “Knittelvers, verso nudoso" (N. 19-2426). || $A I L, 10$ (1970), 121-122 (Rastrilla). 21-5247. Macri, ORESTE - Ensayo de métrica sintagmática. (Ejemplos del "Libro 
de buen amor" y del "Laberinto" de Juan Mena). - Gredos, Madrid, 1969. 295 pp. (BRH, Estudios y ensayos, 122). II BHS, 47 (1970), 252-253 (Adams); BAbr, 44 (1970), 281 (Chambers); PhP, $13(1970), 114-116$ (Volek).

21-5248. Díkz Echarri, Emiliano - Teorias métricas del Siglo de Oro. Apuntes para la historia del verso español. C.S.I.C., Madrid, 1970. 355 pp. (RFE, anejo 47). [Reimpresión de la ed. de 1949]. - V. núm. 5-5602.

21-5249. BaLbín, R. DE - "Sobre la intensión versal en la estrofa castellana".RLiR, 34 (1970) , 107-112. [=HGS, 2, 107-112].

21-5250. NAvARRo, T.-“En torno al verso libre". - BICC, 25 (1970), 84-87.

21-5251. LĆ Pez Estrada, Francisco-Métrica española del siglo $x x$. - Gredos, Madrid, 1969. 226 pp. (BRH, Manuales, 24). $\| R O c c, 35$ (1971), 116-117 (Amorós); Ins, 1970, núm. 286 (Benito de Lucas); PEsp, 1970, núm. 208 (Murciano) .

V. tambièn núms. 4515-7, 4738, 5878 .

\section{Cancioneros y antologías}

21-5252. González Castresana, Carlos (ed.) - Antologia poética española.Acervo, Barcelona, 1971. 451 pp.

21-5253. Morales, María Luz (ed.)-Libro de oro de la poesia en lengua castellana. (España y América). - Juventud, Barcelona, 1970. 2 ts.: $1347 \mathrm{pp}$.

21-5254. Montagut, Jorge (comp.)-Las mejores poesias de amor españolas. Bruguera, Barcelona, 1970. 224 pp. (Libro amigo, 127).

21-5255. Roldán, Mariano (ed.)-Poesia hispánica del toro. Antologia del siglo xiii al xx. - Escelicer, Madrid, 1971. $364 \mathrm{pp}$.

21-5256. Turnbull, Eleanor L. (ed.) Ten centuries of Spanish poetry.-The Johns Hopkins Univ., Baltimore, 1969. $\mathrm{xv}+452$ pp.-V. núm. 11-25155.

21-5257. Marín, Diego (ed.) - Poesia española. Siglos $x y$ al $x x$. Antología comentada. Introd., notas y vocabulario (en inglés). Nueva ed., rev. y aum.Castalia, Valencia, 1971. 537 pp. (Estudios de $H f, 16)$. - V. núm. 17-5256.

21-5258. Alvar, Manuel (ed.) - Antigua poesia española lirica y narrativa (siglos xi-xiii).-Porrúa, México, 1970. xvii + 227 pp. (Sepan cuantos, 151).
21-5259. Díaz Plaja, Fernando - La historia de España contada por los poetas. -Barcelona, 1971. $456 \mathrm{pp}$.

21-5260. De Vries, H, - "Un conjunto estructural: el Poema triptico del nombre de Dios en la ley. (Tres nuevos poemas medievales, NRFH, 14, 1960)". -BRAE, 51 (1971), 305-325.

21-5261. Alonso, Dámaso, y José M. BlecUA-Antologia de la poesía española. T. 1: Lirica de tipo tradicional. 2a ed. 1\% reimp.-Gredos, Madrid, 1971. Ixxxvi +266 pp. (Antología hispánica, 3).V. núm. 19-2441.

21-5262. Green, O. H. - "Courtly love in the Spanish cancioneros". - LMMS, 40-92.

21-5263. Hoyos, EnRiQue - Temas y tópicos en el "Cancionero de Baena".[Tesis, Univ. of Kentucky; resumen en DAI, 31 (1970-71), 360A].

21-5264. Hetric, W. DeANe - The eulogy of the lady in the early poetry of the "Cancionero de Baena". - [Tesis, Case Western Reserve Univ., 1970-71].

21-5265. Bl.ANco Suárez, P. (ed.)-Poetas de los siglos xvi y xvii. 2a ed.-C.S.I.C., Madrid, 1970. 356 pp. (Bibl. literaria del estudiante, 19).

21-5266. WARdropper, Bruce W. (ed.) Spanish poetry of the Golden Age. Appleton-Century-Crofts, New York, 1971. xvi +353 pp.

21-5267. Marco, J.-“El "pliego sueltos". -ROcc, 34 (1971), 334-340.

21-5268. Rodríguez Moñino, Antonio Diccionario bibliográfico de pliegos sueltos poéticos del siglo xvi.-Madrid, 1970. 735 pp. || Uro, 1971, núm. 9 (Amorós); îns, 1970, núm. 287 (Maldonado) .

21-5269. Askins, A. L.-F. - "Hojas sueltas zaragozanas a la muerte de Felipe II".$B B M P, 46(1970), 109-125$. [Sonetos].

21-5270. Relaciones poéticas sobre las fiestas de toros y cañas. (Siglos xuii a xix). T. 1. - La fonte que mana y corre, Cieza, 1971. [128] pp. (El ayre de la almena, 29) .

21-5271. Simón Díaz, J. (ed.) - "Doce relaciones poéticas de sucesos ocurridos en Madrid y su provincia en los años 1649-1687".-AIEM, 6 (1970) , 531-598.

21-5272. Benítez Claros, Rafael (ed.) Verdores del Parnaso. - Inst. "Miguel de Cervantes", Madrid, 1969. xv + 321 pp. (Bibl. de antiguos libros hispanicos, $30)$.

21-5273. Gómez, César Armando (ed.) - 
Antologia de fábulas. - Labor, Barcelona, 1969. 919 pp. || ins, 1971, núm. 298 (X).

21-5274. Carnero, Guillermo (ed.) - $A n$ tología de los poetas prerrománticos españoles. - Barral, Barcelona, 1970. 275 pp. (Libros de enlace). || Ins, 1970, núm. 288 (Cano).

21-5275. García Arias, Pedro (ed.) $-A n$ tologia de poetas asturianos. T. 1: Poesia en bable. 2a ed. - Instituto de Estudios Asturianos, Oviedo, 1970. $191 \mathrm{pp}$. 21-5276. Quintana, José (ed.) -Antologia de la poesia canaria, siglo $x x$. - Comunicación Literaria de Autores, Las Palmas, 1970. II Azor, 1970, núm. 40 (J. J. M.) .

21-5277. González Martín, Jerónimo PaBLo (ed.) - Poesia hispánica, 1939-1969. Estudio y antologia.-Saturno, Barcelona, 1970. 378 pp. (El bardo).

21-5278. OnRubia de MendozA, José (ed.) -Sonetos del siglo xx.-Bruguera, Barcelona, 1970. 219 pp. [M. de Unamuno, A. Machado, J. R. Jiménez y G. Diego]. 21-5279. Luis, LeOpoldo DE (ed.) - Poesia española contemporánea. Antologia (1939-1964). Poesia religiosa. - Alfaguara, Madrid-Barcelona, 1969. 586 pp., ilustr. II Ins, 1970, núm. 281 (Miró); CuH, 79 (1969), 519-520 (Velázquez).

21-5280. Crusat, Paulina (ed.) - Voces que te han cantado. Selección de poesia religiosa española. - Barcelona, 1970. $295 \mathrm{pp}$.

21-5281. Champourcin, Ernestina de (ed.) -Dios en la poesia actual. Sel. de poemas españoles e hispanoamericanos. La Editorial Católica, Madrid, 1970. xvi +264 pp. (BAC de bolsillo, 19) .

21-5282. Puccini, Dario-Romancero della resistenza spagnola.-Laterza, Bari, 1970. 2 ts.: 587 pp.-V. núm. 16-44177.

21-5283. Puccini, Dario - Romancero de la resistencia española. - Era, México, 1969. 512 pp. - V. núm. 16-44177.

21-5284. Machado, Antonio, Juan Ramón Jiménez y Federico García lorca [Antología poética]. Pról, de R. Alberti. Selección de Aitana y R. Alberti. Nauta, Barcelona, 1970. 569 pp., ilustr. (Clásicos Nauta).

21-5285. Martín Pardo, Enrique (ed.) Nueva poesia española.-Escorpio, Madrid, 1970. || Uro, 1970, núms. 5/6, 138139 (Barnatán).

21-5286. Martínez Ruiz, Florencio (ed.) - La nueva poesia española. Antologia critica (segunda generación de postgue- rra, 1955-1970).-Biblioteca Nueva, Madrid, 1971. $321 \mathrm{pp}$.

21-5287. ZimmermanN, Marie-Claire (ed.) -Poesias españolas contemporáneas. Masson, Paris, 1970. 120 pp. (Regards sur le monde hispanique, 2). II Carav, 1970, núm. 15, 195-196 (Fonquerne).

21-5288. Ynduráin, Francisco (ed.) -Poesia española 1969. Antologia de La Magdalena. - Univ. "Menéndez Pelayo", Santander, 1969, 135 pp.

21-5289. Luis, Leopoldo DE (ed.) - Poesia social. Antologia, 1939-1968. 2a ed., rev. y aum. - Alfaguara, Madrid-Barcelona, 1969. 450 pp. (La palma de la mano). - V. núm. 19-2460. || Ins, 1970, núm. 281 (Miró); $\mathrm{CuH}, 79$ (1969), 521522 (Velázquez).

21-5290. Cuarenta poemas. Antología de la poesia comprometida española. Madrid, 1970. 102 pp.

V. también núms. $3316,5168$.

\section{A utores antiguos}

21-5291. SOLÁ-SOLÉ, J. M. - “Nuevas jarchas mozárabes". - KRQ, I7 (1970), 29-46.-V. núm. 20-6134.

21-5290. HuLty, G.-“La poésie mozarabe". $-T L L, 8 \quad(1970), 85-100$. || ZRPh, 87 (1971), 628 (Söll) .

21-5293. Armistead, S. G. - "On the interpretation of harğas 57,58 , and 59 ".$H R, 38$ (1970), 243-250.

21-5294. Marcos Marín F. - "Formas verbales en las jarchas de moaxajas árabes". - RUM, 19 (1970), núm. 74, 169 184.

21-5295. CaAmaño Martínez, J. M. "Berceo, como fuente de iconografía cristiana medieval". - Boletin del Seminario de Arte y Arqueologia, Valladolid, 34/5 (1969).

21-5296. Berceo, Gonzalo de - Milagros de Nuestra Señora. Nota de E. Gascó Contell. - Ateneo, México, 1970. 144 pp. (Obras inmortales).

21-5297. Ferreiro Alemparte, J. - "Las versiones latinas de la leyenda de San Ildefonso y su reflejo en Berceo". $B R A E, 50$ (1970), 233-276.

21-5298. Berceo, Gonzalo DE - Martirio de San Lorenzo. Ed. critica a cura di P. Tesauro. - Liguori, Napoli, 1971. 67 pp. || AO, 21 (1971), 401-403 (Uría). V. también núm. 4514 .

21-5299. MICHAEL, IAN - The treatment of classical material in the Libro de Alexandre. - University Press, Manches- 
ter, 1970. xvi + 323 pp. $\| S p, 46$ (1971), 527-530 (Keller); $H, 54$ (1971), 967 (Scholberg) .

21-5300. Stelzmann, R. A. - "A critical note on «leones. . lydones" in the Libro de Alexandre". - RNo, 11 (1969-70), 186-189.

21-5301. Casanova, Wilfredo - El Libro de Apolonio: cristianización de un tema clásico. - [Tesis, Yale Univ., 1970].

21-5302. Del Piero, R. A. - "Explicación literal de la Doctrina de la discriçión [de Pedro de Veragüe]". - PMLA, 85 (1968) , 1334-1346.

V. también núm. 6644 .

21-5303. Ruiz, JUAN - The book of good love. Tr. by R. Mignani and M. A. Di Cesare. - State Univ. of New York Press, Albany, 1970. 365 pp.

21-5304. Ayerbe, Reinaldo - Valoración de la critica en torno al "Libro de buen amor". - [Tesis, New York Univ., 1970].

21-5305. Dutron, B. - "«Buen amor»: Its meaning and uses in some medieval texts". - LBAS, 95-121.

21-5306. Adams, K. W. J. - "Juan Ruiz's manipulation of rhyme: Some linguistic and stylistic consequences". - LBAS, $1-28$.

21-5307. Adams, K.--"Rhythmic flexibility in the Libro de buen amor: A linguistic orientation, with particular reference to heptasyllabic hemistiches". - N, 54 (1970), 369-380.

21-5308. Michael, I. - "The function of the popular tale in the Libro de buen amor". - LBAS, 177-218.

21-5309. Chapman, J. A. - “Juan Ruiz's alearned sermon". - LBAS, 29-51.

21-5310. Deyermond, A. D.-"Some aspects of parody in the Libro de buen amor". $-L B A S, 53-78$.

21-5311. Green, O. H. - "On Juan Ruiz's parody of the canonical hours".-LMMS, 22-39.-V. núm. 13-37135.

21-5312. Piraster, Linda LANG - The vision of earthly love in the "Libro de buen amor" of Juan Ruiz, Archpriest of Hita. - [Tesis, Yale Univ., 1970].

21-5313. GybBON-MONYPeNNy, G. B. "Dixe la por te dar ensienpro: Juan Ruiz's adaptation of the Pamphilus".LBAS, 123-147.

21-5314. Murray, James C. - A study of some virtues and vices en the "Libro de buen amor".-[Tesis, Cornell Univ.; resumen en DAI, 31 (1970-71), 395A$396 \mathrm{~A}]$.

2I-5315. Hamilton, R. - "The digression on confession in the Libro de buen amor". - LBAS, 149-157.

21-5316. KINKADE, R. P. - "Intellectum tibi dabo...: the function of free will in the Libro de buen amor",-BHS, 47 (1970) , 296-315.

21-5317. Walker, R. M. - " "Con miedo de la muerte la miel non es sabrosan: Love, sin and death in the Libro de buen amor". - LBAS, 231-252.

21-5318. Dunn, P. N. - "De las figuras del arçipreste". - LBAS, 79-93.

21-5319. Molina, R. A. - "La copla cazurra del Arcipreste de Hita: hipótesis interpretativa". - Ins, 1970, núm. 288.

21-5320. TATE, R. B.-“Adventures in the *sierra"”. $-L B A S, 219-229$.

21-5321. Villegas, J. - "Hacia el sentido de las serranas en el Libro de buen amor".-BdFS, 21 (1970), 275-291.

21-5322. LAUReNCE, K. M. - "The battle between Don Carnal and Doña Cuaresma in the light of medieval tradition". -LBAS, 159-176.

21-5323. RrQuer, M. DE - "La Cuaresma del Arcipreste de Hita y el problema de la doble redacción del Libro de buen amor".-HRL, 511-521. || MA, 76 (1970), 527-528 (Joset).

V. también núm. 5247 .

21-5324. Johnson, William W. - The "Poema de José": a transcription and comparison of the extant manuscripts. -[Tesis, Univ. of Kentucky; resumen en $D A I, 31$ (1970-71), 391A].

21-5325. KLeNK, URsula - "La leyenda de Yúsuf", ein Aljamiadotext. Edition und Glossar. - [Tesis, Univ. de Göttingen, 1970].

21-5326. Vida de Santa María Egipcíaca. Est., vocabulario y ed. de M. Alvar.Madrid, 1970. xxiii + 329 pp., ilustr.

21-5327. Ferraresi, Alicia C. DE - "Sentido y unidad de Razón de amor".-Fil, 14 (1970), 1-48.

21-5328. CaravagGI, G. - "Villasandino et les derniers troubadours de Castille". $-H R L, 395-421$.

Mena: v. núm. 5247.

21-5329. Pérez, ARMando - La poética del Marqués de Santillana. - [Tesis, Michigan State Univ., 1970].

21-5330. Barreda-Tomás, P. M. - "Un análisis de la Comedieta de Ponça".BdFS, 21 (1970), 175-191.

21-5331. Cepeda Calzada, P. - "Evocación de Jorge Manrique". - Publicaciones de la Institución Tello de Meneses, $\mathrm{Pa}$ lencia, 1969, núm. 28, 25-43. 
21-5332. MichaËLIS DE VASCONCelos, C."Recuerde el alma dormida". - CMD, 1, 119-129.

21-5333. Mancini, G. - " "Schema per una lettura delle Coplas di Jorge Manrique". -Proh, 1 (1970), 7-18.

21-5334. Caravaca, F. - "La qasîda de Abu'l Baqa, el Rondeño, y algunas Coplas de Jorge Manrique". - BBMP, 46 (1970), 171-259.

21-5335. Cruz, I. Z. - "La muerte en dos grandes elegías españolas”.-EPR, 1970 , núm. 28, 129-146. [Jorge Manrique y García Lorca].

21-5336. Guglielmi, N. - "Los elementos satíricos en las Coplas de la panadera". -Fil, 14 (1970), 49-104.

21-5337. Cantera Burgos, Francisco-El poeta Ruy Sánchez Cota (Rodrigo Cota) y su familia de judios conversos. - Fac. de Filosofía y Letras, Madrid, 1970. 160 pp. If BIFG, 1970, 171-173 (I.G.R.); Sef, 30 (1970), 89-91 (Lacave).

21-5338. Cantera Burgos, F. - La familia judeo-conversa de los Cota de Toledo.Academia de Doctores, Madrid, 1969. 71 pp.

21-5339. Cantera Burgos, F. - "Maguaque, remoquete de Rodrigo Cota y otros detalles acerca de éste". - Sef, 30 (1970), 339-347.

21-5340. Rodríguez Pú́rtolas, J. - “Algunos aspectos interesantes en la lengua de fray fñigo de Mendoza, poeta castellano del siglo $\mathrm{xv}^{*}$. - CL(10), 4, 11491153.

21-5341. Rodríguez-Puértolas, J. - “Leyendas cristianas primitivas en las obras de fray fñigo de Mendoza". - $H R, 38$ (1970) , 368-385.

21-5342. Rodríguez-Puértolas, J. - “Montesino y Mendoza: un caso de "plagio» en el siglo $\mathrm{xv}$ ".-BHS, 47 (1970), 10-18. V. también núm. 5784 .

21-5343. Morreale, M. - "Las Epistolas $y$ evangelios de Ambrosio Montesino, eslabón entre los romanceamientos medievales y la lectura de la Biblia en el Siglo de Oro". - Studi in onore di $A$. Corsano (1970), 451-463.

V. también núm. 5342 .

21-5344, Anderson, J. A. - "Juan del Encina: An abuse of form?" - RNo, 10 (1968-69), 353-358.

21-5345. Michä̈LIS DE VASCONCELOS, C."Nótulas sobre cantares e vilhancicos peninsulares e a respeito de Juan del Enzina". - CMD, 1, 186-208.

21-5346. GreeN, O. H. - "Boscán and $I l$
Cortigiano: the Historia de Leandro $y$ Hero". - LMMS, 133-140.

21-5347. Saulnier, V. L. - "Saint-Gelais, l'Espagne, et Garcilaso". - BHR, 32 $(1970), 532-537$.

21-5348. Bertini, G. M. - “Originalità del Rinascimento spagnolo: Garcilaso de la Vega". - Studi di Lett. IspanoAmericana, Milano, 2 (1970?).

21-5349. BlecuA, J. M. - "Las Obras de Garcilaso con anotaciones de Fernando de Herrera". - SPEO, 100-105.-V. núm. 8-12896.

21-5350. Garcillaso de LA VEGA - Poesias castellanas completas. Ed., introd. y notas de E. L. Rivers. - Castalia, Madrid, 1969. 214 pp. (Clás. Castalia, 6) - || BHS, 47 (1970), 154-155 (Terry).

21-5351. Caldera, E.-"Il tema dell'ausencia in Garcilaso". - Studi di Lett. IspanoAmericana, Milano, 2 (1970?) .

21-5352. Cabañas, P. - "Garcilaso, Góngora y Arguijo. (Tres sonetos sobre el mismo tema) ". - BHS, 47 (1970), 210222.

21-5353. BlecuA, J. M. - "Garcilaso y Cervantes". - SPEO, 151-160.

21-5354. Granell, E. F. - "Paisaje superpuesto. (Transparencia del visto por Garcilaso, en el del Greco) ". $-L T, 1970$, núm. $68,11-54$.

21-5355. Araya, G. - "La fuente y los rios en Garcilaso". - EFil, 6 (1970).

V. también núms. $4587,5110,5215$.

21-5356. Iventosch, H. - "The Renaissance pastoral and the Golden Age: A translation of a sonnet of Giraldi Cinthio by Gutierre de Cetina". - $M L N$, $85(1970), 240-243$.

21-5357. Triwedi, M. D. - "A possible source for Cetina's Heron sonnet". $R N o, 10$ (1968-69), 359-361.

21-5358. Blecua, J. M. - "Poemas menores de Gutierre de Cetina”. - SPEO, 44-73. - V. núm. 9-15289.

V. también núm. 4783 .

Acuña: v. núm. 4783.

21-5359. SpIVAKovsky, Eva-Son of Alham bra: Diego Hurtado de Mendoza.-Univ. of Texas Press, Austin, 1970. 500 pp., ilustr.

21-5360. Blanco-González, B. - "La juventud de don Diego Hurtado de Mendoza y Pacheco".-CFM, 2 (1968), 7-21.

21-5361. Spivakovsky, E. - “[Hurtado de] Mendoza's renuntiation of fame as revealed in his Carta $V I$ from Alcántara". - H, 53 (1970), 220-224.

21-5362. Hurtado de Mendoza, Diego - 
Guerra de Granada. Ed., introd. y notas de B. Blanco-González. - Castalia, Madrid, 1970. 449 pp. (Clás. Castalia, 22). V. también núm. 6044 .

21-5363. Reynosa, Rodrico DE - Coplas. Introd., sel. y notas de M. I. Chamorro Fernández. - Taurus, Madrid, 1970. 143 pp. (Temas de España, 89).

Santa Teresa: v. núms. 6858-9.

Montemayor: v. núm. 4783.

21-5364. Blecua, J. M. - "El Discurso en eco, de Baltasar del Alcázar". SPEO, 74-80.

V. también núm. 4783 .

Luis de León: v. núms. 6888-92.

21-5365. Carrasco, A. - "Documentos de 1584 a 1595, relativos a don Luis Zapata de Chaves, existentes en el archivo municipal de Llerena". - REE, 25 (1969), 333-371.

21-5366. VARGas SAavedra, L.-"Don Alonso de Ercilla y $L a$ Araucana vistos por Gabriela Mistral". - Map, 1970, núm. 20, 5-22.

21-5367. Bulnes, Alfonso - Visión de Ercilla y otros ensayos. - Ed. Andrés Bello, Santiago de Chile, 1970. 204 pp. If Map, 1970, núm. 21, 276-277 (R.T.).

21-5368. Lira Urquieta, P. - "I.a grandeza de España y La Araucana".-BACh, 1970, núm. 58.

21-5369. Golc, C. - "Poética del exordio en La Araucana”. - Revista Chilena de Literatura, 1970, núm. 1, 5-22.

21-5370. BLECUA, J. M. - "De nuevo sobre los textos poéticos de Herrera".- $S P E O$, 110-144. - V. núm. 13-37150.

21-5371. Blecua, J. M. - "Dos nuevos sonetos de Herrera".-SPEO, 106-109.

V. también núms. 4783, 5215, 5349 .

21-5372. Blecua, J. M. - “¿Un nuevo poema de Pedro Laynez?"-SPEO, 89-95. -V. núm. 19-6348.

Juan de la Cruz: v. núms. 6869-72.

Cervantes: v. núms. 6166-70.

21-5373. Randolph, Julian Fitz - The life and works of Pedro Liñán de Riaza. - [Tesis, Univ. of California, Berkeley, $1970]$.

21-5374. Iglesias, A. - "A propósito del soneto anónimo A cristo crucificado y algunas apostillas sobre el misticismo literario español en sus vinculaciones con el smanierismos americano". $B A C h, 1970$, núm. 59.

Arguijo: v. núm. 5352.

21-5375. Blecua, J. M. - "El viaje de Góngora a Navarra". - SPEO, 209-210.

21-5376. Orozco DíAz, E. - "La última guerra literaria entre Lope y Góngora". -Atl, 8 (1970), 504-532.

21-5377. Camón Aznar, JosÉ - Góngora en la teoria de los estilos. - Madrid, 1962. 23 pp.

21-5378. Alonso, DÁmaso-Estudios y ensayos gongorinos. $3^{\mathrm{a}}$ ed. - Gredos, Madrid, 1970. 601 pp. (BRH, Estudios y ensayos, 18). - V. núm. 16-48143.

21-5379. GoldberG, R. - "Un modo de subsistencia del romancero nuevo. Romances de Góngora y de Lope de Vega en bailes del Siglo de Oro". - $B H i, 72$ (1970) , 56-95.

21-5380. Pellicer de Salas $\mathbf{Y}$ Tovar, JosÉ DE-Lecciones solemnes a las obras de don Luis de Góngora y Argote, Pindaro andaluz, principe de los poetas liricos de España. - Georg Olms Verlag, Hildesheim-New York, 1971. dliv + 448 pp. [Reimpr. de la ed, de Madrid, $1630]$.

21-5381. Góngora, Luss DE-Poesie e poemi. A cura di L. Fiorentino. - Ceschina, Milano, 1970.

21-5382. Góngora, Lưs DE - Poesias escogidas. Sel. y nota biográfica de E. Gascó Contell. - Ateneo, México, 1970. 102 pp. (Poesia universal).

21-5383. GóNGORA, LUIS DE - Sonetti funebri e altre composizioni. Trad. da Piero Chiara. Pref. di Jorge Guillén.-Torino, 1970. 83 pp. - V. núm. 17-1833. || CuN, 30 (1970), 218-219 (Bianchi).

21-5384. Orozco DíAz, E. - "Estructura manierista y estructura barroca en la poesía. Introducción y comentarios a unos sonetos de Góngora". - HEOL, 97-115.

21-5385. Góngora, Luis DE - Soledades. A cura di Cesco Vian. - La Goliardica, Milano, 1964. 98 pp.

21-5386. Orozco Díaz, Emilio - En torno a las "Soledades" de Góngora. Ensayos, estudios y edición de textos críticos de la época referentes al poema.-Granada, 1969. 327 pp.

21-5387. Blecua, J. M. - "Una nueva defensa e ilustración de la Soledad primera". - SPEO, 213-223. - V. núm. 20-6275.

21-5388. BleccuA, J. M. - "Cinco versillos que no son de Góngora". - SPEO, 211212. [Sino de Juan Navarro]. - V. núm. 11-26512.

21-5389. Gates, E. J. - "Góngora and Calderón". - $H F C B, 131-151$.

21-5390. Heydenreich, T. - "Neue Daten zur Biographie des aragonischen Gon- 
goristen Gaspar Buesso de Arnal". $R J, 21$ (1970), 294-327.

21-5391. PABst, W. - Luis de Góngora im Spiegel der deutschen Dichtung und Kritik (N. 20-2073) . \|RF, 82 (1970), 213-217 (Salomonski).

V. también núms. 4561, 4783, 5110, 5215, 5352.

Lope de Vega: v. núms. 5379, 5814-9.

21-5392. Ledesma, Alfonso DE - Conceptos espirituales y morales. Ed., introd. y notas de E. Juliá Martínez. - Inst. "Miguel de Cervantes", Madrid, 1969. 3 ts. (Bibl. de antiguos libros hispánicos, Serie $A, 27 / 29)$. II RLit, 35 (1969), 115116 (Cuevas García).

21-5393. Rodríguez MoÑINo, A.-"El $R a$ millete sacro, cancionero manuscrito con poesías de Alonso de Ledesma".ESeg, 21 (1969), 189-220.

Quevedo: v. núms. 6901-10.

21-5394. Orozco Díaz, E. - "La lírica amorosa de Carrillo Sotomayor a la luz de un poema inédito". - Cuadernos de Arte y Literatura, Granada, 1967, núm. 1 .

Soto de Rojas: v. núm. 5215 .

21-5395. Rico, F. - "Villamediana, octava de gloria”. - Ins, 1970, núm. 282.

21-5396. Villamediana, CONDE DE - Obras. Ed., introd. y notas de J. M. Rozas.Castalia, Madrid, 1969. 399 pp. (Clís. Castalia, 8). I Ins, 1970, núm. 282 (Rico) ; Fil, 14 (1970), 232-234 (Vassallo); $B H S, 47$ (1970), 167-170 (Wilson).

21-5397. Blecua, J. M. - "Poesías de Martín Miguel Navarro". - SPEO, 271-305.

21-5398. BlecuA, J. M. - "Poemas juveniles de Paravicino". - SPEO, 257-270.

21-5399. Filgueira Valverde, J. - “Trillo de Figueroa, $O h$ llanos de Andalucia”. -CuEG, 25 (1970), 135-142.

V. también núm. 5215 .

21-5400. Arbolanche, Jerónimo dE - Las Abidas. T. 1: Estudio y vocabulario. Ed., est., vocabulario y notas de F. González Ollé. - Madrid, 1970. xi + 340 pp.

\section{Autores modernos}

21-5401. Marín, Nicolás-Poesia y poetas del setecientos. Torrepalma y la Academia del Tripode. - Fac. de Filosofía y Letras de la Universidad, Granada, 1971. 267 pp. - V. núm. 19-2571.

21-5402. Ríos, FRANCISCO - An eighteenth century poetic sensibility: Fray Diego
Tadeo González. - [Tesis, Univ. of Oklahoma, 1971].

21-5403. Samaniego, Félrx MARíA-Fäbulas. Introd. de B. Losada.-Barcelona, 1970. 191 pp., ilustr.

21-5404. Allué y Morer, F. - "Un precursor de las formas modernistas: don Tomás de Iriarte".-PEsp, 1970, núm. 210.

21-5405. Demerson, Georges - Don Juan Meléndez Valdés y su tiempo (17541817). Trad. rev. por A. Guillén.-Taurus, Madrid, 1971. 2 ts.: 578, 495 pp.V. núm. 17-5408.

21-5406. Demerson, G. - "El poeta extremeño D. Juan Meléndez Valdés en la Real Sociedad Económica Matritense'. -REE, 25 (1969), 215-232.

21-5407. Arriaza, Juan Bautista - Emilia $y$ otros poemas. Ed. y pról. de J. Marco. -Llibres de Sinera, Barcelona, 1970. 119 pp. || Ins, 1970, núm. 286 (Mainer) . 21-5408. Aguilar Piñal, F. - "Joaquín Dominguez Bécquer y el retrato de Lista",-RFE, 52 (1969), 11-13.

21-5409. Montiex, I. - "Juan Nicasio Gallego, traductor de Ossián”. - RLit, 35 (1969), 57-77.

21-5410. ADAms, N. B. - “El primer romanticismo del Duque de Rivas". BACórd, 1965-67, núm. 87.

21-5411. RuIz Lagos, M. - "Método y diatriba política en la estructura dramática del Duque de Rivas". - HEOL, 225-241.

21-5412. Rivas, DuQue DE - Don Alvaro o la fuerza del sino. - J. Pérez del Hoyo, Madrid, 1970. $156 \mathrm{pp}$.

21-5413. MuÑoz, J. A. - "Biografía y crítica de D. José Espronceda". - $R E E, 26$ (1970), 299-340.

21-5414. Espronceda, José DE - Poésies lyriques et fragments épiques. Ed. et critique par R. Marrast. - Paris, 1969. 497 pp.

21-5415. EsProncedA, José DE - Poesías liricas y fragmentos épicos. $\mathbf{E d}$. de $\mathbf{R}$. Marrast. - Castalia, Madrid, 1970. 319 pp. (Clás. Castalia, 20) .

21-5416. EsProncFDA, José DE - El estudiante de Salamanca. El diablo mundo. -J. Pérez del Hoyo, Madrid, 1970. $201 \mathrm{pp}$.

21-5417. Hutman, N. L. - "Dos círculos en la niebla: $E l$ estudiante de Salamanca y El diablo mundo".-PSA, 59 (1970), 5-29.

21-5418. VASARI, STEPHEN - Interpretación temática y simbólica de "El diablo 
mundo" de Espronceda. - [Tesis, Univ. of California, Los Angeles, 1970].

V. también núms. 5199, 5475 .

21-5419. Pastor Díaz, Nicomedes - Obras completas. Ed. J. M. Castro y Calvo. T. 3. - Atlas, Madrid, 1970. (BAE, 24l) . 21-5420. PAstor díaz, Nicomedes - Obras. Est. prel. y ed. de J. M. Castro y Calvo. -Atlas, Madrid, 1969. 315 pp. (BAE).

21-5421. Ruiz Lagos, M. - "El maestro

Rodriguez Zapata en sus afinidades becquerianas. Apuntes sobre su magisterio estético en G. A. Bécquer".-RFE, $52(1969), 425-475$.

21-5422. Basalisco, L.-"Debiti di Enrique Gil y Carrasco (1815-1846) verso il Manzoni". - QIA, 5 (1970), 103-106.

21-5423. Martínez Fernández, J-- “Dudas y polémicas en torno a Campoamor".$B I E A, 24 \quad(1970), 387-409$.

21-5424. Diez Taboada, J. M. - "Bibliografía sobre G. A. Bécquer y su obra”. -RFE, 52 (1969), 651-695.

21-5425. PÉrez Rioja, J. A. - "Bibliografía becqueriana”. - MuH, 1970, núm. 272.

21-5426. Сhatham, G. R.-“'Bécquer studies in the United States. A tentative, annotated bibliography".-REH, 4 (1970), 319-354.

21-5427. Rodríguez Padrón, J. - “A modo de homenaje". - CuH, 83 (1970), 335340 .

21-5428. Homenaje a Gustavo Adolfo Bécquer. - Alto Duero, Soria, 1970, núm. 17; $57 \mathrm{pp}$.

21-5429. [Homenaje a Bécquer]. - MuH, 1970, núm. 272. [Escriben R. Azuar, G. Baquero, C. Bravo-Villasante, J. A. Cabezas, C. Conde, J. de Entrambasaguas, D. Gamallo Fierros, E. Laorden Miracle, L. López Anglada, J. G. Manrique de Lara, G. Marañón Moya, A. Marqueríe, R. Montesinos, A. Paso, J. M. Pemán, M. Pérez Ferrero, A. Pérez-Rioja, F. C. Sainz de Robles y M. Sánchez de Palacios].

21-5430. "Homenaje a Gustavo Adolfo Bécquer”. - BRAE, 50 (1970), 431-470. [Escriben L. Rosales, V. Aleixandre, G. Diego, J. M. de Cossío y J. M. Pemán]. 21-5431. Bécquer y Soria. Homenaje en el primer centenario de su muerte. C.S.I.C., Soria, 1970. 144 pp., ilustr.

21-5432. AguAdo, L.-"Bécquer, cien años después". - Gaceta Ilustrada, Madrid, 1970, núm. 712 .

21-5433. Burbano, J. I. - "Gustavo Adolfo Bécquer y la conmemoración del primer centenario de su muerte".-Memorias de la Academia Ecuatoriana, 1970, núm. 28.

21-5434. Martín, D. - "Un simposio becqueriano en Canadá”--íns, 1970, núm. 289.

21-5435. Barbachano, Carlos J.-Bécquer. -Epesa, Madrid, 1970. 208 pp. (Grandes escritores contemporáneos, 16). II PEsp, 1970, núm. 216 (Pedemonte).

21-5436. Grupo CoAyBAy - Nuestro Gustavo Adolfo Bécquer. - Eds. Universal, Miami, 1970. 16 pp.

21-5437. Cossío, J. M. DE - "En torno a Bécquer".-BRAE, 50 (1970), 451-462.

21-5438. Sáenz García, C. - "Miscelánea becqueriana". - [En] Bécquer y Soria (Soria, 1970), 131-140.

21-5439. García-Viñó, Manuel - Vida $y$ obra de Bécquer. - Editora Nacional, Madrid, 1969. 28 pp. (Temas españoles, 504) .

21-5440. Montoro, S. - "Antecedentes familiares de Bécquer".-RFE, 52 (1969), $1-9$.

21-5441. Díaz-Plaja, Gulllermo, y XaVIER DE SALAS - Significación y permanencia de Gustavo Adolfo Bécquer $y$ Valeriano Bécquer. - Instituto de España, Madrid, 1970. $32 \mathrm{pp}$.

21-5442. Pardo Canalís, E. - "En el centenario de Valeriano y Gustavo Adolfo Bécquer". - RIEs, 28 (1970), 71-79.

21-5443. Tudela, J.-“Valeriano Bécquer". - [En] Bécquer y Soria (Soria, 1970), 111-130.

21-5444. Caravaca, F. - "Sobre el origen de los Bécquer. ¿Por qué Gustavo Adolfo?" - $L T, 1970$, núm. 67, 33-62.

21-5445. VÁlgoma, D. DE LA - "El linaje de Bécquer en España”. - Hidalguia, Madrid, 1970, 465-480.

21-5446. Lorenzo Rivero, L. - "La orfandad de Bécquer como explicación de su actitud en la vida".- $-\mathrm{CuH}, 83$ (1970), $421-435$.

21-5447. BoRDEJÉ, F. - "Gustavo Adolfo Bécquer y el Somontano del Moncayo". - [En] Bécquer y Soria (Soria, 1970). $55-72$.

21-5448. GONZÁlez Y Gómez, SimóN-Bécquer, Veruela y el Somontano del Moncayo. - Caja de Ahorros, Zaragoza, 1970. 198 pp.

21-5449. Carpintero, H. - "Geografía literaria soriana de Gustavo Adolfo Bécquer'.-LT, 1970, núm. 69, 47-67; [y en] Bécquer y Soria (Soria, 1970), 33-52.

21-5450. Aparicio, T. - "Bécquer, Soria y 
Veruela". - $[\mathrm{en}]$ Bécquer y Soria (Soria, 1970), 75-88.

21-5451. Pérez-Rioja, J. A. - "Los Bécquer en Soria y Soria en la vida y la obra de los Bécquer". - [En] Bécquer y Soria (Soria, 1970), 11-30.

21-5452. Corella Estella, Faustino- $A n$ danzas de Bécquer en Navarra. - Imp. La Acción Social, Pamplona, 1960. 22 pp.

21-5453. Benítez, R. A. - "Bécquer y la política de su tiempo".-EFil, 5 (1969), 128-147.

21-5454. Montesinos, R. - "Julia Cabrera, la novia sevillana de Bécquer". - $E L$, 1970, núm. 446.

21-5455. Montesinos, R. - "Adiós a Elisa Guillén”. - İns, 1970, núm. 289.

21-5456. BaLbín, R. DE - "Sobre la creación poética becqueriana". - RFE, 52 (1969) , 217-225.

21-5457. Balbín lucas, R. DE - Poética becqueriana (N. 21-2023). \| Atl, 8 (1970), 337-341 (Roldán).

21-5458. Jones, M. E. W. - "The rôle of memory and the senses in Bécquer's poetic theory". $-R E H, 4$ (1970), 281-291.

21-5459. Tamayo, J. A. - "Contribución al estudio de la estilística de G. A. Bécquer".-RFE, 52 (1969), 15-51.

21-5460. Casalduero, J. - "La naturaleza de Bécquer". - REH, 4 (1970), 201-212.

21-5461. Montes Huldobro, M. - "Gustavo Adolfo Bécquer: el exilio poético como determinante del estilo". - REH, 4 (1970), 261-279.

21-5462. Pedemonte, H. E. - "Los mecanismos de expresión en Gustavo Adolfo Bécquer". - PEsp, 1970, núm. 216.

21-5463. GIL, I.-M. - “"Dualismo» y estructuras bimembres en la poesía de Gustavo Adolfo Bécquer". - $\mathrm{CuH}, 83$ (1970) , 350-359.

21-5464. Vaquero, G. - "La vida inventada, es decir, la poesía". - PEsp, 1970, núm. 216. [Bécquer].

21-5465. Vivanco, L. F. - "Música celestial de Gustavo Adolfo Bécquer".- $\mathrm{CuH}$, 83 (1970), 449-471.

21-5466. Galán, J. - "Bécquer: su sentir humano y religioso". - CuH, 83 (1970), 436-448.

21-5467. García-Viñó, M. - "La religión de Bécquer". - RyF, 181 (1970), 61-68.

21-5468. Cortina, R. J. - "Bécquer y la poesía mística". - REH, 4 (1970), 223228.

21-5469. GIL, I.-M. - "Los espacios misteriosos de Gustavo Adolfo Bécquer".RFE, 52 (1969) , 119-129.
21-5470. Manrique de Lara, J. G.--“Bécquer, poeta de la ensoñación". - $\mathrm{CuH}$, 83 (1970), 373-392.

21-5471. Geada-Prulletti, R. - "Lo inasequible como objeto estético en Gustavo A. Bécquer".-CuH, 83 (1970), 341-347. 21-5472. Dízz Taboada, J. M. - "Dolor eterno. Historia posromántica de un tema literario". - IR, 2 (1970), 1-14. [Bécquer].

21-5473. Huerta, E. - "E1 simbolismo de la mano en Bécquer". - EFil, 6 (1970), 7-95.

21-5474. Pageard, R. - "Gustavo Adolfo Bécquer et le romantisme français”. RFE, 52 (1969), 477-524.

21-5475. Caballero, J. A. - "El amor en Bécquer y en Espronceda",-PEsp, 1970, núm. 216.

21-5476. Cano, J. L. - "La fusión con la naturaleza en Bécquer y Aleixandre".RFE, 52 (1969), 641-649.

21-5477. Sainz de Medrano, L.- "Bécquer en la Ilustración de Madrid". - REH, 4 (1970) , 293-302.

21-5478. Bécquer, Gustavo Adolfo-Obras completas. Pról. de Joaquín y Serafín Álvarez Quintero. - Aguilar, Madrid, 1969. 1268 pp. (Col. Joya). - V. núm. 19-6426.

21-5479. Bécquer, Gustavo Adolfo-Obras completas. Ed. y est. prel. de A. Cardona de Gibert y J. Alcina Franch. Bruguera, Barcelona, 1970. 894 pp. (Libro clásico, 80) .

21-5480. BÉcquer, Gustavo Adolfo-Obras escogidas. Rimas, leyendas, cuentos, cartas. 7a ed. - Ebro, Zaragoza, 1970. 329 pp.

21-5481. Bécquer, Gustavo Adolfo-Poética, narrativa, papeles personales. Introd. y sel. de J. M. Guelbenzu.-Alianza Editorial, Madrid, 1970. 233 pp. (El libro de bolsillo, 284) .

21-5482. Bécquer, Gustavo Adolfo-Antologia. Pról. de H. Carpintero.-Salvat, Madrid, 1970. 172 pp. || PEsp, 1970, núm. 216 (Murciano).

21-5483. Bécquer, Gustavo Adolfo-Antologia poética. Sel. y pról. de J. Benito de Lucas. Trad. al árabe de Kamal Fawzi al Sarbi. - Instituto Hispanoárabe, Madrid, 1966.

21-5484. Bécquer, Gustavo Adolfo-Rimas. Est. prel. de J. García Morejón.Instituto de Cultura Hispánica, São Paulo, 1968. lii +69 pp. (Textos literários, 15).

21-5485. Bécquer, Gustavo Adolfo-Ri- 
mas y leyendas.-Aguilar, Madrid, 1970. 380 pp. - V. núm. 19-6434.

21-5486. Bécquer, Gustavo Adolfo-Rimas y leyendas. - Difusión, Buenos Aires, $1970,320 \mathrm{pp}$. (Bibl. clásica, 3).

21-5487. BécQuer, Gustavo Adolfo-Rimas, leyendas y cartas. Introd. y notas de L. Jiménez Martos.-Magisterio Español, Madrid, 1970. $250 \mathrm{pp}$. (Novelas y cuentos, 65) . || PEsp, 1970, núm. 216 (Murciano).

21-5488. BÉCQUER, G. A. - Rimas y prosas, ed. R. de Balbín y A. Roldán (N. 206335). $\| A t l, 8$ (1970), 341-343 (Nieto). 21-5489. Díez TABOADA, J. M. - La mujer ideal. Aspectos y fuentes de las "Rimas" de Gustavo Adolfo Bécquer (N. 192626). \| BFE, 1970, núms. 34/5, 83-88 (Rull). - V. núm. 20-6336.

21-5490. Entrambasacuas, J. de - "La posible discriminación erótica en las $R i$ mas de Bécquer". - RFE, 52 (1969), 131-185.

21-5491. Ribbans, G. - "Objetividad del análisis del desengaño en las Rimas".RFE, 52 (1969), 67-81.

21-5492. ZaRdoya, C. - "E1 alma becqueriana. (A través de las Rimas)".-REH, $4 \quad(1970), 303-318$.

2I-5493. Penna, M. - "Las Rimas de Bécquer y la poesía popular”. - RFE, 52 (1969), 187-215.

21-5494. Zardoya, C. - "Espacialidad interior de las Rimas becquerianas". RFE, 52 (1969) , 83-118.

21-5495. Forastieri Braschi, E. - "Las Rimas de Bécquer a través de sus imágenes". - SNo, 1970, núm. 1, 59-68.

21-5496. Díez Taboada, J. M. - " "Oro" en las Rimas de Gustavo Adolfo Bécquer”. - REH, 4 (1970), 229-245.

21-5497. Gutiérrez, J. - "Aspectos religiosos en las Rimas de Bécquer".- $\mathrm{CuH}$, $83(1970), 360-372$.

21-5498. Entrambasaguas, J. de - "Génesis y estructura poética de una leyenda $\mathrm{y}$ tres rimas de Bécquer". - $R E H, 4$ (1970) , 247-260.

21-5499. Torres Martínez, J. C. DE-"La Rima IX de Gustavo Adolfo Bécquer". -RFE, 52 (1969) , 227-243.

21-5500. Díez Taboada, J. M. - "Nueva versión autógrafa de la Rima XVI".RFE, 52 (1969) , 245-259.

21-5501. Balbín Lucas, R. DE - "La Rima XVII". - REH, 4 (1970), 181-186.

21-5502. Montesinos, R. - "Josefa Espín y la Rima XXVII".-MuH, 1970, núm. 272.
21-5503. Fresno, L, - "Una rima de Bécquer. La Rima XXXVII". - [En] Critica literaria (León, 1969), 153-161.

21-5504. Roldán, A. - "Anotaciones a la Rima LXXII”. - RFE, 52 (1969), 261277.

21-5505. Fernández Alonso, M. del R."Interpretación de la Rima LXXIV".$\mathrm{CuH}, 83$ (1970) , 404-418.

21-5506. Rozas, J. M. - "La fuga de la Rima LXXV". - RFE, 52 (1969), 279304.

21-5507. Rull, E.-"Pensamientos de Bécquer y Nocturnos de Dario". - RFE, 52 (1969), 563-579.

21-5508. Casalduero, J. - "El teatro de Bécquer". - RFE, 52 (1969), 393-408. 21-5509. VAReLA, J. L. - "Mundo onírico y transfiguración en la prosa de Bécquer". - RFE, 52 (1969) , 305-334; [y en su libro] La transfiguración literaria (Madrid, 1970), 147-194.

21-5510. BÉcquer, G. A. - Leyendas y narraciones. Pról. de J. García Morales.Libra, Madrid, 1970. 209 pp. || PEsp, 1970, núm. 216 (Murciano) .

21-5511. García-Viñó, M. - “Las leyendas de Bécquer".-NT, 1970, núm. 198, 5-17.

21-5512. García-Viñó, M. - "Los escenarios de las leyendas becquerianas". RFE, 52 (1969) , 335-346.

21-5513. Cubero Sanz, M. - "La mujer en las leyendas de Bécquer". - RFE, 52 (1969), 347-370.

21-5514. Herrero Salgado, F. - "Las leyendas sorianas de Gustavo Adolfo Bécquer: Aspectos temático y estilístico".Bécquer y Soria (Soria, 1970), 91-107. 21-5515. Benítez, R. - "La elaboración literaria de El caudillo de las manos rojas". - RFE, 52 (1969), 371-392.

21-5516. Bécquer, Gustavo Adolfo-Cartas literarias desde mi celda. Est. y ed. de J. Montero Padilla. - Anaya, Salamanca, 1970. 153 pp. (Bibl. Anaya, 7). 21-5517. SÁnchez Reboredo, J. - "Romanticismo conservador en las Cartas desde mi celda". - CuH, 83 (1970), 394-403.

21-5518. Martínez Rulz, J. - "Bécquer y el costumbrismo español". - RDTP, 26 (1970), 65-91.

21-5519. BENítez, R, A. - "Bécquer, prefolklorista". - REH, 4 (1970), 187-199.

21-5520. Mancini, G. - "Popolarismo e socialità in Bécquer".-RFE, 52 (1969), 53-66.

21-5521. Escobar, J. - "Bécquer, viajero sensible”. - MuH, 1970, núm. 264. 
21-5522. Marañón Moya, G. - "Bécquer, periodista". - RFE, 52 (1969), 409.413. -V. núm. 12-31425.

21-5523. Benito, V. - "El "pozo árabe de Toledo», de G. A. Bécquer”. - RFE, 52 (1969), 415-424.

21-5524. Gaya Nuño, J. A. - "Bécquer ante el arte".-RIEs, 28 (1970), 181-188.

21-5525. García-Viñó, Manuel - Vigencia de Bécquer. - Univ. of Toronto, Toronto, 1970.

21-5526. Brown, R. - "La fama póstuma de Bécquer: nuevos datos". - RFE, 52 (1969) , 525-535.

21-5527. Caravaca, F. - "Notas exegéticocríticas sobre traducciones, en doce lenguas, de cuarenta y cuatro rimas, y en particular veintiuna de la VII (13)". -RFE, 52 (1969), 581-639.

21-5528. DuQue, A. - "La sombra de Bécquer”. - Ins, 1970, núm. 289.

21-5529. GRANDE, F. - "Donde no habita el olvido". - CuH, 83 (1970) , 472-474.

21-5530. Rosales, L. - "Bécquer en su diaria resurrección”. - CuH, 83 (1970), 317-334.

21-5531. Entrambasaguas, J. DE-“El mensaje de Bécquer en canciones de hoy”. -RLit, 35 (1969), 79-91.

21-5532. MaKeever, Sister Mary Terence -Echoes of Bécquer in Unamuno, Machado and Juan Ramón Jiménez.-[Tesis, Univ. of New York; resumen en $D A$, $29 \quad(1968-69), 268 \mathrm{~A}]$.

21-5533. Molina, A. F. - "Bécquer y Luis Cernuda". - EPR, 1970, núm. 31, 103107; PEsp, 1970, núm. 216.

21-5534. Guelbenzu, J. M. - "Ideas sobre un Bécquer moderno”.-CuH, 83 (1970), 307-316.

21-5535. Ríos Ruiz, M. - "El Bécquer de 1936”. - PEsp, 1970, núm. 216.

21-5536. "Bécquer, hoy. Encuesta a la joven poesía”. - Ins, 1970, núm. 289.

21-5537. Clinkscales, Orline - Bécquer in Mexico, Central America, and the Caribbean countries. - Ed. Hispanonorteamericana. Madrid, 1970. $216 \mathrm{pp}$. (Libros Hispanort).-V. núm. 13-35364.

21-5538. Clinkscales, O. - "Becquerian poets in the Dominican Republic". REH, 4 (1970), 213-222.

21-5539. Esquer Torres, R. - "Juan Zorrilla de San Martín y Gustavo Adolfo Bécquer". - RFE, 52 (1969) , 537-561. V. también núms. 4587, 5109, 5421, 5565. Rosalía: v. núms. 4587, 5038-40.

21-5540. Pappas, Luke Theodore - Breve biografia de Salvador Rueda con sus cartas inéditas dirigidas a su primo.The Citadel, Charleston, S. C., 1970. 63 pp.

Unamuno: v. núms. 5278, 5532, 6987-9.

21-5541. Fernández-Shaw, Guillermo Un poeta de transición. Vida y obra de Carlos Fernández Shaw (1865-1911). Gredos, Madrid, 1969. x +329 pp. (BRH, Estudios y ensayos, 129) \|BAbr, $44(1970), 282-283$ (Durán); $H, 54$ (1971), 394 (Galbis) ; BHi, 72 (1970), 234-235 (Ricard).

Valle-Inclán: v. núms. 6410-1.

21-5542. Gascó Contell, E. - "Gabriel y Galán, poeta y hombre cabal”. - LEsp, $13(1970)$, núm. 148.

21-5543. López Bustos, C. - “Clima, paisaje y naturaleza en la obra de Gabriel y Galán". - REE, 26 (1970) , 383-397.V. núm. 12-31437.

21-5544. Gabriel y Galán, José María Poesia y prosa. Introd., sel. y notas de L. Jiménez Martos. - Magisterio Español, Madrid, 1970. 192 pp.

21-5545. Carrasco, C. - "La musa cordial de Gabriel y Galán”.-Alc, 1971, núm. 162.

V. también núm. 7022 .

21-5546. Pérez Ferrero, M. - “Manuel Machado". - $M u H$, enero 1970.

21-5547. Aguilar Piñal, F. - "El abuelo de los Machado en la Real Academia Sevillana de Buenas Letras".-Ins, 1970, núm. 279.

21-5548. Совоs, P. DE A.-“Sobre Antonio Machado en Segovia". - Ins, 1971, núms. $300 / 01$.

21-5549. Gil Novales, Alberto - Antonio Machado. 2a ed.-Fontanella, Barcelona, 1970. 178 pp. (Testigos del siglo $x x)$. - V. núm. 20-2133.

21-5550. Garciasol, R. DE - "Leonor Izquierdo de Machado”.-EL, 1970, núm. 438.

21-5551. Navas-Ruiz, R. - “Guiomar y el proceso creador de Antonio Machado". -RLit, 35 (1969), 105-110.

21-5552. ANdrés CoBos, P. DE - "Antonio Machado y Mariano Quintanilla”. ESeg, 22 (1970), 61-80.

21-5553. Совоs, P. dE A. - "Una identificación en Antonio Machado". - Ins, 1970, núm. 279.

21-5554. Chamorro, José - Antonio Machado en la provincia de Jaén.-Diputación Provincial, Jaén, 1966. 96 pp.V. núm. 16-44341.

21-5555. Lapuerta, Francisco, y Antonio NAvARrete - Baeza y Machado. Evoca- 
ción de la ciudad y el poeta.-Madrid, 1969. 40 pp., ilustr.

21-5556. Cobos, P. DE A. - "Frente a un enigma de Antonio Machado". - Ins, 1970 , núms. $284 / 5$.

21-5557. Rosselli, Ferdinando - Contributo a una tematica generale della poesia di Antonio Machado. - Unversità, Pisa, 1970. $148 \mathrm{pp}$.

21-5558. Rivacoba, M. DE - "Crimen y poesía en la obra de Antonio Macha. do". - Boletin de la Universidad de Chile, Santiago de Chile, 1969, núms. $95 / 6$.

21-5559. FinzI, A. - "EI análisis numérico como instrumento crítico en el estudio de la poesía de Antonio Machado".Proh, 1 (1970), 203-224.

21-5560. Gullón, Ricardo - Una poética para Antonio Machado. - Gredos, Madrid, 1970. 270 pp. (BRH, Estudios y ensayos, 139). II fns, 1970, núm. 281 (Cano); BAbr, 45 (1971), 293 (Chambers); PEsp, 1970, núm. 213 (del Villar).

21-5561. SÁnchez Barbudo, A. - Los poemas de Antonio Machado (N. 20-6381). || BAbr, 44 (1970), 273 (Debicki).

21-5562. Machado, Antonio - Poesias completas. 9: ed. - Espasa-Calpe, Madrid, 1970.520 pp. - V. núm. 19-2668.

21-5563. Machado, Antonio - Poesias selectas. Sel. y nota biográfica đe E. Gascó Contell.-Ateneo, México, 1970. 128 pp. (Poesia universal).

21-5564. Machado, Antonio - Campos de Castilla. Ed. de R. Ferreres. - Taurus, Madrid, 1970. 245 pp. (Temas de España, 84).

21-5565. Ángeles, J. - "Presencia de Bécquer en las Soledades primeras de Antonio Machado". - Ins, 1970, núm. 289.

21-5566. Albornoz, A. DE - La presencia de Miguel de Unamuno en Antonio Ma. chado (N. 20-6391). \| ALM, 8 (1970), 271-273 (Fernández Molina); RR, 61 (1970), 160-161 (Gullón).

21-5567. Coвos, PABlo DE A. - Humorismo de Antonio Machado en sus apócrifos. -Ancos, Madrid, 1970. $180 \mathrm{pp}$.

21-5568. Davis, Richard LeE - $A$ study of the heteronyms of Antonio Machado, with special emphasis on "Abel" and "Martin". - [Tesis, Univ. of Texas, 1970].

21-5569. TudelA, J. - "Textos olvidados de Antonio Machado". - Ins, 1970, núm. 279. [Sobre Unamuno, Valle-Inclán, Azorín y Baroja].
21-5570. MarRast, R.-“Antonio Machado: trois nouveaux textes oubliés". - LNL, 1970, núm. 194, 30-36.

21-5571. Gullón, R. - "Machado reza por Dario". - INO, 33-36.-V. núm. 20-2164.

21-5572. Gómez Paz, J. - "Francisco Romero y Antonio Machado". - Ins, 1970, núm. 283.

V. también núms. 5110, 5141, 5224, 5278, 5284, 5532, 6949.

Carrere: v. núm. 5224.

21-5573. Gullón, R. - "Juan Ramón Jiménez y Norteamérica".-INO, 41-51.

21-5574. Совв, C. W.-“J. R. Jiménez and Emily Dickinson: is there really an influence?" - REH, 4 (1970), 35-48.

21-5575. Santos Escudero, C. - "Presencia del pensamiento hindú en el último Juan Ramón Jiménez". - $R y F, 182$ $(1970), 487-504$.

21-5576. Segovia, T.-“Juan Ramón uno y trino". - [En su libro] Actitudes (Guanajuato, 1970), pp. 59-127.

21-5577. YNdurárn, F. - "De la sinestesia en la poesía de Juan Ramón". - CMod, 185-191.-V. núm. 12-33401.

21-5578. Jiménez, JuAN RAMÓN - Trescientos poemas. 2a ed. - Plaza \& Janés, Barcelona, 1970. 277 pp.-V. núm. 182863.

21-5579. Bertrand de MuÑoz, M.-“Almuradi del monte".-LT, 1970, núm. 69, 115-127. [Poema de Juan Ramón].

21-5580. JIMÉNeZ, J. R. - "Dos pocmas inéditos". - PEsp, 1970, núm. 215.

21-5581. JIMÉnez, Juan Ramón - Pájinas escojidas. Prosa. 1: reimpr. - Gredos, Madrid, 1970. 264 pp. (Antologia hispánica, 13) . - V. núm. 14-39065.

21-5582. Jiménez, JuAN RAMón - Platero y yo. $16^{*}$ y $17^{\text {a }}$ eds. - Fernández, México, 1970. 100 pp., ilustr. (Páginas de oro).V. núm. 20-6415.

21-5583. PREDMoRe, M. P.-"The structure of Platero y yo". - PMLA, 85 (1970), 56-64.

21-5584. OWRE, J. R. - "Zenobia estudiante".-LT, 1970, núm. 67, 120-123.

V. también núms. 5278, 5284, 5532, 5953. Pérez de Ayala: v, núms. 6448-9.

21-5585. Artiles, J. - "Tomás Morales en la Revista Latina".-MCan, 27/30 (196669) , 77-125.

V. también núm. 5235 .

Autores contemporáneos

2I-5586. Arenal de Rodríguez, Electa"Homo ethicus": Patterns and processes 
in the poetry of León Felipe--[Tesis, Columbia Univ., 1970].

21-5587. Rrvera, Tomás - La ideologia del hombre en la obra poética de León Felipe. - [Tesis, Univ, of Oklahoma; resumen en $D A I, 30(1969-70), 3021 \mathrm{~A}$ $3022 \mathrm{~A}]$.

21-5588. IzQUIERDo, J. - "Notas sobre León Felipe y su idea de la muerte".CrıA, 1970, núm. 6, 151-157.

21-5589. Rublúo, L. - "Tiempo e historia en la voz de León Felipe". - CuA, 1970, núm. 5, 97-105.

21-5590. LEón FELIPE - iOh, el barro, el barro! - Finisterre, México, 1970. 12 pp.

21-5591. Armas, J. R. DE - "La columna, el círculo y sus variantes en la poesía primera de Pedro Salinas". - $H, 53$ (1970) , 53-58.

21-5592. Villegas, J. - "El amor y la salvación existencial en dos poemas de Pedro Salinas". - PMLA, 85 (1970), 205-211; PSA, 58 (1970), 197-218.

21-5593. Morris, C. B. - "Pedro Salinas and Marcel Proust". - RLC, 44 (1970), 195-214.

V. también núm. 5227 .

21-5594. Debicki, A. P. - "La poesía de amor de Jorge Guillén".-Rev. de Bellas Artes, México, 1970, núm. 32, 13-24.

21-5595. ROBbins, StephanIE M. - "Persona" in the poetry of César Vallejo, Jorge Guillen, and Nicanor Parra.-[Tesis, Univ. of Texas, 1970].

21-5596. Guillén, Jorge - Antologia. Sel. y pról. de J. M. Blecua.-Anaya, Salamanca, 1970. 150 pp. (Bibl. Anaya).

21-5597. Guillén, JoRGE - Obra poética. Antologia. Pról. de J. Casalduero. Alianza Editorial, Madrid, 1970. 229 pp. (El libro de bolsillo, 250). U Uro, 1970, núms. 5/6, 142-145 (de Luis).

21-5598. Gulllén, JORGE - Selección de poemas. 2a ed., aum.-Gredos, Madrid, 1970. 354 pp. (Antologia hispánica, 23) . -V. núm. 19-2774.

21-5599. Geiltín, JORGe - Guirnalda civil. - Halty Ferguson, Cambridge, Mass. 1970. $40 \mathrm{pp}$.

V. también núm. 5227.

21-5600. Vivanco, L. F.-"Poemas de Juan Larrea". - ROcc, 31 (1970), 303-314.

21-5601. LARREA, JUAN - Versión celeste. Trads, de L. F. Vivanco, G. Diego, Carlos Barral y el autor--Barral, Barcelona, 1970. 343 pp. (Eds. de bolsillo). I| ALM, 8 (1970) , 273-276 (Fernández Molina).

21-5602. Larrea, Juan - Versione celeste.
Introd. e trad. di V. Bodini--Einaudi, Torino, 1969. $\mathrm{xx}+249$ pp. $\| L T, 1970$, núm. 67, 148-151 (Fernández Molina); SNo, 1970, núm. 2, 95-96 (Fernández Molina); $\quad B H S, \quad 47 \quad(1970), \quad 365-366$ (Nield); Diál, 1970, núm. 31 (Xirau).

21-5603. Hernández-Vista, E. - "Gerardo Diego: El ciprés de Silos". - Proh, 1 (1970) , 19-46.

21-5604. Diego, Gerardo - Versos escogidos, - Gredos, Madrid, 1970. 394 pp. (Antologia hispánica, 29). II Ins, 1970 , núm. 286 (Cano); BAbr, 45 (1971), 292-293 (Ciplijauskaité); PEsp, 1970, núm. 213 (Murciano).

21-5605. Diego, Gerardo - Poesia amorosa (1918-1969). 2a ed. aum. - Plaza \& Janés, Barcelona, 1970. 244 pp. (Sels. de poesía española). - V. núm. 19-2802.

21-5606. Diego, Gerardo - La fundación del querer. - La Isla de los Ratones, Santander, 1970. $49 \mathrm{pp}$.

V. también núm. 5278.

21-5607. López Landeira, R.-"'Un puente entre dos poetas". - RHM, 35 (1969), 261-267. [Mayakovski y Garcia Lorca].

21-5608. FoNT, M. T. - "Tres manifestaciones de especialismo poético: Federico García Lorca, Nicolás Guillén y Jorge Luis Borges". - Revlb, 36 (1970), 601612 .

21-5609. Donahue, F. - "Hacia un credo lorauiano". $-L T, 1970$, núm. $69,105-114$.

21-5610. Higcingotham, V. - "Lorca's apprenticeship in surrealism". $-R R$, $61(1970), 109-122$.

21-5611. Halliburton, C. Lloyd - Garcia Lorca's rejection of mechanical civilization. - [Tesis, Lousiana State Univ., $1970]$

21-5612. Campbell, Roy - Lorca: An appreciation of his poetry. - Haskell House, New York, 1970. 79 pp. - V. núm. 8-11019.

21-5613. Eich, Christoph - Federico García Lorca, poeta de la intensidad. Versión de G. Sobejano. 2a ed., revisada.Gredos, Madrid, 1970. 204 pp. (BRH, Estudios y ensayos, 42). - V. núm. 16-44456.

21-5614. Sopeña Ibáñez, ÁNgeL-Concepto de la mujer española en la obra de Garcia Lorca. - Madrid, 1966. 38 pp. 21-5615. García Lorca, Federico - Obras completas. Pról. de J. Guillén. Recopilación y notas de A. del Hoyo. 15a ed.Aguilar, Madrid, 1969. lxxix +2018 pp., ilustr. (Obras eternas). [16a ed., 1971]. - V. núm. 20-2230. 
21-5616. García Lorca, Federico - Poesias selectas. Sel. y nota biográfica de E. Gascó Contell. - Ateneo, México, 1970. 110 pp.

21-5617. García Lorca, F. - "Un soneto olvidado”. - Ins, 1970, núm. 278.

21-5618. Wells, C. M. - "The natural norm in the plays of F. García Lorca". $-H R, 38$ (1970), 299-313.

21-5619. Brunel, Pierre (ed.) - La mort de Godot: attente et évanescence au théâtre. - Minard, Paris, 1970. 191 pp. [Incluye a García Lorca].

21-5620. Feal-Deibe, C. - "Crommelynck y Lorca: variaciones sobre un mismo tema". - RLC, 44 (1970), 403-409.

21-5621. Rrncón, C. - "La zapatera prodigiosa de F. García Lorca. Ensayo de interpretación". - IR, 4 (1970), 290313.

21-5622. SALAÜN, S. - "Essai de (nouvelle) critique: Yerma”. - LNL, 1970, núm. 194, 24-29.

21-5623. ARCE DE VÁzQUEZ, M. - "La casa de Bernarda Alba”. - SNo, 1970, núm. 2. 5-14.

21-5624. Martínez, M. A. - "Realidad y símbolo en La casa de Bernarda Alba”. $-R E H, 4$ (1970), 55-66.

21-5625. ZIOMEK, H. - "El simbolismo del blanco en La casa de Bernarda Alba y en La dama del alba". - S, 24 (1970), $81-85$.

21-5626. Bull, J. M. - "Santa Bárbara' and La casa de Bernarda Alba". - BHS, $47(1970), 117-123$.

21-5627. Martínez Nadal, Rafael - "E $t$ público". Amor, teatro y caballos en la obra de Federico Garcia Lorca. - The Dolphin Book, Oxford, 1970. $272 \mathrm{pp}$. || Ins, 1970, núm. 282 (Cano) ; Uro, 1970, núms. 5/6, 145-146 (Marinero).

21-5628. UMBral, F. - "Análisis y sintesis de Lorca". - ROcc, 32 (1971), 221-229. [El público].

21-5629. García Lorca, Federico - Prosa. -Alianza Editorial, Madrid, 1970. 208 pp. (El libro de bolsillo, 219) . || CuH, 83 (1970), 286-287 (Quiñones).

21-5630. Cominciol, JAcQues - Federico Garcia Lorca. Textes inédites et documents critiques. - Éds. Rencontre, Lausanne, 1970. 341 pp.

21-5631. Gallego Morel., A. - "Unas cartas de García Lorca a Antonio Gallego Burín". - Cuadernos de Arte y Literatura, Granada, 1967, núm. 1.

V. también núms. 5227, 5231, 5284, 5335, 5806.
21-5632. Molina-Forx, V. - "Vicente Aleixandre: 1924-1969".-CuH, 81 (1970), 281-299.

V. también núms. 5231, 5476.

21-5633. Dust, Patrick Henry-The poetry of Dámaso Alonso. - [Tesis, Univ. of Illinois, 1970].

21-5634. Alonso, DÁmaso-Hijos de la ira. Diario intimo. Ed., pról. y notas de E. L. Rivers, - Labor, Barcelona, 1970. 149 pp. (Textos hispánicos modernos, 4).

21-5635. Gonçalves Pires, L. - "O mundo poético de Dámaso Alonso: Hijos de la ira”. - Co, 1970, núm. 61 .

21-5636. SHLVer, P. - "Tradition as originality in Hijos de la ira". - BHS, 47 (1970) , 124-130.

21-5637. Silver, PH. - "Un comentario sobre En la sombra”. - PSA, 58 (1970), 185-190.

21-5638. "Emilio Prados y Manuel Altolaguirre”. - Litoral, Málaga, 1970, núms. 13/14. [Homenaje].

21-5639. González Martíx, J. P. - "Rafael Alberti en Anticoli”. - Ins, 1970, núm. 282.

21-5640. Wesseling, Pieter - The poetry of Rafael Alberti: traditionalism and revolution. - [Tesis, Univ. of Wisconsin, 1970].

21-5641. Cardwell, R. A. - "Rafael A1berti's El hombre deshabitado". - IR, 2 $(1970), 122-133$.

21-5642. Alberti, RAfael - Sobre los ángeles. - Llibres de Sinera, Barcelona, 1970. 101 pp. (Ocnos).

21-5643. Mayoral, M. - " "Se equivocó Ia paloma . (Comentario a un poema de Alberti)". - Ins, 1970, núm. 282.

$V$. también núms. 5227, 5231.

21-5644. BRAU, S. - "In memoriam Luis Cernuda".-LNL, 1970, núm. 194, 63-67.

21-5645. Capote, J. M. - "Bibliografía cernudiana".-CuH, 83 (1970), 572-576.

21-5646. WEgMANN, B. - "EI crepúsculo en cinco poemas de Luis Cernuda".CuH, 85 (1971), 285-301.

21-5647. CernudA, LuIs - Antologia poética. Introd, y sel. de R. Santos Torroella. - Plaza \& Janés, Barcelona, 1970. 256 pp. (Sels. de poesia española). I Ins, 1970, núm. 280 (Cano).

21-5648. Cernuda, Luis - La realidad y el deseo (1924-1962). 4a ed., aum.-F.C.E., México, 1970. 381 pp. (Tezontle.) V. núm. 19-2788.

V. también núms. 5227, 5291, 5533.

21-5649. Alvarez de Harvey, M. L. - "La vida poética extraordinaria de Manuel 
Altolaguirre". - CuA, 1970, núm. 3, 171-174.

21-5650. Álvarez Harvey, María luisaCielo y tierra en la poesia lírica de Manuel Altolaguirre. - [Tesis, Univ. of Arizona, 1970].

21-5651. Altolaguirre, M. S. - "Dos elegías inéditas del poeta Manuel Altolaguirre". - Proh, 1 (1970), 122-124.

V. también núm. 5638 .

21-5652. Comandone Medina, Mirta Dora -La poesia de Leopoldo Panero. Algunos aspectos del mundo poético. [Tesis, Univ. de Madrid; resumen en RUM, 17 (1968), 31-32].

21-5653. Connolly, Elleen M. - Optionhope: A study of the poetry of Leopoldo Panero.-[Tesis, New York Univ.; resumen en DAI, 30 (1969-70), 4978A$4979 \mathrm{~A}]$.

21-5654. Pıontek, H. - "Miguel Hernández". - [En su libro] Männer, die Gedichte machen. Zur Lyrik von heute (Hoffmann \& Campe, Hamburg, 1970).

21-5655. Pérez, ARTURo - El sino sangriento: Estudio temático en la poesia de Miguel Hernández. - [Tesis, Univ. of Oklahoma, 1970].

21-5656. Hernández, Miguel - Poesias. Introd. y sel. de J. L. Guereña. 4a ed.Taurus, Madrid, 1970. 134 pp. (Temas de España, 49). - V. núm. 20-2305.

21-5657. Berns, G. - "Familiar and natural violence in the early poetry of Miguel Hernández: Perito en lunas".HR, 38 (1970) , 386-404.

21-5658. Gullón, R. - "El rayo de Miguel".-INO, 178-191.-V. núm. 19-6581.

21-5659. Berns, G. - "Más allá de la violencia. (Los últimos poemas de Miguel Hernández) ". - ROcc, 29 (1970), 299318.

21-5660. Guereñ A, J. L. - "Entronque de Miguel Hernández y Paul Éluard". $\mathrm{CuH}, 83$ (1970), 611-617.

21-5661. Rosales, Luis - El contenido del corazón. - Cultura Hispánica, Madrid, 1969. $156 \mathrm{pp}$.

Celaya: v. núm. 5236.

21-5662. Zupanchich, M. J.- "Two moments in the life and poetry of Dionisio Ridruejo".-RNo, 10 (1968-69), 218-225.

21-5663. Garciasol, RAMón DE - Los que viven por sus manos. - Javalambre, Zaragoza, 1970. (Col. Fuendetodos, 3). |) ROcc, 30 (1970), 251-252 (de Luis); İns, 1970, núm. 287 (Miró).

Otero: v. núms. 5235-6.

21-5664. CÁceres Peña, José Antonio de-
La poesia de Leopoldo de Luis.-Málaga, 1970. $120 \mathrm{pp}$.

21-5665. LuIs, LEOPOLDo DE-Con los cinco sentidos. - Javalambre, Zaragoza, 1970. || PSA, 61 (197l), 213-219 (Manrique de Lara).

21-5666. Hidalgo, José LuIs - Antologia poética. Introd. y sel. de J. Uceda. Aguilar, Madrid, $1970.176 \mathrm{pp}$.

Hierro: v. núm. 5235.

21-5667. Zipfel y García, C. - "La temporalidad en Carlos Bousoño". - USC, 1968-69, núms. 77/8, 63-68.

21-5668. Martino, F.- "La poesía de Ángel González”. - PSA, 57 (1970), 229247.

21-5669. Alarcos Llorach, Emilio-Angel González, poeta. Variaciones criticas.Universidad, Oviedo, 1969. $169 \mathrm{pp}$.

21-5670. Albornoz, A. DE - "La vida contada, de J. M. Caballero Bonald". ROcc, 29 (1970), 328-335.

V. también núm. 5236 .

\section{Epica}

21-5671. Alonso, D.-“La tradición épica castellana en la obra de Menéndez Pidal". $-L T, 1970-71$, núms. $70 / 1,15-49$.

21-5672. Richthofen, ERICH von - Nuevos estudios épicos medievales.-Gredos, Madrid, 1970. 294 pp. (BRH, Estudios $y$ ensayos, 138). - V. núm. 10-22981. II BHi, 72 (1970), 386-405 (Cotrait); H, 54 (1971), 596 (Sturcken).

21-5673. RichthofeN, E. von - "sTradicionalismo», *individualismos y positivismo en el estudio de la épica y la novela primitivas". - Proh, 1 (1970), 397 435.

21-5674. Galmés de Fuentes, A. - "Épica árabe y épica castellana. (Problema crítico de sus posibles relaciones". - [En] La poesia epica e la sua formazione (Roma, 1970), 196-259.

21-5675. Sutron, D. - "The Cid: A tentative bibliography to January 1969". $B d F S, 21$ (1970), 21-173.

21-5676. MagnotTa, Michael - Historia de la critica sobre el "Poema de mio Cid". - [Tesis, Case Western Reserve Univ., 1970].

21-5677. Poema del Cid. Hrsg. von Alwin Kuhn. 2., verbesserte und erw. Aufl. von Ulrike Ehrgott. - Max Niemeyer, Tübingen, 1970. xxiv +102 pp. $-\mathrm{V}$. núm. 6-8878.

21-5678. Poema del Cid, ed. F. López Es- 
trada (N. 20-2346) . \| PEsp, 1970, núm. 207 (Ruiz Copete).

21-5679. Poema de mio Cid. Ed. y pról. de L. Guarner-Barcelona, 1970. 152 pp.

21-5680. Cantar de mio Cid. Transcripción moderna versificada, seguida del texto medieval, con pról. y notas de $\mathbf{L}$. Guarner. 3a ed.-E.D.A.F., Madrid, 1970. 645 pp., ilustr. - V. núm. 18-6475.

21-5681. Menéndez Pidal, Ramón - El Cid Campeador. 6a ed. - Espasa-Calpe, Madrid, 1968. 246 pp. (Austral, 1000). -V. núm. 18-6470.

21-5682. Menéndez Pidal, Ramón - En torno al "Poema del Cid". 3a ed. Edhasa, Barcelona, 1970. 235 pp. (El puente literario). - V. núm. 19-2847.

21-5683. Chiarini, G.-“Osservazioni sulla tecnica poetica del Cantar de mio Cid". -Lavori Ispanistici, 1970, 7-45.

21-5684. Chasca, E. DE - "Toward a redefinition of epic formula in the light of the Cantar de mio Cid". - HR, 38 (1970) , 251-263.

21-5685. Jehie, Frederick F. - A study of the formulaic diction in the "Poema de mio Cid" and the "Chanson de Roland".-[Tesis, Catholic Univ., 1970].

21-5686. Alonso, D. - "El anuncio del estilo directo en el Poema del Cid y en la épica francesa". - $H R L, 379-393$.

21-5687. Dunn, P. N. - "Levels of meaning in the Poema de mio Cid". - MLN, $85(1970), 109-119$.

21-5688. Grassotti, H.-"La ira regia en León y Castilla" (N. 19-6639). \|sp, 45 (1970), 300-301 (O'Callaghan).

21-5689. Criado de Val, M. - "Geografía, toponimia e itinerarios del Cantar de mio Cid". - ZRPh, 86 (1970), 83-107.

21-5690. Lrón, Adolfo F. - "The Cid" as its influence appears in literature.¡Tesis, Univ. of South Carolina, 1970ך.

21-5691. Armistead, S. G., \& J. H. SilverMaN - "Avengalvón in Luis de Pinedo's Liber facetiarum". - RPh, 23 (1969$70), 56-57$.

21-5692. SHolod, B. - Charlemagne in Spain: The cultural legacy of Roncesvalles (N. 19-2868) . $\| B H R, 31$ (1969), 405-407 (Mandach).

21-5693. HORRENT, J.- "L'allusion à la chanson de Mainet contenue das le Roncesvalles".-MRo, 20 (1970) , 85-92.

21-5694. Lothrop, Thomas A.-A critical edition of two chroniclized versions of the "Siete infantes de Lara" epic theme. - TTesis, Univ. of California, Los Angeles, 1970].
21-5695. Menéndez Pidal, R. - "Los Infantes de Salas y la epopeya francesa. Influencias recíprocas dentro de la tradición épica románica". - HRL, 485501. \| $M A, 76$ (1970), 526-527 (Joset).

21-5696. PÉREZ DE URBeL, J. - "Notas histórico-críticas sobre el poema Fernán Gonzílez".-BIFG, 1970, 42-75, 231-265.

21-5697. González Herrero, Manuel Fernán González y el pueblo castellano. Palabras para una nueva frontera de Castilla. - Imp. E1 Adelantado, Segovia, 1970. $20 \mathrm{pp}$.

21-5698. SÁNCHEZ-CAstañER, F. - "Huellas épicas en la poesía de Rubén Darío".RUM, 19 (1970), núm. 75, 221-247.

V. también núms. $3419,4524,5094$.

\section{Romancero}

21-5699. Armistead, S. G., et al.-"Coloquio sobre el Romancero tradicional". -Sef, 31 (1971), 468-469.

21-5700. Álvarez Villar, A. - "El Romancero en la obra de $\mathbf{R}$. Menéndez $\mathrm{Pi}$ dal, desde la perspectiva de la psicología de la cultura". - RUM, 19 (1970), núm. 74, 7-23.

21-5701. Horrent, J. - "Traits distinctifs du Romancero espagnol". - MRo, 20 (1970), 29-38.

21-5702. Estelle, Robert Francis - The interrelationship of assonance, verb forms, and syntax in the "Romances viejos". - [Tesis, Univ. of Minnesota; resumen en DAI, 31 (1970-71), 1225A$1226 \mathrm{~A}]$.

21-5703. Szertics, J. - Tiempo y verbo en el "Romancero viejo" (N. 20-2374). II $A L M, 8(1970), 264-265$ (Colombo Airoldi) .

21-5704. Lockart, J. G. (ed.) - Ancient Spanish ballads, historical and romantic. - New York, 1970. 242 pp. [Reimpr. de la ed. de 1841].

21-5705. Maldonado, Felipe C. R. (comp.) -Romancero del Cid. 2a ed. - Taurus, Madrid, 1970. 214 pp. (Temas de España, 41) . - V. núm. 19-6656.

21-5706. Cancionero de romances (Anvers, $1550)$, ed. A. Rodríguez Moñino (N. 20-2368). $\|$ BHi, 72 (1970), 185-187 (Chevalier); BHS, 47 (1970), 356-358 (Smith) ; HR, 38 (1970), 324-328 (Wilson).

21-5707. Silva de romances (Zaragoza, 15501551). Estudio, bibliografía e índices por A. Rodríguez-Moñino. - Ayuntamiento, Zaragoza, 1970. 570 pp. 
21-5708. RodrígueZ-MoÑino, ANTONIO-La "Silva de romances" de Barcelona, 1961. Contribución al estudio bibliográfico del romancero español en el siglo xvi.Universidad, Salamanca, 1969. 609 pp. 21-5709. RoDríguez, Lucas - Romancero historiado (Alcalá, 1582), ed. A. Rodríguez-Moñino (N. 20-2369) . \| BHi, 72 (1970), 187-188 (Chevalier); $M L N, 85$ (1970) , 295 (Rivers) ; BHS, 47 (1970), 356-358 (Smith) ; HR, 38 (1970), 324328 (Wilson).

21-5710. SEPúlvedA, L. DE - Cancionero de romances (Sevilla, 1584), ed. A. Rodríguez-Moñino (N. 20-2370) . II BHi, $72(1970)$, 188-190 (Chevalier); $M L N$, 85 (1970) , 295 (Rivers) ; BHS, 47 (1970), 356-358 (Smith); HR, 38 (1970), 324328 (Wilson).

21-5711. Lópfz de TortajadA, DamiáNFloresta de varios romances (Valencia, 1652). Ed., est., bibliografía e índices por A. Rodríguez-Moñino. - Castalia, Madrid, 1970. 312 pp. (Romanceros de los Siglos de Oro, 4).

21-5712. Saulnier, V. L. - "Mellin de Saint-Gelais, Pernette du Guillet et l'air Conde Claros",-BHR, 32 (1970), 525532.

21-5713. Caravaca, F. - “El Romance del conde Arnaldos en textos posteriores al del Cancionero de romances de Amberes, s, a." - BBMP, 46 (1970), 3-70.

21-5714. Caravaca, F.-"Notas sobre cinco versiones italianas del Romance del conde Arnaldos". - QIA, 5 (1970) , 80-102.

21-5715. Caravaca, F. - "Notas sobre una traducción neerlandesa del Romance del conde Arnaldos". - $R L V, 36$ (1970), 178-182.

21-5716. Magalhães Pinto, A. dE - "Romance de D. Silvina”. $-R B F, 10$ (1970), 118-126.

21-5717. ZAYAs, Francisco J. - La estructura paralelistico-conceptual del romance "Nuño Vero". - [Tesis, Univ. of Miami, 1970].

21-5718. Rogers, E. - "A new genealogy of Rico Franco". - JAF, 82 (1969), 369-373.

21-5719. Leizaola, Jesús Ma de - Los romances vascos $y$ sus relaciones con reliquias literarias de la prehistoria.-Edit. Vasca Ekin, Buenos Aires, 1969. 294 pp. 21-5720. Catalán, Diego (ed.) - La flor de la marañuela. Romancero general de las Islas Canarias. - Seminario Menéndez Pidal de la Universidad-Gredos, Madrid, 1969. 2 ts.: 366, 265 pp.
21-5721. Sosa Barroso, Sebastián - Galas en el romancero de Lanzarote. - Las Palmas, 1966. 74 pp.

21-5722. ARMistead, SAMUel. G., \& JOSEPH H. Silverman - The Judeo-Spanish ballad chapbooks of Yacob Abraham Yoná.-Univ. of California Press, Berkeley, 1970. 544 pp. (Folk-literature of the Sephardic Jews, 1).

21-5723. Armistead, S. G., y J. H. SilverMAN-"Para un gran romancero sefardí. I. El romancero judeoespañol en los Estados Unidos. II. Sobre la historia del proyecto". - SES(1), 281-294.

21-5724. Attias, M. - "Reconstrucción de una romansa sefardi”. - OYS, 11/12 $(1969-70), 46-51$. [En hebreo].

21-5725. Armistead, S. G., \& J. H. SilverMAN - "Arabic refrains in a JudeoSpanish romance".-IR, 2 (1970), 91-95. 21-5726. Armistead, S. G., y J. H. SilverMAN - "Exclamaciones turcas y otros rasgos orientales en el romancero judeoespañol". - Sef, 30 (1970), 177-193.

21-5727. Bertini, G. M. - "Romances novelescos españoles en Hispanoamérica". - Studi di Lett. Ispano-Americana, Milano, 1 (1969?) . - V. núms. 16-44614, 21-2186.

21-2728. Canino Salgado, M. J. - La copla y el romance populares en la tradición oral de Puerto Rico. - Instituto de Cultura Puertorriqueña, San Juan de Puerto Rico, 1968. 176 pp.

21-5729. Beutlfr, Gisela - Studien zum spanischen Romancero in Kolumbien in seiner schriftlichen und mündlichen Überlieferung, von der Zeit der Eroberung bis zur Gegenwart.-Carl Winter, Heidelberg, 1969. 386 pp. \|RJ, 21 (1970) , 389-394 (Rivarola); BICC, 25 (1970) , 305-315 (Schütz); Noticias Culturales, Bogotá, 1970, núm. 114, 12-14 (X) .

V. también núms. 3316, 4406-7, 4836.

\section{TEATRO}

21-5730. Grismer, RAYMond L. - Bibliography of the drama of Spain and Spanish America. T. 2: M-Z.-BurguessBeckwith, Minneapolis, 1969. xxiv + 231 pp. - V. núm. 20-2383.

21-5731. Forradellas Figueras, J. - "Para los orígenes del teatro español”. $-\boldsymbol{B H}$, 72 (1970), 328-330.

21-5732. AmícolA, J. - "El siglo xv y el teatro castellano".-Fil, 14 (1970), 145169. 
21-5739. Ronríguez-PuÉrtolas, J. - “La transposición de la realidad en el Códice de autos viejos". - Fil, 14 (1970), 105-125.

21-5734. Sánchez Escribano, F.-“La búsqueda de la estructura dramática en el siglo xvi". - HEOL, 215-218.

21-5735. Hesse, Everett W., y Juan O. VALENCIA (eds.) -El teatro anterior a Lope de Vega.-Alcalá, Madrid, 1971. 416 pp. (Aula magna, 23).

21-5736. REIGHENBERGer, A. G. - "The uniqueness of the comedia".-HR, 38 (1970), 163-173.-V. núm. 14-41208.

21-5737. BentLey, E. - "The universality of the comedia".-HR, $38(1970), 147$ 162.

21-5738. López, M. E. - "Introducción al teatro clásico español: Lope, Tirso de Molina y Calderón". - Cults, 1970, núm. 55, 52-72.

21-5739. Sánchez Escribano, F., y A. PorQUERAS MAYo - Preceptiva dramática española del Renacimiento al barroco (N. 19-2908) . \|BHS, 47 (1970), 160162 (Moir) .

21-5740. Jones, C. A. - "Tragedy in the Spanish Golden Age". - [En] Elmer M. Blistein (ed.), The drama of the Renaissance: Essays for Leicester Bradner (Providence, 1970), 100-107.

21-5741. Martínez, Enrique José - Tragedy in the Spanish theater of the Golden Age.-[Tesis, Univ. of Pennsylvania, 1970$]$.

21-5742. FLOECK, W. - "Die Gestalt des Herrschers in der spanischen Comedia des Goldenen Zeitalters".- $R J, 21$ (1970), 262-284.

21-5743. Floeck, W. - “Das Ritterideal in der spanischen Comedia des Goldenen Zeitalters". - IR, 2 (1970), 15-55.

21-5744. SELIG, K. L. - "Spanish proverbs and the Comedia de Aman y Mordochay". - Prov, 1970, núm. 15, 114.

21-5745. Martinenche, ERnest - La "comedia" espagnole en France de Hardy à Racine.-Slatkine Reprints, Genève, 1970. 380 pp. [Reimpr. de la ed. de París, 1906].

21-5746. Loftis, J. - "Dryden's criticism of Spanish drama". - [En] HENRY K. Mir.LER, et al. (eds.), The Augustan milieu: Essays presented to Louis $A$. Landa (Oxford, 1970).

21-5747. WEINER, J. - "El teatro español del Siglo de Oro en Rusia durante la primera mitad del $\mathrm{xIx}^{\prime \prime}$. - $\mathrm{CuH}, 8 \mathrm{I}$ $(1970), 46-76$.
21-5748. BAHNer, Werner (ed.), - Klassisches spanisches Theater. Aus dem Spanischen übersetzt. - Rütten \& Loening, Berlin, 1970. 2 ts.: 1048 pp. [Lope, Fuenteovejuna y El caballero del milagro; Tirso, Marta la piadosa y El convidado de piedra; Calderón, El alcalde de Zalamea, La dama duende y La vida es sueño].

21-5749. Onrubia de Mendoza, J. (ed.) Trece autos sacramentales. - Barcelona, 1970. $668 \mathrm{pp}$.

21-5750. Bergman, Hannah E. (ed.) Ramillete de entremeses y bailes nuevamente recogido de los antiguos poetas de España. Siglo xvii. - Castalia, Madrid, 1970. 471 pp. (Clás. Castalia, 21).

21-5751. Rodrícuez CepedA, E. - "Problemas del teatro en 1800 y un documento inédito de Isidoro Máiquez". - $R O C c$, 29 (1970), 357-364.

21-5752. KLEIN, RICHARD BARRY - The development of "realism" in late nineteenth-century Spanish drama. - [Tesis, Univ. of Illinois, 1970].

21-5753. McGaha, Michael Dennis-The Spanish theatre during the Second Republic, 1931-1936. - [Tesis, Univ. of Texas, 19707.

21-5754. Roca Franquesa, J. M. - "Estructura y tendencias del teatro español de postguerra". - HEOL, 253-279.

21-5755. Dillingham, MARJORIE C.-Social theater in contemporary Spain.-[Tesis, Florida State Univ., 1970].

21-5756. Er.zalde, I. - "Algunos aspectos del teatro actual en España”. $-L D, 1$ (1971) , 187-194.

21-5757. Boring, P. Z.-"Traces of Giraudoux in the contemporary Spanish theatre". - RNo, 11 (1969-70), 8-11.

21-5758. Halsey, M. T. - "Esquilache, Velázquez, and Quevedo: Three historical figures in contemporary Spanish drama". - KRQ, 17 (1970), 109-126.

21-5759. Guardia, Alfredo de LA - Visión de la critica dramática.-Siglo $\mathrm{XX}$, Bue. nos Aires, 1970. 360 pp. (La pléyade).

21-5760. Sáinz de Robles, F. C. (ed.) Teatro español 1967-68.-Aguilar, Madrid, 1969. xxxv + 382 pp. - V. núm. 21-2236.

21-5761. SAINz de Robles, Federico CarLOS (ed.) - Teatro español 1968-1969. -Aguilar, Madrid, 1969. xxxv + 402 pp. (Col. literaria). $\| B A b r, 45$ (1971), 668-669 (Wellwarth).

V. también núms. 4526-36, 4578, 5168, 5173,6128 . 
Autores antiguos

21-5762. MANdel, Adrienne Schizzano-A thematic survey of Celestina studies, 1824-1968. - [Tesis, Univ. of California, Los Angeles, 1970$]$.

21-5763. Rubio García, Luis - Estudios sobre "La Celestina". - Universidad, Murcia, 1970. 241 pp.

21-5764. Lida de MALKIEL, María RosaLa originalidad artistica de "La Celestina". Teoria e investigación.-Eudeba, Buenos Aires, 1970. 784 pp. - V. núm. 18-3191.

21-5765. Rodríguez Pú́rtolas, J.-“Nueva aproximación a $L a$ Celestina". - $A E M$, 6 (1969) . - V. núm. 21-2239.

2I-5766. BARBERA, R. E.-“"Medieval iconography in the Celestina".-RR, 61 (1970), 5-13.

21-5767. Brancaforte, B. - "La Celestina y La Mandragola: La razón como medio de corrupción". - BHS, 47 (1970), 201-209.

21-5768. HoRton, JAMEs F. - Syntactical analysis of "La Celestina". - [Tesis, Univ. of Oklahoma, 1970].

21-5769. Benítez, Frank - Perspectivismo semántico en "La Celestina". - [Tesis, Univ, of California, Riverside, 1970].

21-5770. Alonso, M. R. - "Actualidad de La Celestina”. - Ins, 1970, núm. 279.

21-5771. Ruggerio, M. J. - "La Celestina: Didacticism once more".- $R F, 82$ (1970), 56-64.

21-5772. ERNotF, ANITA - "Sententiae", proverbs and proverbial phrases in the "Celestina". - [Tesis, Columbia Univ., 19707.

21-5773. Ayllón, C. - "La ironía de $L a$ Celestina”. RF, 82 (1970), 37-55.

21-5774. Lida de Malkiel, M. R. - “El ambiente concreto en La Celestina" (N. 19-6742). || $R P h, 24$ (1970-71), 147-148 (Deyermond) .

21-5775. RoJAs, Fernando DE - Tragicomedia de Calixto y Melibea. Libro también llamado La Celestina. Ed, crítica por M. Criado de Val y G. D. Trotter. 3: ed., corr. - C.S.I.C., Madrid, 1970. $\mathrm{xv}+322$ pp. (Clásicos hispánicos). V. núm. 19-3006.

21-5776. Rojas, Fernando de - La Celestina. Ed., introd. y notas de J. Cejador y Frauca. - Espasa-Calpe, Madrid, 1968. 2 ts.: xxxix + 263, 237 pp. (Clás. cast., 20, 23), - V. núm. 17-5700.

21-5777. RoJAs, FERNANDO DE - La Celestina. An edition of the first Italian translation, by Kathleen Kish.-[Tesis, Univ. of Wisconsin, 1970].

V. también núm. 5112.

Gil Vicente: v. núms. 4749-65, 5947.

21-5778. Torres Naharro, Bartolomé DETeatro selecto: Comedia Soldadesca. Comedia Ymenea. Comedia Jacinta. Comedia Calamita. Comedia Aquilana. Pról. y notas de H. López Morales.-Escelicer, Madrid, 1970. $431 \mathrm{pp}$.

21-5779. TORRES NAHARro, BARTOlomé DE -Comedias: Aquilina. Calamina. Soldadesca. Ymenea. Jacinta. Pról. y notas de H. López Morales. - Madrid, 1970. 436 pp. (Teatro selecto).

V. también núm. 5879 .

21-5780. Fernández, LucAs-Farsas y églogas. Ed. de I. Lihani. - Las Américas, New York, 1969. 235 pp.

21-5781. La Comedia Thebaida. Ed. by G. D. Trotter and Keith 'Whinnom-Tamesis Books, London, 1969. lxi +270 pp. II $B H S, 48$ (1971), 62-66 (Deyermond) ; $R Q, 23$ (1970), 451-452 (Fucilla); ZRPh, 88 (1972), 342-346 (López Molina); HR, 39 (1971) , 319-322 (McPheeters) ; BHR, 32 (1970), 705706 (Ramírez).

21-5782. Rueda, LOPE DE - Pasos: El deleitoso, Registro de representantes. Ed. by Kathleen Louise Geib.-[Tesis, Univ. of Iowa; resumen en $D A I, 31$ (1970. 71), 1275 A].

21-5783. Vill.amar, PABlo (adapt.)-Tres pasos de Lope de Rueda y tres entremeses de Cervantes. - Escelicer, Madrid, 1970. 88 pp. (Teatro, 652).

V. también núm. 4160 .

21-5784. Rodríguez-Puértolas, J. - "Fray fñigo de Mendoza, el Aucto de la quinta angustia y Juan de Timoneda".-MLN, $85(1970), 235-240$.

21-5785. Timoneda, JUAN de - El Patrañuelo. - Libra, Madrid, 1970. 179 pp. V. también núm. 5834 .

21-5786. BATtle, John WAyne-Dramatic unity in the plays of Juan de la Cueva. -[Tesis, Duke Univ., 1970].

21-5787. Buendía, IGNAcIo DE - Triunfo de llaneza. Comedia inédita del siglo xvi. - Estudio y ed. de E. M. Wilson.Alcalá, Madrid, 1970.75 pp. (Aula magna, 21). II Íns, 1970, núms. 284/5 (Alonso); BHi, 73 (1971), 199-201 (Canavaggio) .

Cervantes: v. núms. 5783, 6161-5.

21-5788. Delgado Mesonero, FernandoAvila en la vida de Lope de Vega. (Lope, capellán de S. Segundo).-Inst. de Inves- 
tigaciones y Estudios Abulenses "Gran Duque de Alba”, Avila, 1970. 180 pp., 30 láms.

21-5789. Guarner, L. - "Venturas y desventuras de Lope de Vega en tierras valencianas". - BSCC, 46 (1970), 1-57.

21-5790. BlecuA, J. M. - "Más sobre la muerte y entierro de Lope". - SPEO, 24l-243.

21-5791. Green, O. H. - "Lope and Cervantes: peripeteia and resolution". LMMS, 201-209.

21-5792. "Aspectos de Lope de Vega y la tradición literaria culta". - Cuadernos de Arte y Literatura, Granada, 1967, núm. I.

21-5793. Bejarano Pérez, Rafael - Par ticularismo genial de Lope de Vega.Málaga, 1969. $52 \mathrm{pp}$.

21-5794. Esquer ToRres, R. - "La estructura de los personajes en el teatro de Lope de Vega". - HEOL, 219-224.

21-5795. ExUM, Frances BeLL - The treatment of Pedro I de Castilla in the drama of Lope de Vega. - [Tesis, Florida State Univ., 1970].

21-5796. Lanahan, Kathryn Mary M.El elemento religioso en la obra dramática profana de Lope de Vega.-Universidad, Madrid, 1967. 43 pp.-V. núm. 21-2284.

21-5797. Reynolds, Kay Bissell - The dramatic function of the supernatural in non-religious comedies by Lope de Vega. - [Tesis, Univ. of Connecticut, 1970-71].

21-5798. Müller, Gerd F. - Studien zum hagiographischen Theater Lope de Vegas. Exemplarische Interpretation von sechs "comedias de santos". - [Tesis, Univ. de Colonia, 1970]. $178 \mathrm{pp}$.

21-5799. Rodríguez-Pú́rtolas, J. - “La transposición de la realidad en los autos sacramentales de Lope de Vega".BHi, $72(1970), 96-112$.

21-5800. Fernández González, A. R.-“El Arte nuevo de hacer comedias y el teatro del siglo xvII". - Mayurqa, 1969, núm. 2, 130-146.

21-5801. Dulsey, B. - "EI Acero de Madrid de Lope y Le médecin malgré lui de Molière".-Hf, 1970, núm. 40, 9-13.

21-5802. VEGA, LOPE DE - Amor, pleito y desafio. A critical annotated ed. of the autograph manuscript by Leland $D$. Wright, Jr. - [Tesis, Univ. of Washington, St. Louis, 1970].

21-5803. VEGA, LOPE DE - La boba para los otros y discreta para si. A critical ed. by William Irvin Miller. - [Tesis, Univ. of Florida, 1970].

21-5804. VEGA, LOPE DE - El caballero de Olmedo. Ed. de J. Pérez.-Castalia, Madrid, 1970. 164 pp. (Clás. Castalia, 19).

21-5805. Blecua, J. M. - "Nota al Caballero de Olmedo". - SPEO, 231-232.V. núm. 8-13030.

21-5806. JAREÑo, E. - "El caballero de Olmedo, García Lorca y Albert Camus". - PSA, 58 (1970), 219-242.

21-5807. VegA, LOPE DE - El castigo sin venganza. La moza de cántaro.-EspasaCalpe, Madrid, 1970. 221 pp. (Austral, 1434).

21-5808. Dixon, V., \& A. A. Parker - " $E l$ castigo sin venganza: Two lines, two interpretations". $-M L N, 85(1970), 157$ 166.

21-5809. VEGA, LOPE DE - Fuente ovejuna. Peribáñez y el comendador de Ocaña. La dama boba. El caballero de Olmedo. Est. prel. y bibliografía por A. Isasi. -Bruguera, Barcelona, 1970. 559 pp.

21-5810. VEGA, LOPE DE - El lacayo fingido. Ed. e introd. de C. Bravo-Villasante. - Taurus, Madrid, 1970. 205 pp. (Ternas de España, 87).

21-5811. VeGA, LOPE DE - El perro del hortelano. El castigo sin venganza. Ed., introd. y notas de A. D. Kossoff.-Castalia, Madrid, 1970. 369 pp. (Clás. Castalia, 25) .

21-5812. Pelorson, J.-M. - "Lope de Vega et Alonso de Contreras. Une mise au point à propos de El rey sin reino".BHi, 72 (1970), 253-276.

21-5813. Clark, F. M. - "Objective tests of authenticity and the attribution of El toledano vengado to Lope de Vega". $-H f$, 1970, núm. 38, 13-18.

21-5814. Vitiello, Justin-The lyric poetry of Lope de Vega.-[Tesis, Univ. of Michigan, 1970].

21-5815. VEGA, LOPE DE - Obras sueltas. T. 3.-La fonte que mana y corre, Cieza, 1970. [116] pp. (El ayre de la almena, 27) . [Reimpr. facsimilar de tres impresos].-V. núm. 21-2314.

21-5816. VEGA, LOPE DE - Poesía lirica. Est. prel., antología y bibliografía de L. Guarner.-Bruguera, Barcelona, 1970. 549 pp. (Libro clásico).

21-5817. Paoli, R. - "Le Rimas di Lope de Vega e la crisi del petrarchismo".Lavori Ispanistici (Firenze, 1970), 97141.

21-5818. AREs Montes, J. - "Un ruiseñor que huye. (De Lope de Vega a Veiga 
Tagarro)". - Homenaje universitario $a$ D. Alonso (Madrid, 1970), 127-133. 21-5819. Blecua, J. M. - "Villancicos de Lope de Vega a Santa Teresa". - SPEO, 233-240. - V. núm. 17-5802.

21-5820. Tiemann, Hermann - Lope de Vega in Deutschland. Kritisches Gesamtverzeichnis der auf deutschen Bibliotheken vorhandenen älteren Lope-Drucke und-Handschriften, nebst Versuch einer Bibliographie der deutschen Lope-Literatur 1629-1935. - Georg Olms Verlag, Hildesheim-New York, 1970. xv +310 pp. [Reimpr. facs. de la ed. de Hamburgo, 1939].

21-5821. Vosters, S. A. - "Lope de Vega y la lexicografía neerlandesa”. - Hf, 1970, núm. 38, 19-47.

21-5822. VEGA, LOPE DE - La Estrella de Sevilla. - Ed. Nacional, Madrid, 1970. 128 pp.

21-5823. Sturm, H., \& S. Sturm-“The two Sancho's in La Estrella de Sevilla",-RJ, 21 (1970), 285-293.

V. también núms. 4587, 5112, 5376, 5379, $5738,5748,5886,6086$.

21-5824. Piluso, R. V. - "Honor in Valdivielso and Cervantes". $-K R Q, 17$ (1970), 67.81 .

21-5825. Pappanastos, Georgia - The heroic ideal in Guillén de Castro. [Tesis, Univ. of Kentucky; resumen en DAI, 31 (1970-71), 365A-366A].

21-5826. SCHNEIdER Escribano, JEAN-The function of classical myth in the theater of Guillén de Castro. - [Tesis, Emory Univ., 1970-71].

21-5827. Aghe.ANA, Ion T. - The situational drama of Tirso de Molina. [Tesis, Harvard Univ., 1970].

21-5828. KREIS, KARL-WILHELM - Studien zur Liebesmetaphorik im Theater Tirso de Molinas. - [Tesis, Georg-AugustUniversität, Göttingen, 1970]. 495 pp.

21-5829. JAeschKe, SigRid - Grenzen der Charakterdarstellung bei Tirso de Moli. na. - [Tesis, Univ. Libre, Berlin, 1970].

21-5830. Loud, MARY BETH - The concept of comedy in the theater of Tirso de Molina.-[Tesis, Univ. of Kentucky, 1970 .

21-5831. DomeIer, Sister Renée - The parable of the prodigal son in the theater of Tirso de Molina. - [Tesis, Univ. of Michigan, 1970].

21-5832. Brown, SANDra Lou - Tirso's treatment of medieval Spanish history. -[Tesis, Univ. of North Carolina; resumen en DAI, $30(1969-70), 3450 A]$.
21-5833. Tirso DE Molina - Los balcones de Madrid. Éd. critique, introd., texte, notes et variantes par G. Cazottes. Toulouse, 1970. 397 pp. [Tesis de la Univ. de Montpellier].

21-5834. McGrady, D. - "More on Timoneda's Tan largo de lo fiáis story and El burlador de Sevilla". - REH, 4 (1970) , 107-112.

21-5835. Cuartero y Huerta, B. - "Mateo Vázquez [de Lecca], modelo del Burlador". - RLit, 35 (1969), 5-38.

21-5836. Fernández, X. A. - “¿Cómo se llamaba el padre de don Juan?"-REH, 3 (1969), 145-159.

21-5837. TIRso DE Molina - El condenado por desconfiado. Versión de M. y A. Machado.-Edit. Nacional, Madrid, 1970. 133 pp. (Obras del teatro español).

21-5838. Tirso DE Molina - La dama del olivar. Adaptación de J. A. Hormigón. -Edicusa, Madrid, 1970. 236 pp. (Cuadernos para el diálogo).

21-5839. WADE, G. E. - "Tirso's Privar contra su gusto". - KRQ 17 (1970), 93-107.

21-5840. Darst, David High - $A$ thematic and structural analysis of the "Próspera" and "Adversa fortuna de don Alvaro de Luna" attributed to Tirso de Molina. -[Tesis, Univ. of Kentucky, 1970].

21-5841. Tirso DE MolinA - La venganza de Tamar. Ed. by A. K. G. Paterson. Cambridge Univ. Press, London-New York, 1969. 150 pp. || RQ 23 (1970), 452-453 (Fucilla) ; BHS, 47 (1970), 164165 (Wilson).

V. también núms. 5738, 5748, 5894.

21-5842. Mira de Amescua, Antonio-La casa del tahur. Ed. crítica y anotada por John Fameli. - [Tesis, Univ. of Southern California, 1970].

21-5843. Palls, B. P. - "Una justificación hermafrodita del título de la comedia de Mira de Amescua La fénix de Salamanca". - PH, 12 (1968-70), 499-509.

21-5844. Mira de Amescua, Antonio Nuestra Señora de los Remedios. An ed. and study by Sister M. Carmel Therese Favazzo. - [Tesis, St. John's Univ., 1970].

21-5845. Vélez de Guevara, Lurs-Los hijos de la Barbuda. Introd., texto crítico y notas por M. G. Profeti. - Università, Pisa, 1970. 319 pp.

21-5846. Martín Jiménez, J. - "El autor de El diablo cojuelo". - BACórd, 196567, núm. 87.

21-5847. Holtz, UwE - "Der hinkende 
Teufel" von Vélez de Guevara und Lesage. Eine literatur- und sozialkritische Studie. - A. Henn, WuppertalElberfeld, 1970. 172 pp. [Tesis de la Univ. de Colonia].

V. también núm. 6057 .

21-5848. Anibal, C. A. - "Juan Ruiz de Alarcón". - LWRA, 71-86.

21-5849. Claydon, Ellen - Juan Ruiz de Alarcón, baroque dramatist. - Garden City, N. Y., 1970. 175 pp. (Estudios de Hf).-V. núm. 19-3093.

21-5850. Alatorre, A. - "Para la historia de un problema: la mexicanidad de Ruiz de Alarcón". - LWRA, $11-43$, 263276.-V. núm. 19-3091.

21-5851. KenNedy, R. L. - “Contemporary satire against Ruiz de Alarcón as a lover". - LWRA, 45-60, 276-285.

21-5852. Green, O. H. - "Juan Ruiz de Alarcón and the topos chomo deformis et pravus ". - $-L W R A, 63-68,285-286 .-$ V. núm. 10-23705.

21-5853. Hamilton, T. E. - "Comedias attributed to Alarcón in the light of his known epistolary practices". $-L W R A$, 151-161, 295-297.

21-5854. VÁzquez-ArJona, C. - "Elementos autobiográficos e ideológicos en el teatro de Alarcón". - LWRA, 91-137, 286-292.

21-5855. Dr Lillo, LeONARD M. - Characterization and ethics in the plays of Juan Ruiz de Alarcón.-[Tesis, Rutgers Univ., 1970].

21-5856. Castellanos, R. - "Juan Ruiz de Alarcón: una mentalidad moderna". -ALM, 8 (1970), 147-172.

21-5857. Asнсом, B. B. - "Verbal and conceptual parallels in the plays of Alarcón". - LWRA, 163-184, 297-304.V. núm. 11-26633.

21-5858. Silverman, J. H. - “El gracioso de Juan Ruiz de Alarcón y el concepto de la figura del donaire tradicional".LWRA, 187-195, 304-306. - V. núm. 8-13056.

21-5859. Pollin, A. M. - "The religious motiv in the plays of Juan Ruiz de Alarcón". - LWRA, 139-148, 293-295. -V. núm. 16-48748.

21-5860. Casalduero, J. - “E1 gracioso de El Anticristo". - LWRA, 199-211.V. núm. 9-14314.

21-5861. Espantoso-Folvy, A. M. - "The problem of astrology and its use in Ruiz de Alarcón's $E l$ dueño de las estrellas". -LWRA, 213-222, 307-309. - V. núm. 18-6657.
21-5862. Gómez de las Cortinas, J. F."La génesis de Las paredes oyen de Ruiz de Alarcón”. - LWRA, 247-258, 312-313.

21-5863. Soons, A. - "La verdad sospechosa in its epoch". - LWRA, 239-245, 311.-V. núm. 19-6865.

21-5864. Tyler, R. W. - "A possible influence on $L a$ verdad sospechosa".-BC, $22(1970), 6-7$.

21-5865. Rirey, E. C. - “Alarcón's mentiroso in the light of the contemporary theory of character".-LWRA, 225-236, 310-311. - V. núm. 17-5823.

Castillo Solórzano: v. núm. 6179.

21-5866. Flasche, H.-“Vorbemerkungen" [sobre estudios de Calderón]. - HFCB, vii-xxv.

21-5867. BrüGgemanN, W. - "Zur deutschen Calderón-Forschung des 19. Jahrhunderts". - $S p F, 25$ (1970), 176-272.

21-5868. Trench, Richard C. - An essay on the life and genius of Calderon, with translations from his "Life's a dream" and "Great theatre of the world". $2 \mathrm{~d} \mathrm{ed}$. -Haskell House, New York, 1970. 229 pp. [Reimpr. de la ed. de 18801.

21-5869. Cruickshank, D. W.-“Calderón's handwriting". - MLR, 65 (1970) , 65-77. 21-5870. Muir, K. - "The comedies of Calderón". - [En] Elmer M. Blistein (ed.), The drama of the Renaissance: Essays for Leicester Bradner (Providence, R. I., 1970), 123-133.

21-5871. Cossio, J. M. DE--"Der Rationalismus von Calderóns Dramenkunst".HFCB, 89-111.

21-5872. BercheM, T. - "Algunos aspectos de la expresión literaria de Calderón". - Mélanges... Pierre Fouché (Paris, 1970) , 183-193.

21-5873. Pérez Bautista, Florencio-la medicina y los médicos en el teatro de Calderón de la Barca.-Salamanca, 1968. $105 \mathrm{pp}$.

21-5874. Wilson, E. M. - “The four elements in the imagery of Calderón”. $-H F C B, 112-130$.

21-5875. Тномаs, L.-P. - “Les jeux de scène et l'architecture des idées dans le théâtre allégorique de Calderón".$H F C B, 1-40$.

21-5876. PÁramo Pomareda, J.-"Betrachtungen zu Calderón de la Barcas mythologischen Autos". - HFCB, 347-381.

21-5877. Frasche, H. - “Calderón als Paraphrast mittelalterlicher Hymnen”. $-H F C B, 425-464$. - V. núm. 18-6688.

21-5878. HrLborN, H. W. - "Calderón's ssilvas". - HFCB, 152-180. 
21-5879. Wilson, E. M. - "Shakespeare and Christian doctrine: some qualifications". - Shakespeare Survey, 1970, núm. 23, 79-89. [En relación con la censura española del Siglo de Oro (v.gr. Torres Naharro) y con los autos de Calderón]. 21-5880. Baver, Hflga - Der Index Pictorius Calderóns. Untersuchungen zu seiner Malermetaphorik. - Ibero-Amerikan. Forschungs-Institut-Gram de Gruyter, Hamburg, 1970. 267 pp., ilustr.-V. núm. 20-6836.

21-5881. Ruiz Lacos, M. - "Apuntes sobre acotaciones musicales en los autos de Calderón". - AIEM, 6 (1970), 63-77.

21-5882. SaGe, J. - "Calderón und die Theatermusik". - HFCB, 291-320. V. núm. 11-28484.

21-5883. Calderón de la Barca, PedroTeatro escogido: La vida es sueño. El alcalde de Zalamea. El mágico prodigioso. - Aguilar, Madrid, 1970. 472 pp.

21-5884. Calderón de la Barca, PedroDrammi e misteri sacramentali. Introd. e trad. di C. Vian.-Istituto Editoriale Italiano, Milano, 1970. $574 \mathrm{pp}$.

21-5885. Rull, E., У J. C. TORRes-"Manuscritos calderonianos de autos sacramentales". - BFE, 1970, núms. 34/5, 29-72.

21-5886. Calderón de la Barca, PedroEl alcalde de Zalamea. En las versiones de..., y LOPE DE VEGA. Ed., pról. y notas de J. Alcina Franch. - Juventud, Barcelona, 1970. 322 pp. (Libros de bolsillo $Z, 180)$.

21-5887. Calderón de la Barca, PedroDarlo todo, y no dar nada. A study and critical ed. by John J. Portera.-[Tesis, Univ, of Southern California, 1970].

21-5888. KrYNen, J. A. - "Del honor en el teatro español. (Algunas observaciones en torno a La devoción de la cruz, de Calderón) ".-RUM, 19 (1970), núm. 73, 195-205.

21-5889. Entwistle, W. J. - "Calderón's $L a$ devoción de la cruz".-HFCB, 206-217.

21-5890. Valblena Pratt, A.-"Die Inszenierung einer "Comedia "Calderóns". $-H F C B, 41-88$. [La fiera, el rayo y la piedra].

21-5891. Calderón de la Barca, PedroEl gran Duque de Gandia. Ed., introd. y notas de G. Siebenmann. - Anaya, Salamanca, 1970. 192 pp. (Bibl. Anaya).

21-5892. WHitaker, S. B. - "Schoolboy actors in El gran Duque de Gandia".BC, 22 (1970) , 3-5.

21-5893. Calderón de la Barca, Pedro-
El gran teatro del mundo. La dama duende. - Libra, Madrid, 1970. 174 pp. 21-5894. López Palmero, M. - "La doctrina de la salvación por las obras en el teatro occidental". - RETe, 1970, núm. 11, 65-68. [El gran teatro del mundo, El condenado por desconfiado].

21-5895. Calderón de la Barca, PedroGuárdate del agua mansa. Amar después de la muerte. - Espasa-Calpe, Madrid, 1970. 244 pp. (Austral, 1422).

21-5896. Calderón de la Barca, PedroGustos y disgustos son no más que imaginación. A critical ed. and study by Claudio Ybarra Silva. - [Tesis, Univ. of Southern California, 1970].

21-5897. Hesse, E. W.- "The two versions of Calderón's El laurel de Apolo". HFCB, 181-205.

21-5898. Thiner, R. J.-“The final ambiguity of El médico de su honra".-SPh, $67(1970), 237-244$.

21-5899, Cruickshank, D. W.-“Calderón's King Pedro: just or unjust?" $-S p F, 25$ (1970), 113-132.

21-5900. Parker, A. A. - "The meaning of "discreción * in No hay más fortuna que Dios: The medieval background and 16th- and 17th-century usage". HFCB, 218-234.

21-5901. Glaser, E. - "Calderón de la Barca's $E l$ orden de Melchisedech". $H F C B$, 401-424. - V. núm. 18-3416.

21-5902. WARDROPPER, B. W. - "The unconscious mind in Calderón's $\mathrm{El}$ pintor de su deshonra". - HFCB, 235-256.

21-5903. SLoANe, R. - "Action and role in El principe constante". - $M L N, 85$ (1970), 167-183.

21-5904. Kayser, W. - "Zur Struktur des Standhaften Prinzen von Calderón".HFCB, 321-346. - V. núm. 14-39208.

21-5905. Lofrss, J. - "El principe constante and The Indian emperour: A reconsideration".-MLR, 65 (1970), 761767.

21-5906. Rivers, E. L. - "Fénix's sonnet in Calderón's Principe constante". $-H R$, 37 (1969) , 452-458.

21-5907. Smieja, F. -- "El Príncipe de Polonia ante Breda, según un diario coetáneo". - RLit, 35 (1969), 95-103. [A propósito de El sitio de Bredá].

21-5908. Calderón de la Barca, PedroLa vida es sueño. El alcalde de Zalamea. Pról. de G. Díaz Plaja. 3a ed.-Porrúa, México, 1970. xxxvi + 165 pp. (Sepan cuantos, 41) . [4. ed., 1972].-V. núm. 20-6886. 
21-5909. González, Roberto Óscar A proximación estructuralista a "La vida es sueño": Ensayo de un método.-[Tesis, Yale Univ., 1970].

21-5910. Aubrun, C.-V. - "La langue poétique de Calderón, notamment dans $L a$ vida es sueño". - HFCB, 382-400.-V. núm. 16-44766.

21-5911. SUÁrez MUÑIz, D. - "El existente cristiano en $L a$ vida es sueño". $-U d A$, 46 (1970), 57-79.

21-5912. Urrutia, J. - "Una escena de La vida es suer̃o. Su organización dramática”. - CuH, 83 (1970), 173-191.

21-5913. Suárez-Galbán, E. - "Astolfo: La moral y su ilustración dramática en La vida es sueño".-Hf, 1970, núm. 38, $1-1 \%$.

21-5914. Flasche, H. - "Baustein IV zu einer kritischen und kommentierten Ausgabe Calderóns. (Vers 803-1345 des Auto Sacramental La vida es sueño)."$S p F, 25$ (1970), 133-175. - V. núm. 19-3149.

21-5915. Larios, L. - "Calderón de la Barca y las fiestas de la Fuencisla en 1662". - ESeg, 22 (1970), 55-60.

21-5916. Heselhaus, C. - "Calderón und Hofmannsthal". - HFCB, 257-290.-V. núm. 10-21119.

21-5917. Flasche, H. - "Calderón intra. ducible. Calderónverse im französischen Gewand". - HMW, 661-687.

21-5918. Cerny, V. - "Le sbaroquisme" du Soulier de satin". - RLC, 44 (1970), 472-498. [Y, en concreto, su calderonismo].

V. también núms. 4587, 5389, 5738, 5748, 6335.

21-5919. Proferi, M. G. - "La traduzione francesc del Para todos di J. Pérez de Montalbán".-Proh, 1 (1970), 109-119.

21-5920. Profeti, Maria Grazia-Montalbán: un commediografo dell'età di Lope. -Università, Pisa, 1970. $187 \mathrm{pp}$.

21-5921. Rojas Zorrilla, FrAncisco DE Del rey abajo, ninguno. Ed. de B. Wittmann. - Anaya, Salamanca, 1970. 133 pp. (Bibl. Anaya).

21-5922. Rojas Zorrilla, Francisco deNuestra Señora de Atocha. An annotated critical ed. by Kevin Thomas Schmelter. -[Tesis, Univ. of New Mexico; resumen en DAI, 31 (1970-71), 1770A].

21-5923. Moreto, Agustín - El desdén con el desdén. Introd., ed. y notas de $\mathrm{J}$. $\mathrm{H}$. Parker. - Anaya, Salamanca, 1970. 131 pp. (Bibl. Anaya).

21-5924. Moreto, Agustín - El lego del
Carmen, San Franco de Sena. Ed. de F. Smieja. - Anaya, Salamanca, 1970. 141 pp. (Bibl. Anaya).

21-5925. Moreto, A. - El poder de la amistad, ed. D. E. Dedrick (N. 20-6897). || BHS, 47 (1970) , 165-166 (Heathcote); Proh, 1 (1970), 127-130 (Profeti); H, 53 (1970), 572 (Ruiz-Fornells).

21-5926. Godínez, Felipe - La traición contra su dueño. A critical ed., together with an introductory study, by Thomas Charles Turner. - [Tesis, Univ. of Missouri, 1970].

21-5927. Mathias, Julio - Un dramaturgo del siglo xvii: Francisco de Leiva (1630-1676). - Edit. Nacional, Madrid, 1970. 161 pp. (Prosistas españoles).

21-5928. Bances Candamo, Francisco Theatro de los theatros de los passados $y$ presentes siglos. Prol., ed. and notes by D. W. Moir.-Tamesis Books, London, 1970. 191 pp. \|ZRPh, 87 (1971), 675 (Rothe).

21-5929. Pérez Feliú, José Jorge - Los autos sacramentales de Bances Candamo.-Universidad, Madrid, 1969. 26 pp.

21-5930. Pérez Feliú, José J.-Los autos sacramentales de Bances Candamo. [Tesis, Univ. de Madrid; resumen en RUM, 18 (1969), núm. 72, 44-45].

21-5931. OnRubia de Mendoza, José-El teatro de José de Cañizares.-Universidad de Barcelona, 1964.

Autores modernos

21-5932. GatTI, J. F. - "Le triomphe de Plutus de Marivaux y El triunfo del interés de Ramón de la Cruz". - Fil, 14 (1970) , 171-179

21.5933. Fernández de Moratín, LeAndro -Teatro completo. T. 1: El viejo y la niña. El si de las niñas. Ed., pról. y notas de F. Lázaro Carreter.-Labor, Barcelona, 1970. $358 \mathrm{pp}$. (Textos hispánicos modernos, 2) .

21-5934. Fernández de Moratín, Leandro -La comedia nueva. Ed., introd., notas y documentos de J. Dowling. - Castalia, Madrid, 1970. $346 \mathrm{pp}$.

21-5935. Dowling, J. C.-“Moratín's La comedia nueva and the reform of the Spanish theater". - $H, 53(1970), 397-$ 402.

21-5936. Johnson, R. - "Moratín's diary". -BHS, 47 (1970), 24-36.

21-5937. Fernández de Moratín, Leandro -Epistolario.-J. Pérez del Hoyo, Madrid, 1970. $168 \mathrm{pp}$. 
21-5938. Rodríguez CF.peda, E. - "Más cartas inéditas de Moratín". - ROcc, 30 (1970), 343-352.

V. también núms. 5094, 5952.

Martínez de la Rosa: v. núm. 6941.

Duque de Rivas: v. núms, 5411-2.

21-5939. Hartzenbusch, JuAN EUGENIo Los amantes de Teruel. Introd. ("Le théâtre à Madrid de 1833 à 1850") et éd. crit. par J.-L. Picoche.-Centre de Recherches Hispaniques, Paris, 1970. 2 ts. \| $L N L, 1971$, núm. 197, 78-79 (Larrieu) .

21-5940. Mathias, Julio - Echegaray.E.P.E.S.A., Madrid, 1970. 190 pp. (Grandes escritores contemporáneos, 24).

Bécquer: v. núm. 5508.

Galdós: v. núms. 6333-8.

Unamuno: v. núms. 6990-3.

Valle-Inclán: v. núms. 6395-6409.

21-5941. Griffin, Julia - El teatro de Benavente desde sus comienzos hasta 1914. - Tesis, New York Univ.; resumen en $D A I, 31 \quad(1970-71), 1799 A-$ 1800A].

21-5942. Alonso, Armando José - Lo sentencioso en la obra dramática de Jacinto Benavente. - [Tesis, Univ. of Florida, 1970].

21-5943. DíAz, J. A. - "Los dramas «negros» de Jacinto Benavente". - H, 53 (1970) , 207-211.

21-5944. Mainer, J. C. - "Consideraciones sobre Benavente, los intelectuales y la política". - fns, 1970, núm. 281.

21-5945. Benavente, Jacinto - Obras completas. T. 10. - Aguilar, Madrid, 1969. $970 \mathrm{pp}$.

21-5946. Villa Selma, J. - "Notas en torno a Los intereses creados y sus posibles fuentes". - CuH, 81 (1970), 588-611.

21-5947. PIRES DE LIMA, F. DE C. - "Influência de Gil Vicente em Os interesses criados de Jacinto Benavente". - RDTP, $26(1970), 303-313$.

V. también núms. 5108, 5194.

21-5948. Seco, Manuel - Arniches y el habla de Madrid. - Alfaguara, Madrid, 1970. 614 pp. (Estudios de literatura contemporánea, 5). $\| P S A, 61$ (1971), 105-108 (Amorós); RLit, 35 (1969), 125-127 (Ramoneda Salas).

21-5949. Trinidad, Francisco - Arniches: Un estudio del habla popular madri. leña. - Góngora, Madrid, 1969. 197 pp. -V. núm. 2I-2444.

21-5950. Díaz-Cañabate, A. - "La fórmula teatral del arnichismo". - ROcc, 29 (1970) , 93-99.
21-5951. García Lorenzo, L. - "De Jacinto Grau a Antonio Buero Vallejo: variaciones sobre un mismo tema".$\mathrm{CuH}, 82(1970)$, 169-177.

21-5952. Montero Padilla, J. - “De Leandro Fernández de Moratín a Gregorio Martínez Sierra: Un tema y dos comedias". - HEOL, 243-251.

21-5953. SAlgado, M. A. - "Teatro de ensueño: colaboración modernista de Juan Ramón Jiménez y G. Martínez Sierra". -Hf, 1970, núm. 38, 49-58.

García Lorca: v. núms. 5618-28, 5806.

21-5954. CABAT, ROBERT - Time and tradition in the lyric plays of Alejandro Casona.-[Tesis, New York Univ,; resumen en $D A I, 31 \quad(1970-71), 1790 A-$ $1791 \mathrm{~A}]$.

21-5955. Bernal Labrada, Hilda - Simbolo, mito y leyenda en el teatro de Casona. - [Tesis, Columbia Univ., 1970]. 21-5956. Casona, Alejandro -Flor de leyendas. 4: ed, - Fernández, México, 1970. 95 pp., ilustr. (Páginas de oro).V. núm. 20-6937.

V. también núms. 5625, 5758 .

Max Aub: v. núms. 6498-9.

21-5957. Haverbeck O., E. - "Aproximaciones al teatro de Buero Vallejo”. Stylo, 1970, núm. 10, 25-87.

21-5958. Giulrano, W. - "The role of man and of woman in Buero Vallejo's plays". - Hf, 1970, núm. 39, 21-28.

21-5959. BEJEL, EMILIo F. - Lo moral, lo social, y lo metafísico en el teatro de Buero Vallejo. - [Tesis, Florida State Univ., 1970].

21-5960. Puente, P. DE LA - "El teatro histórico de Buero Vallejo”.-Uro, 1970, núm. 2, 90-95.

21-5961. Atlef, A. F. M. - "Las cartas boca abajo: clave del teatro de Buero". -PS. 59 (1970), 91-112.

21-5962. Buero Vallejo, Antonio - El sueño de la razón. Fantasía en dos partes. - Escelicer, Madrid, 1970. $106 \mathrm{pp}$.

21-5963. Kronik, J. W. - "Buero Vallejo y su Sueño de la razón". - Uro, 1970 , núms. 5/6, 151-156.

21-5964. FERnÁndez SANTos, A. - "El sueño de la razón de Antonio Buero Vallejo". -Ins, 1970, núm. 280.

21-5965. Martínez Ruiz, F. - "Buero Vallejo o El sueño de la razón". - $R y F$, $181(1970), 464-468$.

21-5966. Buero Vallejo, Antonio - El tragaluz. El sueño de la razón.-EspasaCalpe, Madrid, 1970. 213 pp. (Austral, 1496) . 
21-5967. CASA, F. P. - "The problem of national reconciliation in Buero Vallejo's El tragaluz". - RHM, 35 (1969), 285-294.

V. también núms. 5758, 5951 .

21-5968. Olmo, LAURo - La camisa. El cuerpo. El cuarto poder. - Taurus, Madrid, 1970. 256 pp. (El mirlo blanco, 14).

21-5969. Fraile, M. - "Teatro y vida en España. La camisa, La corbata y Tres sombreros de copa". - Proh, 1 (1970), 253-269.

21-5970. ZeLler, LOREN Louis - Carlos Muñiz and the Spanish theater of social protest. - [Tesis, Univ. of Iowa, 1970].

21-5971. Micnon, P.-L.-"Fernando Arrabal". - Avant-Scène, Paris, 1970, núm. 443.

21-5972. Messerman, Lois M. Frolkis The theatre of Fernando Arrabal: $A$ garden of earthly delights.-[Tesis, Ohio State Univ., 1970].

21-5973. Honingsblum, Gerald-Le théatre d'Arrabal.-[Tesis, Univ. of Chicago, 1970-71].

21-5974. Cavazzana, R.-“Un sclaroscuro* español: Fernando Arrabal". - RETe, 1970, núm. 11, 45-50.

21-5975. Arrabal, Fernando - Teatro 1. Teatro 2. - Milano Libri, Milano, 1970.

\section{PROSA NARRATIVA}

21-5976. Ayala, Francisco - Reflexiones sobre la estructura narrativa. - Taurus, Madrid, 1970. 78 pp. (Cuadernos Taurus, 91) .

21-5977. GÁndara, CARMen - El mundo del narrador. - Sudamericana, Buenos Aires, 1968. [Estudia, entre otros, a Ortega y Gasset y a Valle-Inclán].

21-5978. Durán, A. - "Las técnicas de la novela sentimental española". - SNo, 1970 , núm. 1, 69-82.

21-5979. Krauss, W. - "Algunas observaciones sobre la novela pastoril española". - Eco, 23 (1971), 652-698.

21-5980. Prieto, A. - "La sextina provenzal y su valor como elemento estructural de la novela pastoril". - Proh, 1 (1970), 47-70.

21-5981. SPIEKER, JosepH B. - The "novela ejemplar" in the Golden Age. [Tesis, Catholic Univ., 1970].

21-5982. Gran JA, F. DE LA - "Dos cuentos árabes de ladrones en la literatura española del siglo xvr".-AlAn, 33 (1968), 459-469.
21-5983. GranJA, F. DE LA - “El castigo del galán. (Origen árabe de un cuento de Luis Zapata)". - AlAn, 34 (1969), 229-243.

21-5984. Herrero Salgado, Félix (ed.) Narraciones de la España del barroco. - Magisterio Español, Madrid, 1970. 159 pp. (Novelas y cuentos, 73). II AION-R, 14 (1972), 175-176 (Bagnati).

21-5985. Ferreras, J. I. - "Novela y costumbrismo".-CuH, 81 (1970), 345-367.

21-5986. Castañón, L. - “Bibliografía de novelas asturianas".-BIEA, 24 (I970), 83-103.

21-5987. Ferreras, J. I. - “La generación del 68”. - CuH, 83 (1970), 549-561.

21-5988. Godoy Gallardo, E. - "El movimiento naturalista y la crítica española del siglo xix". - Map, 1970, núm. 23, 55-70.

21-5989. Sánchez de Palacios, M. - “La novela española en la encrucijada de dos siglos". - Arb, 76 (1970) , 327-333.

21-5990. SÁInz de Robles, F. C. - Raros y olvidados. (La promoción de "El Cuento Semanal"). - Prensa Española, Madrid, 1971. 174 pp.

21-5991. Fuentes, V. - "La novela de la mina en la narrativa española 1903-1930: sobre su significación ideológica". Norte, 1970 , núm. 3.

21-5992. Ferreras, Juan Ignacio - Tendencias de la novela española actual, 1931-1969, seguidas de un catálogo de urgencia de novelas y novelistas de la posguerra española. - Eds. Hispanoamericanas, París, 1970. 266 pp.

21-5993. Miller, JOHN Charles L. - Cuatro testimonios literarios de la guerra de Marruecos, 1921-1926: "Notas marruecas de un soldado" de Ernesto Giménez Caballero; "El blocao" de José Diaz Fernández; "Imán" de Ramón Sender y "La ruta" de Arturo Barea.[Tesis, Middlebury College, 1970$].$

21-5994. Shune-Young, Chang - Castilla y la novela española actual. - [Tesis, Univ. de Madrid; resumen en $R U M$, 18 (1969), núm. 72, 39-41].

21-5995. Corrales EgeA, José-La novela española actual. Ensayo de ordenación.Edicusa, Madrid, 1971. 270 pp. (Cuadernos para el diálogo).

21-5996. Bosch, RAFAEL - La novela española del siglo $x \times$. T. 1: De la Restauración a la Dictadura. - Las Américas, New York, 1970. 260 pp. \|BAbr, 45 (1971), 482-483 (Childers).

21-5997. PONCE dE LEÓN, José LUIS S. - 
Cuatro novelistas de la Guerra Civil de España (1936-39). - [Tesis, Stanford Univ.; resumen en $D A, 27$ (1966-67), 3467A].

21-5998. Ponce de León, J. L. S. - "La novela de la guerra civil de España y el modelo Tolstoi".-Íns, 1970, núm. 283.

21-5999. Sobejano, Gonzalo - Novela española de nuestro tiempo. (En busca del pueblo perdido). - Prensa Española, Madrid, 1970. 479 pp. || Ins, 1971, núm. 294 (Amorós); PSA, 61 (1971), 220224 (F.G.C.) .

2I-6000. Conte, Rafael (ed.) - Narraciones de la España desterrada.-Edhasa, Barcelona, 1970. 248 pp. (El puente literario). || fns, 1970, núm. 286 (Domingo) .

21-6001. Rubio, Rodrigo (ed.) - Narrativa española 1940-1970. - E.P.E.S.A., Madrid, 1970. 202 pp. (Grandes escritores contemporáneos).

21-6002. Godoy Gallardo, E. - "Indice crítico-bibliográfico del premio Eugenio Nadal: 1944-1968". - Map, 1970, núm. 22, 109-136.

21-6003. Entrambasaguas, Joaquín de (ed.) -Las mejores novelas contemporáneas. T. 12: 1950-1954. - Planeta, Barcelona, 1971. 1506 pp.-V. núm. 21-2486.

21-6004. Tola de Habich, F., y P. Grieve -"Sobre la novela española e hispanoamericana. (Opiniones de J. M. Caballero Bonald)". - Map, 1970, núm. 23, 39-54.

21-6005. Oguiza Santoyo, Tomás - Temática y técnica del testimonio en la novela española contemporánea. (19581968),-[Tesis, Univ, of Wisconsin, 197071].

21-6006. Corrales Egea, J. - "Situación actual de la novela española. La scontraola".-Ins, 1970, núm. 282, supl.

21-6007. García Pavón, Francisco (ed.) Antología de cuentistas españoles contemporáneos. 2a ed. actualizada. Reimpr. -Gredos, Madrid, 1971. 452 pp. (Antologia hispánica, 16). - V. núm. 19-7055.

21-6008. Hernández, Guillermo, Edenia y JUANa Amelia - La novelistica española de los 60.-New York, 1971. 194 pp. [L. Martín-Santos, J. Marsé, M. Delibes, J. Goytisolo, J. Benet, A. M. Matute].

21-6009. Fernández Santos, Jesús (ed.) Siete narradores de hoy. 2: ed.-Taurus, Madrid, 1970. 190 pp. (Temas de España).-V. núm. 18-6884.

V. también núms. 4537-43, 5673.
A utores antiguos

21-6010. González de Mendoza, Ángel El libro de caballería en la Fiesta del Libro. - Instituto de España, Madrid, 1970. $31 \mathrm{pp}$.

21-6011. Jones, Cameron Davis - Realism in Spanish chivalresque fiction before 1500.-[Tesis, Univ. of Southern California, 1970].

21-6012. Durán, A. - "La eamplificatio» en la literatura caballeresca española”. -MLN, 86 (1971), 123-135.

21-6013. Amadis de Gaula. Ed. de E. B. Place. T. I. Reimpr, aum. - Instituto Miguel de Cervantes, Madrid, 1971. li +358 pp.-V. núm. 17-5939.

21-6014. BARET, EUGÈnE-De l" $A$ madis de Gaule" et de son influence sur les mours et la littérature au 16 e au 17 e siècle. 2e éd.-Slatkine, Genève, 1970. 236 pp. [Reimpr. de la ed. de París, 1873].

21-6015. Cravens, Sydney Paul-Feliciano de Silva y los elementos pastoriles en sus libros de caballeria.-[Tesis, Univ. of Kansas, 1971].

21-6016. Ortúñez de Calahorra, DiegoEspejo de principes y cavalleros, $\mathrm{El}$ Caballero del Febo. A critical ed. of a sixteenth century romance of chivalry by Daniel B. Eisenberg. - [Tesis, Brown Univ., 1970].

21-6017. Historia de los amores de Paris y Viana. Ed. A. Galmés de Fuentes.Gredos, Madrid, 1970.350 pp. $\| A I O N-R$, 13 (1971), 366-367 (Cirillo).

V. también núms. 3316, 5094 .

21-6018. LANGBEHN-ROHLAND, REgUlA Zur Interpretation der Romane des Diego de San Pedro. Hrgs. von Kurt Baldinger et al.-C. Winter, Heidelberg, 1970. 227 pp.-V. núm. 20-7003.|| BICG, 25 (1970), 499-501 (Schütz).

21-6019. San Pedro, Diego DE - Cárcel de amor. Arnalte e Lucenda. Sermón. Poesias. Desprecio de la fortuna. [Seguido de] Questión de amor. Introd. de $\mathbf{A}$. Souto Alabarce. - Porrúa, México, 1971. $\mathrm{xxx}+187$ pp. (Sepan cuantos, 199).

21-6020. Whinnom, K. - "Lucrezia Borgia and a lost edition of Diego de San Pedro's Arnalte y Lucenda". $-A I O N-R$, 13 (1971), 143-151.

21-6021. Flores, JUAN DE - Grimalte $y$ Gradissa. Ed. by Pamela Waley.-Tamesis Books, London, 1971. Ixi + 75 pp.

21-6022. Delicado, F.-La Lozana andaluza, ed. B. Damiani (N. 21-2512) . $\| H, 54$ (1971), 968 (Jones) . 
21-6023. Hernando Ortiz, José Antonio -La originalidad artistica de "La Lozana andaluza".-[Tesis, Yale Univ. 1970].

21-6024. BAGBY, A. I. - "La primera novela picaresca española". - $L T, 1970$, núm. 68, 83-100. [La Lozana andaluza].

21-6025. ZAMora Vicente, Alonso - Qué es la novela picaresca. 2a ed.-Columba, Buenos Aires, 1970. 68 pp. (Esquemas, 54) .-V. núm. 18-3508.

21-6026. Laurenti, Joseph L. - Estudios sobre la novela picaresca española. C.S.I.C., Madrid, 1970. xii + 144 pp. (RLit, anejo 29) .

21-6027. Burón, ANTonio - Hacia una evaluación exacta de lo que se entiende por literatura picaresca. - [Tesis, Univ. of Minnesota, 1971].

21-6028. Rico, Francisco - La novela picaresca y el punto de vista. - Seix Barral, Barcelona, 1970. 141 pp. (Bibl. breve). II fns, 1970, núms. 284/5 (Mainer); Fil, 14 (1970), 210-214 (Sabor de Cortazar) .

21-6029. WALKer, John MARLAN - The "Satyricon", the "Golden ass" and the Spanish Golden Age picaresque novel. -[Tesis, Brigham Young Univ., 1970-71].

21-6030. Parker, A. A. - Literature and the delinquent. The picaresque novel (N. 20-7014) . || Fil, 14 (1970), 201-205 (Sabor de Cortazar).

21-6031. Laurenti, Joseph L. - Los prólogos en las novelas picarescas españo. las.-Castalia, Madrid, 1971. 140 pp.

21-6032. Alfaro, G. A. - "El cuento intercalado en la novela picaresca", $-H f$, 1970, núm. 40, 1-8.

21-6033. Prieto, A. - "De un símbolo, un signo y un síntoma (Lázaro, Guzmán y Pablos)". - Proh, 1 (1970), 357-395.

21-6034. Valbuena Prat, A. (ed.) - Dos novelas picarescas. - Bedout, Medellín (Colombia), 1970. 208 pp.

21-6035. Carrasco, Hazel - A critical and annotated edition of " $E l$ guitón Honofre", an unpublished picaresque novel of the early seventeenth century. $-[$ Tesis, Univ. of California, Los Angeles, 1971].

21-6036. WICKS, UlRICH - Metamorphoses of the "picaro": Picaresque episode. [Tesis, Univ. of Iowa, 1970].

21-6037. Heidenreich, Helmut (ed.) Pikarische Welt. Schriften zum europäischen Schelmenroman. - Wissenschaftliche Buchgesellschaft, Darmstadt, 1969. 501 pp.

V. también núm. 5109.
21-6038. LaURenti, J. L.-“Ensayo de una bibliografía del Lazarillo de Tormes (1554) y de la Segunda parte de la vida de Lazarillo de Tormes... de Juan de Luna (1620): Suplemento". - ATON-R, 13 (1971), 293-330. - V. núm. 19-7081.

21-6039. Damiani, B. M. - "Lazarillo de Tormes: present state of scholarship".AION-R, 12 (1970), 5-19.

21-6040. Caso González, J. - "La génesis del Lazarillo de Tormes".-HEOL, 175196.-V. núm. 20-2807.

21-6041. Rico, F, - "En torno al texto crítico del Lazarillo de Tormes".-HR, 38 (1970), 405-419.

21-6042. García-Angulo, Efraín - Vocabulario del "Lazarillo de Tormes". Garcián, Barcelona, 1970. 207 pp.

21-6043. Hiтchсоск, R. - "Lazarillo and vuestra merced”. - MLN, 86 (1971), 264-266.

21-6044. SpIvakovsky, E.-“New arguments in favor of Mendoza's authorship of the Lazarillo de Tormes". - S, 24 (1970), 67-80.

21-6045. Todesco, V. - "Rileggendo il Lazarillo".-QIA, 5 (1970), 73-79.

21-6046. Ayala, Francisco - El "Lazarillo" reexaminado. Nuevo examen de algunos aspectos.-Taurus, Madrid, 1971. 98 pp. (Cuadernos Taurus).

21-6047. Casalduero, J. - "Sentido y forma del Lazarillo". - Exilio, 1971, núm. 2, 47-61.

21-6048. Minguet, Charles - Recherches sur les structures narratives dans le "Lazarillo de Tormes". Préf. de B. Pottier.-Centre de Recherches Hispaniques, Paris, 1970. 132 pp., ilustr. (Thèses, mémoires et travaux, 15) .

21-6049. Puccini, D. - "La struttura del Lazarillo de Tormes". - Annali delle Facoltà di Lett. e Fil. e Magistero, Cagliari, 23 (1970); 41 pp.

21-6050. LidA DE MALKiel, M. R. - "Función del cuento popular en el Lazarillo de Tormes" (N. 18-3514) . \| RPh, 24 (1970-71), 143-144 (Armistead \& Silverman) .

21-6051. Perry, T. A.-"Biblical symbolism in the Lazarillo de Tormes".-SPh, 67 (1970) , 139-146.

21-6052. Casanova, W. - "Burlas representables en el Lazarillo de Tormes".ROcc, 31 (1970), 82-94.

21-6053. WeINer, JACK - El ciego y las dos hambres de Lázaro de Tormes. Universidad Católica, Valparaíso, 1971. 36 pp. (Monografias, 20). 
21-6054. Lazarillo de Tormes. Est. prel., notas y bibliografía por A. Isasi Angulo. -Bruguera, Barcelona, 1970. 213 pp.

21-6055. El Lazarillo de Tormes. Adaptación de M. T. Díaz.-Bruguera, Barcelona, 1970. $191 \mathrm{pp}$.

21-6056. El Lazarillo de Tormes. - J. Pérez del Hoyo, Madrid, 1970. $166 \mathrm{pp}$. (100 clásicos universales). [Contiene la Segunda parte de Juan de Luna (1620)

y la Historia del Abencerraje y la hermosa Jarifa].

21-6057. Lazarillo de Tormes. [Seguido de] Luis Vélez de Guevara, El diablo cojuelo. Pról. de F. Rico. Ed. y notas de I. Ferrer, - Salvat-Alianza Editorial, Madrid, 1970. 178 pp.

21-6058. Lazarillo de Tormes. [Seguido de] Francisco de Quevedo, Vida del Buscón don Pablos. Est. prel. de G. Díaz Plaja. 8a ed. - Porrúa, México, 1971. 188 pp. (Sepan cuantos, 34).-V. núm. 21-2557.

V. también núms. 5139, 6033 .

21-6059. RudDer, R. - "La segunda parte de Lazarillo de Tormes. La originalidad de Juan de Luna". - EFil, 6 (1970) .

21-6060. ZwEZ, RICHARd E. - Hacia la revalorización de la segunda parte de. "Lazarillo" (1555). - Albatros, Valencia, 1970. 60 pp. || $L T, 1970-71$, núms. $70 / 1$, 351-354 (Reynal).

V. también núms. 6038, 6056.

21-6061. Debas, Michelle - Lexique de la "Diana" de $J$, de Montemayor. (A-Z). -Université, Toulouse, 1971. 2 ts.

21-6062. Johnson, C. B. - "Montemayor's Diana: A novel pastoral". - BHS, 48 (1971) , 20-35.

21-6063. EL Saffar, R. - "Structural and thematic discontinuity in Montemayor's Diana". - MLN, 86 (1971) , 182-198.

21-6064. Perry, T. A. - "Ideal love and human reality in Montemayor's $\mathrm{La}$ Diana". - PMLA, 84 (1969), 227-234.

21-6065. Jones, J. R. - " Human time» in La Diana". - RNo, 10 (1968-69), 139 146.

V. también núm. 4783 .

Abencerraje: v. núm. 6056 .

21-6066. W'iegman, Neal A. - Ginés Pérez de Hita y la novela romántica.-Plaza Mayor, Madrid, 1971. 139 pp.-V. núm. 21-2562. || EL, 1972, núm. 483 (Correas). 21-6067. McGrady, D. - Mateo Alemán (N. 21-2564). $\| R R, 62$ (1971) , 134-135 (Ricapito) ; Fil, 14 (1970), 205-210 (Sabor de Cortazar).

21-6068. Alemán, Mateo - Guzmán de
Alfarache. Introd. de A. Bolaño e Isla. -Porrúa, México, 1971. xxii + $427 \mathrm{pp}$. (Sepan cuantos, 182).

21-6069. Fernández GonzÁlez, Ánger RaIMUNDo - El "Guzmán de Alfarache".Estudio General Luliano, Palma de Mallorca, 1970. 24 pp.

21-6070. Fernández GoNzález, A. R. "Tradición literaria y coyuntura histórica en el Guzmán de Alfarache".-Mayurga, 1971, núm. 5, 5-24.

21-6071. Rodrícuez-Luis, J. - "Caracterización y edad del joven Guzmán". BHS, 47 (1970), 316-326.

V. también núms. 5112, 5139, 6033 .

21-6072. Pelorson, JeAn-Marc-Cervantes. -Seghers, Paris, 1970. 192 pp. Ecrivains d'hier et d'aujourd'hui, 32).

21-6073. MONDADORI, ARNOLDO (ed.) Cervantes: his life, his times, his works. Anthology by T. G. Bergin. Tr. from Italian by S. Attanasio. - American Heritage Press, New York, 1970. 167 pp., ilustr. (Giants of world literature).

21-6074. Krauss, W. - Miguel de Cervantes' Leben und Werk (N. 20-2844). $\|$ Fil, 14 (1970), 234-236 (Huber). - V. núm. 20-7051.

21-6075. Guenoun, Pierre-Cervantès par lui-même. - Ed. du Seuil, Paris, 1971. 187 pp.

21-6076. Olmos Garcia, Francisco-Cervantes en su época. 2*. ed. - R. Aguilera, Madrid, 1970. 228 pp.-V. núm. 20-7056. 21-6077. Palacín, G. B. - "Cervantes y Esquivias". - RNo, 10 (1968-69), 335341.

21-6078. Revuflta, M. - "La casa de Cervantes de Esquivias (Toledo)". - Bol. de la Real Academia de Bellas Artes de San Fernando, Madrid, 1970, núm. 30.

21-6079. Purg Campillo, Antonio - Cervantes en Murcia y Cartagena. Ed. y pról. de A. Colao. - Cartagena, 1970. $113 \mathrm{pp}$.

21-6080. Echeverry Cardona, H. - "El ilustre camarero de 1569”. - $U d A, 1969$ núm. 175, 717-726. [Cervantes].

21-6081. Makías, Julián - La imagen de la vida humana y dos ejemplos literarios: Cervantes, I'alle-Inclán. - Revista de Occidente, Madrid, 1971. 186 pp. ( $E l$ alción).

21-6082. RuAno, A. - "Consideraciones cervantinas". - Atl, 9 (1971), núm. 53.

21-6083. Roessler, D. - Voluntad bei Cervantes (N. 20-7062). $H H R, 39$ (1971), 324-327 (Morón Arroyo).

21-6084. Forcione, A. K. - “Cervantes, 
Tasso, and the romanzi polemic".- $R L C$, 44 (1970), 433-443.

21-6085. Forcione, A. K. - "Cervantes and the freedom of the artist". $-R R, 61$ (1970) , 243-255.

2I-6086. Allué y MORER, F. - "Cervantes y Lope de Vega. Puntualización de una frase".-PEsp, 1970, núm. 207.

21-6087. Cervantes, Miguel De $-\mathrm{El}$ ingenioso hidalgo Don Quijote de la Mancha. 4a ed.-Bruguera, Barcelona, 1971. 955 pp. (Joyas literarias). - V. núm. 20-2867.

21-6088. Cervantes, Miguel de - Don Quijote de la Mancha. Est. prel. y bibliografía por J. Alcina Franch. Notas por C. Oriol y T. Suero. - Bruguera, Barcelona, 1971. 2 ts. (Libro clásico, $96)$.

21-6089. Cervantes, Miguel de - El ingenioso hidalgo Don Quijote de la Mancha. Pról. de L. Rosales y F. Gutiérrez. -Credsa, Barcelona, 1970. 2 ts.: 1495 pp.

21-6090. Cervyantes, Miguel de - El ingenioso hidalgo Don Quijote de la Mancha. Estudio de A. Castro. - Magisterio Español, Madrid, 1971. 2 ts. (Novelas y cuentos, $100 / 1$ ).

21-6091. Cervantes, Miguel De - Aventuras de Don Quijote. I. El ingenioso hidalgo Don Quijote de la Mancha. Adaptación de J. Giménez.-España Errante, México, 1970. $103 \mathrm{pp}$.

21-6092. Cox, R. M. - "The Rev. John Bowle: the first editor of Don Quixote [1781]". - SPh, 67 (1970), 103-115.-V. núm. 20-2889.

21-6093. WEIGERT, L. - Untersuchungen zur spanischen Syntax auf Grund der Werke des Cervantes. - Georg Olms Verlag, Hildesheim-New York, 1971. 241 pp. [Reimpr. facs. de la ed. de Berlín, 1907].

21-6094. Mancing, Howard Terrance Chivalric language and style in "Don Quijote". - [Tesis, Univ. of Florida, 19707.

21-6095. Caballero, Justo - Guía diccionario del "Quijote". - España Errante, México, 1970. 366 pp.

21-6096. PAGán de Soto, G. - "Siempre el Quijote...". - EPR, 1971, núm. 32, $129-135$.

21-6097. Moreno Báez, Enrique - $R e$ flexiones sobre el "Quijote". 2a ed., corr. - Prensa Española, Madrid, 1971. 171 pp.-V. núm. 20-7092. || fns, 1971, núms. $300 / 01$ (Viña Liste).

21-6098. Serrano, C. - “Don Quijote, pensée sauvage et idéologie". $-L N L$, 1971, núm. 196, 6-22.

21-6099. Miles, Robert Lee $-A$ pheno menologico-existential analysis of "Don Ouixote". - [Tesis, Pennsylvania State Univ., 1971].

21-6100. Aveleyra A., Teresa - Autobiografia sentimental de Alonso Quijano. -Inst. Tecnológico y de Estudios Superiores, Monterrey, 1970. $91 \mathrm{pp}$.

21-6101. Allfo, J. J. - "Don Quixote": hero of fool? (N. 21-2617) . \| HR, 39 (1971) , 450-453 (Riley).

21-6102. LebRón SAviñón, M.-“La locura de Alonso Quijano, el Bueno".-BADL, 1971, núms. 12/3.-V. núm. 17-2436.

21-6103. Ruano Busquets, D. - "Quijotismo". - Azor, 1970, núm. 40.

21-6104. BeNítez, F. - "El ingenioso hidalgo Don Quijote de la Mancha". Anales Toledanos, 2 (1969).

21-6105. Green, O. H. - "El ingenioso hidalgo". - LMMS, 171-184.-V. núm. 13-35634.

21-6106. Avalle-Arce, J. B. - "Don Quijote, o la vida como obra de arte".$\mathrm{CuH}, 81$ (1970), 247-280.

21-6107. Holmes, T.-"Don Quixote and modern man".-SR, 78 (1970), 40-59.

21-6108. KUdLATY, JOHN M.-The stylistic and structural function of names in the "Quixote". - [Tesis, Univ. of Iowa, 19707.

21-6109. ABRAMOWITZ, Barbara - Don Quijote's ambiguous names. - [Tesis, Johns Hopkins University, 1971].

21-6110. Green, O. H. - "Don Quijote and the alcahuete". - LMMS, 193-200. -V. núm. 19-7185.

21-6111. SeliG, K.-L. - "Cervantes: «En un lugar de...". - MLN, 86 (1971), 266-268.

21-6112. Díez de URdanivia, F. - "Sobre lo que comían y bebian Don Quijote y Sancho". - Abs, 34 (1970), 45-61.

21-6113. Palacín, G. B. - "Sobre el acto de armar caballero a Don Quijote".Hf, 1971, núm. 42, 1-6.

21-6114. Piñera, E. - "En torno al Caballero de la Triste Figura". - LT, 1970, núm. $68,135-143$.

21-6115. Rivas Sainz, Arturo-Dulcinea. -Summa, Guadalajara, 1971. 166 pp.

21-6116. Peltzer, Federico - El amor, creación en la novela (Beatriz-DulcineaJustine).-Columba, Buenos Aires, 1971. 203 pp. (Nuevos esquemas, 28).

21-6117. Garavente, J. - "Sancho Panza y el monomito".-PSA, 63 (1971), 35-49. 
21-6118. Brantley, F. O.-“'Sancho's ascent into the spheres".-H, 53 (1970), 37-45.

21-6119. Flores, R. M.-“Sancho's fabrications: A mirror of the development of his imagination".-HR, 38 (1970), 174182.

21-6120. LARson, M. - "A clever-judge tale in Don Quijote". - Journal of the Folklore Society of Greater Washington, 1969-70, núm. 1, 10-13.

21-6121. Sieber, H. - "Literary time in the Cueva de Montesinos". - MLN, 86 (1971), 268-273.

21-6122. KatTaN, O. - "Algunos paralelos entre Gerónimo de Pasamonte y Ginesillo, en el Quijote". - CuH, 82 (1970), 190-206.

21-6123. Ferreras, JuAn Ignacio-Teotía y praxis de la novela. La última aventura de "Don Quijote". - Paris, 1970.

21-6124. Echeverría, J. - "La muerte de Don Quijote". - SNo, 1972, núm. 3, 34-42.

21-6125. Chambers, L. H. - "Irony in the final chapter of the Quijote". - RR, $61(1970), 14-22$.

21-6126. Chávez Camacho, Armando-La ultima salida de Don Quijote.-Tezontle, México, 1970. $76 \mathrm{pp}$.

21-6127. Descouzis, Paur - Cervantes y la generación del 98. La cuarta salida de Don Quijote. - Eds. Iberoamericanas, Madrid, 1970. 158 pp. || $R y F, 184$ (1971), 508-509 (Hornedo).

21-6128. Getтo, G. - "I Promessi sposi, i drammaturghi spagnoli e Cervantes". -LIt, 22 (1970), 425-499.

21-6129. Cox, Ralph Merritt - The Rev. John Bowle. The genesis of Cervantean criticism. - Univ. of North Carolina Press, Chapel Hill, 1971. 123 pp. - V. núm. 20-2889.

21-6130. Ruz MENÉNdez, Rodolfo - El cervantismo en Yucatán. Pref. de C. Menéndez. - Universidad, Mérida, Yuc., 1971. 39 pp.

21-6131. Sarmento Pimentel, J.-“A propósito de D. Quixote (Leon Hebreo ou Cristóbal de Fonseca)". - SN, 1971, núm. 1511, 24-25.

21-6132. BAwcuTt, N. W. - "Don Quixote, Part I, and The Duchess of Malfi".$M L R, 66$ (1971), 488-491.

21-6133. Or.tra, J. A. - "Notas para un estudio comparado de Don Quijote y Moby Dick".-Atl, 1970, núm. 43, 92-101.

21-6134. Serrano-Plaja, A. - Realismo "mágicos en Cervantes (N. 20-7121). Il RHM, 35 (1969), 148-149 (Tudisco).
21-6135. Serrano-Plaja, Arturo-"Magic" realism in Cervantes. "Don Quijote" as seen through "Tom Sawyer" and "The idiot". 'Tr. by R. S. Rudder. - Univ. of California Press, 1970. 216 pp. - V. núm. 20-7121.

21-6136. Calle Iturrino, E. - Napoleón, Don Quijote, Lenin. - Caja de Ahorros Vizcaína, Bilbao, 1970. 261 pp.

21-6137. DAY, ROBERT - The "Quijote" criticism of Unamuno, Ortega and Castro. - [Tesis, The Johns Hopkins Univ., $1971]$.

21-6138. López-Baralt, L. - "Las Novelas ejemplares o el triunfo sobre la circunstancia". - LT, 1971, núm. 72, 73-101. 21-6139. Soons, A.-“Three Novelas ejemplares of Cervantes. Diptych patterns and spirituals intentions". - OL, 26 (1971), núm. 2.

21-6140. Peniche Vallado, L. - "La sustancia teatral en las novelas de Cervantes". - CuA, 1971, núm. 5, 153-159.

21-6141. Cervantes, Miguel de - Novelas ejemplares. Comentario de S. Fernández. 8. ed. - Porrúa, México, 1970. xxiv +

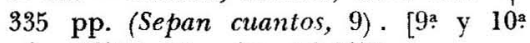
eds., 1971]. $-\mathrm{V}$. núm. 20-2971.

21-6142. PaYás, Armando - La critica social en las "Novelas ejemplares" de Cervantes. - [Tesis, Florida State Univ., 19707.

21-6143. SELIG, K.-L. - "The books in the prologue to the Novelas exemplares".$M L N, 85$ (1970), 249.

21-6144. Lloris, M. - "El casamiento engañoso". - Hf, 1970, núm. 39, 15-20.

21-6145. Cervantes, Miguel de - El celoso extremeño. - Inst. Colombiano de Cultura, Bogotá, 1971. (Col. popular). 21-6146. Cervantes, Miguel De-Le mariage trompeur (El casamiento engañoso) et Colloques des chiens (Coloquio de los perros). Prol. et trad. par M. Molho. -Aubier-Flammarion, Paris, 1970. 251 pp. I| Carav, 1970, núm. 15, 183-185 (Arnaud).

21-6147. Cervantes, Miguel De-Two short novels: El curioso impertinente, El celoso extremeño. Ed. by F. Pierce. Pergamon Press, Oxford, 1970. 107 pp. || H, 54 (1971) , 413-414 (Rudder); Fil, 14 (1970), 214-215 (Weber de Kurlat).

21-6148. Lowe, JenNifer - Cervantes, two novelas ejemplares: "La gitanilla" and "La ilustre fregona". - Grant \& Cutler, London, 1971. 80 pp. (Critical guides to Spanish texts, 2).

21-6149. Cervantes, Miguel de - El li. 
cenciado Vidriera. Est. prel, de J. Zamudio de Predan. - Kapelusz, Buenos Aires, 1971.

21-6150. Green, O. H. - "El licenciado Vidriera: its relation to the Viaje del Parnaso and the Examen de ingenios of Huarte". - LMMS, 185-192. - V. núm. 19-3405.

21-6151. Engstrom, A. G. - "The man who thought himself made of glass, and certain related images".-SPh, 67 (1970), 390-405.

21-6152. VARELA, J. L. - "El realismo cervantino en Rinconete". - [En su libro] La transfiguración literaria (Madrid, 1970), 53-89.

21-6153. Pascual Buxó, J. - "Estructura y lección de Rinconete y Cortadillo".Rev. de Bellas Artes, México, 1970 , núm. 32, 39-55; Lavori Ispanistici, Firenze, 1970, 67-96.

21-6154. BeLio, O. - "Rinconete y Cortadillo en Praga". - IAP, 4 (1970), 9-22.

21-6155. Soons, A. - "Characteristics of the late mediaeval facetia in La tia fingida".-AION-R, 12 (1970), 275-279.

21-6156. Forcione, ALBAN K. - Cervantes, Aristotle, and the "Persiles". - Princeton Univ. Press, Princeton, 1970. x + 365 pp.-V. núm. 20-2984. || $M L J, 55$ (1971), 412 (Zimik) .

21-6157. Strgmann, Tilbert Diego-Cervantes' Musterroman "Persiles". Epentheorie und Romanpraxis um 1600 (El Pinciano, Heliodor, "Don Quijote"). Mit einer "Persiles"-Bibliographie. - [Tesis, Univ. de Hamburgo, 1970].

21-6I58. Osuna, R. - "Las fechas del Persiles". - BICC, 25 (1970), 383-433.

21-6159. Cervantes, M. DE - Los trabajos de Persiles y Sigismunda, ed. J. B. Avalle-Arce (N. 21-2671) . || BHS, 48 (1971), 67-68 (Lowe).

21-6160. Cervantes, Miguel De - Los trabajos de Persiles y Sigismunda. Introd., sel. y notas de E. Carilla,-Anaya, Salamanca, 1971. 169 pp. (Bibl. Anaya).

21-6161. Cervantes, Miguel De - El cerco de Numancia. Introd., ed. y notas de R. Marrast. - Anaya, Salamanca, 1970. 130 pp. (Bibl. Anaya).-V. núm. 18-7136.

21-6162. ShIvers, G. - "La historicidad de El cerco de Numancia de Miguel de Cervantes Saavedra". - Hf, 1970, núm. $39,1-14$.

21-6163. Cervuantes, Miguel de - Comedias y entremeses. - Editora Nacional, México, 1970. 303 pp. (Col. económica, 27).
21-6164. Cervantes, Miguel de - Entremeses. Ed., introd. y notas de E. Asensio. - Castalia, Madrid, 1971. 219 pp. (Clás. Castalia, 29).

21-6165. Cervantes, Miguel de - Ocho entremeses. Ed. J. B. Avalle-Arce. Prentice-Hall, Englewood Cliffs, N. J., 1970. 210 pp. $\| H, 53 \quad(1970), 1030$ 1031 (Coughlin).

21-6166. Cervantes, Miguel de - Poesias. Introd., sel. y notas de V. Gaos. - Taurus, Madrid, 1970. 121 pp. (Temas de España).

21-6167. Blecua, J. M. - "La poesía lírica de Cervantes". - SPEO, 161-195.

21-6168. Lewis de Galanes, Adriana - El plano de la belleza: la poesia de Miguel de Cervantes.-[Tesis, Bryn Mawr College, 1970].

21-6169. Rivers, E. L.-“Cervantes' journey to Parnassus". $-M L N, 85$ (1970), 243-248.

21-6170. BlecuA, J. M. - "Un nuevo soneto atribuido a Cervantes y un romance del Conde Lemos". - SPEO, 147-150.

V. también núms. $3516,4551,4647,4834$, $5051,5094,5108-9,5112,5183,5190,5353$, $5783,5791,5824,6515,6894,7018-9$.

21-6171. Trice, Francis Leadley-A literary study of La picara Justina.-[Tesis, Svracuse Univ., 1970-71].

21-6172. De Gregorio Formichi, G.--"Narratori del Seicento. Le Noches de invierno di Antonio de Eslava". - Lavori Isthanistici (Firenze, 1970), 143-256.

Vélez de Guevara: v. núms. 5846-7, 6057 . Quevedo: v. núms. 6033, 6911-7.

21-6173. Brownstein, LeONARD A.- "Unity" and "variety" in the novels of Salas Barbadillo.-[Tesis, Bryn Mawr College, $1970]$.

21-6174. Salas Barbadillo, Alonso JeróNIMO DE - El subtil cordovés Pedro de Urdemalas. Ed. por Marcel Andrade, junto con la comedia El gallardo Escarramán. - [Tesis, Louisiana State Univ., $1970]$.

21-6175. Soons, A. - "A morphological survey of Salas Barbadillo's Peregrinación sabia". - KRQ, 17 (1970), 47-53.

21-6176. Cunningham, Malcolm A. Castillo Solórzano: A reappraisal. - [Tesis, Tulane Univ., 1970].

21-6177. Castillo Solórzano, Alonso del -Los amantes andaluzes. Historia en. tretenida, prosas y verso. - Georg Olms Verlag, Hildesheim-New York, 1971. 221 pp. [Reimpr. facs. de la ed. de Barcelona, 1633]. 
21-6178. Castillo Solórzano, Alonso dex. - Las aventuras del bachiller Trapaza.Libra, Madrid, 1970. 201 pp.

21-6179. Castillo Solórzano, Alonso dEL -Fiestas del jardin, que contienen tres comedias y cuatro novelas.-Georg Olms Verlag, Hildesheim-New York, 1971. 599 pp. [Reimpr. facs. de la ed. de Valencia, 16347.

21-6180. Cortés de Tolosa, Juan $-E l L a$ zarillo de Manzanares. Introd., notas y glosario de M. I. Chamorro Fernández.Taurus, Madrid, 1971. 168 pp. (Temas de España).

21-6181. VAsILESKI, IRMA V. - La creación novelistica de doña María de Zayas y Sotomayor. - [Tesis, Florida State Univ., 19701.

21-6182. Estebanillo González. Vida y hechos de... Pról. de J. de Ontañón.Porrúa, México, 1971. xlvi + 151 pp. (Sepan cuantos, 163).

21-6] 83. Vida y hechos de Estebanillo González. Coment. por A. Carreira y J. A. Gid. - Narcea, Madrid, 1971. 568 pp. (Bitácora, 19) .

21-6184. Bolaño E Isla, Amancio - Estudio comparativo entre el "Estebanillo González" y el "Periquillo Sarniento". -U.N.A.M., México, 1971. 64 pp.

21-6185. Mariani, H., \& A. Rodríguez"A probable source of Giuseppe Parini's Il giorno".-CL, 22 (1970), 61-69. [Juan de Zabaleta].

21-6186. SuÁrez-Galbán, E. - “La estructura autobiográfica de la Vida de Torres Villarroel". - Hf, 1971, núm. 41, 23-53.

21-6187. Torres Villarroel, Diego-Vida, ascendencia, nacimiento, crianza y ven. turas del doctor don Diego Torres de Villarroel, escrita por él mismo. Pról. y notas de A. Espina. - Madrid, 1970. 516 pp.

21-6188. GARcía ABAD, A. - "Correcciones y nuevos datos sobre la biografía del Padre Isla". - RLit, 35 (1969) , 39-55.

21-6189. RAETz, ANNELIESE - Francisco José de Isla. Der Mensch, der Reformer, der Kritiker. - [Tesis, Univ. de Colonia, 1970]. 261 pp.

\section{Autores modernos}

21-6190. Fernán Caballero - La familia de Alvareda. Ed. de E. Careño.-Anaya, Salamanca, 1971. 185 pp. (Bibl. Anaya). 21-6191. García, S. - "Cartas bornesas. Un inédito de T. Trueba y Cosío".BBMP, 46 (1970), 127-170.
21-6192. Quirk, Ronald J--Serafin Estébanez Calderón: his work and place in Spanish letters. - [Tesis, Brown Univ., $1971]$.

21-6193. CAmpos, Jorge - La Andalucia de Estébanez Calderón. - Madrid, 1964. $142 \mathrm{pp}$.

V. también núms. 6194, 6210 .

21-6194. Tosi Fogliani, L. (ed.) - Dos escritores costumbristas, - La Goliardica, Milano, 1967. 102 pp. [Mesonero Romanos y Estébanez Calderón].

21-6195. MEsonero Romanos, RAMóN DE -Escenas matritenses. Introd., ed. y notas de E. Correa Calderón. - Anaya, Salamanca, 1970. 165 pp. (Bibl. Anaya). -V. núm. 19-3425.

V. también núm. 6339 .

21-6196. HAfTER, M. Z.-“Escosura's Noches lúgubres, an unpublished play based on Cadalso's life". - BHS, 48 (1971) , 36-43.

21-6197. Gil y Carrasco, Enrique - El señor de Bembibre. Ed. y pról. de R. Carnicer. - Barral, Barcelona, 1971. 352 pp. 21-6198. Fuentes IrurozQui, Manuel Mi abuelo Antonio de Trueba.-Diputación de Vizcaya, Bilbao, 1969. 57 pp. || $R D T P, 27$ (1971), 438-439 (Manrique).

V. también núm. 7008 .

21-6199. Fernández y González, ManueLEl pastelero de Madrigal.-J. Pérez del Hoyo, Madrid, 1970. 452 pp.

V. también núm. 5173 .

21-6200. DeCoster, Cyrus C.-Bibliografía critica de Juan Valera.-C.S.I.C., Madrid, 1970. 181 pp. (Cuadernos bibliográficos).

21-6201. Azaña, Manuel - Ensayos sobre Valera. Pról. de J. Marichal. - Alianza Editorial, Madrid, 1971. 283 pp. (El libro de bolsillo, 300).

21-6202. Botrel, J.-F. - "Sur la condition de l'écrivain en Espagne dans la seconde moitié du xıxe siècle. Juan Valera et l'argent". - BHi, 72 (1970), 292-310.

21-6203. Montesinos, José F. - Valera o la ficción libre.-Castalia, Madrid, 1970. xxiii + 219 pp. (Estudios sobre la novela española del siglo xix, 5). - V. núm. 14-39348.

21-6204. VALERA, JUan - Doña Luz. Comentado por B. Varela Jácome.-Narcea, Madrid, 1970. 236 pp. (Bitácora, 3).

21-6205. VAlera, JuAN - Las ilusiones del doctor Faustino. Ed., introd. y notas de C. C. DeCoster.-Castalia, Madrid, 1970. 452 pp. (Clás. Castalia, 26). 
21-6206. Valera, Junn-Juanita la Larga. -Salvat, Barcelona, 1970. 185 pp.

21-6207. Valera, JuAN - Morsamor. Peregrinaciones heroicas $y$ lances de amor y fortuna de Miguel de Zuheros y Tiburcio de Simahonda. Ed., pról. y notas de J. B. Avalle-Arce.-Labor, Barcelona, 1970. 342 pp. (Textos hispánicos modernos, 7).

21-6208. Valera, Juan - Pepita Jiménez. -Bedout, Medellín (Colombia), 1970. $176 \mathrm{pp}$.

21-6209. Valera, Juan - Pepita Jiménez y Juanita la Larga. Pról. de J. de Ontañón. 3a ed. - Porrúa, México, 1971. xlvi +222 pp. (Sepan cuantos, 56).V. núm. 20-3024.

21-6210. SÁENZ de TeJada, CaRlos-Correspondencia entre Juan Valera y Serafin Estébanez Calderón (1850-1858). Crónica histórica y vital de Lisboa, Brasil, Paris y Dresde, como coyunturas humanas a través de un diplomático intelectual-Moneda y Crédito, Madrid, 1971. $395 \mathrm{pp}$.

V. también núms. 5110, 5139, 5182.

21-6211. Pérez Escrich, EnriQue - El mártir del Gólgota. Pról. de J. A. Peñalosa. -Porrúa, México, 1971, xxiv + 429 pp. (Sepan cuantos, 188).

21.6212. Ocano, ARMando - Alarcón.Epesa, Madrid, 1970. 181 pp. (Grandes escritores contemporáneos).

21-6213. Alarcón, Pedro antonio de-El final de Norma.-Novaro, México, 1971. 249 pp. (Joyas de bolsillo). - V. núm. 13-35680.

21-6214. Alarcón, Pedro Antonio DE-El Niño de la Bola. El sombrero de tres picos. El capitán Veneno. Introd. de J. de Ontañón. - Porrúa, México, 1970. 240 pp. (Sepan cuantos, 134). [2a ed., 19717 .

V. también nủm. 5109.

21-6215. FERNÁNDEZ-CORDFRO Y AZORÍN, CONCEPCIÓN - La sociedad española del siglo xix en la obra literaria de José Maria Pereda.-Santander, 1971. 363 pp.

21-6216. Luque Magh de Pérez, Colomba -Paralelismos y divergencias en la novelistica de Pereda y Hardy. - [Tesis, Univ. de Madrid; resumen en RUM, 18 (1969), núm. 72, 89].

21-6217. Luque de Pérez, Colomba - Paralelismos y divergencias en la novelistica de Pereda y Hardy. - Porrúa, Madrid, 1970. $355 \mathrm{pp}$.

21-6218. Pereda, José María de - La leva $y$ otros cuentos.-Alianza Editorial, Ma- drid, 1970. 252 pp. (El libro de bolsillo, 253).

21-6219. Clarke, A. H. - "E1 Hero y Leandro, de Pereda. Historia y crítica de un fragmento de novela, con fotocopia $y$ traslado del manuscrito y cotejos textuales de ediciones anteriores".- $-B B M P$, 46 (1970), 261-324.

V. también núm. 6340.

21-6220. Varey, J. E.-"Galdós in the light of recent criticism". - GS, 1-35.

21-6221. Homenaje al profesor W. H. Shoemaker. Estudios sobre Galdós.-Castalia, Valencia, 1970. 295 pp.

21-6222. VAREY, J. E. (ed.) -Galdós studies. -Tamesis Books, London, 1970. xii + $206 \mathrm{pp}$. [Volumen colectivo]. || $\mathrm{BAbr}$, 45 (1971), 671 (Angeles) ; $H, 54$ (1971), 597-598 (Fedorchek); MLR, 66 (1971), 911-912 (Lowe).

21-6223. García Lorenzo, L. E. - "Bibliografía galdosiana". - $\mathrm{CuH}, 84$ (1970), 758-797.

21-6224. Sampelayo, J. - "Nuevas adquisiciones de la Biblioteca Nacional". $A r b, 76(1970), 121-123$. [Pérez Galdós].

21-6225. Ruiz-Fornells, E. - "Benito Pérez Galdós y la crítica norteamericana". $-\mathrm{CuH}, 84$ (1970), 712-719.

21-6226. BESER, S. - "J. F. Montesinos crítico de Pérez Galdós".-AG, 4 (1969). 21-6227. Blanquat, J. - "Lecturas de juventud". - $\mathrm{CuH}, 84$ (1970), 161-220. [De Galdós].

21-6228. Aguirre Prado, L. - "Galdós y la Guerra románica".-Africa, Madrid, $1970,340-343$.

21-6229. Martínez Palacto, J. - "Miseria y parodia galdosiana de la Restauración". - Ins, 1971, núm. 291.

21-6230. Bravo-Villasante, C. - "Polé micas en torno a Galdós en la prensa de Santander. (La Atalaya contra El Atlántico en 1893. La Atalaya contra El Cantábrico en 1901)". - CuH, 84 (1970), 694-711.

21-6231. Casalduero, JoaQuín - Vida y obra de Galdós (1843-1920). 3a ed., aum. -Gredos, Madrid, 1971. 294 pp. (BRH, (Estudios y ensayos, 5). - V. núm. 17-6129.

21-6232. Bravo Villasante, Carmen Galdós, visto por si mismo. - Magisterio Español, Madrid, 1970. 314 pp. (Novelas y cuentos, 70). II Ins, 1970, núm. 287 (Cano); $M L J, 55$ (1971), 541 (Fedorchek)

21-6233. SaInz de Robles, F. C. - Pérez Galdós. Vida, obra y época. - Vasallo 
de Numbert, Madrid, 1970. 305 pp. (Bibl. literaria Tomás Borrás). \|CuH, $84(1970), 756-757$ (Sampelayo).

21-6234. Penuel, A. M. - "Galdós, Freud, and humanistic psychology". - H, 55 (1972) , 66-75.

21-6235. Gascó Contell, E. - “Don Benito Pérez Galdós". - LEsp, 14 (1971), núm. 159.

21-6236. Madariaga, S. DE - "La universalidad de Galdós". - CuH, 84 (1970), 52-57.

21-6237. SchraibMaN, J.-"El ecumenísmo de Galdós". - $H, 53$ (1970), 881-886.

21-6238. Cardona, R. - "Nuevos enfoques críticos con referencia a la obra de Galdós". - CuH, 84 (1970), 58-72.

21-6239. Quiñonero, J. P. - “Propuesta para una revisión galdosiana”. - $\mathrm{CuH}$, $84(1970), 678-693$.

21-6240. Guereña, J. L. - "Galdós en notas concéntricas". - CuH, 84 (1970), $720-726$.

21-6241. Casalduero, J. - "Conjunción y divergencia de vida y arte en Galdós".$H, 53$ (1970), 828-835.

21-6242. Camón Aznar, J. - "La mirada de Pérez Galdós"--Goya, 1970, núm. 95.

21-6243. Blanco Amor, J. - "Pérez Galdós, nuestro contemporáneo". - CuA, 1971, núm. 1, 187-196.

21-6244. SAlleNave, P. E. - "Notas sobre una lectura política de Galdós",- $\mathrm{CuH}$. $84(1970), 109-116$.

21-6245. Goldman, P. B. - "Galdós and the politics of conciliation". - $A G, 4$ (1969) .

21-6246. Sopeña IbáÑEZ, Federico-Arte $y$ sociedad en Galdós. - Gredos, Madrid, 1970. 179 pp. (Campo abierto, 28). ॥ ROcc, 31 (1970), 379-380 (Amoros); Ins, 1971, núm. 292 (Mainer).

21-6247. Chueca Gortia, F. - "La ciudad galdosiana"-CuH, 84 (1970), 83-108.

21-6248. Gillespie, G. - "Galdós and the humoristic tradition”. $-A G, 4$ (1969).

21-6249. Baquero Goyanes, M. - "Pers. pectivismo irónico en Galdós". - CuH, $84(1970), 143.160$.

21-6250. LEVY, MATILDE - Estructura na. rrativa e ironia en las novelas de Gal. dós. - [Tesis, Univ. of Texas, 1971].

21-6251. Gillespie, G. - "Galdós and the unlocking of the psyche".- $H, 53(1970)$, $852-856$.

21-6252. SOBEJANo, G. - "Aburrimiento y erotismo en algunas novelas de Gal. dós". - AG, 4 (1969).

2I-6253. GoodALE, H. K. - "Allusions to
Shakespeare in Galdós",-HR, 39 (1971) 249-260.

21-6254. Pattison, W. T. - "How well did Galdós know English?” $-S, 24$ (1970), 148-157.

21-6255. Walton, L. B. - Pérez Galdós and the Spanish novel of the nineteenth century. - Gordian Press, New York, 1970. xi +250 pp. [Reimpr. de la ed. de 19281 .

21-6256. SOTO VERGÉs, R. - "La narrativa galdosiana. Realismo y metafísica al estilo español".-CuH, 84 (1970), 382-392.

21-6257. Amorós, A. - "Sobre Técnicas de Galdós, de Ricardo Gullón”. - Ins, 1971 , núm. 295.

21-6258. EmBeita, M. - "Balzac y Galdós: un paralelismo". - Ins, 1971, núm. 298. 21-6259. Jelelaty, Joseph M.-Les grands thèmes de Balzac et de Galdós. - Universidad, Salamanca, 1965. $56 \mathrm{pp}$.

21-6260. Rogers, D. - "The descriptive simile in Galdós and Blasco Ibáñez: A study in contrasts". - $H, 53$ (1970), 864-869.

21-6261. RiCARD, R. - "En marge de Galdós: *révolution des allumettes et clichés romanesques". - BHi, 72 (1970), 148-151.

21-6262. Shoemaker, W. H. - “ «Los Pepes, of Galdós en 1968 and 1887: Two stages of his style". $-H, 53(1970), 887$ 898.

21-6263. CorreA, G. - "Tradición mística y cervantismo en las novelas de Galdós, 1890-97". - H, 53 (1970), 842-851.

21-6264. Alvar, M. - "Novela y teatro en Galdós". - Proh, 1 (1970), 157-202.

21-6265. Ynduráin, Francisco - Galdós entre la novela y el folletin. - Taurus, Madrid, 1970. 82 pp. (Cuadernos Taurus, 98) .

21-6266. SMith, V. A., \& J. E. VAREY "Esperpento: Some early usages in the novels of Galdós". - GS, 195-204.

21-6267. Medina, Jeremy T.-Galdós and the concept of literary realism.-[Tesis, Univ. of Pennsylvania, 1970].

21-6268. Muñoz Simonds, P. - "Benito Pérez Galdós, romantic-realist". - Mexico Quarterly Review, 1970, núm. 1, 69-85.

21-6269. EARLE, P. G. - "La interdependencia de los personajes galdosianos".CuH, 84 (1970), 117-134.

21-6270. Granjel, L. S.-“Personajes médicos de Galdós". - CuH, 84 (1970), $656-663$.

21-6271. López Piñero, J. M. - “La medi- 
cina y la enfermedad en la España de Galdós”. - CuH, 84 (1970), 664-677.

21-6272. Rubin, W. - "Galdós y la medicina”. - Atl, 1970, núm. 43, 68-80.

21-6273. Oliver, Walter Carl-The short stories of Benito Pérez Galdós.-[Tesis, Univ. of New Mexico, 1970].

21-6274. PÉrez Galdós, Benito - Novelas $y$ miscelánea. Introd. de F. Sainz de Robles. T. 3.-Aguilar, Madrid, 1970. 1482 pp. (Obras eternas).

21-6275. Pérez Galdós, Benito - La Fontana de Oro. - Alianza Editorial, Madrid, 1970. 394 pp. (El libro de bolsillo).

21-6276. Dérozier, A. - "El \&pueblos de Pérez Galdós en La Fontana de Oro". $-\mathrm{CuH}, 84$ (1970), 285-311.

21-6277. Amorós, A. - "La sombra: realidad e imaginación". - CuH, 84 (1970), 523-536.

21-6278. Lowe, J. - "Theme, imagery and dramatic irony in Doña Perfecta". $-A G$, 4 (1969).

21-6279. García Lorenzo, L. E. - "Sobre la técnica dramática de Galdós: Doña Perfecta. De la novela a la obra teatral". $-\mathrm{CuH}, 84$ (1970), 445-471.

21-6280. Matus, E. - "Sobre Doña Perfecta y Marianela”. - EFil, 6 (1970).

21-6281. PatTISON, W. T. - "The manuscript of Gloria".-AG, 4 (1969).

21-6282. Pérez Galdós, Beniro - Marianela. - Losada, Buenos Aires, 1970. 184 pp. (Bibl. clásica y contemporánea).

21-6283. Rurz, M. E. - "El idealismo platónico en Marianela de Galdós". - $\boldsymbol{H}$, 53 (1970) , 870-880.

21-6284. Rodgers, E. - "Realismo y mito en El amigo Manso”. - CuH, 84 (1970), 430-444.

21-6285. Gullón, R. - “Unidad en El doctor Centeno”. - CuH, 84 (1970), 579.585 .

21-6286. Gullón, R.-“Claves de Galdós". -íns, 1970, núms. 284/5. [La de Bringas].

21-6287. Pérez Galdós, Bentro-Lo prohibido. Ed., introd. y notas de J. F. Montesinos. - Castalia, Madrid, 1971. 487 pp. (Clás. Castalia, 34) .

21-6288. Terry, A. - "Lo prohibido: Unreliable narrator and untruthful narrative". - GS, 62-89.

21-6289. Pérez Galdós, Benrto - Fortunata y Jacinta. (Dos historias de casadas). Est. prel. de T. Silva Tena.-Porrúa, México, 1971. xlvi +654 pp. (Sepan cuantos, 185).

21-6290. PÉrez Galdós, Benito - Fortunata et Jacinta. Histoire de deux fem- mes mariées. Trad. par R. Marrast. Éds. Recontre, Lausanne, 1970. 3 ts.

21-6291. DíEz-Alonso, ANdrés - Estructuralismo y realismo critico en "Fortunata y Jacinta".-[Tesis, Indiana Univ., 1971].

21-6292. ENGLeR, K.-"Notes on the narrative structure of Fortunata $y$ Jacinta". $-S, 24$ (1970), 111-127.

21-6293. RibBaNs, G. - "Contemporary history in the structure and characterization of Fortunata y Jacinta". - GS, 90-113.

21-6294. KatTan, O. - "Madrid en Fortunata y Jacinta y en La lucha por la vida: dos posturas". - CuH, 84 (1970), 546-578.

21-6295. Braun, L. V.-_Galdós' re-creation of Ernestina Manuel de Villena as Guillermina Pacheco".-HR, 38 (1970), 32-55.

21-6296. Lassalerta, M. C. - “Algunos coloquialismos en el lenguaje de Galdós: Un estudio del verbo hablar en Fortunata y Jacinta". - H, 54 (1971), 907-914.

21-6297. Pérez Galdós, Benito - Miau. Ed. by E. R. Mulvihill and R. Sánchez. -Oxford Univ. Press, London-New York, 1970. XXv + 339 pp. $\| H, 54$ (1971), 226-227 (Smith) .

21-6298. SACKETt, T. A. - "The meaning of Miau". - AG, 4 (1969).

21-6299. Paradissis, A. G. - "La mezcla satírica de características humanas y animales en Miau de Benito Pérez Galdós". - BICC, 26 (1971), 133-142.

21-6300. Gillespie, G. -- "Miau: hacia una definición de la sensibilidad de Galdós". - CuH, 84 (1970), 415-429.

2I-6301. Parker, A. A. "Villaamil: tragic victim or comic failure?" $-A G, 4$ (1969).

21-6302. Penuel, A. M.-“The ambiguity of Orozco's virtue in Galdós' La incóg. nita and Realidad". - H, 53 (1970), 411-418.

21-6303. Colin, V. - "Tolstoy and Angel Guerra”. - GS, 114-135.

21-6304. Hafter, M. Z. - “Bálsamo contra bálsamo> in Angel Guerra". - $A G$, 4 (1969).

21-6305. Miró, E. - “Tristana o la imposibilidad de ser". - CuH, 84 (1970), 505-522.

21-6306. Alonso, M. R. - “Tristana”Ins, 1970, núm. 282. [Galdós y Buñuel]. 21-6307. VILlEGas LóPez, M.-“Tristana". -ROcc, 30 (1970), 231-236. [Galdós y Buñuel]. 
21-6308. DurÁN, M. - "Observaciones acerca del último Buñuel”. - LT, 1970, núm. 68, 123-135. [En particular, su película Tristana].

21-6309. Alonso Ibarrola, J. M. - "Don Benito Pérez Galdós y el cine. Tres mujeres, dos películas y un cincuentenario".-CuH, 84 (1970), 650-655. [Fortunata y Jacinta y Tristana].

21-6310. SмITH, Gilbert G. - The Torquemada novels of Pérez Galdós: $A$ structural and thematic analysis.-[Tesis, Brown Univ., 1970].

21-6311. Ayala, F. - "Los narradores en las novelas de Torquemada”. - CuH, $84(1970), 374-381$.

21-6312. HALL, H. B. - “Torquemada: The man and his language". - GS, 136 163.

21-6313. NÄumL, B. J. Z.-“"The mundane demon: The bourgeois grotesque in Galdós' Torquemada en la hoguera".$S, 24(1970), 158-165$.

21-6314. Pattison, W. T. - "Verdaguer y Nazarin'.-CuH, 84 (1970), 537-545.

21-6315. Bleznick, D. W., y M. E. RuIZ"La Benina misericordiosa: Conciliación entre la filosofía y la fe".-CuH, 84 (1970), 472-489.

21-6316. VAREY, J. E.-"Charity in Misericordia". - GS, 164-194.

21-6317. Seco Serrano, C. - "Los Episodios nacionales como fuente histórica". - CuH, 84 (1970), 256-284.

21-6318. Olson, P. R. - "Galdós and history”. - $M L N, 85$ (1970), 275-279.

21-6319. Jutglar, A. - "Sociedad e historia en la obra de Galdós". - CuH, $84(1970), 242-255$.

21-6320. Casalduero, J. - "Historia y novela”. - CuH, 84 (1970), 135-142. [En Galdós].

21-6321. Llorens, V. - "Historia y novela en Galdós". - CuH, 84 (1970), 73-82.

21-6322. Patrison, W. T. - "The prehistory of the Episodios nacionales". - H, $53(1970), 857-863$.

21-6323. Glendinning, N. - “Psychology and politics in the first series of the Episodios nacionales". - GS, 36-61.

21-6324. Arnálz Amigo, P. - "Particularitati ale limbajului popular în prima serie a Episoadelor nationale de Benito Pérez Galdós".-SH, 1970, 7-22.

21-6325. BALseIro, J. A. - "Anticlericalismo y religiosidad en Benito Pérez Galdós. (Desde los primeros Episodios nacionales)". - LT, 1970, núm. 63-83.
21-6326. HoAr, L. J., JR. - “Dos de mayo de 1808, dos de septiembre de 1870, por Benito Pérez Galdós, un cuento extraviado y el posible prototipo de sus Episodios nacionales".-CuH, 84 (1970), 312-339.

21-6327. Pérez Galdós, Bentro - Napoleón en Chamartín. Zaragoza. Pról. de Teresa Silva Tena.-Editorial Porrúa, México, 1970. xxiii + 239 pp. (Sepan cuantos, 158) .

21-6328. García Mercadal, J. - “Galdós, Aragón y la ópera Zaragoza". - CuH, $84(1970), 727-736$.

21-6329. Avalle-Arce, J. B. - “Zumalacárregui”. - CuH, 84 (1970), 356-373.

21-6330. Colin, V. - “Tolstoy and Galdós' Santiuste. Their ideology on war and their spiritual conversion". - H, 53 (1970) , 836-841.

21-6331. RICARD, R. - "Mito, sueño, historia y realidad en Prim". - CuH, 84 $(1970), 340-355$.

21-6332. DendeE, B. J. - "Galdós and the death of Prim". - AG, 4 (1969).

21-6333. Rodríguez Padrón, J. - "Galdós, el teatro y la sociedad de su época".$\mathrm{CuH}, 84(1970), 623-640$.

21-6334. Chamberlin, V. A.-“A Galdósian statement in 1899 concerning dramatic theory". - $S, 24$ (1970), 101-110.

21-6335. Correa, G. - “Pérez Galdós y la tradición calderoniana". - $\mathrm{CuH}, 84$ (1970) , 221-241.

21-6336. Nougué, A. - “Antón Caballero, de Benito Pérez Galdós". - CuF, 84 $(1970), 641-649$.

21-6337. Exton, W .H. - "Sobre el género de La loca de la casa, de Galdós". CuH, 84 (1970), 586-607.

21-6338. Fox, E. I.-"En torno a Mariucha: Galdós en 1903”. - CuH, 84 (1970), 608-622.

21-6339, HOAR, L. J., JR. - "Mi calle, another «lost» article by Galdós, and a further note on his indebtedness to Mesonero Romanos". - S, 24 (1970), 128-147.

21-6340. Bravo Villasante, C. - "Veintiocho cartas de Galdós a Pereda”. CuH, 84 (1970), 9-51.

21-6341. GonzÁlez Araúzo, A. - "Relaciones epistolares entre Maura y Galdós". - AG, 4 (1969).

V. también núms. 5139, 5141, 6381, 6421 . 21-6342. Coloma, Luis - Pequeñeces. Editora Nacional, México, 1970. $605 \mathrm{pp}$ (Col. económica, 334) .

21-6343. Carnicer, R. - "La etapa de 
Leopoldo Alas en la Universidad de Za. ragoza". - Ins, 1970, núms. 284/5.

21-6344. Vázquez AzPIRI, Héctor-Clarín. -Epesa, Madrid, 1970. 140 pp. (Grandes escritores contemporáneos).

21-6345. Ramos, Antonio - Clarín y la gente nueva. - [Tesis, Univ. of California, San Diego, 1970$]$.

21-6346. Hortas Moragón, Carlos - The moral vision of Leopoldo Alas. - [Tesis, Yale Univ., 1970].

21-6347. Agudiez, Juan Ventura - Inspiración y estética en "La Regenta" de Clarin. - Instituto de Estudios Asturianos, Oviedo, 1970. $190 \mathrm{pp}$.

21-6348. Caviglia, John LAWRENGE-Flaubert and Leopoldo Alas: An essay in comparative anatomy. - [Tesis, Indiana Univ., 1970].

21-6349. Agudiez, J. V. - “La sensibilidad decadentista de Barbey d'Aurevilly y algunos temas de La Regenta". - ROcc, 33 (1971), 355-365.

21-6350. Wiltrout, A. - "El cosmos de La Regenta y el mundo de su autor".$A O, 21$ (1971), 47-64.

21-6351. IFE, B. W. - "Idealism and materialism in Clarín's La Regenta: Two comparatives studies".-RLC, 44 (1970), 273-295.

21-6352. Lebredo, Gerardo G. - Fermin de Pas y Ana Ozores en "La Regenta". - [Tesis, Florida State Univ., 1970].

21-6353. Alas, Leopoldo (Clarín)-Supercheria. Cuervo y Doña Berta. Pról. de R. Pérez de Ayala. - Taurus, Madrid, 1970. 201 pp. (Temas de España).

21-6354. Round, N. G. - "The fictional integrity of Leopoldo Alas' Supercheria”. -BHS, 47 (1970), 97-116.

21-6355. AlAs, LeOpoldo - Cuentos de Clarin. (Doña Berta. Cuervo. Superchería). - Taurus, Madrid, 1970. 208 pp. (Temas de España).

V. también núm. 5139.

21-6356. Armesto, V. - "Emilia Pardo Bazán (1852-1921)". - Uro, 1971, núm. 9, 55-58.

21-6357. Pattison, Walter T. - Emilia Pardo Bazin. - Twayne, New York, 1971. 134 pp. (TWAS, 134).

21-6358. Dende, B. J. - "The racial theories of Emilia Pardo Bazán”. - HR, 38 (1970), 17-31.

21-6359. Barroso, Fernando José - $L a$ intención naturalista y reformadora en la novelistica de Emilia Pardo Bazán. -[Tesis, Univ. of Virginia, 1970].
21-6360. Ridgway, Eliza L. - The "Novelas breves" of Emilia Pardo Bazán.[Tesis, Louisiana State Univ., 1970].

21-6361. MENGE, U. - Die dialektische Struktur der Kurzgeschichten Doña Emilia Pardo Bazáns (N. 20-3114). $H R, 38$ (1970), 232-234 (Cano).

21-6362. PARdo BAzÁn, Emiria - Insolación. Introd. de J. Hesse. - Taurus, Madrid, 1970. 194 pp. (Temas de España, 87) .

21-6363. Pardo Bazán, Emilia - Los pazos de Ulloa. - Aguilar, Madrid, 1971. 382 pp. (Crisol literario). - V. núm. $16-49256$.

21-6364. Stanton, E. - “Los pazos de Ulloa y la pintura". - PSA, 58 (1970), 279-288.

21-6365. Pardo BazÁn, Emilia - La sirena negra. Insolación. Est. prel. y notas de J. Onrubia de Mendoza. - Bruguera, Barcelona, 1970. 446 pp.

21-6366. SÁnchez, P. - “La dualidad mística en La sirena negra de Pardo Bazán". - H, 53 (1970), 189-197.

21-6367. SÁnchez, P. - “La función del tiempo en La sirena negra, de doña Emilia Pardo Bazán".-PSA, 57 (1970), 15-32.

21-6368. Pardo Bazán, Emilia - Un viaje de novios. Ed., pról. y notas de $\mathbf{M}$. Baquero Goyanes. - Labor, Barcelona, 1971. 278 pp. (Textos hispánicos modernos).

21-6369. Pardo Baz.Án, EMilia - La vida contemporánea. - Magisterio Español, Madrid, 1971. (Novelas y cuentos, 103). V. también núms. 5041, 5139.

21-6370. Palacio Valdés, ARMANDo-Tristán o el pesimismo. Comentado por M. Baquero Goyanes.-Narcea, Madrid, 1971. 472 pp. (Bitácora, 15).

Unamuno: v. núms. 6994-7014.

21-6371. Xandró, Mauricio-Blasco Ibáñez. -Epesa, Madrid, 1971. 196 pp. (Grandes escritores contemporáneos, 39).

21-6372. Cortina, Rodolfo José-Blasco Ibáñez: El primer momento de su serie de novelas evocativas. - [Tesis, Case Western Reserve Univ., 1970-71].

21-6373. KroE, Donald R. - Vicente Blasco Ibáñez: a critical survey of the novels from 1910-1928. - [Tesis, Univ. of Virginia, 1971].

21-6374. León Roca, José LuIs - Vicente Blasco Ibáñez: politica $i$ periodisme.Casanova, Barcelona, 1970. 186 pp. (Tres i quatre, 4). II Carav, 1971, núm. 16, 250-252 (Loubés). 
21-6375. Smiтh, P. - "On Blasco Ibáñez's Flor de mayo". - S, 24 (1970), 55-66. V. también núms. 5173, 6260, 6953.

21-6376. ZavalA, I. M.-“Valle-Inclán y sus críticos". - $M L N, 85$ (1970), 279-286.

21-6377. Phillips, A. W. - "Rubén Darío and Valle-Inclán: the story of a literary friendship". - [En el vol.] Rubén Dario Centennial Studies (Austin, Texas, 1970), 49-83. - V. núm. 20-3181.

21-6378. Carballo Calero, R. - "Escolios valleinclanescos”.-CuEG, 25 (1970), 89-100.

21-6379. LloRÉNS AlleN, Eva - La esté tica de Valle-Inclán en sus relaciones con la pintura. - [Tesis, Yale Univ., $1970]$.

21-6380. McGrady, D. - "Elementos folclóricos en tres obras de Valle-Inclán”. $-B I C C, 25$ (1970), 49-58.

21-6381. YNDURÁIN, F. - "Valle-Inclán y Galdós: un estudio de imágenes". CMod, 170-184.

21-6382. Phillips, A. W. - "Flor de santidad: novela poemática de Valle-Inclán”. - Homenaje a S. H. Eoff (Madrid, 1970), 137-171.

21-6383. VALLE-INCLÁN, RAMóN DEL - El yermo de las almas. Una tertulia de antaño. - Alianza Editorial, Madrid, 1970. 174 pp. (El libro de bolsillo, 272).

21-6384. VALLE-INCLÁN, RAMóN DEL - La guerra carlista: Los cruzados de la causa. El resplandor de la hoguera. Gerifaltes de antaño. - Aguilar, Madrid, 1970. $292 \mathrm{pp}$.

21-6385. VALLE-INCLÁN, RAMÓN DEL-Sonata de primavera. Sonata de estio. Sonata de otoño. Sonata de invierno. Memorias del Marqués de Bradomin. Estudio prel. de A. W. Phillips, - Porrúa, México, 1970. 1xii + 170 pp. (Sepan cuantos, 135).

21-6386. Tolman, Rosco Nelson-Dominant themes in the "Sonatas" of ValleInclán. - [Tesis, Univ. of Utah, 1970].

2I-6387. Di Biase, V. C. - "La Sonata de primavera: una novela teatral". - RUZ, 1970, núms. 48/50, 47-65.

21-6388. SмIтH, Verity - Valle-Inclán, "Tirano Banderas". - Grant \& Cutler, London, 1971. 88 pp. (Critical guides to Spanish texts, 3).

21-6389. SILLAND, DANIELlE - Etude $d u$ temps dans "Tirano Banderas" de ValleInclán. - [Mémoire de maîtrise, Univ. de Strasbourg, 1970].

21-6390. VALLE-INCLÁN, RAMóN DEL - El ruedo ibérico. Viva mi dueño.-Alianza
Editorial, Madrid, 1971. 372 pp. (El libro de bolsillo, 342) .

21-6391. YNdurín, F. - "El ruedo ibérico de Valle-Inclán”. - CMod, 126-135.

21-6392. YNDURÁIN, F. - "Imaginería en El ruedo ibérico". - CMod, 136-169.

21-6393. Boudreau, H. L. - "La corte de los milagros: The title in the work".RNo, 10 (1968-69) , 286-291.

21-6394. Gilabert, J. J.-"Baza de espadas, - Valle-Inclán y el problema de Espaกิa”. - PSA, 58 (1970), 101-116.

21-6395. LIMA, R. - "Valle-Inclán in the theatre: The second phase". - H, 53 (1970) , 419-428.

21-6396. Ling, David Chang - The theme of lust, greed and death in the theater of Valle-Inclán. - [Tesis, Univ. of Wisconsin, 1970].

21-6397. Cardona, Rodolfo, y ANThony N. Zahareas - Visión del esperpento. Teoría y práctica en los esperpentos de Valle-Inclán. - Castalia, Madrid, 1970. 255 pp. (La lupa y el escalpelo, 9).

21-6398. Gullón, R. - "Realidad del esperpento". - INO, 100-112. - V. núm. 20-7328.

21-6399. VARELA, J. L. - “El muindo de lo grotesco en Valle-Inclán". - [En su libro] La transfiguración literaria (Madrid, 1970), 211-255. - V. núm. 20-3195.

21-6400. VALLE-INCLÁN, RAMóN DEL-Tablado de marionetas. - Aguilar, Madrid, 1971. (Col. literaria).

21-6401. VALLE-INCLÁN, RAMón deL - Tablado de marionetas (para educación de principes). Retablo de la avaricia, la lujuria y la muerte. - Aguilar, Madrid, 1970. 350 pp.

21-6402. SÁinz de MEdrano ArCe, LuisLa "Farsa y licencia de la Reina Castiza" de don Ramón Maria del Valle-Inclán. Estudio critico. - [Tesis, Univ. de Madrid; resumen en $R U M, 18$ (1969), núm. 72, 48-50].

21-6403. DAGUM, D. E. - "Una incursión: Divinas palabras de Valle-Inclán”. CuA, 1970, núm. 3, 205-223.

21-6404. VAlle-INCLÁN, RAMóN DEL - $L a$ marquesa Rosalinda. - Editora nacional, Madrid, 1970. 131 pp.

21-6405. SÁINZ DE MEdRANO-ARCE, L. "Valle-Inclán en La reina castiza"-- CuH, 81 (1970), 395-406; 82 (1970), 442-460.

21-6406. VALLE-INCLÁN, RAMÓN DEL - Luces de Bohemia.-Edinburg, 1971. [Ed. bilingüe].

21-6407. VAlle-INCLÁN, R. M. DEL-Lights of Bohemia (Luces de Bohemia).-Mod- 
ern International Drama, 2 (1969), núm. 2.

21-6408. Schiavo, L. - "La parodia de Dante en Luces de Bohemia". - Fil, 14 (1970), 181-184.

21-6409. Lyon, J. E. - "A note on the two versions of Luces de Bohemia".BHS, 47 (1970) , 52-56.

21-6410. Varela JÁcome, B. - "Análisis de La pipa de Kif”. - CuEG, 25 (1970), 101-118.

21-6411. Lima, R. - "Valle-Inclán, Obregón and the Mexican Indian: a basis for the autograph poem iNos vemos!" REH, 4 (1970) , 19-26.

V. también núms. 5109, 5112, 5569, 5977, 6081, 6266.

21-6412. Bfrmúdez-CAÑete, Federico Baroja en la novela actual. - [Tesis, Univ. de Madrid; resumen en $R U M$, 18 (1969), núm. 72, 37-38].

21-6413. Gullón, R. - "Saquemos a Baroja del purgatorio". - INO, 94-99.V. núm. 20-3267.

21-6414. Robledo, F. - "Don Pío Baroja y la pintura".-PSA, 59 (1970), 31-55. 21-6415. Fuentes, V. - "Baroja y la pintura". - RNo, 11 (1969-70), 68-72.

21-6416. Rivera, Haydée - Pio Baroja y las novelas del mar. - [Tesis, New York Univ.; resumen en DAI, 31 (1970-71), 1811A].

21-6417. Corrales Egea, José - Francia en Baroja y Baroja en Francia. - [Tesis, Univ. de Madrid; resumen en $R U M$, 17 (1968), 32-34].

21-6418. Corrales Egea, José - Baroja y Francia. I. Francia en Baroja. II. Baroja en Francia. - Taurus, Madrid, 1970. 429 pp., ilustr. (Persiles). \| Ins, 1970, núms. 284/5 (Alfaro) .

21-6419. ANTón ANDRÉs, A.--"Baroja ante los alemanes y Alemania". - IR, 2 (1970) , 169-196.

21-6420. Baroja, Pío - El árbol de la ciencia. Ed. by G. C. Flynn. - AppletonCentury-Crofts, New York, 1970. xxii + 314 pp. || H, 54 (1971), 414 (Hatton). 21-6421. Ortriz Armengol, Pedro - Aviraneta y diez más. - Prensa Española, Madrid, 1970. 217 pp. [Personajes de Galdós y de Baroja]. \| $R y F, 183$ (1971), 551-552 (Hornedo).

21-6422. Baroja, Pío - Las ciudades: César o nada. El mundo es ansi. La sensibilidad pervertida. 2a ed. - Alianza Editorial, Madrid, 1971. 718 pp. (El libro de bolsillo, 100) . - V. núm. 20-3280.
21-6423. Baroja, Pío - Los confidentes audaces.-Planeta, Barcelona, 1970. 231 pp. (Autores españoles $e$ hispanoam.). 21-6424. Baroja, Pío - Crónica escandalosa. - Planeta, Barcelona, 1970. 241 pp. (Autores españoles $e$ hispanoam.). 21-6425. Baroja, Pío - Desde la última vuelta del camino. - Barcelona, 1970. 2 ts.: 1565 pp.

21-6426. Baroja, Pío - Las inquietudes de Shanti Andia. Pról. y notas de J. Caro Baroja. - Anaya, Salamanca, 1970. 371 pp. (Bibl. Anaya).-V. núm. 20-3284.

21-6427. BarojA, Pío - Juan Van Alen, el oficial aventurero. - Espasa-Calpe, Madrid, 1970. 248 pp. (Austral, 1401).

21-6428. Lebors, A. - "Pour le centenaire de Pío Baroja (1872-1956)". - AFLT, 1971, núm. 2, 103-139. [Con su traducción inédita de La leyenda de Juan de Alzate].

21-6429. Puértolas, Soledad - El Madrid de "La lucha por la vida". - Helios, Madrid, 1971. 136 pp.

21-6430. Baroja, Pío-La venta de Mirambel. - Planeta, Barcelona, 1970. 215 pp. (A utores españoles e hispanoamericanos).

V. también núms. 5194, 5569, 6294.

Azorín: v. núms. 7040-4.

21-6431. Zamacois, Eduardo - El misterio de un hombre pequeñito. - Eds. Andorra, Andorra la Vieja, 1970. II Ins, 1971, núms. 296/7 (Domingo) .

21-6432. GUILLÉN, JORGE - En torno a Gabriel Miró. Breve epistolario. - Eds. de Arte y Bibliofilia, Madrid, 1970, || Ins, 1970, núm. 288 (Alfaro) .

21-6433. Gullón, R. - "Reflexiones en torno a Miró". - INO, 113-125.

21-6434. Laguna díaz, Elpidio - El tratamiento del tiempo subjetivo en la obra de Gabriel Miró.-Madrid, 1970. 130 pp.

21-6435. Miró, Gabriel - El humo dormido. Ed. de V. Ramos. - Anaya, Salamanca, 1970. 141 pp. (Bibl. Anaya).V. núm. 18-3706.

21-6436. ONTAÑ́́N DE LOPE, P. - "Miró crítico: la mujer de la provincia". $A L M, 8 \quad(1970), 173-184$.

21-6437. Sallenave, P. - "Ramón Pérez de Ayala, teórico de la literatura". $-\mathrm{CuH}$, $82(1970), 178-189$.

21-6438. DeRNDARSKY, RoswITHA - Ramón Pérez de Ayala. Zur Thematik und Kunstgestalt seiner Romane. - V. Klostermann, Frankfurt/M., 1970. 192 pp. (Studien zur Philosophie und Literatur, 8) . - V. núm. 20-3302.

21-6439. Matas, JULio-Las "novelas nor- 
mativas" de Ramón Pérez de Ayala.[Tesis, Harvard Univ., 1970].

21-6440. Cargill, MaruXa-Los mitos clásicos y modernos en la novela de Pérez de Ayala. - [Tesis, Univ. of California, Irvine; resumen en $D A I, 30$ (1969-70), 2999A-3000A].

21-6441. Fernández Avello, Manuel Pérez de Ayala y la niebla. - Inst. de Estudios Asturianos, Oviedo, 1970. 100 pp. || ROcc, 31 (1970), 228-230 (Amorós).

21-6442. Zamora, C. - "La concepción trágica de la vida en la obra novelesca de Ramón Pérez de Ayala". - Hf, 1971, núm. 42, 21-34.

21-6443. Fonr, M. T. - "La sociedad del futuro en Pérez de Ayala, Huxley y Orwell". - REH, 4 (1970), 67-83.

21-6444. Pérez de Ayala, Ramón - Belarmino and Apolonio. Tr., with an introd., by G. Berns and M. Baumgarten. - Univ. of California Press, Berkeley, 1971. $220 \mathrm{pp}$.

21-6445. Lozano Alonso, M. B.-"E1 tiempo en Belarmino y Apolonio, de Ramón Pérez de Ayala". - BRAE, 51 (1971), 413-458.

21-6446. Pérez de Ayala, Ramón - La pata de la raposa. Ed., pról. y notas de A. Amorós. - Labor, Barcelona, 1970. 328 pp. (Textos hispánicos modernos, 5) .

21-6447. Pérez de Ayala, Ramón - Tiniebla en las cumbres. Ed., introd. y notas de A. Amorós. - Castalia, Madrid, 1971. 311 pp. (Clás. Castalia, 36).

21-6448. García Domínguez, E. - "Sobre la poesía de Pérez de Ayala". - BIEA, 25 (1971), 385-400.

21-6449. CONCHA, Víctor G. DE LA - Los senderos poéticos de Ramón Pérez de Ayala. - Universidad, Oviedo, 1970. fns, 1971, núm. 299 (Mainer).

21-6450. CELA, C. J.--"Sobre un romance de circunstancias de Ramón Pérez de Avala".-PSA, 64 (1972), 115-123.

21-6451. Berthelot, A. - "Curiosité: un autographe (et une anecdote) de Pérez de Ayala".-LNL, 1971, núm. 196, 79-81.

21-6452. GranjeL, L. S. - "Vida y obra de Félix Urabayen”. - CuH, 81 (1970), 515-530.

21-6453. Gascó Contell, E. - "Wenceslao Fernández Flórez". - LEsp, 14 (1971), 508-509.

21-6454. MaIner, J.-C. - "W. Fernández Flórez, un noventayocho olvidado". PSA, 62 (1971), 23-42.
21-6455. ZAETtA, R, - "Wenceslao Fernández Flórez: The evolution of his technique in his novels". - KRQ, 17 (1970), 127-137.

21-6456. McInerney, Francis W. - The novels of Salvador de Madariaga.-[Tesis, Univ. of Nebraska, 1971].

21-6457. Fuentes, v. - "De la novela expresionista a la revolución-proletaria. En torno a la narrativa de Joaquín Arderíus". - PSA, 60 (1971), 197-215.

Gómez de la Serna: v. núms. 7054-7.

Jarnés: v. núm. 7061.

21-6458. Castroviejo, C. - "Libros recientes de Corpus Barga". - ROcc, 28 (1970), 338-349.

21-6459. NúñEz, A. - "Corpus Barga en Madrid". - tns, 1970, núm. 283.

21-6460. BARga, Corpus - Hechizo de la triste marquesa. (Crónica cinematográfica de 1700). - Seix Barral, Barcelona, 1971. 222 pp. (Bibl. Formentor).

Barea: v. núm. 5993.

21-6461. Quiñonero, J. P. - "Rosa Chacel, o los laberintos de la infelicidad".- $C u H$, 85 (1971), 255-260.

21-6462. Chacel, Rosa - La sintazón. Barcelona, 1970. $554 \mathrm{pp}$.

21-6463. Zunzunegui, JUAN ANTONIO DE Obras completas. T. 2, pról. de J. de Entrambasaguas. T. 3, pról. de J. A. Tamayo. - Noguer, Barcelona, 1971. 1173, 929 pp. - V. núm. 20-3316.

21-6464. Zunzunegui, Juan Antonio - El contrabando. - Prensa Española, Madrid, 1971. 257 pp.

21-6465. Zunzunegui, Juan Antonio DE Una ricahembra. - Prensa Española, Madrid, 1970. 822 pp. $\| R y F, 183$ (1971), 665-666 (Hornedo).

21-6566. Dомingo, J. - "Sender". - Ins, 1971, núm. 291.

21-6467. Peñuelas, Marcflino C. - La obra narrativa de Ramón J. Sender. Pról. de R. J. Sender. - Gredos, Madrid, 1971. 294 pp. (BRH, Estudios y ensayos, 153). IIns, 1971, núms. 300/01 (Mainer) .

21-6468. O'Brien, Mary Margaret EideFantasy in the fiction of Ramon J. Sender. - [Tesis, Univ. of Colorado, 1970]. 21-6169. Álvarez, Elsa Delia - La obra de Ramón J. Sender. Un estudio de sus personajes femeninos. - [Tesis, Michigan State Univ., 1970-71].

21-6470. BÉJAR, MANUEt - Personality in the novels of Ramón J. Sender. - [Tesis, Univ. of Utah, 1970]. 
21-6471. UCEDA, J. - "Realismo y esencias en Ramón Sender”. - ROcc, 28 (1970), 39-53.

21-6472. SENDER, RAMón J. - La antesala. -Destino, Barcelona, 1971. 242 pp.

21-6473. Sender, Ramón J. - El bandido adolescente. Pról. de $\mathbf{R}$. Vázquez Zamora. - Salvat-Alianza Editorial, Madrid, 1970. $183 \mathrm{pp}$.

21-6474. SENDER, RAMón J. - Carolux Rex. 2a ed. - Destino, Barcelona, 1971. 227 pp. (Ancora y delfin).

21-6475. Sender, Ramón J. - Comedia del diantre $y$ otras dos. - Destino, Barcelona, 1970. 265 pp. (Ancora y delfin). I) $B A b r, 45$ (1971), 491 (Lord).

21-6476. Sender, RaMón J. - Crónica del alba. Hipogrifo violento. La quinta Julieta. - Alianza Editorial, Madrid, 1971. 3 ts.: $427,459,587$ pp. (El libro de bolsillo, 316/8).

21-6477. CARRASQUeR, F. - “Imán” y la novela histórica de Sender (N. 20-7413). |) ZRPh, 87 (1971), 675 (Rothe).

21-6478. SENDER, RAMóN J. - Relatos fronterizos. - Editores Mexicanos Unidos, México, 1970. $352 \mathrm{pp}$.

21-6479. Godoy Gallardo, E. - "Problemática y sentido de Réquiem por un campesino español, de Ramón Sender". $-L D, 1$ (1971), 63-74.

21-6480. SENDER, RAMón J. - Siete domingos rojos, 2a ed. - Proyección, Buenos Aires, 1970. 240 pp. (Tiempo vital).

21-6481. Sender, Ramón J. - Tánit. Planeta, Barcelona, 1970. 325 pp. (Autores españoles e hispanoamericanos).

21-6482. SENDER, RAMón J. - El verdugo afable.-Aguilar, México, 1970. 384 pp. (Novela nueva).

21-6483. Peñuelas, M. C. - "En torno a La vida de Ignacio Morel, de Sender". -PSA, 59 (1970), 251-260.

21-6484. Sender, Ramón J. - Zu, el ángel anfibio. - Planeta, Barcelona, 1970. 229 pp.

21-6485. Senjer, Ramón J. - Ensayos del otro mundo.-Destino, Barcelona, 1970. 265 pp. (Áncora $y$ delfin, 357).

V. también núm. 5993.

21-6486. López. Molina, L. - “Notas sobre Max Aub". - BSCC, 46 (1970), núm. 2. 21-6487. KOHLER, PAUL - The literary image of the Spanish Civil War of 193639 in Max Aub's "El laberinto mágico". -[Tesis, Univ. of Toronto, 1970].

21-6488. AUb, MAX - Novelas escogidas. Pról. y notas de M. Tuñón de Lara.-
M. Aguilar, México, 1970. 1339 pp., ilustr. (Bibl. de autores modernos).

21-6489. AUB, MAX - Las buenas intenciones. - Alianza Editorial, Madrid, 1971. 256 pp. (El libro de bolsillo, 302).

21-6490. Carenas, F. - "Análisis de los grupos sociales en Campo cerrado".CuA, 1971, núm. 1, 197-213.

21-6491. AuB, Max-La calle de Valverde. -Seix Barral, Barcelona, 1970. 417 pp. (Bibl. breve de bolsillo, 72).

21-6492. Aub, Max - Diario de Djelfa. 2. ed.-J. Mortiz, México, 1970. 110 pp., ilustr. (Obras incompletas).

21-6493. AUB, MAx - Jusep Torres Campalans. - Barcelona, 1970. 344 pp. ( $P a-$ labra en el tiempo). II Ins, 1970, núm. 288 (Cano)

21-6494. Aub, MAX - La gallina ciega. Diario español. - J. Mortiz, México, 1971. 417 pp.

21-6495. AUB, Max - Los muertos. - J. Mortiz, México, 1971. $156 \mathrm{pp}$.

21-6496. AUB, MAX - Subversiones,-Madrid, 1971. 89 pp., ilustr. (Saco roto).

21-6497. Aub, MAx - Vida y obra de Luis Alvarez Petreña. - Seix Barral, Barcelona, 1971. 225 pp. (Bibl. breve, 310) .

21-6498. Monlé́n, José - El teatro de Max Aub. - Taurus, Madrid, 1971. 145 pp. (Cuadernos Taurus).

21-6499. AUB, Max - Teatro: El desconfiado prodigioso. Jácara del avaro. Discurso de la Plaza de la Concordia. Los excelentes varones. Entremés de «El Di-

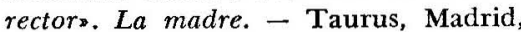
1971. 238 pp. (El mirlo blanco).

21-6500. Fraile, Medardo - Elementos románticos en la vida y la obra de Samuel Ros (1904-1945). - [Tesis, Univ. de Madrid; resumen en $R U M, 17$ (1968) , 34$35]$.

21-6501. Buckley, R. - "Francisco Ayala y el arte de vanguardia. (Hacia una nueva valoración de la generación de 1927) ". - Ins, 1970, núm. 278.

21-6502. Domingo, J. - "Narrativa española. El retorno de los exiliados".-Ins, 1970, núm. 288. [En particular, Ayala]. 21-6503. IrIZARRY, Estelle DIANE - Francisco Ayala: Relaciones entre su obra critica y teórica con la de ficción.-[Tesis, George Washington Univ.; resumen en $D A I, 41 \quad(1970-71), 1801 \mathrm{~A}]$.

21-6504. IRIZARRX, EsTElle - Teoria $y$ creación literaria en Francisco Ayala.Gredos, Madrid, 1971. 274 pp. (BRH, Estudios y ensayos, 151). 
21-6505. Hiriart, Rosario H. - Las alusiones literarias en la obra narrativa de Francisco Ayala. - [Tesis, New York Univ., 1970-71].

21-6506. Blanco Amor, J. - "América en la narrativa de Francisco Ayala".-CuH, $83(1970), 269-273$.

21-6507. Ayala, Francisco - The lamb's head. Transl. and critical study by Celice Craig F. Wiseman. - [Tesis, Univ, of Texas, 1971$]$.

21-6508. Ayala, Francisco - Cazador en el alba y otras imaginaciones. - Seix Barral, Barcelona, 1971. 128 pp. (Bibl. breve de bolsillo).

21-6509. Ayai.A, Francisco - El fondo del vaso. - Alianza Editorial, Madrid, 1970. 220 pp. (El libro de bolsillo, 229). ROcc, 30 (1970), 243-244 (Amorós).

21-6510. PAGÁN DE Soro, G. - "Estudio de la novela $E l$ fondo del vaso, de Francisco de Ayala".-EPR, 1970, núm. 30, 117-125.

21-6511. Ayala, Francisco - El Inquisidor y otras narraciones españolas.-Anaya, Salamanca, 1970. 133 pp.

21-6512. Ayala, Francisco - El jardin de las delicias. - Seix Barral, Barcelona, 1971. 175 pp. (Bibl. breve). || fns, 1971, núms. 300/01 (Cano).

21-6513. Joly, M. - "Sistemática de perspectivas en Muertes de perro". - CuH, $82(1970), 415-429 .-V$. núm. 20-7423.

21-6514. Hiriart, R. - "Dos apuntes sobre Muertes de perro y $E l$ fondo del vaso de Francisco Ayala". - Razón y Fábula, Bogotá, 1971, núm. 24, 45-51.

21-6515. Elcrs, K.-“Cervantes and Ayala's El rapto: The art of reworking a story". -PMLA, 84 (1969), 14-19.

21-6516. Ayala, Francisco - Los usurpadores. Pról. de A. Amorós. - Andorra, 1970. 235 pp. || BAbr, 45 (1971), 494 (Crispin) .

21-6517. Ayala, Francisco - Los ensayos. -Aguilar, Madrid, 1971. 129 pp. (Autores nuevos).

21-6518. Moore, David Pitman-Günter Grass and Alejandro Núñex Alonso: $A$ comparative study of their novels. [Tesis, Univ. of Arkansas, 1970-71].

21-6519. Serrano Poncela, SEgundo - El hombre de la Cruz Verde. - Eds. Andorra, Andorra, 1969. 259 pp. (Bibl. Valira, 1) . || Ins, 1971, núms. 296/7 (Castroviejo); $B A b r, 45$ (1971), 490 (Williams).

21-6520. Domingo, J.-“C. J. Cela goza de buena salud".-Ins, 1970, núm. 279.
21-6521. Amorós, A. - "Conversación con Cela”. - ROcc, 33 (1971), 267-284.

21-6522. LAPUENTE, F.-A.-“"La crítica norteamericana frente a Cela". $-B F E, 1970$, núms. 36/7, 11-20.

21-6523. Tudela, Mariano-Cela. - Epesa, Madrid, 1970.197 pp. (Grandes escritores contemporáneos).

21-6524. Ferrer, Olga P. - El sistema estético de Camilo José Cela. 2a ed.-Castalia, Valencia, 1966. 171 pp. (La lupa y el escalpelo, 2) . - V. núm. 17-6320.

21-6525. IlIE, PAUL - La novelistica de Camilo José Cela. 2: ed.-Gredos, Madrid, 1971. 242 pp. (BRH, Estudios y ensayos, 65). - V. núm. 19-3518.

21-6526. Cela, Camilo José - Obra completa. T. 8: Los viejos amigos, primera y segunda serie, y Tobogán de hambrientos. - Destino, Barcelona, 1971. 1069 pp. - V. núm. 20-3350.

21-6527. Cela, Camilo José-La colmena. -Noguer, Barcelona, 1971. 273 pp. (Nueva galeria literaria). - V. núm. 19-7606.

21-6528. Carenas, F. - "La colmena: novela de lo concreto". - PSA, 61 (1971), 229-255.

21-6529. HeNN, D. - "Cela's portrayal of Martín Marco in La colmena”. - N, 55 (1971) , 142-149.

21-6530. SPIREs, R. - "Técnica y tema en La familia de Pascual Duarte. Tres incidentes claves". - Íns, 1971, núm. 298.

21-6531. Marbán, Jorge Antonio - Pascual Duarte y Meursault: Dos actitudes ante la vida y la sociedad. - [Tesis, Emory Univ.; resumen en $D A I, 31$ $(1970-71), 764 \mathrm{~A}]$.

21-6532. Cela, Camilo José - Garito de hospicianos. 2a ed. - Noguer, Barcelona, 1971. 302 pp. (Nueva galería literaria). -V. núm. 18-7436.

21-6533. Cela, Camilo José - rzas, rabizas y colipoterras. - Barcelona, 1971. 109 pp. (Ediciones de bolsillo).-V. núm. 19-3533.

21-6534. Cella, Camilo José - Maria Sabina. El carro de heno, o el invento de la guillotina.-Alfaguara, Madrid, Barcelona, 1969. 282 pp.-V. núm. 20-3361.

21-6535. Beardsley, T. S., JR. - "El estreno mundial de Maria Sabina. Apuntes bibliográficos". - PSA, 60 (1971), 321-336.

21-6536. Cela, Camilo José - El molino de viento $y$ otras novelas cortas. - Noguer. Barcelona, 1971. 189 pp. (Nueva galería literaria). - V. núm. 17-6328.

21-6537. Cela, Camilo José - Nuevas an- 
danzas y desventuras de "Lazarillo de Tormes". - Noguer, Barcelona, 1970. 234 pp.-V. núm. 18-7437.

21-6538. Cela, Cammo José - Timoteo, el incomprendido, $y$ otros papeles ibéricos. - Magisterio Español, Madrid, 1970. 375 pp. (Novelas y cuentos, 69) . \| $R y F, 183$ (1971), 441 (Guillén).

21-6539. Cela, Camilo José - Visperas, festividad y octava de San Camilo del año 1936 en Madrid.-Alfaguara, Madrid, 1970. 443 pp. (Alfaguara literaria, 24). II ROcc, 29 (1970), 379-381 (Amorós); $L N L, 1970$, núm. 195, 100-103 (Berthelot); Ins, 1970, núm. 279 (Domingo) ; $M N, 1970$, núm. $49,84-87$ (Iglesias) ; $E L, 1970$, núm. 437 (Iglesias Laguna); $R y F, \quad 181 \quad(1970), \quad 205-210$ (Zamarriego).

21-6540. Uriarte, F. - Apuntes sobre San Camilo, 1936". - PSA, 59 (1970), 323-325.

21-6541. Callanan, James - Cela's "libros de vagabundaje": anatomy of a genre. -[Tesis, Univ. of St. Louis, 1971].

21-6542. Cella, Camilo José - Barcelona. -Barcelona, 1970. 79 pp., ilustr.

21-6543. Cela, Camilo José - Avila. 2a reed. - Noguer, Barcelona, 1970. 60 pp., ilustr. - V. núm. 17-2711.

21-6544. Cela, Camilo José - La Mancha en el corazón y en los ojos.-Edisven, Barcelona, 1971. 257 pp.

21-6545. Cela, Camilo Jost-Primer viaje andaluz. Notas de un vagabundaje por Jaén, Córdoba, Sevilla, Huelva y sus tierras. - Noguer, Barcelona, 1971. 376 pp. (Nueva galeria literaria).

21-6546. Gironella, José MARíA - Condenados a vivir.-Planeta, Barcelona, 1971. 2 ts.: 351, 395 pp.

21-6547. Gironella, José María - Peace after war. Trad. by J. MacLean.-A. A. Knopf, New York, 1969. 762 pp.

V. también núm. 5110 .

21-6548. Medio, Dolores - Asturias. Destino, Barcelona, 1971. 610 pp., ilustr. (Guias de España).

21-6549. Gómez GIL, A. - "José Luis Castillo-Puche”. - CuA, 1971, núm. 4, 234-247.

21-6550. Castrllo Puche, José Luis - El cingulo. Como ovejas al matadero. Destino, Barcelona, 1971. 295 pp. ( $A n$ cora $y$ delfin).

21-6551. McGloin, Sister Genevieve Time and the mask: a study of Quiroga's novel, "La careta". - [Tesis, Univ. of St. Louis, 1971].
21-6552. QUiroga, Elena - Escribo $t u$ nombre. - Noguer, Barcelona, 1970. 487 pp. - V. núm. 19-7634.

21-6553. Quiroga, Elena - Plácida la joven, $y$ otras narraciones.-Noguer, Barcelona, 1970. $206 \mathrm{pp}$.

21-6554. Alonso dE LOS Ríos, CÉSAR Conversaciones con Miguel Delibes. Magisterio Español, Madrid, 1971. 235 pp. (Novelas y cuentos, 83). || Ins, 1971, núm. 295 (Cano).

21-6555. Hickey, DeNis JoHN - Miguel Delibes, autor católico. - Univ. de Madrid, 1969. 31 pp. - V. núm. 20-3378.

21-6556. Rogers, Elizabeth Senick - Life and works of Miguel Delibes.-[Tesis, Univ. of Illinois, 1970].

21-6557. Pauk, Edgar - Miguel Delibes: Development of a writer (1947-1969).[Tesis, Yale Univ, 1970$]$.

21-6558. Davis, Mrchael M. - Alienated man in the novels of Miguel Delibes.[Tesis, Univ, of Miami, 1971].

21-6559. Delibes, Miguel - La mortaja.Alianza Editorial, Madrid, 1970. 204 pp. (El libro de bolsillo, 223). I| Ins, 1970, núm. 286 (Domingo) ; BAbr, 45 (1971), 494-495 (Klibbe).

21-6560. Delibes, Miguel - USA y yo. Ed. by F. L. Gordon, - The Odyssey Press, New York, 1970. xvi +223 pp. \| $H, 54$ (1971), 986 (Rivas).

21-6561. Delibes, Miguel - Viejas historias de Castilla la Vieja.-Alianza Editorial, Madrid, 1970, 152 pp. (El libro de bolsillo, 164) . \|tns, 1969, núms. $275 / 6$ (Domingo) .

V. también núm. 6008 .

21-6562. Illlanes Adaro, Graciela - La novelistica de Carmen Laforet.-Gredos, Madrid, 1971. 202 pp.-V. núm. 17-6333.

21-6563. LAfForet, CARMEN-Novelas. T. 1 -Barcelona, 1970. $1347 \mathrm{pp}$.

21-6564. LAfFoRet, CARMEN - La niña y otros relatos. - Magisterio Español, Madrid, 1970. 249 pp. (Novelas y cuentos, 68). If Ins, 1971, núm. 290 (Castroviejo) . 21-6565. Martín-Santos, Luis - Apólogos $y$ otras prosas inéditas. Ed. y pról. de S. Clotas. - Seix Barral, Barcelona, 1970. 154 pp. (Bibl. breve). || BAbr, 45 (1971), 287-288 (Crispin); $H, 54$ (1971), 396 (Díaz) .

21-6566. Martín-Santos, Luis - Prometeo. -Burgos, 1970. 88 pp.

21-6567. Martín-Santos, Luis - Tempo di silenzio. - Feltrinelli, Milano, 1970.

21-6568. Eoff, S. H., \& J. Schraibman "Dos novelas del absurdo: L'étranger y 
Tiempo de silencio". - PSA, 56 (1970), 213-241.

V. también núm. 6008 .

21-6569. Fischer, OTto O. - La tragedia humilde en la narrativa de Ignacio Aldecoa.-[Tesis, Univ. of Miami, 1971].

21-6570. AldecoA, IgNacio - La tierra de nadie $y$ otros relatos. Pról. de A. M. Matute. - Madrid, 1970. 200 pp.

V. también núm. 6573.

21-6571. Ferres, ANTonio - En el segundo hemisferio. - Seix Barral, Barcelona, 1970. 260 pp. (Nueva narrativa hispánica). \|BAbr, 45 (1971) , 665 (Childers); fns, 1971, núm. 290 (Domingo) .

21-6572. Rodríguez-Padrón, J. - "Jesús Fernández Santos y la novela española de hoy". - CuH, 81 (1970), 437-448.

21-6573. Fernández Santos, I. - " "Ignacio Aldecoa y yo". - Ins, 1970, núm. 280. 21-6574. FernÁNdez SANTos, Jesús - Las catedrales.-Seix Barral, Barcelona, 1970. 193 pp. \| BAbr, 45 (1971), 487 (Crispin); Ins, 1970, núm. 286 (Domingo); Uro, 1970, núms. 5/6, 139-140 (García Luengo) .

21-6575. Fernandez Santos, Jesús - Libro de las memorias de las cosas.-Destino, Barcelona, 1971. $389 \mathrm{pp}$. (Ancora y delfin). If fns, 1971, núm. 294 (Domingo); $R v F, 184$ (1971), 121-126 (Hornedo). 21-6576. Gómez Gil, A. - "Ana María Matute". - CuA, 1971, núm. 5, 250-254. 21-6577. Winecoff DíAz, JANET - Ana $M a$ ria Matute. - Twayne, New York, 1971. 165 pp. (TWAS, 152).

21-6578. Winecoff Díaz, J. - "La Comedia dell'arte en una novela de Ana María Matute". - Hf, 1970, núm. 40, 15-28.

21-6579. Matute, ANA MaRíA - Fiesta al noroeste. Ed. by L. Alpera. - Prentice Hall, Englewood Cliffs, N. J., 1971. 100 pp. II H, 54 (1971), 988-989 (Dial); MLJ, 55 (1971), 543 (Díaz).

21-6580. Alpera, L. - "Ambigüedad, análisis y síntesis en Fiesta al noroeste, de Ana M. Matute". - IAP, 4 (1970), 161164.

21-6581. Matute, ANa María - Los niños tontos. - Barcelona, 1971. 72 pp.

21-6582. MATUTE, ANa María - La torre vigia.-Lumen, Barcelona, 1971. 237 pp.

V. también núm. 6008 .

21-6583. Carenas, F. - "Compilación del legado de Juan Goytisolo a la Universidad de Boston". - LT, 1971, núm. 72 : 170-176.

21-6584. Schwartz, Kessel - Juan Goytisolo.-Twayne, New York, 1970. 155 pp.
21-6585. Forrest, GeNe Steven - The novelistic world of Juan Goytisolo.[Tesis, Vanderbilt Univ.; resumen en DAI, 30 (1969-70), 4449A].

21-6586. RoMFro, HÉCTOR RENÉ - La no velistica de Juan Goytisolo. - [Tesis, Univ. of Illinois, 1970].

21-6587. Gordon, Robert Alan - An analysis of the narrative techniques of Juan Goytisolo. - [Tesis, Univ, of Colorado, 19711.

21-6588. Durán, M. - "El lenguaje de Juan Goytisolo". - CuA, 1970, núm. 6, 167-179.

21-6589. Cox, Randolph C. - Aspects of alienation in the novels of Juan Goytisolo.-[Tesis, Univ. of Wisconsin, 1971].

21-6590. Goytisolo, JuAN - Fin de fiesta. Tentativas de interpretación de una listoria amorosa. - Seix Barral, Barcelona, 1971. 176 pp. (Bibl. breve de bolsillo). - V. núm. 17-7647.

21-6591. Goytrsolo, JUAN - Reivindicación del conde don Julián.-J. Mortiz, México, 1970. 242 pp. (Novelistas contemporáneos). I| BAbr, 45 (1971), 286287 (Alfieri); $\boldsymbol{H}, 54$ (1971), 960-966 (Schwartz) .

21-6592. Castrillet, I. M. - "Introducción a la lectura de Reivindicación del conde don Julián, de Juan Goytisolo". -Papeles, Caracas, 1971, núm. 13, 9-17.

21-6593. ORTEGA, T. - "Reivindicación del conde don Julián, última novela de Juan Goytisolo".-Carav, 1971, núm. 17, 153-167.

21-6594. Durán, M. - "Vindicación de Juan Goytisolo: Reivindicación del conde don Julián". - fns, 1971, núm. 290. 21-6595. GoYTisolo, JUAN - Marks of identity. Trad. by G. Rabassa.-Grove Press, New York, 1969. 352 pp.

V. también núm. 6008 .

\section{PROSA VARIA}

21-6596. TATE, RoBERT B. - Ensayos sobre la historiografía peninsular del siglo $x y$. Versión de J. Díaz. - Gredos, Madrid, 1970. 358 pp. (BRH, Estudios y ensayos, $145)$.

21-6597. Fraile, Guillermo - Historia de la filosofia española. - Editorial Católica, Madrid, 1971. 418 pp. (BAC, 327). 21-6598. Lucas Marracín, Istoro - Séneca en tres ensayistas del barroco español: Quevedo, Saavedra Fajardo y Baltasar Gracián. - Madrid, 1970. 52 pp.

21-6599. MarTí, A. M. - "La retórica sa- 
cra en el Siglo de Oro".-HK, 38 (1970), 264-298.

21-6600. Herrero Salgado, Félix-A portación bibliográfica a la oratoria española. -C.S.I.C., Madrid, 1971. 742 pp. (RLit, anejo 30 ) .

21-6601. Cabantous, M. - "Viaje de Roque Antón, manuscrit inédit du xvirre siècle". - BHi, 72 (1970), 338-345.

21-6602. Erorza, ANtonio (ed.) -Socialismo utópico español. - Alianza Editorial, Madrid, 1971. 240 pp. (El libro de bolsillo).

21-6603. López Campillo, E. - "Apuntes sobre una evolución en la temática del ensayo español (1895-1930)". - CuH, 85 (1971), 445-460.

21-6604. Mermale, T. - "Concepts of humanism in the contemporary Spanish essay". - HR, 39 (1971), 237-248.

21-6605. López Quintas, Alfonso - Filosofia española contemporánea. Temas y autores. - La Editorial Católica, Madrid, 1970. 719 pp. $(B A C, 298)$. $\| R U N P$, 22 (1970), 284-286 (Farré); EAg, 5 (1970), 498 (Ferrero); Carav, 1971, núm. 17, 276-278 (Kourim); $C D, 183$ (1970), 621-622 (Uña).

21-6606. ABellán, J. L.- Filosofia española en América (1936-1966) (N. 20-3404). || EAg, 3 (1968), 437-438 (Casado).

21-6607. Fernández de la Mora, Gonzalo -Pensamiento español 1969. De Sanz del Rio a Morente. - Madrid, 1971. 377 pp. -V. núm. 21-3016.

\section{A utores antiguos}

21-6608. SierRA, L. - "E1 padre Juan Francisco Masdeu y la Chronica Roderici, con una referencia a $\mathbf{R}$. Menćndez Pidal".-RUM, 19 (1970), núm. 74, 249264.

21-6609. Mackenzie, D. - "García Álvarez y la Crónica de Iria”--AEM, 6 (1966). 21-6610. Collins, Larry LeE - An "un. known" manuscript of the "Crónica de veinte reyes". - [Tesis, Univ. of Minnesota, 1970].

21-6611. Crónica general de España de 1344, que ordenó el Conde de Barcelos don Pedro Alfonso. Ed. crítica del texto español por D. Catalán y Ma S. de Andrés. T. 1. - Seminario Menéndez Pidal (Gredos), Madrid, 1971. xciv + 360 pp. 21-6612. Catalín, D. - "Poesía y novela en la historiografía castellana de los siglos xII y XIV". - HRL, 423-441.

21-6613, LOAISA, JOFRÉ DE - Crónica. Est. prel., ed. e indices por A. Ubieto Arteta. - Valencia, 1971. 66 pp. (Textos medievales).

V. también núm. 3316.

21-6614. Keller, J. E. - Alfonso X, el Sabio (N. 20-3410). II $S p, 46$ (1971), 157-158 (Burns) . - V. núm. 20-7489.

21-6615. Brewre, W. B.-"Extent of verbal influence and choise between $l e$ and $l o$ in Alphonsine prose". - HR, 38 (1970), 133-146.

21-6616. Chalon, L. - "De quelques vocables utilisés par la Primera crónica general de España". - MA, 77 (1971), 79-84.

21-6617. Chalon, L. - "Le miracle de Cascajares dans la Primera crónica general".-LNL, 1971, núm. 196, 51-54.

21-6618. Alfonso EL SABIo-General estoria, 2a parte, t. 2, ed. A. G. Solalinde (N. 18-3777). II RPh, 24 (1970-71), 216-221 (Rico).

21-6619. GrNzLER, JOHN ROBERT - The role of Ovid's metamorphoses in the "General estoria" of Alfonso el Sabio. - [Tesis, Univ. of Wisconsin, 1971].

21-6620. Pinkernell, G. - "Die Geschichte Ganymeds in der General Estoria Alfonsos des Weisen. Eine Illustration zur Methode mittelalterlicher Quellenbenutzung”. - RJ, 21 (1970), 257-261.

21-6621. Nienerehe, H. J. - "Boccaccio als Etymologe".-HJMP, 166-171. [Comparación con la General estoria].

21-6622. RoubIL, J. - "Alphonse Ie Savant, rédacteur de définitions lexicographiques. (Premier essai)". - Mélanges... Pierre Fouché (Paris, 1970).

21-6623. SIMón, José GREgorio-Definición de vocablos en las "Partidas" de Alfonso $X$, el Sabio. - [Tesis, Emory Univ.; resumen en $D A I, 31$ (1970-7I), 1240A].

21-6624. Bermejo CABRERo, J. L.-"En torno a la aplicación de las Partidas. Fragmentos del Espéculo en una sentencia real de 1261".-HM, 30 (1970), 169-177.

V. también núms. 3987, 4731-8.

21-6625. Bocados de oro. Kritische Ausgabe des altspanischen Textes von Mechtild Crombach. - Romanisches Seminar der Universität, Bonn, 1971. 204 pp. - V. núm. 20-3418.

21-6626. Kahane, H. \& R., \& A. PietrancELI-"Hermetism in the Alfonsine tradition".-HRL, 443-457. [Sobre todo en los Bocados de oro].

21-6627. Buchthal, Hugo-Historia troiana: Studies in the history of mediaeval secular illustration.-Warburg Institute, 
London; Brill, Leiden, 1971. xxii +74 pp. ilustr.

21-6628. La Corónica troyana. A medieval Spanish translation of Guido de Colonna's "Historia destructionis Troiae". Ed. by F. Pelletier Norris. - Univ. of North Carolina Press, Chapel Hill, N. C., 1971. 176 pp. Studies in the Romance languages and literatures, 90).

21-6629. Juan Manuel, DoN - El conde Lucanor. Texto antiguo y versión moderna e introd. de A. Bolaño e Isla. 6a ed. - Porrúa, México, 1970. xxiv + 201 pp. (Sepan cuantos, 28). [7 7 a ed., 19717. - V. núm. 19-7690.

21-6630. Juan Manuel, Don - El conde Lucanor. Est. prel. y notas de M. E. Foix y L. León de Tedesco. - Kapelusz, Buenos Aires, 1971.

21-663I. MacPherson, I. - "Dios y el mundo, the didacticism of $E l$ conde Lucanor". - $R P h, 24$ (1970-71), 26-38.

21-6632. Juan MANuel, Don - Libro de los Estados. Edición según un manuscrito de la Biblioteca Nacional. Ed. de J. M. Castro y Calvo.-Barcelona, 1968. $257 \mathrm{pp}$.

21-6633. MacPherson, I. - "Amor and Don Juan Manuel".-HR, 39 (1971), 167-182.

21-6634. Fernández de Heredia, J. - $\boldsymbol{L} a$ grant crónica de Espanya (N. 19-3598). || $R P h, 24$ (1970-71), 648-651 (Armistead) .-V. núm. 20-3429.

21-6635. López Molina, L. (ed.) - Tucidides romanceado en el siglo xvi (N. 17-4566) . || $Z R P h, 86(1970), 273-286$ (Geijerstam) .

21-6636. KINKADE, R. P. - "Un nuevo manuscrito de la Semeiança del mundo".HR, 39 (1971) , 261-270.

21-6637. Luna, PEDro DE - Libro de las consolaciones de la vida humana. A critical edition by William R. Delford. - Tresis, Univ. of North Carolina, 1971].

21-6638. Custer, Marilyn EMmons - The "tropi" and "figurae" of "ornatus" in Pedro López de Ayala's "Crónicas de los Reyes de Castilla". - [Tesis, Univ. of Connecticut, 1970].

21-6639. López de Ayala, Pero - Crónica del rey don Juan el primero. An edition and study of the manuscripts by Roderic Charles Diman.-[Tesis, Univ. of Wisconsin, 1971].

21-6640. López de Ayala, Pero-Las muertes del rey Don Pedro. - Alianza Editorial, Madrid, 1971. 216 pp. (El libro de bolsillo, 352).
21-6641. Sturm, H. - "A note on the sources of the Libro de los ejemplos por a.b.c.". - KRQ 17 (1970), 87-91. [Sánchez de Vercial].

21-6642. López Duque, Micaela - Comentario crítico al libro "Ars cisoria" [de Enrique de Villena].-[Tesis, Univ. de Madrid; resumen en $R U M, 1969$, núm. 72,4507 .

21-6643. Satorre Grau, J. J. - "Pedro de Corral y la estructura de su Crónica del rey don Rodrigo".-AlAn, 34 (1969), 158-173.

21-6644. Del Piero, R. A. - Dos escritores de la baja Edad Media castellana (Pedro de Veragüe y el arcipreste de Talavera, cronista real). - Madrid, 1971. (BRAE, anejo 23).

21-6645. WhitBourn, C. J. - The a Arcipreste de Talavera" and the literature of love.-Hull, 1970. 64 pp.

21-6646. Martínez de Toledo, AlfonsoArcipreste de Talavera o Corbacho. Ed., introd. y notas de J. González Muela.Castalia, Madrid, 1970. 304 pp. (Clás. Castalia).

21-6647. Martínez de Toledo, AlfonsoEl Corbacho. Introd., notas y revisión por C. Pastor Sanz. - Magisterio Español, Madrid, 1971. 234 pp. (Novelas $y$ cuentos).

21-6648. Stahl, Verlan H. - Vocabulatio del "Corbacho". - [Tesis, Univ. de Madrid; resumen en RUM, 18 (1969), núm. 72, 51-52].

21-6649. Sharrer, Harvey Leo - The legendary history of Britain in Lope García de Salazar's "Libro de las bienandanças e fortunas". - [Tesis, Univ. of California, Los Angeles, 1970].

21-6650. Rodriguez de Lena, Pedro-Passo honroso defendido por Suero de Quiñones. Reimpr. facs. de la ed. de Llaguno (Madrid, 1784), con índices por $\mathbf{F}$ Arroyo.-Valencia, $1970.80 \mathrm{pp}$.

21-6651. Rodríguez de Cuenca, Juan-Su. mario de los Reyes de España. Ed. de E. de Llaguno y Amirola. Indices por M. de los Desamparados Pérez Boldo. Ed. facs. de la original de 1781.-Valencia, 1971. $116 \mathrm{pp}$.

21-6652. Palencia, Alonso DE - Cuarta década. Estudio, texto y trad. de J. Ló. pez de Toro. T. 1. - Madrid, 1970. $267 \mathrm{pp}$.

21-6653. Martínez Carreras, J. U. - "Ga. briel Alonso de Herrera y su Obra de agricultura". - RIM, 31 (1971), 11-68. 21-6654. Herrera, Gabriel Alonso De- 
Obra de agricultura. Ed. y est. prel. de J. U. Martínez Carreras. - Atlas, Madrid, 1970.408 pp. (BAE).

21-6655. Córdoba, Fr. MarTín DE-Jardin de nobles donzellas. A critical edition and study by Harriet Goldberg.-[Tesis, Univ. of Pennsylvania, 1971].

21-6656. López-SAIz, J. M. - "Sobre el Arte de marear, de fray Antonio de Guevara". - REH, 4 (1970), 125-134.

21-6657. González, Manuel José - "Lo guevariano en el Simplicius Simplicissimus". - LD, 1971, núm. 2, 83-101.

21-6658. Nieto, J. C. - "Was Juan de Valdés an ordained priest?" - $B H R, 32$ (1970) , 603-606.

21-6659. Márouez, A. - "Juan de Valdés, teólogo de los alumbrados". - CD, 184 (1971) , 214-229.

21-6660. Nreto, José C. - Juan de Valdés and the origins of the Spanish and Italian Reformation. - Droz, Genève, 1970. xviii + 356 pp. (Travaux d'Humanisme et Renaissance, 108). \|HAHR, 51 (1971), 191-192 (Strauss).

V. también núm. 5112.

21-6661. Valdés, ALfonso DE-Due dialoghi. Trad. italiana del sec. xvi a cura di G. de Gennaro. - Istituto Universitario Orientale, Napoli, 1968. xciii +440 pp.

21-6662. Torquemada, ANTONio DE - Manual de escribientes. Ed. de M. J. C. de Zamora y A. Zamora Vicente. - Madrid, 1970. 267 pp.

21-6663. Kincaid, Joskph James - Cristobal de Villalon: The authorship of the anonymous works and the problem of identity. - [Tesis, Vanderbilt Univ.; resumen en DAI, 31 (1970-71), 1281A$1282 \mathrm{~A}]$.

21-6664. Moncada, E. J. - "The Spanish source of Edmund Tilney's Flower of friendshippe". - MLR, 65 (1970), 241247. [Pedro de Luján, Coloquios matrimoniales (1550) ].

21-6665. Pérouse, G. A. - "Le Dr. Huarte de San Juan: pédagogie et politique sous Philippe II". - BHR, 32 (1970), 81-93.

21-6666. Pérouse, Gabriel A. - L'examen des esprits du docteur Juan Huarte de San Juan. Sa diffusion et son influence en France aux xvie et xviie siècles. Paris, 1970. $221 \mathrm{pp}$.

V. también núm. 6150.

21-6667. Bataillon, M. - "Juan Méndez Nieto à l'Université de Salamanque" -ACCP, 2 (1970), 180-191.

21-6668. Martínez MoRell.A, Vicente -
Alicante en la "Chrónica de la inclita y coronada ciudad de Valencia y su reyno", de Martin de Viciana.-Fondo Editorial del Excmo. Ayuntamiento, Alicante, 1970. $41 \mathrm{pp}$.

21-6669. Maravall, J. A. - "Reformismo social-agrario en la crisis del siglo xvII: tierra, trabajo y salario según Pedro de Valencia". - BHi, 72 (1970), 5-55.

Gracián Dantisco: v. núm. 4565.

2I-6670. Robles, M. - "Francisco Cascales.

Ficción poética y arte dramático". Et Caetera (Guadalajara, Méx.), 1971. núm. 21, 43-48.

21-6671. Escalante, Manuel F. - El pen. samiento politico de Álamos de Barrientos.-Sevilla, 1968. $10 \mathrm{pp}$.

21-6672. Ximénez Patón, Bartolomé Decente colocación de la santa cruz (1635). Discurso en favor del estatuto de limpieza (1638). - $\mathrm{La}$ fonte que mana y corre, Cieza, 1971. [120] pp. (El ayre de la almena, 30).

Quevedo: v. núms. 6598, 6918-21.

Saavedra Fajardo: v. núms. 5112, 6598.

21-6673. VII,AR, J. - "Formes et tendances de l'opposition sous Olivares: Lisón y Viedma, defensor de la patria".-MCV, 7 (1971), 263-294.

21-6674. Correa Calderón, E. - Baltasar Gracián. Su vida y su obra. 2a ed., aum. -Gredos, Madrid, 1970. 422 pp. (BRH, Estudios y ensayos, 52). - V. núm. 18-3797.

21-6675. ILIE, P. - "Gracián and the moral grotesque". - HR, 39 (1971), 30-48.

21-6676. Zlotescu-Croranu, 1. - "Medita ción rumana en torno a Gracián".- $A r b$, 75 (1970), 147-157.

21-6677. Gracián, Baltasar - El criticón. Ed., introd. y notas de E. Correa Calderón. - Espasa-Calpe, Madrid, 1971. 3 ts.: xcii + 232, 281, 355 pp. (Clás. cast., $165 / 6 / 7)$.

21-6678. Gracián, Baltasar - El criticón. Comentado por A. Prieto. - Narcea, Madrid, 1970. 672 pp. (Bitácora, I).

21-6679. WELLES, MARCIA - Style and structure of Gracián's "El criticón".[Tesis, Columbia Univ., 1971].

V. también núms. 5112, 5183, 6598, 6900. Melo: v. núm. 4809.

21-6680. León Pinelo, Antonio DE-Anales de Madrid (desde el año 1647 al de 1658). Transcripción, notas y ordenación cronológica de P. Fernández Martín.-Instituto de Estudios Madrileños, C.S.I.C., Madrid, 1971. xii + 384 pp. $\| R y F, 183$ (1971), 661-662 (Hornedo). 
21-6681. Gándara, FRAY Felipe dE LA Armas y triunfos. Hechos heroicos de los hijos de Galicia. (Madrid, 1662). Estudios y pról. por J. Filgueira Valverde. Ed. facs.-Santiago de Compostela, 1970.

21-6682. ANDREws, N., JR. - "Una breve nota sobre fray Juan Interián de Ayala”. $-R N o, 11$ (1969-70), 144-147.

21-6683. Villar Ramirez, JuAN B. - El doctor Diego Mateo Zapata (1664-1745). Medicina y judaismo en la España mo. derna. - Academia Alfonso X el Sabio, Murcia, 1970. 44 pp. If Sef, 31 (1971), 133-134 (Cantera Burgos).

21-6684. Míguez, A. - "Retrato de un hombre sentado". - Uro, 1970, núm. 2, 61-64. [Feijoo].

21-6685. Livermore, A. L. - "Goya y Feijoo". - CuH, 85 (1971), 17-45.-V núm. 16-49504.

21-6686. VARela, J. L. - "El ensayo de Feijoo y la ciencia". - [En su libro] $L a$ transfiguración literaria (Madrid, 1970), 91-146.

21-6687. Navarro de Adruaensens, J. M. - Je ne sais quoi: Bouhours, Feijoo. Montesquieu".-RJ, 21 (1970), 107-115.

21-6688. RICARD, ROBERT - Feijoo y el misterio de la naturaleza animal. Oviedo, 1970. 22 pp. (Cuadernos de la cátedra Feijoo, 23) .

21-6689. Feijoo, Benito Jerónimo - Tea tro critico universal. Cartas eruditas $y$ curiosas. (Antología). Sel., pról. y notas de C. Martín Gaite. - Alianza Editorial, Madrid, 1970. 268 pp. (El libro de holsillo, 225).

21-6690. Mestre, Antonio-Historia, fueros y actitudes politicas. Mayáns y la historiografía del xviii. Pról. de E. Giralt y Raventós.-Ayuntamiento de Oliva, Valencia, 1970. xii + 607 pp. ROcc, 35 (1971), 372-376 (Aguilar PiñaI) ; Carav, 1971, núm. 17, 268-272 (Défourneaux) .

21-6691. MESTRE, A. - Ilustración y reforma... Gregorio Mayáns y Siscar (N. 21-3071) . || Carav, 1971, núm. 17, 268272 (Défourneaux).

21-6692. Ruiz Veintemilla, J. M. - "La primera acción literaria de la Academia de la Historia". - BBMP, 46 (1970), 71-107. [La España primitiva de Francisco Javier de la Huerta].

21-6693. Echánove Tuero, Alfonso - La preparación intelectual del $P$. Andrés Marcos Burriel. - Instituto "Enrique Flórez”, Barcelona, 1971. 327 pp. - V. núm. 20-5945.
21-6694. Fernández Clemente, Eloy Nipho y la educación. El alcañizano que creó el primer periódico en España (1719-1803). - Teruel, 1968. 35 pp., ilustr.

21-6695. García-Pandavenes, Elsa - The "discursos" of Luis Cañuelo in "El censor" (1781-1787). - [Tesis, Univ. of California, Berkeley, 1970$]$.

21-6696. Espinosa, Agustín - Don José Clavijo y Fajardo. Pról. de A. Valbuena Prat. - Cabildo Insular de Gran Canaria, Las Palmas, 1970. 154 pp.

21-6697. Saugnieux, J.-Un prelat éclairé: Don Antonio Tavira y Almazán (17371807). Contribution à l'étude du jansénisme espagnol. - Université, Toulouse, 1970. 326 pp. (France-Ibérie recherche). I| $L N L, 1970$, núm. 195, 107108 (Outin).

A utores modernos

21-6698. Átvarez Gómez, Jesús - Juan Pablo Forner (1756-1797), preceptista y filósofo de la historia. - Ed. Nacional, Madrid, 1971. 586 pp. (Vida y pensamiento españoles). II REE, 27 (1971), 175-176 (Segura).

21-6699. Polt, J. H. R. - “Juan Pablo Forner (1756-1797), preceptista y filósofo de la historia". - REE, 26 (1970), 213-241.

21-6700. Forner, Juan Pablo - Los gramáticos. Historia chinesca. Ed., pról. y notas de J. Jurado. - Espasa-Calpe, Madrid, 1970. xxvi +212 pp. (Clás. cast. 168) .

21-6701. Arroyal, LEón DE - Cartas económico-politicas. Ed., pról. y notas de J. Caso González. - Oviedo, 1971. 305 pp. (Textos y estudios del siglo xviii).

21-6702. Miguel López, Raimundo DE-El Filósofo Rancio. Sus ideas politıcas y las de su tiempo. - Madrid, 1969. 280 pp.

21-6703. Gõ̃I Gaztambide, J. - “E.l adiálogon de José Goya y Muniaín". - $P V$, 1971, núms. 122/23.

21-6704. García Barrón, Carlos-La obra critica y literaria de don Antonio Alcalá Galiano.-Gredos, Madrid, 1970. 248 pp. (BRH, Estudios y ensayos, 146) - - V. núm. 20-3529. II fns, 1971, núm. 290 (Cano) .

21-6705. Escobar, J. - "Sobre la formación del artículo de costumbres: Mariano de Rementería y Fica, redactor del Correo literario y mercantil'. $B R A E$, 50 (1970), 559-573. 
21-6706. Suárez Verdaguer, Federico-Introducción a Donoso Cortés. - Madrid, 1964. $273 \mathrm{pp}$.

21-6707. Domínguez Castañeda, Pedro El orden social según Donoso Cortés.León, 1960. $98 \mathrm{pp}$.

21-6708. Donoso Cortés, JuAN - Obras completas. Ed., introd. y notas de C. Valverde. - Madrid, 1970. 2 ts.: 2060 pp. 21-6709. Balmes, JAIME L. - El criterio. Est. prel. de G. Díaz-Plaja. 2a ed.-Porrúa, México, 1970. xix + 160 pp. (Sepan cuantos, 53). - V. núm. 19-7791.

21-6710. Azcárate, P. DE - Sanz del Río (N. 20-7600) . || EAg, 5 (1970), 770 (Ca. sado) .

21-6711. Pérez-Rioja, José Antonio-Dos centenarios de sorianos: $E l$ filósofo Sanz del Rio (1814-1869) y el abad Gómez Santa Cruz (1869-1949). - Centro de Es. tudios Sorianos, Soria, 1970. $28 \mathrm{pp}$ (Bibl. Soriana, 9) .

21-6712. Quadrado, José M. - Recuerdos $y$ bellezas de España. Selección antoló. gica. - C.S.I.C., Madrid, Valencia, 1971. 127 pp.

21-6713. Jutglar, Antoni - El constitucionalismo revolucionario de $\mathbf{P i}$ y Margall.-Taurus, Madrid, 1970. $85 \mathrm{pp}$.

21-6714. PI Y Margall, Francisco - Et reinado de Amadeo de Saboya y la República de 1873. Pról. de A. Jutglar.Madrid, 1970. 274 pp.

21-6715. Pi y Margall, Francisco-Pensamiento social. Sel. y est. prel. de J. Trías Bejarano. - Madrid, 1968. $365 \mathrm{pp}$.

21-6716. Villalobos, J. - El pensamiento filosófico de Giner (N. 20-7605) . $\| E A g$, 5 (1970), 502-503 (Guerra Galende).

21-6717. SABORIT, ANDRÉs-Joaquín Costa y el socialismo. 2a ed. - Ed. Zero, Algorta, 1970. 178 pp.

21-6718. Azcárate, P. dE - "Algunos manuscritos inéditos (?) de Costa”. - $\mathrm{CuH}$, $82(1970), 5-40$.

21-6719. DíAz de Cerio, F. - "Tres cartas de Joaquín Costa y cinco dirigidas a él'. $-L D, 1$ (1971), 195-200.

21-6720. Abellán, J. L. - "El costismo de Macias Picavea". - RUM, 19 (1970), núm. 73, 7-20.

21-6721. Durán Muñoz, García, y FranCisco Alonso Burón - Ramón y Cajal. Vida y obra. Pról. de P. Laín Entralgo. Zaragoza, 1960. 544 pp., ilustr.

21-6722. RAMón y Cajal, SANTIAGo-Obras literarias completas. - Nota prel. de F. C. Sáinz de Robles. - Aguilar, Madrid, 1969. 1335 pp. - V. núm. 16-49539.
21-6723. Cavia, Mariano DE - Articulos -Madrid, 1971. 198 pp.

21-6794. Beltrán de Heredia, P. - "Confidencias eruditas de Miguel Antonio Caro a Menéndez Pelayo". - $A O, 19$ (1969) , 162-205.

V. también núm. 5112.

21-6725. Baquero Goyanes, Mariano Perspectivismo y ensayo en Ganivet.Murcia, 1967. 52 pp.

21-6726. Gallego Morell, ANtonio - Estudios y textos ganivetianos. - C.S.I.C., Madrid, 1971. xvi + 214 pp. (RLit, anejo 32) . || Ins, 1971, núm. 299 (Cano) .

21-6727. Mellado de Hunter, Elena-El estoicismo de Angel Ganivet. - [Tesis, Univ. of Maryland, 1970].

21-6728. Montes Huidobro, M. - “El dog. ma de la Inmaculada Concepción como interpretación de la mujer en la obra de Ganivet". - DHR. 7 (1969), 9-25.

21-6729. Ganivet, A. - Correspondencia familiar. Cartas inéditas (1888-1897), ed. J. Herrero (N. 20-3587) . \| BHS, 48 (1971), 78-80 (Ribbans). - V. núm. 21-3086.

21-67-30. RamsdeN, H. - Angel Ganivet's "Idearium español" (N. 20-7630). U BHS, 48 (1971), 77-78 (Ribbans).

21-6731. GLABERT, J. J. - "Algunas contradicciones fundamentales en el libro Idearium español, de Ángel Ganivet". -IAP, 4 (1970) , 257-261.

Unamuno: v. núms. 6137, 7015-21.

21-6732. SOlÉ-Tura, Jordi - Catalanismo y revolución burguesa. La sintesis de Prat de la Riba.-Madrid, 1970. 296 pp. -V. núm. 20-5522.

21-6733. GARAGORRi, P. - “La tentación política: Azaña”. - ROcc, 28 (1970), 217-225.

21-6734. Camba, Julio - El destierro. Magisterio Español, Madrid, 1970. 284 pp. (Novelas y cuentos).

21-6735. Amorós, ANDrés - Eugenio d'Ors, critico literario. - Prensa Española, Madrid, 1971. 258 pp.-V. núm. 19-7867. 21-6736. Flórez, Rafael - D'Ors.-Epesa, Madrid, 1970. 203 pp. (Grandes escritores contemporáneos, 30 ).

21-6737. D'Ors, Eugenio - Nuevo Prometeo encadenado. Guillermo Tell. - Magisterio Español, Madrid, 1971. 215 pp. (Novelas y cuentos, 91).

21-6738. RUKSER, Udo - Bibliografia de Ortega. - Revista de Occidente, Madrid, 1971. 417 pp. (Estudios orteguianos, 3) .

21-6739. Aguado, Emiliano - Ortega $y$ 
Gasset. - Madrid, 1970. 107 pp. (Gran. des escritores contemporáneos).

21-6740. Garagorri, Paulino - Introducción a Ortega. - Alianza Editorial, Madrid, 1970. 224 pp. (El libro de bolsillo, 231). || Ins, 1970, núm. 286 (Abellán); $M L J, 55$ (1971) , 336 (Benbow); EAg, 6 (1971), 176 (Garrido).

21-6741. Araya, Gulllermo - Claves filológicas para la comprensión de Ortega. - Gredos, Madrid, 1971. 250 pp. (BRH, Estudios y ensayos, 149). "I ZRPh, 87 (1971), 661-662 (Baldinger). 21-6742. Marías, Julián - Acerca de Ortega. - Revista de Occidente, Madrid, 1971. 271 pp. (El alción).

21-6743. Salmerón, Fernando - Las mocedades de Ortega y Gasset. 2a ed.-Fac. de Fiolsofia y Letras, México, 1971. 374 pp.-V. núm. 16-45313.

21-6744. Oguiza, T. - "Una reevaluación de Ortega". - PSA, 59 (1970), 117-126.

21-6745. DU JOVNE, LEÓN - La concepción de la historia en la obra de Ortega y Gasset. - Buenos Aires, 1968. 218 pp.

21-6746. Kourim, Z. - "Una visión crítica marxista de Ortega".-ROcc, 29 (1970), 176-204.

21-6747. Guy, A. - "Ortega y Gasset et la pensée germanique". - IR, 2 (1970), 197-215. [Trad. española en $H u N L, 11$ (1970), 71-94].

21-6748. ORRINGer, N. R. - "Ortega y Gasset's sportive theories of communication". - MLN, 85 (1970), 207-234.

21-6749. Redondo Gálvez, Gonzalo - Las empresas periodisticas de José Ortega y Gasset. "El Sol", "Crisol" y "Luz" (19171934). - [Tesis, Univ. de Madrid; resumen en $R U M, 18$ (1969), núm. 72, 84-85].

21-6750. Redonio, Gonzalo - Las empresas politicas de José Ortega y Gasset: "El Sol", "Crisol", "Luz" (19171934). - Rialp, Madrid, 1970.2 ts.: 476 , $608 \mathrm{pp}$.

21-6751. Lafuente Ferrari, Enrique Ortega y las artes visuales.-Rev. de Occidente, Madrid, 1971. 268 pp. \|ROcc, 35 (1971), 364-368 (Marías).

21-6752. SCUDERI, M. - "Ortega y las artes visuales”. - Ins, 1971, núm. 299.

21-6753. Roig, Rosendo - La metáfora en Ortega y Gasset. - Valencia, 1967. 298 pp., ilustr.

21-6754. HAMpton, WARREN ReED - La novela y su circunstancia en la critica de Ortega y Gasset. - [Tesis, Tulane Univ., 1971$].$
21-6755. Ortega y Gasset, José - Obras completas. T. 8. 3a ed. - Rev. de Occidente, Madrid, 1971.672 pp. - V. núm. 19-3739.

21-6756. Ortega Y Gasset, JosÉ - Obras completas. Ts. 8 y 9. 3a ed.-Rev. de Occidente, Madrid, 1970-71. 565, 790 pp.

21-6757. ORTEGA y GASsET, J. - Obras completas, ts. 10 y 11 (N. 21-3092). $\| R y F$, 182 (1970), 526-527 (Iturrioz).

21-6758. ORTEGA Y GASSET, JOSÉ - La deshumanización del arte $y$ otros ensayos estéticos. 10a ed.-Revista de Occidente, Madrid, 1970. 209 pp. (El arquero).-V. núm. 19-7896.

21-6759. ORTEGA Y GASSET, JosÉ - Some lessons on metaphysics. Tr. by $\mathbf{M}$. Adams.-Norton, N. York, 1971. 158 pp. 21-6760. OrTEgA y GASSET, Joś́ - Historia como sistema. - Espasa-Calpe, Madrid, 1971. 146 pp. (Austral, 1440).

21-6761. ORTEga y Gasset, JosÉ - El hombre y la gente. - Revista de Occidente, Madrid, 1970. 2 ts.: 192, 216 pp. (El arquero). - V. núm. 19-7898.

21-6762. ORTEga y Gasset, José - Ideas y creencias y otros ensayos de filosofia.Rev. de Occidente, Madrid, 1970. 196 pp. (El arquero). - V. núm. 19-3741.

21-6763. Ortega y Gasset, José - L'évolution de la théorie déductive. L'idée de principe chez Leibniz. Trad. par J.-P. Borel--Gallimard, Paris, 1970. 342 pp. (Bibliothèque des idées). || AFLT, 1970, núm. 4, 169 (Guy) .

21-6764. Ortega y Gasset, José - Notas. Introd. de J. Marías. - Anaya, Salamanca, 1970. 174 pp. (Bibl. Anaya).V. núm. 20-3661.

V. también núms. 5152, 5977, 6137, 6976-9. 21-6765. "Homenaje a Gregorio Marañón". - Et Caetera, Guadalajara (México), 1971, núm. 19. [E. Ramos Meza, "Viajes de Marañón a Hispanoamérica", 322; G. Somolinos D'ARdors, "Marañón y la intemporalidad”, 23-32; V. Pozuelo, "Marañón, médico de hospital", 33-46; "Antología mínima de G. Marañón", 87-159].

21-6766. Homenaje a Marañón. - Madrid, 1970. 85 pp.

21-6767. "Homenaje a D. Gregorio Maranón”. - BRAE, 51 (1971), 7-45. [Once colaboraciones].

21-6768. Cueva Tamariz, A. - "En elogio a Gregorio Marañón". - Memorias de la Academia Ecuatoriana, 1970, núm. 28. 21-6769. MakchesI, S. - Gregorio Marañón. - Milano, 1969. 140 pp. 
21-6770. Pérez Ferrero, M. - "E1 doctor Marañón”. - MuH, 1971, núm. 275.

21-6771. Medina, S. - "Una apreciación sobre Gregorio Marañón”. - OYS, $11 / 12$ (1969-70), xxxv-xxxvi.

21-6772. Laín Entralgo, P. - "Por la integridad del recuerdo de Marañón".CuH, 82 (1970), 511-518.

21-6773. López IBor, J. J. - "Marañón, médico humanista". - CuH, 82 (1970), $519-525$.

21-6774. KeIller, GARY D. - Gregorio Marañón as literary critic, literary historian and biographer of artists and writers: his significance and impact. - [Tesis, Columbia Univ., 1971].

21-6775. RoF Carballo - "Marañón y España”. - CuH, 82 (1970) , 526-539.

21-6776. Marañón, G. - Obras completar (N. 20-3673) . \|BHS, 47 (1970), 273-275 (Reid) .

21-6777. Marañón, Gregorio-Obras completas. Sel. y notas de A. Juderías. Ts. 5-7. - Espasa-Calpe, Madrid, 1971. 1198, 1197, 661 pp.-V. núm. 20-3673. || $R O c c$, 32 (1971), 249-251 (Gil Novales).

21-6778. Amorós, A. - "Conversación con Américo Castro". - $R O_{c c}, 28$ (1970), 1-22.

21-6779. Estudios sobre la obra de Américo Castro. - Taurus, Madrid, 1971. 453 pp. [J. L. Aranguren, P. Laín Entralgo, M. Bataillon, S. Gilman, J. Goytisolo et al.]. V. también núm. 6137 .

Zubiri: v. núm. 6976.

21-6780. Mermalx, T. - "E1 humanismo de Pedro Laín Entralgo". - PSA, 56 (1970), 101-118.-V. núm. 19-7932.

21-6781. Laín Entralgo, Pfero - $A q u e ́$ llamamos España. - Espasa-Calpe, Madrid, 1971. 157 pp. (Austral, 1452). II Ins, 1971, núms. 296/7 (Cano); ROcc, 35 (1971), 347-355 (Guillén).

21-6782. Aranguren, José Lurs L. - Memorias y esperanzas españolas. - Taurus, Madrid, 1970. 225 pp. (Ensayistas de hoy, 64).

21-6783. Zambrano, MARíA - Obras reunidas. - Aguilar, Madrid, 1971. 371 pp. (Estudios literarios).

21-6784. Raley, H. C. - "Hacia una teoría estética en Julián Marías". - Hf, 1971, núm. 41, 55-59.

21-6785. Parajón, M. - “La visión responsable". - CuH, 83 (1970), 192-217. [Sobre Julián Marías].

21-6786. Soler Planas, J. - “ Es original el pensamiento filosófico de Julián Ma- rías?" - Mayurqa, 1971, núm. 5, 57-73.

21-6787. MARÍAs, JULIÁN - Antropologia metafisica. La estructura empirica de la vida humana. - Revista de Occidente, Madrid, 1970. $318 \mathrm{pp}$.

21-6788. TiJeras, E. - "Las constantes de Paulino Garagorri”. - $\mathrm{CuH}, 85$ (1971), 211-216.

21-6789. Fabra Barreiro, G. - "Conversación con Paulino Garagorri'. - ROcc, 35 (1971), 1-15.

\section{LITERATURA RELIGIOSA}

21-6790. Graef, Hilda - Historia de la mistica. - Herder, Barcelona, 1970. 352 pp. - V. núm. 21-3102.

21-6791 MORón ARroyo, Ciriaco - La mistica española. T. 1: Antecedentes y Edad Media. - Alcalá, Madrid, 1971. 254 pp. (Aula magna, 22).

21-6792. Molina, R. A. - "Antecedentes medievales de la mística española”. $P S A, 59$ (1970), 229-250.

21-6793. Bertini, Grovanni Maria - Testi rinascimentali di spiritualità spagnoli $e$ italiani. - Facoltà di Magistero, Università, Torino, 1970. lv $+170 \mathrm{pp}$. \| AION-R, 13 (197I), 359-362 (Chiareno).

21-6794. GonzÁlez Coloma, CARMen Iconografia carmelitana en España. [Tesis, Univ. de Madrid; resumen en RUM, 17 (1968), 63-64].

21-6795. López Martínez, N. - "El Tratado para sacerdotes, de Juan de Calahorra (a. 1468)". - Burg, 12 (1971).

21-6796. GonzÁlez, N. - "Tomás de villanueva, predicador". - $C D, 184$ (1971), 5-35.

21-6797. González, N. - "La predicación según Santo Tomás de Villanueva".$C D, 184$ (1971) , 189-213.

21-6798. GonzÁlez, N. - "Predicador y oyentes en Santo Tomás de Villanueva”. -CD, 184 (1971), 329-364.

21-6799. BuJANda, J. M. DE - "Tratado del amor de Dios de Santo Tomás de Villanueva". - CD, 183 (1970), 38-89.

21-6800. MARQuis, Judith ANN - Las imágenes en los "Abecedarios espirituales" de Francisco de Osuna. - [Tesis, Ohio State Univ., 1970 ].

21-6801. Esquerda Bifet, J. - "Escuela sacerdotal española del siglo xvi: Juan de Ávila (1499-1569)".-AnA, 17 (1970), 133-185.

21-6802. JIMÉNEz DuQUe, B. - "El maes- 
tro Juan de Avila". - Arb, 75 (1970), 17-25.

21-6803. Rulz Jurado, M. - "San Juan de Avila y la Compañía de Jesús". - AHSI, 40 (1971), 153-172.

21-6804. Arce, Rafael-San Juan de Avila y la reforma de la Iglesia en España.Madrid, 1970. $184 \mathrm{pp}$.

21-6805. Sala Balust, Luis, y Francisco Martín Hernández. - El santo maestro Juan de Avila. Ed. especial con motivo de la canonización. - Madrid-Roma, 1970. xxxvii +389 pp.

21-6806. Hornedo, Rafael M. DE - "E1 estilo coloquial del Beato Ávila". $-R y F$, 181 (1970), 513-524.

21-6807. ÁvilA, JuAN DE - Obras completas. Ed. de L. Sala Balust y F. Martín Hernández. T. 1: Biografia, "Audi, filia". T. 2: Sermones, ciclo temporal. T. 3: Sermones, ciclo santoral; Pláticas espirituales; Tratado sobre el sacerdocio. Ts. 4-5: Epistolario. - La Ed. Católica, Madrid, 1970, xliii +867 , xvi +948 , $\mathrm{xvi}+608,817$, xxiii +815 pp. $(B A C)$. -V. núm. 8-11964.

21-6808. Avilla, JUAN DE - Obras completas. T. 3: Comentarios biblicos. Ed. crítica de F. Sala Balust y F. Martín Hernández. - La Editorial Católica, Madrid, 1970. 508 pp.-V. núm. 8-11964.

21-6809. Ávila, JUAN DE - Obras completas. T. 4: Tratados de reforma. Tratados menores. Escritos menores. Indice general de materias. Ed. iniciada por L. Sala Balust. Nueva ed. rev. y continuada por F. Martín Hernández. - La Editorial Católica, Madrid, 1971. 577 pp. (BAC, 324) .

21-6810. Carvalho, J. A. DE - "Notas sobre un tema de Séneca en el Epistolario de Juan de Avila".-AION-R, 13 (1971), 129-141.

Orozco: v. núm. 6874.

21-6811. Jereczek, Bruno - Louis de Grenade, disciple de Jean d'Avila.-Dép. d'Êtudes Ibériques, Université de Nan. tes, 1971. $520 \mathrm{pp}$.

V. también núm. 6831 .

21-6812. Tellechea Idf́goras, J. I. - El arzobispo Carranza y su tiempo (N. 20-7753) . \|AIA, 30 (1970), 262 (Meseguer Fernández).

21-6813. BAKKER, LEO - Freiheit und Erfahrung. Ignatius von Loyola. Redaktionsgeschichtliche Untersuchungen über die Unterscheidung der Geister bei Ignatius von Loyola.-Echter Verl., Würzburg, 1970. $364 \mathrm{pp}$.
21-6814. RAHner, K. - Meditaciones sobre los Ejercicios de San Ignacio.-Herder, Barcelona, 1971. 276 pp. || CD, 184 (1971), 682-683 (Rodríguez).

21-6815. WANDELFels, H. - "Il silenzio di Budda e gli Esercizi spirituali di Ignazio di Loyola". - [En] Nuovi metodi di meditazione (Roma, 1970), 5-30.

21-6816. Giuliani, M. - "Die Ehrfurcht vor Gott und die Indifferenz". - Korrespondenz sur Spiritualität der Exerzitien, Augsburg, 20 (1970), 1-11.

21-6817. MCNALLY, Robert E.-The Council of Trent, the "Spiritual exercises" and the catholic reform.-Fortress Press, Philadelphia, 1970. 24 pp. - V. núm. 19-7994.

21-6818. IturRIoz, J. - "Lo blanco y lo negro, según la determinación de la Iglesia. (Regla 13a para sentir con la Iglesia)". - Man, 42 (1970) , 5-18.

21-6819. Penning de VRies, P. - "Vrouwen op Ignatius' weg”. - Bijdragen, Amsterdam, 31 (1970), 72-85.

21-6820. IgNatius Loyola - The Constitutions of the Society of Jesus. Tr., introd. and commentary by G. E. Ganss. -St. Louis, 1970. xii + $420 \mathrm{pp}$. (Institute of Jesuit sources, 1/1). \| ALitt, 40 (1971), 188-190 (Aldama).

21-6821. Schurhammer, Georg - Francisco Javier. Su vida y su tiempo. Trad. de F. de Areitio. Ts. 1 y 2. - Mensajero, Bilbao, 1969-70. 441, 656 pp. - V. núm. 18-7759. \|| RyF, 183 (1971), 555-556 (Iturrioz).

21-6822. Brodrick, JAMES - L'uomo di Navarra. - Ed. Paoline, Roma, 1970. 452 pp. (Coll. missionaria, 9) --V. núm. 13-35919.

21-6823. Alaimo, F. - "Lultimo atto di un importante carteggio". - Ai Nostri Amici, Palermo, 40 (1969), 259-263. [San Francisco Javier].

21-6824. Moreno Escribano, Julián-Archivo heráldico S. I. Estudio histórico, genealógico y heráldico de varones ilustres de la Compañia de Jesús. T. 1: Javier. - Edit. Católica Española, Sevilla, 1969. xxvi + 354 pp. \|AHSI, 39 (1970) , 367-369 (Schurhammer) .

21-6825. Pastor Gómez, Juan - Borja, espiritu universal. - Mensajero, Bilbao, 1970. 304 pp., ilustr. \|ALitt, 40 (1971), 195-196 (Ruiz Jurado) .

21-6826. "Homenaje a Santa Teresa de Jesús". - UPB, 32 (1970), núm. 110.

21-6827. "Homenaje a Santa Teresa".$B A V, 1970$, núm. 126, 9-21. 
21-6828. Calvo Hernando, M. - "Santa Teresa y su tiempo". - MuH, 1971, núm. 275.

21-6829. Santa Teresa y su tiempo.-Dirección General de Bellas Artes, Madrid, 1970. 123 pp., 31 láms.

21-6830. Hornedo, R. M. DE - "Sobre la exposición de Santa Teresa y su tiempo". - RyF, 183 (1971), 413-426.

21-6831. Junco, A. - "Ámbito de Teresa de Jesús". - Abs, 35 (1971), 127-143. [Fray Luis de Granada, fray Luis de León, San Juan de la Cruz].

21-6832. Sancta Teresia a Iesu, doctor Ecclesiae. Historia. Doctrina. Documenta. - Ed. del Teresianum, Roma, 1970. xvi +424 pp. (Bibl. Carmelitica).

21-6833. Santa Teresa de Jesús, doctora de la Iglesia. - Espiritualidad, Madrid, 1970. $268 \mathrm{pp}$.

21-6834. Royo Marín, Antonio - Doctoras de la Iglesia. Doctrina espiritual de Sta. Teresa de Jesús y Sta. Catalina de Siena. - La Editorial Católica, Madrid, 1970. 183 pp. (BAC, Manuales, 17) .

21-6835. Huerga, A. - "Santa Teresa, doctora para la Iglesia de hoy".- $R E, 29$ (1970), 371-448.

21-6836. Pascual de Aguilar, Ү. A. - "Teresa de Jesús, doctora de la Iglesia".Arb, 76 (1970), 21-31.

21-6837. REstrepo CANAL, C. - "Santa Teresa de Jesús doctora de la Iglesia”. -BACol, 21 (1971), 39-52.

21-6838. MesA, C. E. - "Glosas en torno a la doctora Teresa”. - $U d A, 1970$, núm. 179, 541-550.

21-6839. Auclair, Marcelle - Vida de Santa Teresa de Jesús. Trad. de J. de Echánove--Cultura Hispánica, Madrid, 1970. 387 pp.-V. núm. 6-7643.

21-6840. Werrie, Paul - Therèse d'Avila. Sa naissance, sa passion, sa mort.-Mayenne, 1971. $219 \mathrm{pp}$.

21-6841. Gómez-Menor Fuentes, José C.El linaje toledano de Santa Teresa y de San Juan de la Cruz. - Real Academia de Bellas Artes y Ciencias Históricas, Toledo, 1970. $110 \mathrm{pp}$.

21-6842. Gómfz-Menor Fuentes, José El linaje familiar de Santa Teresa y de San Juan de la Cruz. - Real Academia de Bellas Artes y Ciencias Históricas, Toledo, 1970. 224 pp., ilustr. \| Sef, 31 (1971), 129-130 (Cantera Burgos) .

21-6843. Ortiz, S. E. - "Petición de un sobrino de Santa Teresa de Jesús a la Audiencia de Quito, en 1627".-BACol, 20 (1970), 493-499.
21-6844. Gandarias de Santa Teresa de Jesús, Higinio - Santa Teresa de Jesús y los vascos. - Alzo, Guipúzcoa, 1971. $247 \mathrm{pp}$.

21-6845. RuIz Soler, LuIs - La personalidad económica administrativa de la Santa Madre Teresa de Jesús. - Icharopena, Zarauz, 1970. 494 pp. $\| R y F, 184$ (1971), 140-141 (Iturrioz).

21-6846. Renault, Emmanuel - Ste. Thérèse d'Avila et l'expérience mystique.Éds. du Seuil, Paris, 1970. $190 \mathrm{pp}$.

21-6847. Ruano, Argimiro-Lógica y mistica. La dimensión de razón, notificando lo trascendente, en Teresa de Avila.Univ. de Pucrto Rico, Mayagüez, 1970. 508 pp. $\| B H i, 73$ (1971), 197-198 (Ricard) .

21-6848. Andurnza, M. dE LA C. - "Significado de la luz en la espiritualidad de Santa Teresa". - RE, $29(1970), 190$ 242.

21-6849. RudDER, R. S. - "Santa Teresa's mysticism: The paradox of humility". $-H, 54$ (1971), 341-345.

21-6850. Peterson, Robert T. - The art of ecstacy: Saint Teresa, Bernini, and Crashaw. - Routledge \& Kegan Paul, London, 1970. xv '+ 160 pp., 28 láms. || MLR, 66 (1971), 649-650 (Hagstrum) .

21-6851. Teresa de Jesús, Santa - Antologia. Ed. y pról. de Santiago Magariños. - Imp. Municipal, Caracas, 1970. $199 \mathrm{pp}$.

21-6852. Tfrese de Jesús, SANTA - Amistad con Dios. Introd. y sel. de textos por A. López y P. Alastrué. - Iter, Madrid, 1970. 167 pp.

21-6853. Teresa de Jesús, SANTA - Camino de perfección.-Espiritualidad, Madrid, 197I. 302 pp.

21-6854. Teresa de Jesús, Santa - Castillo interior o Las moradas. Nota prel. de F. C. Sainz de Robles. 7a ed.-Aguilar, Madrid, 1971. 286 pp. (Crisol literario). - V. núm. 13-37806.

21-6855. Teresa de Jesús, SANTA - Las fundaciones. Comentado por G. Mancini. - Narcea, Madrid, 1970. 272 pp. (Bitácora, 4).

21-6856. MANcini, G. - "La crítica actual ante la obra de Santa Teresa. Las fundaciones, un libro a medio camino entre el cielo y la tierra". - Eidos, 16 (1970), 61-82.

21-6857. Montero de Espinosa, RománSiete meditaciones sobre la oración del padrenuestro, escritas por la seráfica 
madre Santa Theresa de Iesús, glosadas en verso (Amberes, 1654). [Y dos apéndices]. Ed. I. F. Peeters Fontainas. Cieza, Murcia, 1970.

21-6858. VegA, Ángel Custodio-La poesia de Santa Teresa de Jesús. Sus fuentes y sus raices. - Coleoio Mayor Mendel, Madrid, 1970. 72 pp. \| Sef, 31 (1971), 130-131 (Cantera Burgos).

21-6859. RECIO, ISRAEL - La lengua poética de Santa Teresa. - [Tesis, Univ. of California, Riverside, 1970-71].

21-6860. SÉrouet, P. - "Un nouvel autographe de sainte Thérèse d'Avila". BHi, 73 (1971), 5-10.

21-6861. MaIA, J. - "Santa Teresa e *os clássicos futuros»”. - Bro, 91 (1970), 498-508.

V. también núms. 5819, 6869 .

21-6862. Gicovate, Bernard - San Juan de la Cruz. (Saint John of the Cross). - Twayne, New York, 1971. 153 pp. (TWAS, 141).

21-6863. Petit, Lucien-Marie, et Marie Jacques - Actualité de Jean de la Croix. -Desclée de Brouwer, Brugues, 1970. 270 pp. (Présence du Carmel, 12).

21-6864. BORD, ANDRÉ - Mémoire et espérance chez Jean de la Croix. - Beauchesne, Paris, 1971. 326 pp. (Bibl. de spiritualité, 8).

21-6865. Concha, V. G. DE LA - “Conciencia estética y voluntad de estilo en San Juan de la Cruz". - BBMP, 46 (1970), $371-408$.

21-6866. Colosio, I. - La castidad consagrada. - Eds. Paulinas, Madrid, 1970. 270 pp. 「Estudia, entre otras, la doctrina de San Juan de la Cruzl.

21-6867. Caldera, E. - "El manierismo en San Iuan de la Cruz". - Proh, 1 (1970), 333-355.

21-6868. Nieto, J. C. - “Two Spanish mystics as submissive rebels". - BHR, 33 (1971) , 63-77. [Fray Francisco Ortiz y San Juan de la Cruz].

21-6869. Mendizábal, F. de (ed.) - Poesía mistica. San Juan de la Cruz, Santa Teresa y Jacinto Verdaguer. Trad. de F. Vidal Jové. - Barcelona, 1971. 320 pp.

21-6870. DUVIVIER, ROgER - La genèse du "Cantique spirituel" de Saint Jean de la Croix. - Les Belles Lettres, Paris, 1971. Ixxix + 561 pp. (Bibl. de la Fac. de Philosophie et Lettres de l'Université de Liège, 189).

21-6871. Morales, José LuIs - El “Cántico espiritual" de San Juan de la Cruz. $S u$ relación con el Cantar de los can- tares $y$ otras fuentes escrituristicas y $l i$. terarias. - Ed. de Espiritualidad, Madrid, 1971, 269 pp.

21-6872. BlecuA, J. M. - "Los antecedentes del poema del Pastorcico de San Juan de la Cruz". - SPEO, 96-99.

V. también núms. 6831, 6842 .

21-6873. Bujanda, J. M. DE - "Comple. mento bibliográfico de fray Diego de Estella. Ediciones hasta ahora desconocidas". - $A I A, 30(1970), 77-80$.

21-6874. ButANdA, J. M. DE - "Sur Orozco et Estella". - LR, 24 (1970), 111-117. 21-6875. MartínEz dE Butanda, Jesús Diego de Estella (1524-1578). Estudio de sus obras castellanas. - Roma, 1971. 187 pp. [ $=A n A, 17(1970), 187-367]$.

21-6876. LYNCH, C. - "Edición francesa de la Vanidad del mundo del P. Estella, París, 1605". - ArA, 31 (1971), 423-424. 21-6877. López, C. M.-Malón de Echaide. - Diputación Foral de Navarra, Pamplona, [1970?]. 31 pp. (Navarra, 77) .

21-6878. Sauls, L. - "Traherne's debt to Puente's Meditations".-PhQ, 50 (1971), 161-174.

21-6879. Cecilia del Nacimiento - Obras completas. Notas críticas y estudio de su vida mística por J. M. Díaz de Cerón.-Espiritualidad, Madrid, 1971. 955 pp. \|AIA, 31 (1971), 583 (Pazos).

21-6880. Velasco Bayón, Balbino - $M i$ guel de la Fuente (1573-1625).--TTesis, Univ. de Madrid; resumen en $R U M$, 18 (1969), núm. 72, 94-95].

21-6881. Ágreda, MARíA DE Jesús DE Cartas inéditas. Ed. de J. Campos. Salamanca, 1969. [Sep. de Salm, 16, 635666]. II $A I A, 30(1970), 245$ (Uribe).

21-6882. Campos, J. - "Otras cartas inéditas de la venerable Sor Maria de Jesús de Ágreda”. - AIA, 30 (1970), 337-369. V. también núm. 3343.

\section{AUTORES Y OBRAS DE GÉNEROS DIVERSOS}

21-6883. Durán, Manuel - Luis de León - Twayne, New York, 1971. 182 pp. ( $T W A S, 136)$.

21-6884. Lorenzo, Pedro de - Fray Luis de León. 2a ed. - Magisterio Español, Madrid, 1970. 248 pp. (Novelas y cuentos, 71) . - V. núm. 18-7875. || Ins, 1971, núm. 290 (Castroviejo).

21-6885. Delgado, María-Elisa - la luz como principio de unidad en fray Luis de León. - [Tesis, Univ. of Cincinnati, $1971]$. 
21-6886. Somville, P. - "Platonisme chez fray Luis de León et chez Pascal". RLV , 36 (1970) , 27-34.

21-6887. Folgado Flórez, S. - Cristocentrismo teológico en Fr. Luis de León (N. 20-7886). \| EAg, 3 (1968), 625 (Fernández).

21-6888. León, FRAY LUIS DE - Poesias. Ed., introd. y notas de A. Custodio Vega. - Barcelona, 1970. lxiv + 511 pp. 21-6889. León, fRAY LuIs DE - Poesia. Introd., ed. crítica y comentario de $\mathbf{O}$. Macrí. - Anaya, Salamanca, 1970. 413 pp. (Bibl. Anaya).

21-6890. León, FRAY LuIs dE - Poesias. El Cantar de los cantares. La perfecta casada. 3a ed. - E.D.A.F., Madrid, 1970. 488 pp. - V. núm. 20-3830.

21-6891. SARmiento, E. - “Luis de León's Qué descansada vida and the first *armen of Tibullus". - BHS, 47 (1970), 19-23.

21-6892. LEón, FRAY LuIs DE - La perfecta casada. Cantar de los cantares. Poesias originales. Introd. y notas de J. A. Peñalosa. - Porrúa, México, 1970. xlvi 262 pp. (Sepan cuantos, 145) .

21-6893. LEćN, FRAY LUIS DE - La perfecta casada. Exposición del "Cantar de los cantares", de Salomón. Ed. y pról. de P. F. Garcia y F. C. Sainz de Robles. 10a ed., la reimpr. - Aguilar, Madrid, 1970. 380 pp. (Crisol literario, 18) .-V. núm. 20-3836.

21-6894. Díaz, R.-“Los Nombres de Cristo y Pietro Bembo, con un apunte sobre Marcela". - MLN, 86 (1971), 199-210.

21-6895. LuBy, B. J. - "The names of Christ in fray Luis de León's Nombres de Cristo". - Names, 18 (1970), 20-28.

V. también núm. 6831 .

21-6896. Ayala, Francisco - Hacia una semblanza de Quevedo. - Bedia, Santander, 1969. 51 pp. - V. núm. 20-3839. 21-6897. BAUM, DORIS L. - Traditionalism in the works of Francisco de Quevedo y Villegas. - Univ. of North Carolina Press, Chapel Hill, 1970. 210 pp. (Studies in the Romance Languages and Literatures, 91) . - V. núm. 20-7893.

21-6898. Golby, K. J. - The theme of justice in Quevedo. - [Tesis, Univ. of Toronto, 1971].

21-6899. LERNER, LíA S. - Satirical style of Quevedo. - [Tesis, Univ. of Illinois, $1971]$.

21-6900. Valbuena Prat, A. - “E1 diverso conceptismo de Quevedo y Gracián”. RUM, 19 (1970), núm. 75, 249-269.
21-6901. Quevedo, Francisco de - Obra poética. Ed. de J. M. Blecua. Ts. 1-3.Castalia, Madrid, 1969-1971. xxxviii + 705, 544, 734 pp. \|IAL, 1969, núm. 256 (Azancot) ; H, 54 (1971), 196 (Rey); $M L N, 85$ (1970), 302 (Rivers); fns, 1970, núms. 284/5 (Rozas).

21-6902. Sobejano, G. - "Sobre la poesía metafísica de Quevedo”. - Tláloc, Stony Brook, N. Y., 1971, núm. 1, 15-18.

21-6903. Navarro Kelley, Emilia - La poesia metafísica de Francisco de Quevedo. - [Tesis, Tulane Univ., 1970].

21-6904. Lebrón Saviñón, M. - “La soledad, la muerte y el amor, en la poesía de Quevedo". - BADL, 1970, núm. 9.

21-6905. Zardoya, C. - "El tema del sueño en la poesía de Quevedo". - SNo, 1970, núm. 2, 15-28.

21-6906. Navarrete, Rosina - Ensayo de adecuación entre tema y métrica en los sonetos de Quevedo. - [Tesis, Univ. of Maryland, 1970].

21-6907. Palomino, A. - "Poetas satíricos. Una luz que le falta a la catarsis". Uro, 1970, núm. 2, 65-69. [Quevedo en especial].

21-6908. Quevedo, Francisco DE - Poemas satiricos y burlescos. Ed., y pról. de J. M. Blecua. - Llibres de Sinera, Barcelona, 1970. 121 pp. (Ocnos).

21-6909. Quevedo, Francisco DE - Musa satirica. Sel. y nota biográfica de $E$. Gascó Contell. - Ateneo, México, 1970. 106 pp. (Poesia universal).

21-6910. Quevedo, Francisco de - Sátiras politicas y literarias. Introd., sel. y notas de J. Hesse. - Magisterio Español, Madrid, 1971. 202 pp. (Novelas y cuentos, 82).

21-6911. Quevedo, Francisco De - La vida del Buscón. - INCIBA, Caracas, 1970. 169 pp. (Grandes autores).

21-6912. Quevedo, Francisco de - Vida del Buscón. Sueños y discursos. $7^{\mathrm{a}}$ ed., 1a reimpr. - Aguilar, Madrid, 1970. 383 pp. (Crisol literario, 31) . - V. núm. 20-3854.

21-6913. Rose, C. H. - “Pablos' damnosa hereditass".-RF, $82(1970), 94-101$.

21-6914. Price, R. M. - "On religious parody in the Buscón'. - MLN, 86 (1971), 273-279.

21-6915. Neufeld, Evelyn-The historical progression from the picaresque novel to the "Bildungsroman" as shown in "El Buscón", "Gil Blas", "Tom Jones" and "Wilhelm Meisters Lehrjahre". [Tesis, Univ. of Washington, 1970]. 
21-6916. Quevedo, Francisco de - Discurso de todos los diablos o Infierno emendado. Kritische und Kommentierte Ausgabe von Jürgen Wahl. - [Tesis, Univ. de Bochum, 1970$].$

21-6917. Quevedo, Francisco de - El siglo del cuerno. - R. Alonso, Buenos Aires, 1970. 85 pp.

21-6918. Etringhausen, H. - "Acerca de las fechas de redacción de cuatro obras neoestoicas de Quevedo". - $B R A E, 51$ (1971), 161-173.

21-6919. Ettinghausen, H. - "Neo-stoicism in pictures: Lipsius and the engraved title-page and portrait in Quevedo's Epicteto y Phocilides". - MLR, 66 (1971), 94-100.

21-6920. Pérez Carnero, Celso - Moral y politica en Quevedo. - Salamanca, 1971. $\mathrm{x}+133$ pp.

21-6921. LóPEz RuIz, A. - “Quevedo: un apócrifo más. La Relación de las trazas de Francia, copia parcial de la Defensa de España, de Pellicer".-PSA, 60 (1971), 121-138.

V. también núms. $4805,5112,5139,5758$, 6033.

21-6922. SEbold, Russell P.-Colonel don José Cadalso. - Twayne, New York, 1971, 187 pp. (TWAS, 143) .

21-6923. Cadalso, José - Noches lúgubres. Ed. de J. Arce. - Anaya, Salamanca, 1970. 76 pp. (Bibl. Anaya).

21-6924. Cadalso, José de - Cartas marruecas. Pról., ed. y notas de L. Dupuis y N. Glendinning. 2a impr. - Tamesis Books, London, 1971. Ixii +211 pp.V. núm. 20-3887.

21-6925. CAdalso, José DE - Defensa de la nación española contra la "Cuarta per. siana LXXVIII" de Montesquieu. Ed., pról. y notas de G. Mercadier. - FranceIbérie, Toulouse, 1970. xiii + 43 pp. I BHi, 73 (1971), 204-206 (Dupuis); LNL, 1971, núm. 197, 76 (Outin).

V. también núm. 6196 .

21-6926. Hueso Chércoles, R. - "En torno a Jovellanos". - BIEA, 25 (1971), 349-370.

21-6927. Martínez Fernández, J. - “La traslación de los restos mortales de Jovellanos".-BIEA, 24 (1970), 75-81.

21-6928. Palacios, José MARíA - Jovellanos. Vida... al alcance de los muchachos. 2a ed., aum. - Autor, Cabueñes (Gijón), 1970. $185 \mathrm{pp}$.

21-6929. Polt, John H. R. - Gaspar Melchor de Jovellanos.-Twayne, New York, 1971. 163 pp.
21-6930. Cienfuegos, Francisco (ed.) Jovellanos y la Cartera de Castilla. Con manuscritos inéditos. - Gijón, 1970. $199 \mathrm{pp}$.

21-6931. Prados Arrarte, Jesús - Jovellanos, economista. - Madrid, 1967. $139 \mathrm{pp}$.

21-6932. Hel.man, EdrTH - Jovellanos y Goya. - Taurus, Madrid, 1970. 294 pp. (Persiles). || fns, 1971, núm. 294 (Cano); ROcc, 33 (1971), 376-379 (Gállego).

21-6933. Galindo García, Francisco - El espiritu del siglo xviii y la personalidad de Jovellanos. (Su criterio acerca de la ganaderia en el "Informe sobre la ley agraria"). - Inst. de Estudios Asturianos, Oviedo, 1971. $309 \mathrm{pp}$.

21-6934. Lloris, M. - "Larra o la dignidad". - HR, 38 (1970), 183-197.

21-6935. Goya, vida y obra. La España de Goya y Larra. - Centro Editor de América Latina, Buenos Aires, 1971. 420 pp., ilustr. (Bibl. fundamental de arte).

21-6936. Lovet, G. H. - "About Larra's afrancesamiento". - REH, 4 (1970), 3-18.

21-6937. Carenas, F. - "Larra: un nuevo estilo". - REH, 4 (1970), 147-156.

21-6938. Konitzer, Eva - Larra und der Costumbrismo. - Anton Hain, Meisenheim/Glam, 1970. 224 pp. (Untersuchungen zur rom. Philologie, 7). [Tesis de la Univ. de Maguncia].

21-6939. SCARI, R. M. - “EI teatro y la moral en el pensamiento de Larra".CuA, 1971, núm. 5, 160-165.

21-6940. Berkowitz, Diana Conway-The nature of Larra's prose: An analysis of the "Articulos". - [Tesis, New York Univ., 1970-71].

21-6941. Di Stefano, G. - "E1 crepúsculo del liberal: Martínez de la Rosa en Roma en el 48 y el drama Amor de padre". - Proh, 1 (1970), 271-278.

21-6942. Agostini de Del Río, A. - "Recordando a Unamuno”. $-L T, 1970-71$, núms. 70/1, 324-331.

21-6943. Pérez Ferrero, M. - "Miguel de Unamuno". - $M u H, 1970$, núm. 264.

21-6944. Ibáñez de García Blanco, L. "Bibliografía unamuniana". - $C M d U$, 20 (1970), 133-138.

21-6945. Abellán, J. L. - “Aportaciones unamunianas”. - Ins, 1970, núm. 217. 21-6946. SAlcedo, EmLio - Vida de don Miguel. Pról. de P. Laín Entralgo. 2a ed., corr. - Anaya, Salamanca, 1970. 445 pp., ilustr. (Bibl. Anaya).-V. núm. 19-3913. 
21-6947. Villamor, MANUel - Unamuno. -Epesa, Madrid, 1970. 197 pp. (Grandes escritores contemporáneos, 18). I! $R y F, 183$ (1971), 439-440 (Iturrioz).

21-6948. Clavería, Carlos - Temas de Unamuno. 2a ed. - Gredos, Madrid, 1971. 168 pp. (BRH, Estudios y ensayos, 10) . - V. núm. 9-15694.

21-6949. RibBans, GeOfFRey - Niebla y soledad. Aspectos de Unamuno y Machado. - Gredos, Madrid, 1971. 332 pp. (BRH, Estudios y ensayos, 162).

21-6950. Marichalar, A. - "Miguel de Unamuno de cuerpo y alma presente". -Bol. del Depto. de Lengua y Lit. Hispánica, La Habana, 1968, núm. 5.

21-6951. Jiménez Hernández, A. - "Unamuno y el siglo diecinueve". - Cuadernos Lingüisticos, Rín Piedras, P. R., 1968, núm. 1.

21-6952. Rico de Estasen, J. - “Cuando Unamuno estuvo en el pueblo de Chinchilla". - MuH, 1971, núm. 275.

21-6953. Couffon, C. - "Cuando Miguel Ángel Asturias se entrevistaba con Miguel de Unamuno y Vicente Blasco Ibáñez". - PSA, 62 (1971), 401-418.

21-6954. Bertrand de Muñoz, M. - "La actividad política de Unamuno y su colaboración en Hojas Libres". - CuA, 1971, núm. 4, 162-174.

21-6955. Ronríguez-Luis, J. - "Una aclaración sobre el socialismo de Unamuno". -SNo, 1970, núm. 2, 75-85; núm. 3, 48-61.

21-6956. VIINUESA, José M. - Unamuno: persona y sociedad. - Algorta, 1970. $104 \mathrm{pp}$.

21-6957. González Marcos, M.-“La europeización de España en la cristianización unamunesca". - LT, 1970, núm. 68, 115-123.

21-6958. PizÁn, Manuel - El joven Unamuno. Influencia hegeliana y marxista. -Ayuso, Madrid, 1970. $70 \mathrm{pp}$.

21-6959. Collado, J. A. - Kierkegaard y Unamuno (N. 18-4053). \|EAg, 5 (1970), 493 (Villalobos).

21-6960. Cuderro, V. - "Filosofía y lenguaje en Miguel de Unamuno". - [En] Lenguaje y filosofia (Madrid, 1969).

21-6961. PARIs, C. - Unamuno. Estructura de su mundo intelectual (N. 20-8018). |) $C M d U, 20(1970), 127-128$ (Cruz Hernández) .

21-6962. Окuво, T. - “E1 existencialismo de Miguel de Unamuno".-Risoo, Tokio, abril 1967, 63-74.

21-6963. Gómez-Moriana, A. - "Unamu- no en su congoja". - $C M d U, 20$ (1970), 77-126. - V. núm. 20-8003.

21-6964. Mataix, A.-“Unamuno filósofo de la muerte". - Risoo, Tokio, dic. 1964, 64-77.

21-6965. Cirarda, José María - El modernismo en el pensamiento religioso de Miguel de Unamuno. - Vitoria, 1963. $42 \mathrm{pp}$.

21-6966. González de Cardenal, O.-“Don Miguel de Unamuno: Un reto a la teología española". - [En su libro] Meditación teológica desde España (Salamanca, 1970).

21-6967. Mercado, J., Jr. - "Unamuno, el heterodoxo". - UdA, 1971, núm. 180, 109-116.

21-6968. Sánghez Morales, N. - "Crisis espiritual de Unamuno y su evasión a Extremadura". - REE, 26 (1970), 531555.

21-6969. Forero Ucrós, C. - "El deseo de inmortalidad en Miguel de Unamuno". $-B C B, 13$ (1970), 49-64.

21-6970. Johnson, W. D. - "La antropología filosófica de Miguel de Unamuno: La conciencia y el sentimiento trágico de la vida". - CMdU, 20 (1970), 41-76.

21-6971. Hurtado, Francisco - Le thème de Dieu chez Miguel de Unamuno.[Tesis, Univ. de Estrasburgo, 1970].

21-6972. Freitas, María Carmelta de Dialéctica y dinamismo de la esperanza cristiana.-Eds. de I'Orante, Paris, 1969. xxii +286 pp. [Estudia, entre otros, a Unamuno]. || $C M d U, 20$ (1970), 130-131 (Echeverría).

21-6973. Lucero de Padrón, D. M. - "Escolio al Unamuno contemplativo". Proh, 2 (1971), 111-116.

21-6974. TURIEL, Pedro - Unamuno. El pensador. El creyente. El hombre. Comp. Bibliográfica Española, Madrid, 1970. 353 pp. || RyF, 183 (1971), 551 (Iturrioz); Atl, 8 (1970), 563-565 (Rodríguez Ramos); EAg, 6 (1971), 176-177 (Villalobos) .

21-6975. García-Alós, M. - "Pascal en Unamuno”. - Atl, 1970, núm. 43, 81-92. 21-6976. González Caminero, N. - "Unamuno, Ortega y Zubiri vistos en contimuidad histórica". - Gr, 50 (1969), 263-290.

21-6977. Garagorri, P. - Unamuno, Ortega, Zubiri, en la filosofia española (N. 20-8024). If EAg, 4 (1969), 205 (Rubio) . 21-6978. Otero, C. P. - "Lingüística y literatura (a propósito de Unamuno y Ortega)".-RPh, 24 (1970-71), 301-328. 
21-6979. Gunndique, J. S. - "Ortega contra Unamuno". - HuNL, 11 (1970), 149-162.

21-6980. Lorda Alaiz, F. M. - "Las alas más grandes que el nido. (Don Miguel de Unamuno y las lenguas españolas minoritarias)". - Ins, 1970, núm. 280.

21-6981. Rubia Barcia, J., \& M. A. ZeItrliN (eds.) - Unamuno: Creator and creation (N. 20-8034) . || MLR, 66 (1971), 419-422 (Ribbans).

21-6982. Morales, Mother Carmen - La mujer en la obra de Unamuno.-[Tesis, Louisiana State Univ,, 1970-71].

21-6983. Unamuno, Miguel DE - Obras completas. T. 9: Discursos y articulos. Ordenación de textos, prólogos y bibliografías de M. García Blanco. Ed. definitiva. - Escelicer, Madrid, 1971. 1169 pp.-V. núm. 21-3222.

21-6984. Unamuno, Miguel de - Diario intimo. Pról. y est. de F. García.-Escelicer, Madrid, 1970. xxv + 412 pp. RyF, 183 (1971), 204-208 (Iturrioz); $E A g, 6$ (1971), 345 (Rubio).

21-6985. Abellán, J. L. - "El diario de Unamuno".-tns, 1971, núm. 295.

21-6986. Rocamora, P. - “Don Miguel de Unamuno y su diario íntimo". $-A r b, 78$ (1971), núm. 304.

21-6987. YNdurÁIN, F. - "Unamuno en su poética y como poeta".-CMod, 59-125. -V. núm. 18-8075.

21-6988. Gullón, R. - "Unamuno y su Cancionero". - INO, 52-76.-V. núm. 19-8278.

21-6989. Feal Deibe, C. - "Símbolos de renacimiento en la obra de Unamuno. (La Oda a Salamanca)".-HR, 39 (1971), $395-414$.

21-6990. Franco, ANDRÉs - Unamuno, autor dramático.-[Tesis, New York Univ.; resumen en $D A I, 30$ (1969-70), 3456A$3457 \mathrm{~A}]$.

21-6991. Gullón, R.-“Teatro del alma”. -INO, 77-93.-V. núm. 18-8095.

21-6992. SegurA, F. - "Medea".-RyF, 183 (1971), 240-243. [De Séneca, trad. de Unamuno, dirigida por González Vergel].

21-6993. Agostini de Del Río, A. - "De Eurípides a Unamuno". - $B A A C, 7$ (1971) , 221-233.

21-6994. Anderson, REed - The novels of Miguel de Unamuno: A study of point of view and narrative technique.-[Tesis, Univ. of Wisconsin, 1970].

21-6995. Gullón, G. - "Juego de ficción: juego de palabras". - Íns, 1971, núm. 293. [Las novelas de Unamuno].
21-6996. Fox, Arturo - El diálogo en la novelistica de Unamuno. - [Tesis, Univ. of Minnesota, 1971].

21-6997. Franz, Thomas R. - The bases of humor in three novels of Unamuno. -[Tesis, Univ. of Kansas, 1970$].$

21-6998. Cowes, H. W.-“"Miguel de Unamuno: Ideas para una ontología de la novela actual". - Razón y Fábula, Bogotá, 1971, núm. 24, 6-18.

21-6999. IRIZARRY, E.-“'Sistemafobia en los relatos novelescos de Unamuno". Language and Linguistics, Washington, núm. 1 (1970).

21-7000, Batchelor, R. E. - "Gide et Unamuno: sotie ou nivola?" - Nottingham French Studies, 9 (1970), 44-53.

21-7001. UnAmuno, Miguel DE-Tres $n i$ volas. Ed. by D. Basdekis. - Prentice Hall, Englewood Cliffs, N. J., 1971. 118 pp. || $H, 54(1971), 983-984$ (Schweitzer) .

21-7002. Unamuno, Miguel de - Amor $y$ pedagogia. Tres novelas ejemplares $y$ un prólogo. Presentación de J. L. Abellán. 2a ed. - Magisterio Español, Madrid, 1970. 330 pp.-V. núm. 20-8061.

21-7003. Unamuno, Miguel de - Niebla. Introd. de H. S. Stevens y R. Gullón. 4a ed.-Taurus, Madrid, 1970. 191 pp. (Temas de España, 28) .-V. núm. 20 8065.

21-7004. GonzÁlez López, E. - "Unamuno y la novela existencialista: Paz en la guerra". - fns, 1971, núm. 298.

21-7005. Unamuno, Miguel de - San Manuel Bueno, mártir.-Nascimento, Santiago de Chile, 1971. 127 pp. (Bibl. popular).

21-7006. Fernández, P. H. - El problema de la personalidad en Unamuno y en San Manuel Bueno (N. 20-3980) . $\| H R$, 39 (1971), 227-229 (Fernández-Turienzo) .

21-7007. Pardo, A. - " "Locus hispanicus» y fondo medieval en San Manuel Bueno, mártir. Contribución al estudio del paisaje en la novela de Unamuno".$B I C C, 25 \quad(1970), 25$ (1970), 349-382.

21-7008. Santana, J. A. - "Influencia de Antonio de Trueba en la obra San $M a$ nuel Bueno, mártir, de Unamuno". $B S V, 26(1970), 205-214$.

21-7009. ReYnal, V. - "Del sentimiento trágico de don Manuel Bueno, mártir" -LT, 1970-71, núms. 70/1, 331-345.

21-7010. Godoy, G. J. - "Dos mártires de la fe según Dostoyevski y Unamuno".CMdU, 20 (1970), 31-40. 
21-7011. Chávez P., F. - "Algunas anotaciones sobre el aspecto psicológico en La tía Tula de Miguel de Unamuno".$H u N L, 11$ (1970), 269-282.

21-7012. AzAR, I. - "La estructura novelesca de Cómo se hace una novela". $M L N, 85$ (1970), 184-206.

21-7013. Aguirre, J. L. - "Notas al margen de La novela de don Sandalio, jugador de ajedrez, de Unamuno".-BSCC, 46 (1970), 46-78.

21-7014. Arroyo, V. M. - "Unamuno, cuentista". - Hipocampo (San José de Costa Rica), 1970, núm. 1, 23-44.

21-7015. Unamuno, Miguel de - En torno al casticismo. Est. y ed. de F. F. Turienzo--Eds. Alcalá, Madrid, 1971. 295 pp. (Aula magna).

21-7016. Unamuno, Miguel de - Por tierras de Portugal y España. Introd., sel. y notas de M. García Blanco. - Anaya, Salamanca, 1970. 199 pp. (Bibl. Anaya). -V. núm. 19-4012.

21-7017. Unamuno, Miguel de - Desde el mirador de la guerra. Textes recueillis et présentés par L. Urrutia avec une introd. à l'étude de $M$. de Unamuno comme collaborateur de $\mathrm{La} \mathrm{Na}$ ción de Buenos Aires. - Centre de Recherches Hispaniques, Paris, 1970. 496 pp. II Carav, 1972, núm. 18, 154156 (Beyrie).

21-7018. Unamuno, M. DE - Our Lord Don Quixate (N. 20-8042) . || BHS, 48 (1971), $76-77$ (Ribbans).

21-7019. Palmer, D. D. - "Unamuno, Freud and the case of Alonso Quijano". $-H, 54$ (1971), 243-249.

21-7020. Unamuno y Maragall - Epistolario y escritos complementarios. Pról. de P. Laín Entralgo. - Seminarios y Ediciones, Madrid, 1971. 266 pp.

21-7021. GAI.LEgo Morell, A. - "Unamuno y el deporte. (Un artículo olvidado) ". - CMdU, 20 (1970), 25-29.

21-7022. Gabriel y Galán, J. A., y E. RoDRíguez CEPEda - "Más sobre Unamuno y Gabriel y Galán. (Once cartas inéditas de Unamuno)". - $C M d U, 20$ (1970) , 5-23.

21-7023. Chiareno, O. - "Unamuno y dos amigos suyos italianos". - QIA, 5 (1970-71) , 243-247.

21-7024. Josia, V. - "Pirandello y Unamuno".-[En su libro] Pirandello. Estudio y antologia (Madrid, 1969), 76-86.

21-7025. García Morejón, Julio - Unamuno y Portugal. 2a ed., corr. y aum.-
Cultura Hispánica, Madrid, 1971. 580 pp. - V. núm. 19-4028.

21-7026. TABorda DE VAsconcelos - "Escritores estrangeiros em Portugal". Ocid, 78 (1970), 97-120. [Uno de ellos, Unamuno].

21-7027. YNdURÁIN, F. - "Afinidades electivas: Unamuno y Holmes". - CMod, 28-58. - V. núm. 18-8174.

21-7028. Chaves, Julio César - Unamuno y América. Pról. de J. Ruiz-Giménez. 2: ed. - Cultura Hispánica, Madrid, 1970. xxiv + 423 pp. - V. núm. 19-4029. I| RevIb, 36 (1970), 658-659 (Ashhurst). 21-7029. INGE, M. T.-"Unamuno's correspondence with North Americans. A checklist". - $H, 53$ (1970), 277-285.

21-7030. INGE, M. T. - "Unamuno's read. ing in American literature". - $H, 54$ (1971), 149-154.

21-7031. González Echevarría, R. - " $L a$ muerte de Artemio Cruz y Unamuno. Una fuente de Fuentes". - CuA, 1971, núm. 4, 197-207.

21-7032. Masia Clavel, J. - "Unamuno y Watsuji". - RyF, [184] (1971), 483496.

V. también núms. 5141, 5183, 5278, 5532, 5566, 5569, 6137.

21-7033. Alcántara, P. DE - "Leyendo a Azorín". - Guadalupe, 1970, núm. 586. 21-7034. Valverde, José María - Azorín. - Planeta, Barcelona, 1971. 411 pp. (Ensayos Planeta).

21-7035. Pérez de la Dehesa, R. - “Azorín en la prensa anarquista de fin de siglo".-CuA, 1970, núm. 6, 111-118.

21-7036. Ramos, Vicente - Raices de Azorin. - Caja de Ahorros del Sureste de España, Alicante, 1970. 43 pp.

21-7037. Espadas, Elizabeth - The language of Azorin. - [Tesis, Univ. of Illinois, 1971].

21-7038. MAzA, A. M. - "Acontecer y tiempo verbal en Azorín”. - EFil, 6 (1970) .

21-7039. Marcos-Marín, F. - "Arabismos en Azorín. (Contribución al estudio del léxico de Las confesiones de un pequeño filósofo)".-AlAn, 34 (1969), 143-158.

21-7040. Piñera, Humberto - Novela y ensayo de Azorin. - Madrid, 1971. $145 \mathrm{pp}$.

21-7041. Parley, J. - "Tmages of time in Doña Inés". - H, 54 (1971), 250-255.

21-7042. Suárez Galbán, E.-"Doña Inés: perpetuo retorno literario y real". SNo, 1970, núm. 1, 50-58.

21-7043. Flores Arroyuelo, F. J. - Anto- 
nio Azorin en "La voluntad". Un personaje desde el silencio.-Murcia, 1966. $46 \mathrm{pp}$.

21-7044. Azonín - Antonio Azorin. Ed., pról. y notas de E. Inman Fox.-Labor, Barcelona, 1970. 200 pp. (Textos hispánicos modernos, 9).

21-7045. AZorín - Reflejos de España. Estudio prel. de B. Mavrakis de Fiore.Kapelusz, Buenos Aires, 1971.

21-7046. Azorín - Tiempos y cosas. Pról. de P. de Lorenzo. - Salvat, Barcelona; Alianza Editorial, Madrid, 1970. 159 pp.

21-7047. Loudet, O. - "Azorín y Marañón". - [En su libro] Figuras próximas $y$ lejanas (Buenos Aires, 1970), 183-190.

21-7048. Tusell Gómez, X., y G. García Queipo de Llano - "Cartas inéditas de Azorín a Juan de la Cierva". - ROcc, 33 (1971), 205-217.

V. también núm. 5569 .

21-7049. PONCE, Frrnando - Ramón Gómez de la Serna. - Epesa, Madrid, 1970. 196 pp. (Grandes escritores contemporíneos). - V. núm. 20-8149.

21-7050. YNDURÁIN, F. - "Sobre el arte dé Ramón". - CMod, 192-201. - V. núm. 18-4128.

21-7051. Daus, Ronald - Der Avantgardismus Ramón Gómez de la Sernas.-V. Klostermann, Frankfurt/M., 1971. 348 pp. (Analetcta romanica, 29). -V. núm. 21-3251.

21-7052. MAZZETTI, R. - "Plurifications in the works of Ramón Gómez de la Serna". - Hf, 1971, núm. 42, 35-43.

21-7053. MAzzerri, R.- "The use of imagery in the works of Ramón Gómez de la Serna". - H, 54 (1971), 80-90.

21-7054. Zlotescu-Cioranu, I. - "Aproximación al novelista Ramón Gómez de la Serna". - Arb, 79 (1971), núm. 306.

21-7055. Gómez de la Serna, Ramón Obras selectas. El rastro. El circo. Goya. Picassismo. Greguerias. Pról. de P. Neruda - A. H. R., Barcelona, 1971. 1034 pp.

21-7056. Gómez de la Serna, Ramón - El caballero del hongo gris y La Nardo. Eds. Andorra, Andorra la Vieja, 1970. || fns, 1971, núms. 296/7 (Domingo) .

21-7057. Gómez de LA SERNA, RAMón-La Nardo (novela). La hiperestésica. Las consignatarias. Se presentó el higado. Pueblo de Morenas. - Edit. Andorra, Andorra, 1970. $263 \mathrm{pp}$.

21-7058. BorinsKy, A. - "Correspondencia de Macedonio Fernández a Gómez de la Serna". - RevIb, 36 (1970), 101-123. V. también núm. 5194.

21-7059. Bernstein, J. S. - "Retorno a Benjamín Jarnés". - Uro, 1970, núm. 4, 30-35. [A continuación, pp. 37-39, "Notas de un cuaderno inédito", de Jarnés].

21-7060. O'NeILL, M. W. - "The role of the sensual in the art of Benjamín Jarnés". - MLN, 85 (1970), 262-268.

21-7061. SMITH, K. S. - El tema de la vida $y$ el arte en las novelas de Benjamin Jarnés.-[Tesis, Univ. of Toronto, 1971]. 21-7062. Jarnés, BeNJAMín - Castelar, hombre del Sinai. - Espasa-Calpe, Madrid, 1971. 230 pp. (Austral).

\section{FOLKLORE}

21-7063. WILdHABER, ROBERT - Bibliographie internationale des arts et traditions populaires. T. 22: 1965-1966, avec compléments des années précédentes. - $\mathbf{R}$. Habelt, Bonn, 1969. xx +747 pp. $-\mathrm{V}$. núm. 19-8358.

21-7064. LANG, A. - "An inventory of the bibliographies (mostly annotated) available in the archives of the Folklore Institute, Indiana University". - The Folklore Forum, Bloomington, 1969, núm. 5, 126-129.

21-7065. Simmons, M. E.-“Folklore bibliography for 1969". - SFQ, 34 (1970), 149-313. - V. núm. 21-3256.

21-7066. Edmonson, Munro S. - Lore: An introduction to the science of folklore and literature.-Holt, New York, 1971. xv $+456 \mathrm{pp}$.

21-7067. Caro Baroja, J. - "Estructura y tradición: dos vocablos usuales en las ciencias antropológicas". - RDTP, 27 (1971) , 3-32.

21-7068. Carvalho-Neto, Paulo de-The concept of folklore. - Univ. of Miami Press, Coral Gables, 1970. 192 pp.-V. núm. 12-32290.

21-7069. Flury, Lázaro - Perspectiva del folklore. - Eds. Colmegna, Santa Fe (Argentina), 1970. 90 pp. - V. núm. 19-4063.

21-7070. GergeLy, J.-"Sur l'aspect historique de la chanson populaire". - Ethnologia Europaea, Paris, 2/3 (1968-69), 144-148.

21-7071. DjoudjefF, S. - "Esquisse d'une méthode musicologique pour l'étude des vers populaires". - To honor Roman Jakobson (The Hague, 1967), 1, 523540. 
21-7072. Elscheková, A. - "Methods of classification of folk-tunes".-JIFM, 23 (1966), 56-76.

21-7073. SeemanN, Erich, et al. (eds.) European folk ballads. - RosenkildeBagger, Copenhague, 1967. xxxii +248 pp. (Europ. folklore ser., 2).

\section{Espa $\tilde{n} a$}

21-7074. Etnologia y tradiciones populares. Primer Congreso nacional de artes y costumbres populares.-C.S.I.C., Zaragoza, 1969. xxviii +648 pp. $[67$ comunicaciones].

21-7075. Gómez Tabanera, José Manued (ed.) -El folklore español. - Inst. Español de Antropologia Aplicada, Madrid, 1968. 455 pp. [Gómez Tabanera, "Etnología y folklore de España", 1-24; G. Nieto Gallo, "La casa tradicional", 2550; J. Caro Baroja, "Modos de vivir", 51-65; Gómez Tabanera, "El curso de la vida humana", 67-128; A. Castillo de Lucas, "La medicina popular", 129-147; Gómez Tabanera, "Fiestas populares", 149-216; G. Llompart, "La religiosidad popular", 217-246; N. de Hoyos Sancho, "El traje regional", 247-258; Marqués de Lozoya, "Arte popular", 259 267; Gómez Tabanera, "Orígenes y determinantes de las fiestas taurinas", 269-295; A. de Larrea, "Aspectos de 1a música popular", 297-318; T. Martínez de la Peña, "Aspectos particulares de las danzas populares", 319-337; A. de Larrea, "EI teatro popular", 339-352; J. Gella Iturriaga, "Etnología y folklore marinero", 353-368; G. Manrique, "Tradiciones pastoriles", 369-388; Gómez Tabanera, "El refranero español", 389 431]. RDTP, 26 (1970), 209-212 (Pérez Vidal) .

21-7076. Epton, Nina Consuelo-Spanish fiestas; including romerias, excluding bull-fights. - Barnes, New York, 1969. xvii $+250 \mathrm{pp}$.

21-7077. MUÑIz TocA, ÁNGeL-Vida y obra de Eduardo M. Torner, musicólogo, folklorista y compositor.-Oviedo, 1961. $46 \mathrm{pp}$.

21-7078. Álvarez Blázquez, Xosé M. O livro da caza.-Castrelos, Vigo, 1969. $59 \mathrm{pp}$.

21-7079. Ramón y Ffrnández OXea, Xosé -Santa Marta de Moreiras. Monografia. dunha parroquia ourensan (1925-1935). -Castrelos, Vigo, 1968. 453 pp., ilustr. 21-7080. Moreno y Moreno, Miguel-So- ria: retrato, misterio y cumbre.-Tip. Urbión, Soria, 1969. 272 pp.

21-7081. Amades, JoAN - Folklore de Catalunya. T. 3: Costums $i$ creences.-Selecta, Barcelona, 1969. 1424 pp. - V. núm. 10-21748.

21-7082. Moreu REY, ENRIQUe-S. Martin de Tours. Su devoción en Cataluña según la toponimia, la antroponimia, el folklore, etc. - Universidad, Barcelona, 1967. $16 \mathrm{pp}$.

21-7083. Galmés, A. - "Folclore balear". $-E L, 1969$, núms. $426 / 28$.

21-7084. Llompart, G. - “La fiesta de Corpus y representaciones religiosas en Zaragoza y Mallorca (siglos Xrv-xvi)". -AST, 42 (1969), 181-209.

21-7085. González Echegaray, M. del C. - "Danzas para el día del Corpus en la Villa de Reinosa". - PIEF, 1 (1969), 175-I 79.

21-7086. Quiroga LosadA, D. - “De la terriña meiga. Gaita, gaiteros célebres, panderos, pandeiras, romaxes". - Rev. de Estudios Turisticos, Madrid, 1969, núm. 21, 31-67.

21-7087. Filgueira Valverde, Xosé (ed.) -Cancioneriño novo de Compostela. Vigo, 1969. 131 pp.

21-7088. Preciado, Dronisio - Folklore español: música, danza y ballet.-Studium, Madrid, 1969. $336 \mathrm{pp}$.

21-7089. Hidalgo Montoya, Juan - Can cionero de Navidad. Villancicos populares españoles. - A. Carmona, Madrid, 1969. 122 pp., con letra y música.

21-7090. Méndez Pérez, D. - “Canción y geografía”. - BIEA, 23 (1969), 85-93. [Asturias].

21-7091. Echevarría, Julián de - Cancionero bilbaino. Historia y anécdota de algunas canciones bilbainas. - Libr. Arturo, Bilbao, 1969. 233 pp., ilustr. \| $B S V, 25$ (1969), 598-599 (Cuadra) .

21-7092. Chesa, Ramón (ed.) - Cancionero aragonés. - Valls, 1966. 165 pp.

21-7093. Pérez VIDAL, J. - "Pico, pico, melarico: un juego infantil en Canarias" (N. 19-4124). \|MCan, 27/30 (1966-69), 225-226 (Siemens Hernández) .

21-7094. Gella ItUrriagA, J. - "La sirena en la literatura oral española".-Studi... Carmelina Naselli (Catania, 1968), t. 1, 117-128.-V. núm. 20-4124.

21-7095. Alcover, M. - "Adaptación de un mito en la cuentística popular de Mallorca". - Mayurqa, 1969, núm. 2, 83-87. 